\title{
THE ECOLOGY OF THE ORTHOP- TERA AND DERMAPTERA OF THE GEORGE RESERVE, MICHIGAN
}

\author{
BY \\ IRVING J. CANTRALL
}

ANN ARBOR

UNIVERSITY OF MICHIGAN PRESS

JANUARY 20, 1943 
PRICE IIST OF THE MISCELLANEOUS PUBLICATIONS OF THE MUSEUM OF ZOOLOGY, UNIVERSITY OF MICHIGAN

Address inquiries to the Director of the Museum of Zoology, Ann Arbor, Michigan.

\section{Bound in Paper}

No. 1. Directions for Collecting and Preserving Specimens of Dragonflies for Museum Purposes. By E. B. Williamson. (1916) Pp. 15, 3 figures

No. 2. An Annotated List of the Odonata of Indiana. By E. B. WILliamson.

No. 3. A Collecting Trip to Colombia, South America. By E. B. WILLIAMson. (1918) Pp. 24. (Out of print)

No. 4. Contributions to the Botany of Michigan. By C. K. DodGE. (1918) Pp. 14

No. 5. Contributions to the Botany of Michigan, II. By C. K. Dodat. (1918) Pp. 44, 1 map

No. 6. A Synopsis of the Classification of the Freshwater Mollusca of North America, North of Mexico, and a Catalogue of the More Recently Described Species, with Notes. By Bryant Walker. (1918) Pp. 213, 1 plate, 223 figures

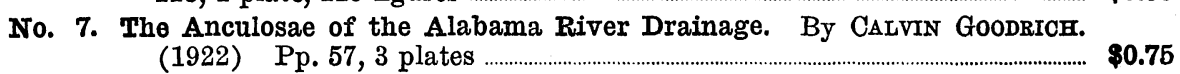

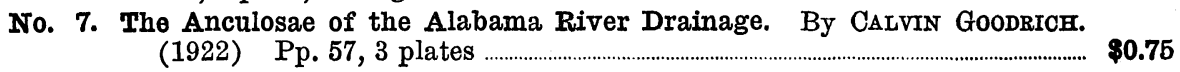

No. 8. The Amphibians and Reptiles of the Sierra Nevada de Santa Marta, Colombia. By ALEXander G. Ruthren. (1922) Pp. 69, 13 plates, 2 figures, 1 map

$$
\text { .... }
$$

\section{.} .

No. 10. A Preliminary Survey of the Bird Life of North Dakota. By NormaN

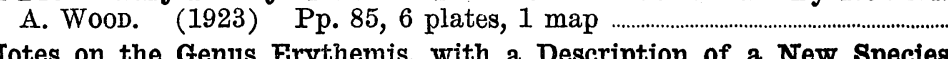
No. 11. Notes on the Genus Erythemis, with a Description of a New Species
(Odonata). By E. B. WILLIAMson.

The Phylogeny and the Distribution of the Genus Erythemis (Odonata).

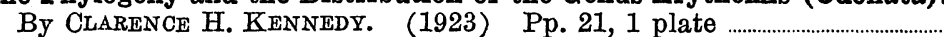

No. 12. The Genus Gyrotoma. By CALvin GoodricH. (1924) Pp. 29, 2 plates ...

No. 13. Studies of the Fishes of the Order Cyprinodontes. By CARL L. HuBBs. (1924) Pp. 23, 4 plates

No. 14. The Genus Perilestes (Odonata). By E. B. Williamson and J. H. WILLIAMSON. (1924) Pp. 36, 1 plate

No. 15. A Check-list of the Fishes of the Great Lakes and Tributary Waters, with Nomenclatorial Notes and Analytical Keys. By CARL L. HUBBS. (1926) Pp. 77, 4 plates

No. 16. Studies of the Fishes of the Order Cyprinodontes. VI. By CARL $L$.

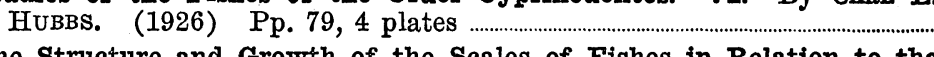

No. 17. The Structure and Growth of the Scales of Fishes in Relation to the Interpretation of their Life-History, with Special Reference to the Sunfish Eupomotis gibbosus. By CharLes W. CReasER. (1926) Pp. 80, 1 plate, 12 figures

\section{$\$ 1.50$}

No. 18. The Terrestrial Shell-bearing Mollusca of Alabama. By BryakT WALKER. (1928) Pp. 180, 277 figures ..............................................

No. 19. The Life History of the Toucan Ramphastos brevicarinatus. By JosSELXN VAN TYNE. (1929) Pp. 43, 8 plates, 1 map ..............................

No. 20. Materials for a Revision of the Catostomid Fishes of Eastern North America. By CARL L. HUBBS. (1930) Pp. 47, 1 plate .........................

No. 21. A Revision of the Libelluline Genus Perithemis (Odonata). By F. RIs.

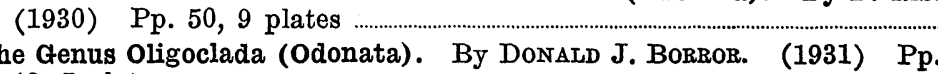

No. 22. The Genus Oligoclada (Odonata). By Donald J. Borror. (1931) Pp.

No. 23. A Revision of the Puer Group of the North American Genus, Melanoplus, with Remarks on the Taxonomic Value of the Concealed Male Genitalia in the Cyrtacanthacrinae (Orthoptera, Acrididae). By THEODORE H. HUBBELL. (1932) Pp. 64, 3 plates, 1 figure, 1 map ..................... 



\section{ADVERTISEMENT}

The publications of the Museum of Zoology, University of Michigan, consist of two series-the Occasional Papers and the Miscellaneous Publications. Both series were founded by Dr. Bryant Walker, Mr. Bradshaw H. Swales, and Dr. W. W. Newcomb.

The Occasional Papers, publication of which was begun in 1913, serve as a medium for original papers based principally upon the collections of the Museum. The papers are issued separately to libraries and specialists, and, when a sufficient number of pages have been printed to make a volume, a title page, table of contents, and index are supplied to libraries and individuals on the mailing list for the entire series.

The Miscellaneous Publications, which include papers on field and museum techniques, monographic studies, and other contributions not within the scope of the Occasional Papers, are published separately, and as it is not intended they will be grouped into volumes, each number has a title page, and, when necessary, a table of contents.

Frederick M. Gaige

Director of the Museum of Zoology

University of Michigan 


\title{
THE ECOLOGY OF THE ORTHOP- TERA AND DERMAPTERA OF THE GEORGE RESERVE, MICHIGAN
}

\author{
BY \\ IRVING J. CANTRALL
}


$$
\text { 。 }
$$ 


\section{CONTENTS}

PAGE

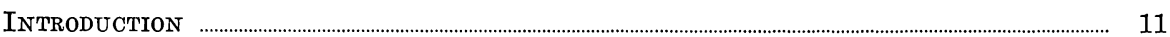

Acknowledgments ……............................................................................................................................... 13

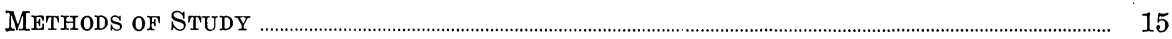

Collecting Methods and the Recording of Data in the Field ............................................... 16

Frequency and Abundance ....................................................................................................... 19

A Classification of the Orthopteran Populations ........................................................................... 21

Analysis of Field Data ........................................................................................... 26

DESCRIPTION OF THE AREA ......................................................................................................................................... 27

Location and Physical Features ............................................................................................................ 27

The Vegetation ….......................................................................................................... 31

The Orthopteran Habitats of the Reserve ................................................................................ 34

The Basis for Recognition and Classification of the Orthopteran Habitats ................ 34

Summary of the Recognized Habitats ...................................................................................................... 37

Deseription of the Habitats ........................................................................................................ 38

Xeric Upland Associations ........................................................................................................................ 38

Xeromesic Associations ........................................................................................................................... 41

Hydric Associations ......................................................................................................................... 47

Some Environmental Peculiarities and Their Influence on the Habitat Distribution of the Orthoptera …............................................................................................................ 56

SEASONAL RELATIONSHIPS OF THE ORTHOPTERA …..................................................................... 58

ANNotated List of the ORthoptera AND DeRMaptera ……............................................................ $\quad 67$

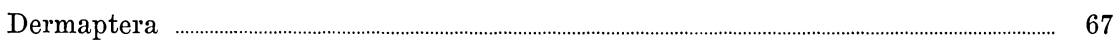

Forficulidae, Forficulinae ................................................................................................... 67

Doru aculeatum aculeatum ......................................................................................................... 67

Orthoptera ……........................................................................................................................................ 71

The Genus Parcoblatta ........................................................................................................ 71

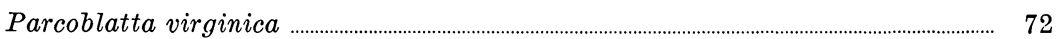

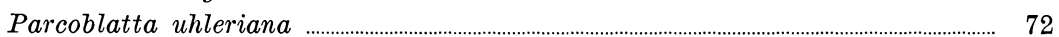

Parcoblatta pensylvanica …….......................................................................................... 73

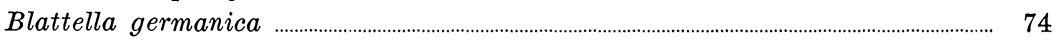

Blattidae, Blattinae ............................................................................................................................ 74

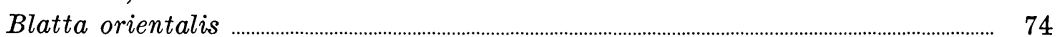

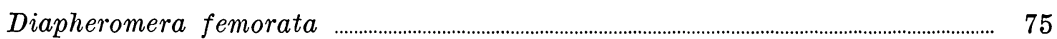

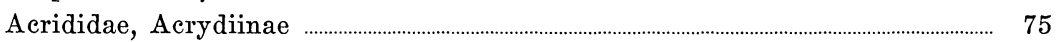

The Acrydiinae (Grouse locusts) ……....................................................................... $\quad 75$

Acrydium subulatum .................................................................................................................. 77

Acrydium acadicum acadicum ........................................................................................ 78

Acrydium ornatum ................................................................................................................ 79

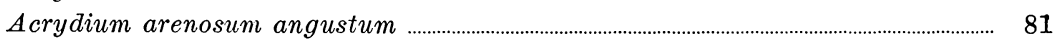

Paratettix cucullatus cucullatus ............................................................................................. 82

Tettigidea lateralis parvipennis ................................................................................................. 83

Tettigidea armata .......................................................................................................................... 88

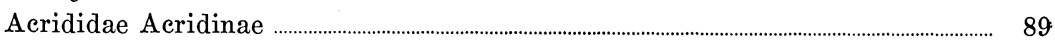

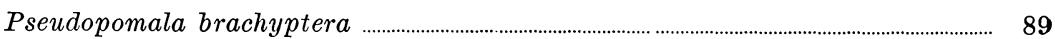




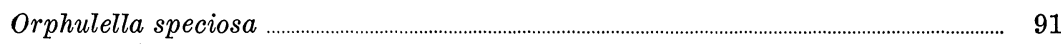

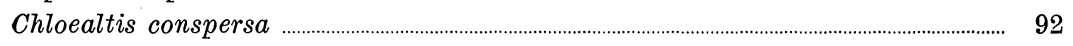

Chorthippus longicornis ..................................................................................................... 94

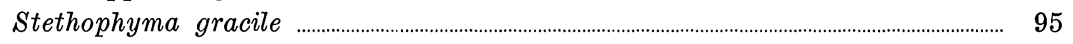

Acrididae, Oedipodinae …….................................................................................................... 96

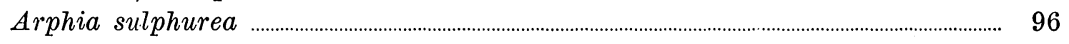

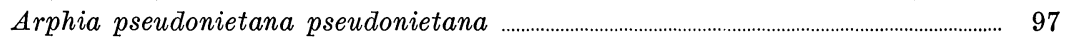

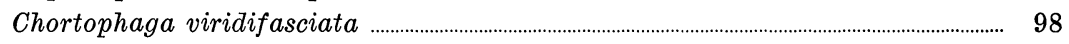

Encoptolophus sordidus sordidus ................................................................................................ 99

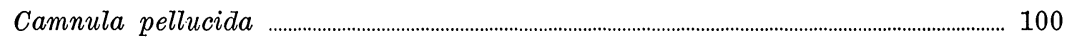

Pardalophora apiculata .................................................................................................................................. 100

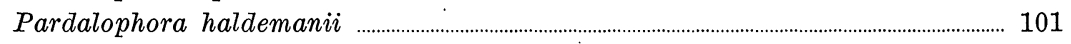

Dissosteira carolina ............................................................................................................................. 103

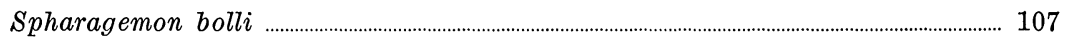

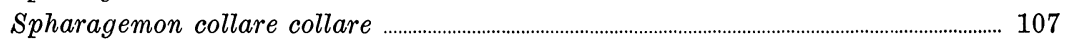

Acrididae, Cyrtacanthacrinae ……………........................................................................................ 108

Schistocerca alutacea .................................................................................................................... 108

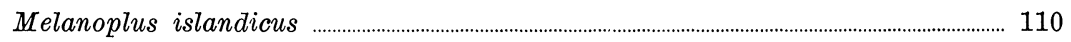

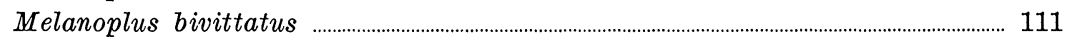

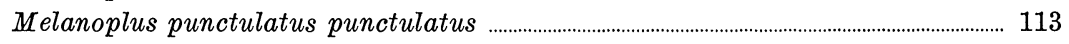

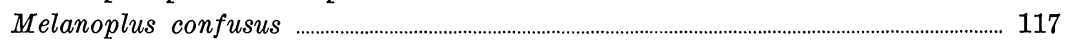

Melanoplus femur-rubrum femur-rubrum ......................................................................... 117

Melanoplus borealis junius ............................................................................................................. 118

Melanoplus fasciatus .......................................................................................................... 119

Melanoplus mexicanus mexicanus ........................................................................................... 119

Melanoplus keeleri luridus .............................................................................................. 121

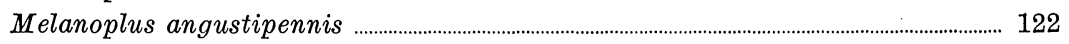

Phoetaliotes nebrascensis ................................................................................................................ 122

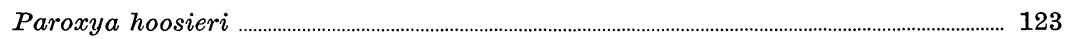

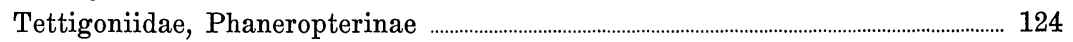

Scudderia septentrionalis ........................................................................................................ 124

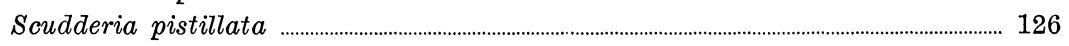

Scudderia curvicauda curvicauda ................................................................................................. 127

Scudderia texensis ...................................................................................................................................... 128

Scudderia furcata furcata .................................................................................................................... 129

Amblycorypha oblongifolia …….................................................................................................. 130

Amblycorypha rotundifolia ................................................................................................. 130

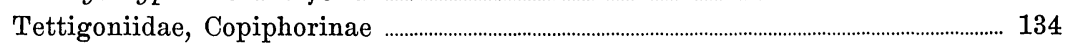

Neoconocephalus ensiger ................................................................................................................ 134

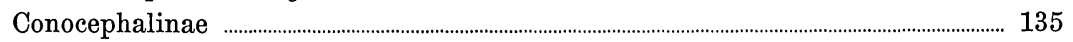

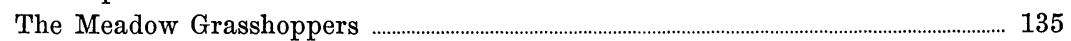

Orchelimum vulgare .............................................................................................................................. 137

Orchelimum gladiator ............................................................................................................. 137

Orchelimum nigripes ................................................................................................................................. 139

Orchelimum concinnum concinnum ............................................................................................. 140

Conocephalus fasciatus fasciatus ............................................................................................... 141

Conocephalus brevipennis ............................................................................................................ 142

Conocephalus strictus ............................................................................................................................ 143

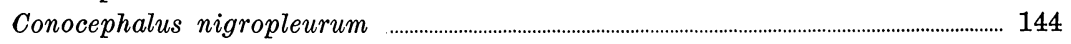

Tettigoniidae, Decticinae ................................................................................................................................ 144

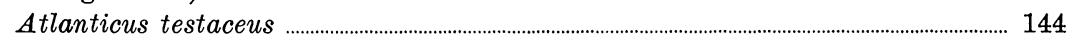


PAGE

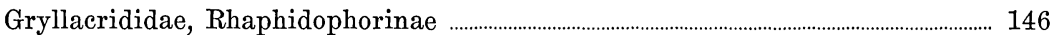

Ceuthophilus brevipes ................................................................................................................ 146

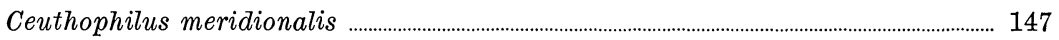

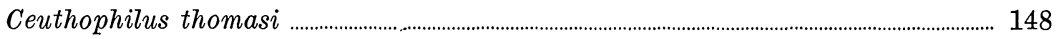

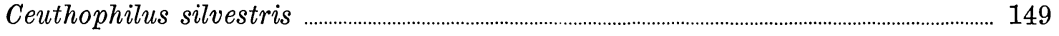

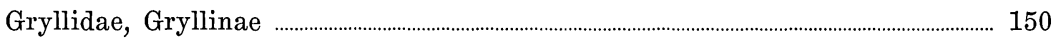

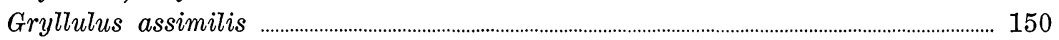

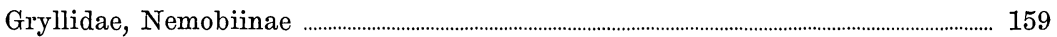

Nemobius fasciatus (DeGeer) and Its Races .................................................................... 159

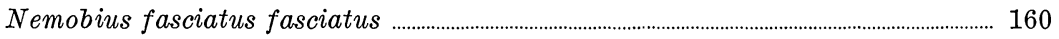

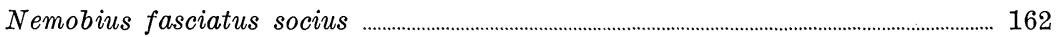

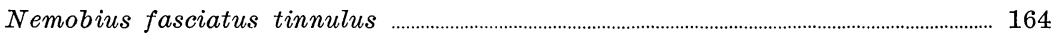

Nemobius griseus griseus ............................................................................................................. 164

Nemobius cubensis palustris ................................................................................................................ 166

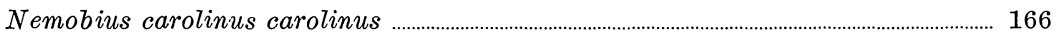

Gryllidae, Oecanthinae ........................................................................................................................ 167

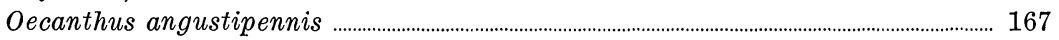

Oecanthus niveus ...................................................................................................................................... 168

Oecanthus nigricornis nigricornis ……….......................................................................... 169

Oecanthus nigricornis quadripunctatus ............................................................................... 170

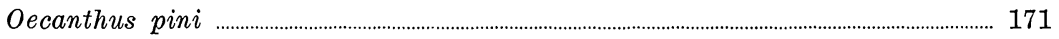

Gryllidae, Trigonidiinae ............................................................................................................. 172

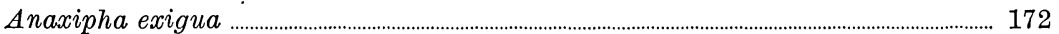

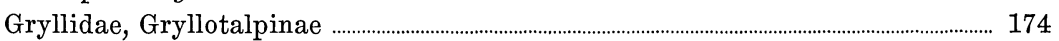

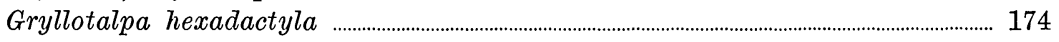

SUMMARY AND CoNCLUSIONS .................................................................................................................................. 176

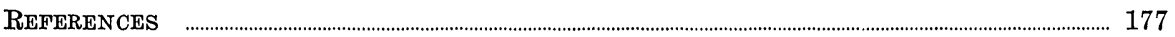





\section{ILLUSTRATIONS \\ PLATES}

(Plates I-X face page 182)

PLATE

I. Fig. 1. Station 11. An area of sparsely-vegetated sand habitat.

Fig. 2. Station 5. Mixed grass-herbacaceous habitat with an area of lichenclad sand.

II. Fig. 1. Station 5. An area just to the right of that shown in Fig. 2, Plate I.

Fig. 2. Station 11. An area of intergradation.

III. Fig. 1. Station 9. A heavy growth of mixed grass-herbaceous habitat.

Fig. 2. Station 3. An area of sunny oak-hickory habitat.

IV. Fig. 1. Station 2. Poa compressa, characteristic of the mixed grass-herbaccous habitat, is the dominant grass of the low shrub-terrestrial stratum.

Fig. 2. Station 2. An area of shady oak-hickory habitat.

V. Fig. 1. Station 2. Heavy growths of sassafras have invaded parts of the shady oak-hickory habitat.

Fig. 2. Station 10. The permanent marsh orthopteran habitat on the far side of the lake.

VI. Fig. 1. The narrow ecotone between grassland and woodland (in the upper center).

Fig. 2. Station 1. Semipermanent marsh habitat.

VII. Fig. 1. Station 6 . An area of semipermanent marsh habitat.

Fig. 2. Burt Hollow.

VIII. Fig. 1. Burt Hollow.

Fig. 2. Station 1. Deer tracks in the foreground show the muddy character of the wet-terrestrial stratum in late August.

IX. Fig. 1. Station 1. This area is the same as that depicted in Fig. 1, Plate VIII. Fig. 2. Station 4. Tamarack islands in the leatherleaf bogs.

X. Figs. 1 and 2. Station 8. The red maple-birch habitat.

\section{MAPS}

1. Aerial photograph of the George Reserve (facing)

2. Contour map of the George Reserve (facing) 


\title{
THE ECOLOGY OF THE ORTHOPTERA AND DERMAP. TERA OF THE GEORGE RESERVE, MICHIGAN*
}

\author{
INTRODUCTION
}

THe study of the Orthoptera of North America has, since the turn of the century, attracted an increasing number of able investigators, among whom J. A. G. Rehn, Morgan Hebard, A. P. Morse, and A. N. Caudell have been pre-eminent. Building on the foundations laid by S. H. Scudder in the latter part of the nineteenth century, these men and their co-workers have carried our knowledge of the taxonomy and geographical distribution of American Orthoptera to a stage of completion surpassed in no other insect order. The morphology and phylogeny of the orthopteroid insects of this continent have also received much attention at the hands of R. E. Snodgrass, G. C. Crampton, E. M. Walker, and others; and fundamental studies in the fields of physiology, genetics and cytology, based on investigation of American Orthoptera, have been made by a group of workers which includes such wellknown names as those of C. E. McClung, J. H. Bodine, E. E. Carothers, R. L. King, Y. F. Yeager, and R. K. Nabours.

In contrast to the situation in the above-named fields, there have been relatively few competent and thorough studies made of the life history, habits, and ecology of North American Orthoptera; and information concerning these subjects is correspondingly scanty. Some excellent work, however, has been done. In the field of ecology the papers of Vestal (1913), Hubbell (1922), Strohecker (1937), and Isely (1937, 1938) are noteworthy. ${ }^{1}$ Earlier papers by Morse (1899, 1904, 1907) and Hancock (1911) were anticipatory of this type of investigation, but were made on a nonquantitative basis and without the attention to detail and the careful recording of data which modern standards require. The classifications of orthopteran habitats proposed by Morse and Vestal in the papers cited above have been rather widely used. Criddle's studies on the life histories of Manitoba Orthoptera $(1915,1922,1925,1932)$ and those of Fulton $(1915,1926,1931$, 1933, 1937) on the ecology and life histories of certain Gryllidae and of Buckell (1922) on the ecology of British Columbia Orthoptera also deserve special notice. Recently, Gause $(1930,1932)$ has published population studies, based on Orthoptera, which have an ecological bearing; these are, however, primarily statistical in treatment and are open to criticism in

* A dissertation submitted in partial fulfillment of the requirements for the degree of doctor of philosophy in the University of Michigan.

1 This paper had been submitted for publication before the appearance of Urquhart's ecological study of the Saltatoria of Point Pelee, Ontario. His publication has been listed with the references, but is otherwise not referred to herein. 
respect to the field methods employed and some of the assumptions which these involve. In summary, and in spite of the examples cited above, one may say that detailed ecological investigations of the Orthoptera of restricted areas in North America are as yet too few and too scattered to have furnished much information on the life of these insects in their natural surroundings.

A great deal of detailed ecological work on Orthoptera has been in progress in the old World in recent years. One notes in particular the field studies of Salfi (1924), Grassé (1929), Bei-Bienko (1930), Vinokurov (1930), Faure (1932), Uvarov (1932, 1933), Nefedov (1933, 1933a, 1936) and Jannone (1936). Much of this work appears to have been admirably planned and executed and has furnished suggestions for the present study; but my own experience has shown that there is much room for improvement in methods of determining abundance in habitats, and in analyzing the significance of field samples.

The present paper embodies the results of three years of work devoted to a detailed study of the environmental relations of the Orthoptera and Dermaptera of a restricted area in southern Michigan-the Edwin S. George Reserve, in Livingston County. Selection of this area for the purpose was made on three counts : first, its proximity to Ann Arbor; second, because of the fact that within the two square miles of the Reserve there are represented a wide variety of habitats characteristic of the region; and third, because of the opportunities afforded by the program of biological investigations centered around the Reserve, in progress under the auspices of the University of Michigan Museum of Zoology. The object of this program is to secure a well-rounded picture of the present biota and its ecology in an area which is to be preserved for future biological studies. The Reserve has been so recently freed from the influences of cultivation and grazing that it will unquestionably be modified by succession and possibly by retrogression, with resulting changes in the fauna. A census of the present biota will, therefore, aid future investigators in estimating the amounts of such changes; and this paper presents a survey of the present orthopteran fauna which may be useful as a basis for future studies of this group of insects on the Reserve.

Emphasis has been placed on determining what species of Orthoptera and Dermaptera are present in the area, their habitat relations, the correlation of their habitat distribution with particular features of the environment, and the seasonal changes that occur in the populations. A classification of the orthopteran habitats of the Reserve has been worked out, which takes into account the influences of soil, drainage, and slope, operating indirectly to a considerable extent through the plant associations, and also of the effects upon orthopteran occurrence of the different habits of the species, by virtue of which some are able to occupy entire major habitats and others are con- 
fined to definite minor habitats or strata. This classification has proved very helpful in understanding the actual distribution of the fauna of the area. To the extent to which it could be gathered without interfering with the primary objectives outlined above, I have also tried to obtain as much information on the life histories, habits, and behavior of the species as possible. The period covered by this study extends from August 1, 1936, to August 1, 1939. The greater parts of three summers were spent in residence on or near the Reserve, and frequent visits have been made at all seasons during the remainder of the year.

Since little is known of the ecology of Orthoptera under natural conditions, I am of the opinion that survey work of the type here attempted is, for the moment, more valuable, and more urgently needed than controlled laboratory experiments on the reactions of individuals to isolated environmental factors. Every field worker is aware of the fact that the ecological behavior of the same species in various parts of its range may be quite different; numerous instances are known in which two or more physiologically and ecologically distinct races of single species are present even in restricted areas. Thus, the assumption often unconsciously made by the physiological ecologist, that distribution of a given species in the field is controlled by the factors which he has determined in the laboratory by testing a few individuals, may or may not be true. Studies of actual habitat distribution in various parts of the range of a species should therefore serve as a guide to experiment and as a check upon assumptions which are otherwise likely to pass unchallenged. It will be of interest in this connection to compare the results of my study on the Reserve with those of a similar study now being carried on in northern Florida, particularly with respect to the twenty-five species common to the two areas. Preliminary results of the Florida survey indicate that at least some of these species react differently to environment in Michigan and in Florida.

\section{AcKNowledgments}

I am indebted to the Museum of Zoology of the University of Michigan for permission to carry on this work on the Edwin S. George Reserve. Professor Frederick M. Gaige, Director of the Museum of Zoology, is accorded my grateful thanks for suggestions, criticisms, and encouragement. Dr. T. $\mathrm{H}$. Hubbell, of the University of Florida, has been most helpful in suggesting procedure, aiding in the solution of taxonomic difficulties, and in the preparation of this paper. Many of the problems involving habitat relations have been discussed to advantage with Dr. J. Speed Rogers, of the University of Florida. Dr. Rogers has also generously allowed me to use certain of his photographs of habitats on the Reserve.

Various other persons have aided me materially in the course of this study. Dr. Frederick Herman, of the Office of Plant Exploration and 
Introduction, Washington, D. C., determined the sedges and other groups of plants and arranged for the determination of many of the remainder. Dr. M. W. Senstius, of the Department of Geology, and the late Mr. Bruce Dick, of the Department of Geography, University of Michigan, aided me in checking the identification and distribution of the soils of the area. Dr. George M. Stanley, of the Department of Geology, University of Michigan, kindly reviewed and approved my interpretation of the glacial history of the Reserve. Mr. Edward S. Thomas, Ohio State Museum, examined specimens of the concinnum group of the genus Orchelimum, and Dr. B. B. Fulton, Department of Zoology, North Carolina State College, verified my identification of Oecanthus pini. Mr. Lawrence Camburn, Custodian of the Reserve, has been most co-operative at all times and has presented me with many specimens. Messrs. Sherman Moore and J. J. Friauf and Dr. W. Frank Blair have also collected and given me much material. My wife, Dorothy Louise Cantrall, has spent many hours helping me, both in the field and in the preparation of specimens and of the manuscript. To all of these persons, and to others who have aided me, I wish to express my grateful appreciation and thanks. 


\section{METHODS OF STUDY}

At the beginning of the investigation one month was spent in making a reconnaisance of the Reserve, in order to determine in a preliminary way what species were present and the relationship between their distribution and the plant communities. I collected as many species as possible during this period and made notes on the occurrence and abundance of each. At the end of this time enough had been learned to warrant the selection of ten areas of different types of environment for intensive study. These areas or "stations" were believed, at the time, to represent clear-cut habitats, although subsequent study necessitated the subdivision of some and the combining of others. The stations were visited as regularly as possible, generally at ten-day intervals, for the balance of the year 1936 and during the first half of the 1937 season. Early in July, 1937, two more were chosen, and the entire twelve were then worked at ten-day periods until freezing weather ended the 1938 season. The 1939 season was devoted to a different type of work as noted below.

In such a long-continued study of definite stations it has been possible to become familiar with the Orthoptera, ${ }^{2}$ plants, soils, fluctuations of water level, and various phenological phenomena in each area; thus a rather accurate picture of ecological conditions and relationships within each station has been obtained. All of the forms of Orthoptera that occur in a given station are soon learned, and in working with these limited assemblages of species one can often identify the nymphs of forms which could not be determined were one dealing with a larger fauna containing groups of closely related species. ${ }^{3}$

In addition to the intensive study of selected areas, general collecting has been extended over the entire Reserve in order to determine the range of movement of the orthopteran species and to secure information regarding any peculiarities in the choice of habitat by the various forms. All of the 1939 season and intermittent periods during the preceding years were devoted to this more general method of investigation, which furnishes an excellent check upon the results based on detailed study of the faunas of the selected stations.

2 Throughout this paper, such phrases as "the Orthoptera of the Reserve" and "'orthopteran habitats," are intended to include also the single species of Dermaptera present in the area.

3 The fact that for the great majority of the species of North American Orthoptera there are no descriptions, keys, or studies of variability of the juveniles, precludes the possibility of determining large numbers of miscellaneous nymphs in any other way than by association with adults. Even this has not always been feasible in this study especially in the occasional instances in which closely related species occupy the same habitat. 


\section{Collecting Methods ${ }^{4}$ and the Recording of Data in the Field}

Many methods of collecting Orthoptera have been employed to advantage in the course of this investigation. Residence close to, or upon, the area has made it possible to collect both by day and by night. It should be emphasized that no ecological study of Orthoptera can be considered even approximately complete without the valuable information obtained by night work. Many species are active only at night and cannot be collected during the day except by difficult and time-consuming methods. Nocturnally active species which are thus collected during the daytime are frequently of no value except as specimens, since one cannot be sure whether they were in their normal habitats, nor whether their observed movements and behavior were typical and significant. Such information must be obtained by observations made during the time of greatest activity of each species.

The collecting method most commonly used was that of sweeping. The length of stroke, its distance above ground, and its speed and timing must all be modified and adapted to the conditions prevailing in various habitats, at different seasons, different hours of the day, and for the various species. Temperature, humidity, type of vegetation, and other factors affect the way in which sweeping must be done to be of maximum effectiveness. Furthermore, the behavior of the species sought is an important factor. The height at which some species of Orthoptera occur in the vegetation varies with differences in meteorological conditions. On the other hand, certain species almost invariably inhabit the tops of plants, while others normally live within a few inches of the ground. Activity and wariness are not the same for any two species; and sweeping methods must be adjusted to the reaction time, escape methods, and clinging powers of particular forms.

The various habits and ecological preferences of the orthopteran species on the Reserve have made it necessary to employ a number of special techniques in studying and collecting them. To observe those species which flush and fly up readily the method of stalking has been most satisfactory. Crickets and grouse locusts are best taken by parting and working over vegetation while one slowly crawls on hands and knees. In areas of rank herbage, dense grass, or sedge marsh, trampling will reveal species that are otherwise very difficult to find. One begins at the periphery of the selected area and works inward in a spiral path, slowly trampling the vegetation to the ground. This is continued until the entire area has been thoroughly covered. By slowly walking back and forth over the matted plants, one causes the Orthoptera to work their way gradually to the surface, where they are easily

4 This section on collecting methods has already appeared in a much more extended and detailed form (Cantrall, 1939-40), and has been revised and published (1941) as a unit in the compendium on the collection and preservation of insects which is being prepared by Ward's Natural Science Establishment, Rochester, New York. 
captured. I have found the beating cloth and club to be the only successful means of obtaining Anaxipha exigua in numbers. The spine-tailed earwig is collected by stripping away the outer leaves of sedges; and cockroaches are to be found beneath piles of dead leaves and under the bark of old logs. Molasses trapping (as described by Hubbell, 1932: 47) is the most satisfactory way of obtaining Ceuthophilus in quantity, although $C$. silvestris has been found only by tearing up the surface burrows of the mole Scalopus aquaticus machrinus. Molasses trapping is also a valuable method of obtaining cockroaches and crickets. The tiny cricket Nemobius cubensis palustris may often be collected in numbers by slowly pressing the sphagnum moss, wherein it lives, beneath the water's surface. The crickets then float on the surface and are easily collected. The nymphs of this species are relatively inactive and can be sucked up with an insect aspirator. The males of cockroaches and of Scudderia septentrionalis often react positively to light, and at such times may come to a lighted sheet. Night collecting with the aid of an electric headlight, by searching, sweeping, and beating, is one of the most indispensable and profitable methods of obtaining data and specimens. Tree trunks baited with a solution of sugar and beer painted near the base (in the manner widely used by lepidopterists) will occasionally attract cockroaches and camel crickets. Small wooden boxes or boards, beneath which grain was placed, have proved successful traps for cockroaches and crickets, and are the only satisfactory means found for capturing members of the spring population of Gryllulus assimilis.

The songs of the various katydids and crickets were learned, either by tracing singing males in the field and thus determining the identity of the species, or by caging specimens in the laboratory and listening to their notes. Once thoroughly familiar with these songs, I was able to recognize them with certainty and, by walking over sections of the Reserve, to record the exact locations in which males of the various species were heard singing. Cover maps of the Reserve were used for making these records, one map for each species. The maps show in detail the distribution of the principal vegetation types of the area, and thus enabled me to mark the location of individuals or groups of a given species in relation to habitat.

The date of each trip was recorded on the back of each species map and numbered, and this was used in locating the individuals heard on that occasion. Since all locations marked by the same number recorded the distribution of the population on a particular date, it was possible, by means of these maps, to trace the spread and movement of some of the species populations. The distribution of nonmusical Orthoptera which possess distinctive characteristics or habits that permit accurate identification in the field has been recorded in a similar manner.

Many hours were spent in observing individuals of various species in the 
field and laboratory. In making field observations, I usually approached the insect very cautiously, taking great care not to alarm it, until its every movement could be clearly seen. Small species, such as grouse locusts and crickets, were brought into the laboratory and kept alive in small cages consisting of one-gallon glass jars with screen or cloth tops, with several inches of moist soil in the bottom. In these cages all activities of the insects could be watched closely and at leisure. Many of the katydids, which are hard to find, or at any rate, are so scattered as to make frequent observation difficult, were confined in a large out-door cage in their natural environment. This cage was about four feet high and covered an area of about ninety square feet; the sides were screened and furnished with large glass windows through which observations could easily be made. The cage covered a section of vegetation sufficiently large so that the feeding activities of the insects did not noticeably affect the plants. On one occasion fifteen individuals representing four species of Scudderia were confined in the cage at the same time; an abbreviation of the name of the species was painted on both tegmina of each individual with white enamel, preventing any possibility of confusion. The enamel did not appear to affect the katydids in any way; and they were never seen to try to remove it.

Approximately seven thousand adult specimens and several thousand nymphs were collected and preserved in the course of the investigation; but this represents only a small proportion of those recorded in the field. In dealing with the limited fauna of the Reserve, I soon became able to recognize the majority of the species with ease and certainty. Collecting was limited to obtaining enough material of each species so that its true identity and the range of variation which it exhibits in this area could be determined. Intensive collecting throughout the period of study would not only have taken time urgently needed for keeping up with the seasonal progress of events in orthopteran population, but also might easily have resulted in serious depletion of the populations of the less abundant forms. Species which could not be certainly recognized in the field were collected on all occasions when notes were made. It was often sufficient to capture and examine individuals of similar forms, after which they were released.

A cover map of the Reserve was ruled horizontally and vertically at intervals of sixteen divisions per scale mile, making squares which scaled 330 feet on a side. The intervals between the vertical lines were numbered consecutively from one to thirty; those between the horizontal lines were lettered from "A" through "V." Thus any given location in the area could be indicated fairly exactly by citing the letter and number of rows of the square, as - "K-15." This simple technique has made it possible to record the place where each specimen was seen, heard, or collected. This system was applied only to observations not made at stations, material taken from 
the latter being recorded by station number. All records were kept in chronological order until, at the beginning of the 1939 season, I changed to the more convenient method of recording information directly under the species to which it pertained. The use of station numbers and key letters and numbers for localities was continued throughout the study.

\section{Frequency and Abundance}

The frequency of occurrence of a species in each type of habitat and the abundance of the populations of this species in particular examples of these habitats are two of the most important factors which must be considered in determining the normal habitat of the species. Many of the papers written on the ecology of Orthoptera and other groups do not give a true picture of actual conditions, either because frequency and abundance are not considered at all, or because the distinction between these two concepts has not been clearly understood. High frequency coupled with high abundance is often indicative of optimum conditions, whereas, either low frequency or low abundance suggests that the environment is in some respect unfavorable. When the habitat preferences of a species are stated on the mere basis of occurrence, as has often been done in literature, such statements may well be open to question.

Since confusion exists in the use of the terms frequency and abundance, it will be well to define them as they are applied to the present study. As here used, frequency is the regularity of occurrence of a given species in a given habitat; abundance is a measure of the density of the population of a species at a particular time and place. These definitions accord with the use of the terms by Vestal (1913). Even in some recent studies this distinction is not made, frequency being used as a term in a scale of abundance, or the two concepts are more or less commingled in some device for indicating occurrence and numbers. Since the distinction between the two concepts aids in analysis of the habitat relations of species, I restrict the term frequency to the sense in which it is defined above. Frequency of species in various habitats on the Reserve has been determined from a compilation of field records and notes, in which the presence or absence of a given species was recorded at the time of making the observations. Frequency is one of the chief criteria used in classing species as characteristic, sporadic, or erratic in a particular habitat.

Determination of the abundance of species has been one of the most difficult problems encountered in this study. A survey of the recent literature bearing on the problem of quantitative sampling of terrestrial populations, together with my own experience, shows very clearly that no satisfactory solution to the problem has yet been reached. Several different techniques for the determination of abundance have been proposed, most of them 
falling into two categories. The first of these, and probably the most popular at the present time, is the sweeping method. The collector, choosing an area of as nearly uniform conditions as possible, sweeps a predetermined number of times and then identifies and counts the catch. Certain authors, particularly Gause (1930), Gray and Treloar (1933), Beall (1935), Treloar and Gray (1935), and Carpenter and Ford (1936) have discussed the application of various statistical formulae to the catch count. DeLong (1932), Vestal (1913), Isely (1937), and Rogers (1942) all oppose the use of the sweep method on various grounds, the most serious of which are its unreliability, owing to variations in behavior of the insects, and the extreme differences which may be introduced by the personal element. So many factors subject to error are involved in the actual sweeping procedure that no dependence can be placed upon its results. At present there are no means whereby reliable quantitative samples may be obtained in practice. The investigations of Gause (1930) were based upon Orthoptera; but he worked with a limited group, the Acrididae, and in a narrow range of habitat. If the differences in behavior, activities, and habitat preferences of the various forms of the Orthoptera are considered, it is obvious that quantitative methods of collecting have not been developed to a point which will permit the successful application of such a concrete science as statistics to the data obtained.

The principal factors bringing about gross errors in sampling by the sweep net method may be stated as follows : (1) No two forms of Orthoptera occupy the same niche in the same habitat. Some inhabit the ground stratum, a few are arboreal, others are thamnophilous, and many find their optimum living conditions in herbaceous vegetation. Even the forms living in the same stratum do not all occur in the same parts of it. Thus arboreal species may occupy the crown of the tree, the tips of the branches, the trunks, or may be indiscriminately scattered over the whole tree. Thamnophilous species are distributed in much the same manner. Those which live on grasses and herbs may be found anywhere from the tops of the plants to the bases. Terrestrial crickets and grouse locusts may burrow beneath debris or be content to bask in the sunlight. Cockroaches and camel crickets are both hypogeic and epigeic in habit. (2) Many different reactions are apparent as one approaches individuals. They may, depending on the species, fly, jump, duck, sidle, drop into the vegetation, dodge, freeze, or burrow beneath leaves and debris. Some species are very difficult to jar loose; others of more wary nature flush easily. (3) The activities of most of the species are modified by variation in temperature, humidity, light, and density of plant cover. (4) Other errors are due, either to the collector, or to his equipment. I have found that a change of net handles, involving a difference of only a few ounces, will appreciably modify the timing and balance 
of my sweeping stroke. A clean, smooth, new net-bag will pass through vegetation much more readily than an old frayed one. The physical condition of the collector is very important; fatigue and meteorological influences definitely affect timing, length, and power of stroke. The field experience of each individual collector determines, to a large extent, the amount of material which he is able to collect. On one occasion three other persons: and I were collecting grouse locusts in a single small area. At the end of an hour, one person had collected no specimens; the second, two; the third, five; and the fourth, thirty-seven.

Abundance of the species of Orthoptera on the George Reserve has been: determined on a basis of a thorough knowledge of the forms, including their activities and behavior. When collecting in a given area at a particular time a general impression of the abundance of each species was formed, based on the number taken, observed, or heard in relation to the length of the collecting period. This impression was then recorded according to a five-term scale-abundant, common, numerous, occasional, or rare. The term "rare" was generally not used; instead, the actual number of specimens taken was recorded.

\section{A Classification of the Orthopteran Populations}

DIFFERENCE BETWEEN TYPES OF OCCUPANCY OF HABITATS.-The current ecological use of the terms dominant, influent, and the like, in characterizing. the relations of species to the environment in which they occur, involves recognition of the great differences in abundance and frequency of occurrence of a given species from one habitat to the next. These terms, however, carry an implication of constancy in the relation of the species to particular habitats and do not permit clear differentiation of frequency and abundance, for which reasons I have found them unsuited for expression of the concept of the relation of species populations to habitat to which my own studies have led me.

On the Reserve I have been able to distinguish between three grades of occupancy of a habitat by a species, which may be characterized as follows: (1) Permanent occupancy, the occurrence with high frequency of a species in a given habitat; in this habitat it may be found at all times in one stage or another of its life history. Its abundance in the habitat will often be high, but will vary from season to season with fluctuations in environmental conditions ; the variation in environmental factors is, however, never so great that the species is entirely killed off. In this paper, species with this relation to a particular habitat are said to be "characteristic" of the habitat. (2) Semipermanent, occasional, or periodic occupancy means the occurrence of a species in a habitat where it may maintain itself for one or more generations; but the habitat is subject to periodic recurrence of variations in eco- 
logical factors past the point of tolerance of the species, so that tenure of the habitat by the species is not continuous, and the habitat must be repopulated periodically from areas of permanent occupancy. Frequency of occurrence of the species in this habitat is naturally less than in the areas of permanent occupancy. Abundance of the species in the habitat may at times be high, but is more often low. The species exhibiting such a relation to a habitat are termed "sporadic." (3) Impermanent occupancy means the occurrence of scattered individuals, or even at times of rather large populations of a species, in habitats where the species cannot survive for even one full generation. Frequency of occurrence and abundance are both usually low, but are not invariably so. This type of occupancy results from the wandering of individuals or mass migrations from areas of permanent occupancy into surrounding habitats. Species exhibiting such relation to a habitat are termed "erratic."

As an example of the application of the above classification to a particular species, one may consider Spharagemon collare collare. This locust is characteristic of the mixed grass-herbaceous habitat, where both the young and adults occur with a high frequency and high abundance. During favorable seasons, the species invades the sparsely vegetated sand habitat. At such times adults and nymphs may be common; the degree of frequency may be low, moderate, or high, depending upon the amount of precipitation and other factors. During very wet or otherwise unfavorable seasons, however, this locust is no longer able to withstand the rigors of this environment and consequently dies out in the habitat. Spharagemon c. collare is therefore sporadic in the sparsely vegetated sand habitat. The species is an active form with excellent flying powers and often wanders into habitats in which it evidently cannot reproduce, but in which the adults are capable of existing for some time. Such wandering individuals are termed erratics within these habitats.

The facts concerning range of tolerance of particular ecological factors for various species are well understood from the viewpoint of laboratory investigations. Little has been done, however, regarding the application of this point to the interrelationship of species and habitat. Many of the papers dealing with the ecological relations of Orthoptera have suffered from the fact that their authors failed to recognize the fundamental differences between the types of occurrence distinguished above; thus one will find listed as characteristic of a given habitat some species which are normal inhabitants, some which are sporadic, and many which are merely erratic therein. Erratics may be important influents in a habitat, but the species which enter and their frequency of occurrence vary with the different environments that lie close to the invaded habitat. Thus Parcoblatta pensylvanica, Atlanticus testaceus, and Melanoplus bivittatus are often present as 
erratics in the grassy upland habitats, within which they would not occur except for the proximity of their own characteristic habitats. Similarly, individuals of Dissosteira carolina commonly move out from their characteristic habitats and become erratics in the marshes, swamps, and woodlands.

An extensive survey of the literature on Orthoptera has shown that most of the recorded data on the species that inhabit the Reserve have little or no bearing upon my problem. Observations that were easy to make have been published again and again; while others that would have furnished needed data are nowhere to be found. I am aware of but a single paper (Hubbell, 1922 ) in which an effort was made to indicate whether or not the species from a given habitat were truly characteristic of that environment. Hubbell (1922:9) stated that "in the lists of species under the different habitats, an asterisk (*) indicates that the species is common or abundant, a dagger $(\dagger)$ that it is of infrequent or rare (perhaps accidental) occurrence in that habitat."

For the reasons just stated my citations of previous work are restricted to the limited group of papers that contain relevant information. Were all the literature dealing with the species found on the Reserve to be cited, the appended bibliography would be much longer. For the convenience of users of this paper who are not familiar with the literature on Orthoptera, a reference to the best or most easily accessible comprehensive treatment of each species is included in the annotated list.

SEASONAL EXPANSIONS AND CONTRACTIONS OF POPULATIONS.-Such variations as appear to occur in the grouse locusts and in certain other orthopteran species on the Reserve, can be best analyzed and understood in terms of the above classification of environmental relations. Acrydium subulatum may be cited as a species typically exhibiting seasonal changes in habitat occupancy. In the fall, a factor of migration enters the lives of these grouse locusts, and the populations become rather widely dispersed or expanded through several habitats of which the species is not characteristic. Adult individuals are able to tolerate the conditions of these new environments, and during the winter the adults hibernate beneath debris in such habitats. In the spring individuals become active and the populations gradually congregate in groups within the characteristic habitat. Mating and ovipositing then occur; when completed, the adults gradually die out and are replaced by the next generation. As fall approaches individuals of this species again spread out as erratics into noncharacteristic habitats.

DIURNAL CYCLES OF SPREAD AND RESTRICTION OF POPULATIONS.-These cycles are also in accord with the types of occupancy. Thus, the cockroaches Parcoblatta pensylvanica, virginica, and uhleriana are characteristic of the terrestrial-hypogeic stratum of the forest habitats of the Reserve; but at night, when increasing humidity permits them to leave their normal habitat, 
they spread as erratics into the low shrub-terrestrial and even into the deciduous-arboreal strata, only to retreat with the approach of day.

THE BEHAVIOR OF ORTHOPTERAN AND OTHER TERRESTRIAL ANIMAL POPULATIONS IN RELATION TO FLUCTUATING ENVIRONMENTAL CONDITIONS.-An interpretation of the significance of the above-described types of occurrence of the orthopteran populations of the Reserve is here formulated as an hypothesis of general application. One may consider first a species population in an area of permanent occupancy-a characteristic species of the habitat. From season to season in the annual cycle, and from year to year, the various environmental factors which affect the species in each stage of its life history do not remain constant; but none of them ever transcends the limits of the range within which the species can survive. When one or more of the factors approaches a limiting value, the population diminishes; when all of them remain throughout one or more years at, or near, the optimum the population increases in numbers and reaches a condition of abundance.

Surrounding the area or habitat of permanent occupancy are other areas or habitats within which one or more of the environmental factors, at least occasionally, exceed the limits of toleration of the species, and within which the species cannot, therefore, permanently maintain itself. A period within which these factors remain at, or near, the optimum in the area of permanent occupancy, however, is likely, also, to result in amelioration of the environment in surrounding areas. This coincides with an increase in the population of the species in the area of permanent occupancy and an increase in the amount of accidental wandering out of this area into the surrounding territory. Since the plant associations are not so mobile, nor so immediately responsive to the changed conditions, this results in spread of the animal species into other habitats. In some parts of these the environment, while not perhaps optimum for the species, is tolerable to it. There the species may maintain itself for several, or many, generations. Eventually, a period of less favorable conditions supervenes, and the species dies out. These sporadic populations must, therefore, be renewed periodically by migration; and the chances are great that many situations which might be populated during favorable conditions are not so populated because they receive no immigrants.

About the areas of permanent and sporadic occupancy there are, at all times, zones more or less thinly populated by wandering individuals, which may soon die, or may be able to survive during their own lifetime, but which leave no progeny. These are the erratics in the zone of impermanent occupancy. Although one may easily distinguish in theory between the types of occurrence characterized above, and not infrequently encounter what appear to be clear-cut examples of each of them, it is, in practice, often very diffcult to determine the actual status of a given population. Some of the criteria which I have applied to the populations encountered on the Reserve 
are as follows. When a species occurred in abundance in a given habitat during all three of the years of my study, when oviposition was observed in the habitat, and when nymphs appeared in the habitat at the proper time, the species was assumed to be characteristic of, and permanently occupying, that habitat. When a species was found in fair numbers in a habitat both as adults and nymphs, but only during one or two years of the study, and close search in the remaining season or seasons failed to reveal it, it was classed as sporadic in that situation. The presence of nymphs was usually considered evidence that the species was reproducing in the habitat, and hence that the population was either permanent (characteristic) or semipermanent (sporadic) there; but there were certain exceptions to this, notably in the instance of Parcoblatta pensylvanica, which is fully discussed in the annotated list. Species were assumed to be erratic in a habitat when they occurred there only as adults, especially if they were present mostly in the fall or spring and in small numbers and were rather sparsely distributed. Among the Orthoptera the adult insects are usually capable of withstanding extremes of temperature and humidity which would be fatal to young. They also have greater powers of locomotion. The predominance of adult individuals in erratic populations is therefore natural. The prevalence of erratics in the fall and spring results from the tendency of the adults to wander out from the areas of permanent habitation in the fall, and, in some species, to hibernate under cover in a variety of situations from which they appear again in the spring.

The factors which are responsible for the type of occurrence for any species in any given habitat vary from species to species and from stage to stage of the life history. For the Orthoptera, they are known to include temperature, humidity, food supply, and sometimes shelter or some particular food plant for the young and adult. For reproduction and survival of the eggs they include a proper medium for oviposition, which often means suitable texture and moisture content of the soil. A variety of other factors are known or surmized to be involved. In areas of semipermanent or occasional occupancy, change in a single one of these factors may cause either migration or death of individuals, and resultant elimination of the population from the area. A hard freeze, an exceptionally warm or humid season, the drying up of the soils and the water of ponds and marshes, the movement and ecesis of other plants and animals, or other changes may have this result.

The interpretation of the behavior of orthopteran populations presented above is given not as an established generalization for which proof can be offered at present, but as an hypothesis which has been gradually evolved from my long-continued observations on the habitat relations, seasonal variation in occurrence, and individual behavior of the species present on the Reserve. It is consistent with all such observations and affords a logical 
and suggestive interpretation of their significance. It has been of value in directing my attention to problems and in leading to observations which would otherwise have been overlooked. Testing of this hypothesis will require studies differently organized and conducted than those which were required by my objectives. A few of the lines of investigation, which should be followed in determining the extent to which orthopteran populations actually follow the pattern of behavior described, may be indicated. Bioclimatographic analysis of the various species in areas of characteristic, sporadic, and erratic occurrence should produce evidence as to the reality and causes for these different types of occupancy (cf. Uvarov, 1932a). Studies of the shifts in large populations of marked individuals would be of value in determining the extent and nature of the movements of individuals and the behavior of the species in relation to the areas of impermanent occupancy. Experiments on the survival of eggs and young in selected areas in the field, together with laboratory experiments on the range of tolerance and behavior of the species concerned, would supplement the above methods and would furnish data for the interpretation of the results obtained by the field studies.

The detailed observations upon which the generalizations concerning the populations were based are summarized in the annotated list under the various species. The data given on the behavior of grouse locust populations, the close restriction of Doru aculeatum to a single habitat, the erratic wandering of Neoconocephalus ensiger and Orchelimum vulgare adults, and the population studies on Gryllulus assimilis are of particular significance in this connection.

\section{Analysis of Field Data}

A large quantity of field records and notes was amassed over the fouryear period covered by this investigation. In organizing and summarizing these data, and in determining from them the status of each species in various habitats, its seasonal distribution and period of maximum abundance, together with what had been learned of its habits, behavior, food, and life history, the following methods were employed. (1) A detailed cross index was prepared by subject and species to all field notes, maps of sight and sound records, and other information. (2) All date-locality records of abundance and frequency of each species were arranged in chronological sequence by habitat, were tabulated, and frequently were graphed to permit analysis by inspection. A summary based on these tabulations is presented in the section on seasonal relationships of the Orthoptera of the Reserve (Tables II-XII). (3) The orthopteran fauna of each type of environment was analyzed by species, according to the criteria discussed in full on page 21 , and on the basis of similarities and differences in the orthopteran faunas thus made evident, the various environments were organized into a classification of habitats applicable to the insects of this group. 


\section{DESCRIPTION OF THE AREA}

\section{Location and Physical Features}

Location.-The Edwin S. George Reserve, an area of approximately two square miles, is situated about four and one-half miles west of Pinckney, twenty-four miles northwest of Ann Arbor, and about thirty-two miles northeast of Jackson in the southwestern corner of Livingston County, Michigan. It lies within Range 4 east (Michigan meridian), Township 1 north (Michigan base line) and covers section 19 and parts of sections 25, 29, and 30 of Putnam Township, and parts of sections 24 and 25 of Unadilla Township.

Physiography.-The Reserve lies on the north edge of an interlobatemorainic region. Little till has been found on the area, the surface features having been largely formed by water action. The region just south of the Reserve represents the tip of a morainic spur formed by the junction of the Kalamazoo moraine coming from the southwest and the Mississinawa moraine coming from the south. The ridge upon which the custodian's residence is situated may represent a spur of this formation. To the north of the Reserve is located the Pinckney channel, through which the glacial Huron River flowed, draining to the south and west. The south terrace of this old river bed borders the north edge of the Reserve. Inspection of the contours of the immediate area suggests that, at stages of high water, the glacial Huron River could and did overflow the lowlands of the Reserve, leaving the hills as islands. If this is true, it furnishes an explanation of the flatness of those areas on the Reserve which are lower than the general outwash. In glacial times the kettle holes and low areas were undoubtedly filled with huge blocks of ice through and between which glacial waters wound their way. One of these streams left an esker-like formation, about one-half mile in length, that extends southwest from the northeast corner of the area. This formation is steep on both sides; the slopes drop sharply for a distance of about eighty feet into a series of kettle holes on the northwest side, and into the "big swamp" on the southeast (Map 1). A smaller spur runs from about the middle of this "esker" in a northwesterly direction. Both the main ridge and the spur of the esker merge at their western ends into a large outwash plain that lies at the same elevation as their crests and occupies much of the center of the Reserve. Here and there, in the southwestern and western parts of the Reserve, are hills and knolls which may represent kames.

The lowland areas of the Reserve lie at elevations above and below 900 feet, (Map 2). The areas below the 900 -foot contour line are occupied by

5 The more prominent features of the Reserve have received names at the hands of the investigators who have been working on the area, and for convenience and clarity some of these are used in the descriptive parts of this report. 
marshes and swamps. Above the level of the lowlands there are considerable areas of land with elevations between 925 and 950 feet. The highest parts of the Reserve consist of the large outwash plain in the center of the area, the top of the esker, and the summits of certain hills; these points reach elevations of from 975 to 1000 feet.

The soils of the Reserve are varied and patchy in distribution. The region of which it is a part lies within the Miami-Kewaunee soil area, as delimited and described by the Soil Survey Division, United States Depart-

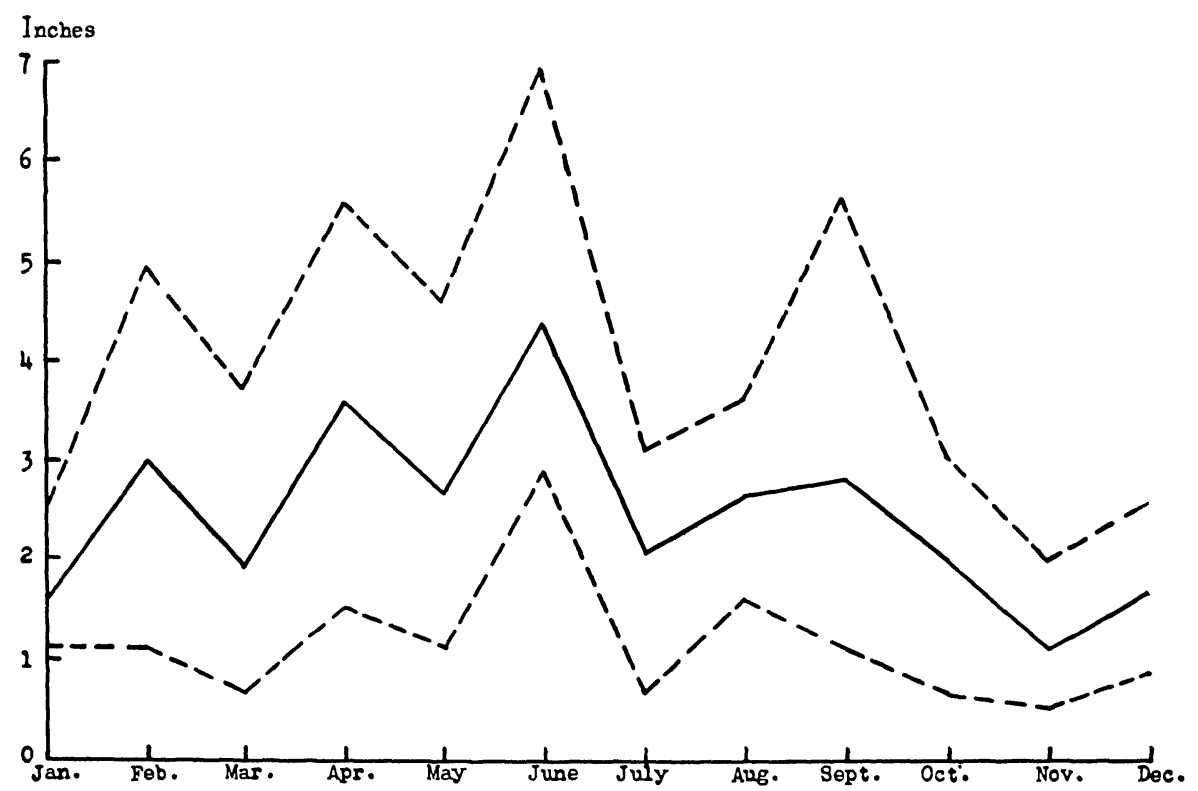

FIG. 1.-Mean monthly precipitation for the years 1936-39 based upon weather records taken at Ann Arbor, Jackson, Lansing, and Milford, Michigan. The unbroken line indicates the monthly mean of means and the broken lines the extremes in monthly means.

ment of Agriculture Yearbook (1938: 1042 and map). The uplands down to the level of the 900 -foot contour line are covered with mineral soils, including the Bellefontaine sandy loam, Plainfield sandy loam, and Coloma loamy sand. A few small patches of Miami loam are principally in the eastern, southern, and western parts of the Reserve. Nearly all the land below the 900 -foot elevation is covered with soils composed of organic peats and mucks ${ }^{6}$ deposited in bogs, marshes, and swamps; the accumulation is often of considerable depth. These organic soils are classified as the highly acid Greenwood peat, the moderately acid Rifle peat, and the more neutral or even alkaline Carlisle and Kerston mucks.

6 The distribution of the organic soils shown by the government soil survey of Livingston County, is, in part, not correct. The soil of the southwest and west central marshes is in reality Carlisle muck, not Greenwood peat, and that of the big Cassandra bog is Greenwood peat, not Carlisle muck. 


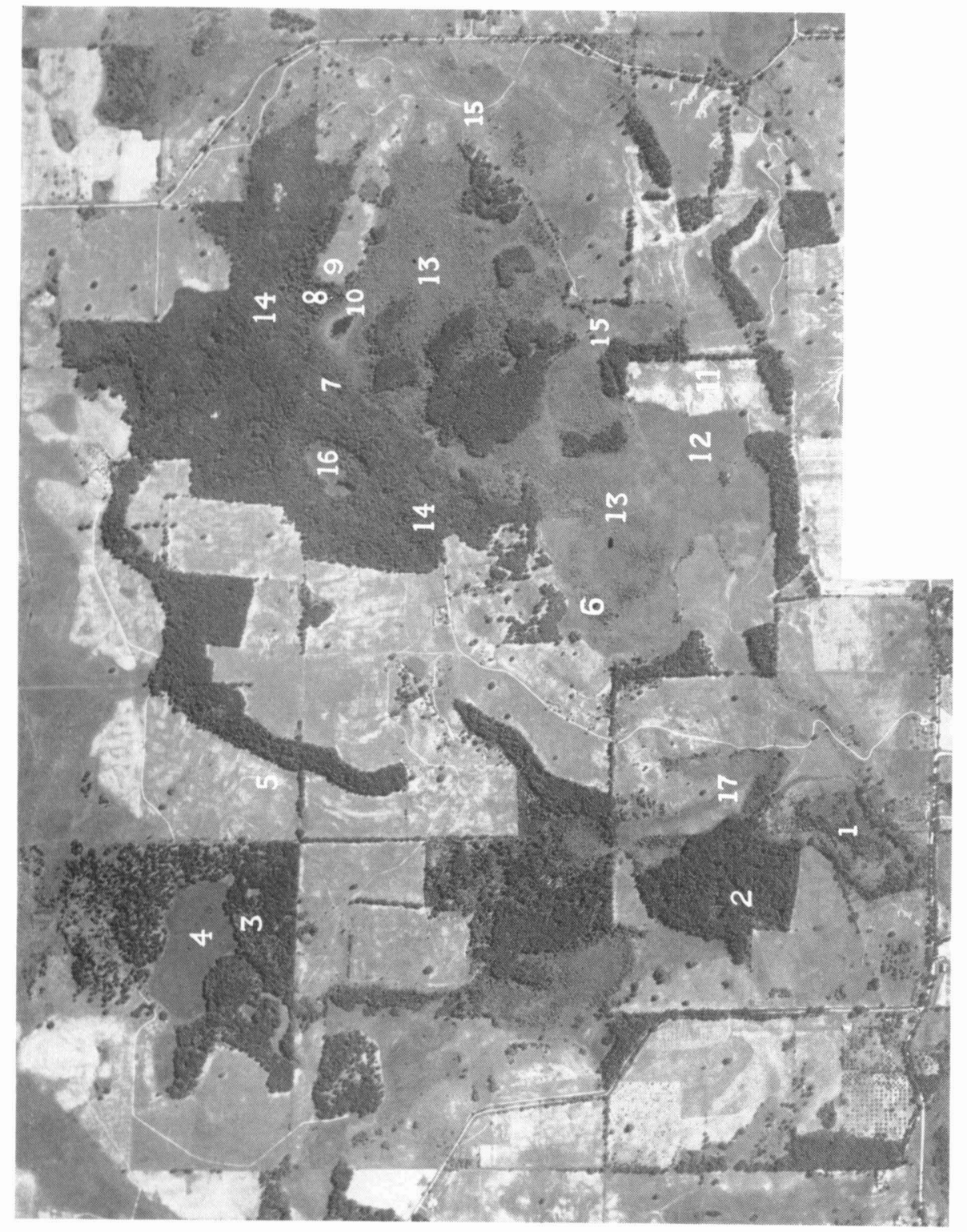

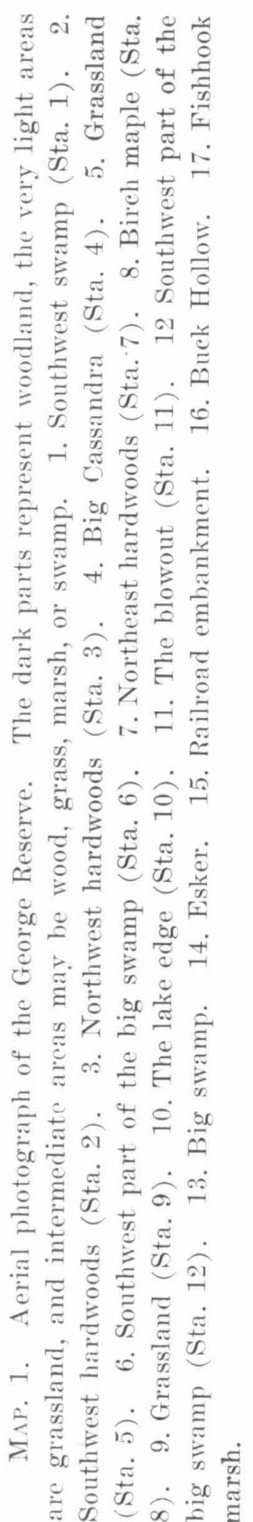





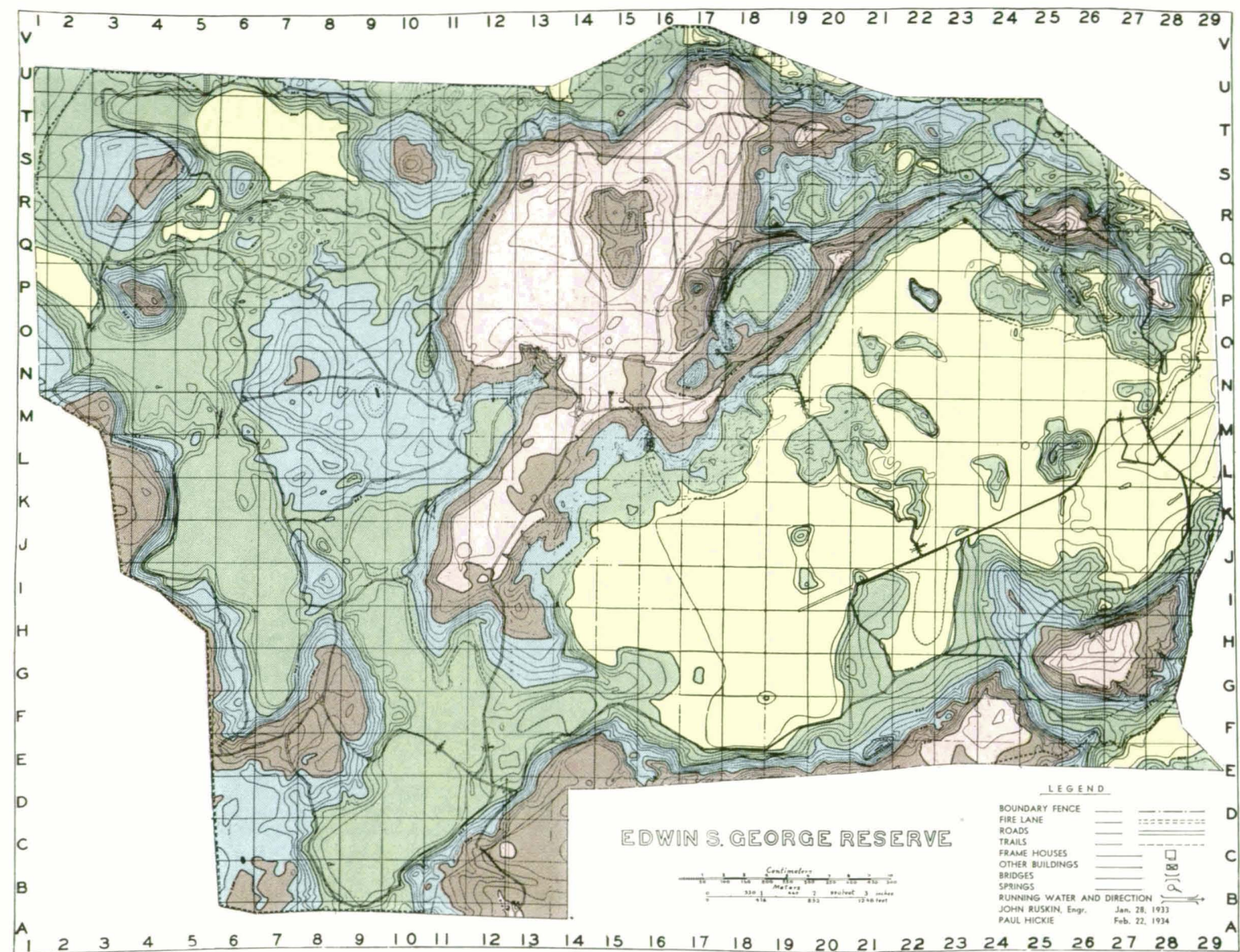

Map 2. Contour map of the George Reserve. Yellow, below 900 feet in elevation; green, 900 to 925 feet; blue-green, 925 to 950 feet; brown, 950 to 975 feet; pink, 975 to 1000 feet; blue, the lake. 



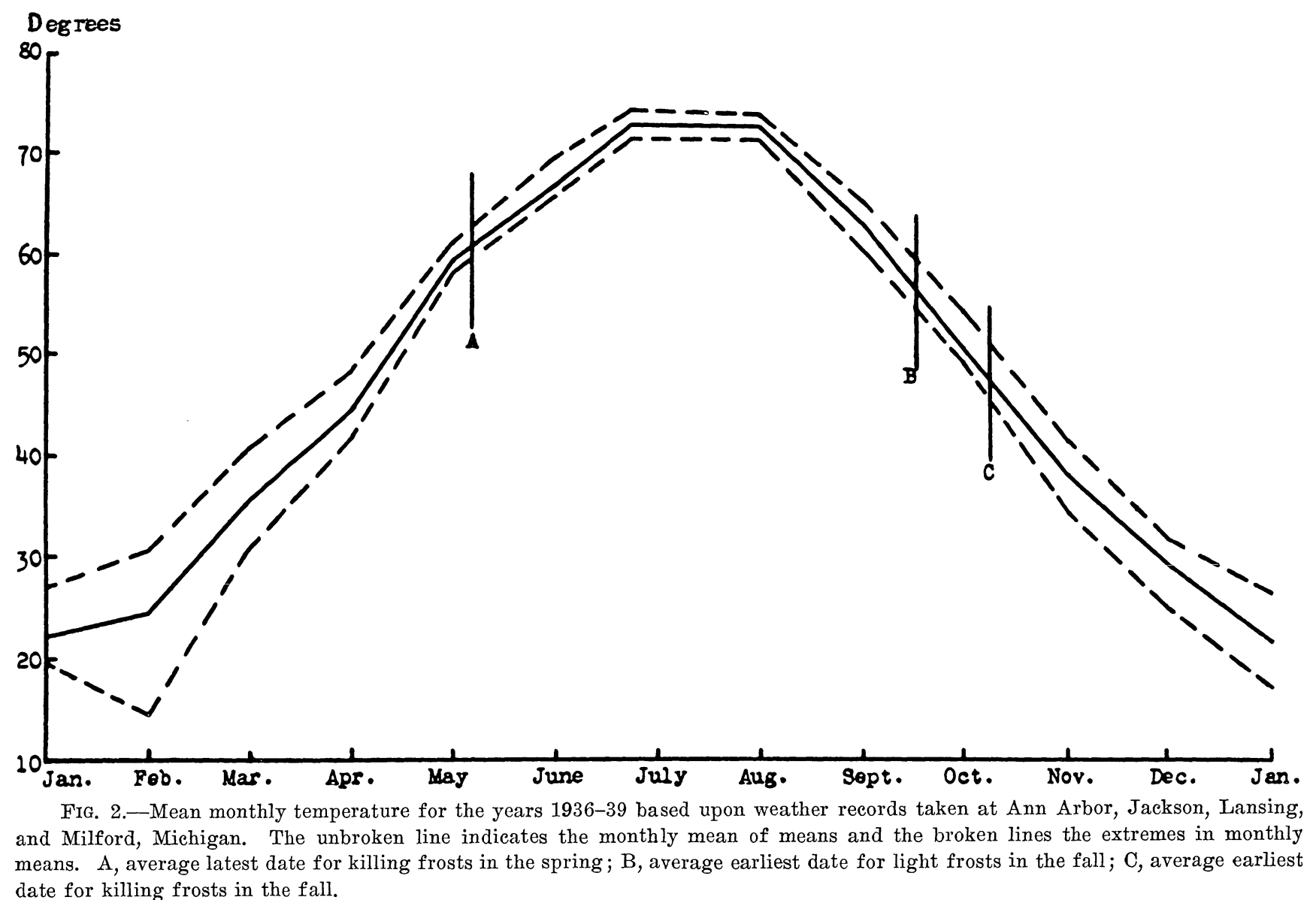


Drainage, which for the most part is good, is by water filtering through the sandy soils. Four springs, however, that flow constantly when not frozen testify to the presence of hardpan under certain parts of the Reserve. The steeper slopes of the upland suffer from excessive drainage, and it has been necessary to take steps to prevent erosion in certain gulleys on the area. Lowland, depending on its elevation, is under water temporarily or permanently.

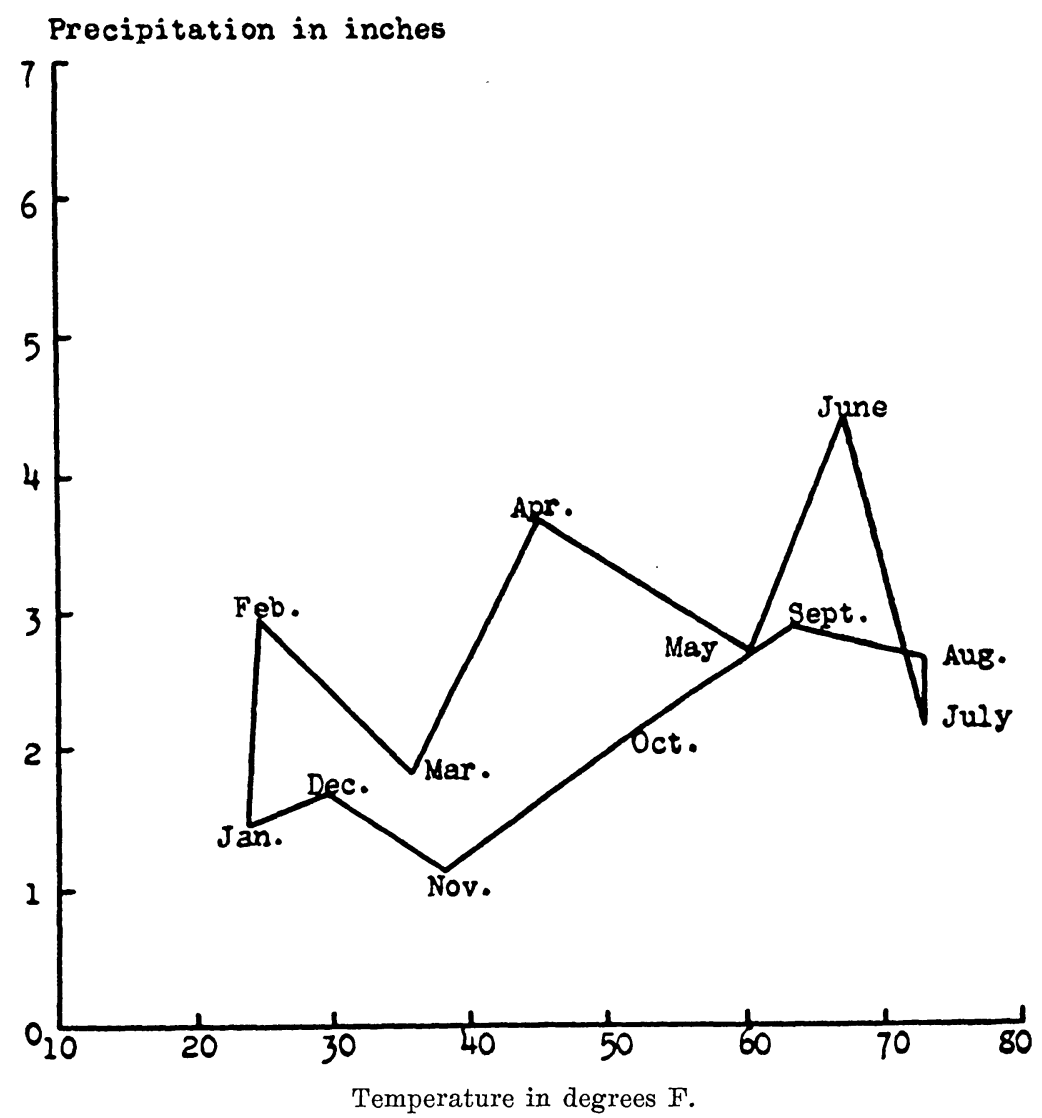

FIG. 3.-Hytherograph of mean monthly temperatures and precipitation for 1936-39 based upon weather records taken at Ann Arbor, Jackson, Lansing, and Milford, Michigan.

Meteorological Influences.- The region of which the Reserve is a part lies within the area that Thornthwaite (1931) has designated as the "BC'r," or which has a humid climate with low thermal efficiency and adequate rainfall at all seasons.

Since weather records have not as yet been taken on the Reserve, it has been necessary to obtain data from near-by stations. Records taken at Ann 
Arbor, Jackson, Lansing, and Milford (southeast, southwest, northwest, and northeast of the Reserve respectively) over the four-year period, 1936-39, were compared and found to deviate little from one station to another. The means of the total monthly precipitation occurring at these four weather stations have been calculated, and the extremes, as well as the mean of means, have been plotted (Fig. 1). The means of the average monthly temperatures have been similarly treated (Fig. 2), and the relation between precipitation and temperature is given in a hytherograph (Fig. 3).

Maximum rainfall (34.71 inches) fell in 1937; the minimum (25.81 inches) was received in 1936 . The average annual temperature varied but $2.4^{\circ}$ for the four-year period. The growing season is about 145 days.

The best correlation between climatological factors and the orthopteran species of the Reserve is found in the effect of the earliest killing frosts of the fall upon the size of the populations. These hard frosts very rapidly reduce the numbers of adult Orthoptera until by late October few, except hibernating individuals, remain alive. The lighter frosts, however, occurring in mid-and late September, are very effective in reducing the numbers of adult Orthoptera, and only the more hardy species are able to live over until the killing frosts of the latter part of that month.

\section{The Vegetation}

Original Condition.-Although it is not possible to make a definite statement regarding the original plant cover of the Reserve, certain features of the area permit one to arrive at tentative conclusions regarding it. The presence of mature oaks and hickories along many of the old fence lines and the rapidity with which oak is reproducing itself in the grassy upland bordering the oak-hickory forests indicate that, at one time, most, if not all, of the upland was covered with an oak-hickory forest of much the same nature as is now present on restricted parts. The vegetation of the lowlands has evidently undergone typical hydric succession to the present stages. The actual seres through which this succession progressed cannot be determined until more definite information has been obtained as to the depth and composition of the organic mucks and peats now in these areas.

Changes PRODUCED BY HUMAN OCCUPATION.-The information presented below was secured from Mike Roche, William Doyle, and Roy McClear by Lawrence Camburn and J. Speed Rogers in 1938. At that time Mr. Doyle was eighty-one years old; Mr. McClear was about sixty to sixty-five years old, and Mr. Roche was sixty-five. These men spent most of their lives on farms which are now part of the Reserve.

Any major clearing or shift in extent of fields and woods on the Reserve antedates the memory of these three men. Many of the larger and better trees were taken from the woodlands about 1900, and a considerable 
amount of lumbering was done during 1918 in the northwest hardwoods. Pasturage of the woodlands, marshes, and swamps was general prior to the establishment of the Reserve, but was heaviest before 1900. Cultivation of the cleared fields of the uplands was general and quite extensive until about 1900. At this time most of the fields in the south and eastern parts and the slopes of the grassy upland elsewhere on the Reserve were utilized as pastures. This was partly owing to the gullying in these sections.

There have been no fires on the Reserve since 1926, at which time a ground fire swept across the southwest corner, burning as far as the edge of the big swamp. Prior to that time, the only fire known to have occurred on the Reserve burned the northwestern grassy fields.

Artificial drainage has not been extensive; only a single line of tile was laid. This runs from near the southwest swamp in an easterly direction toward the big swamp, and is apparently no longer functional.

Present conditions.-The area was purchased and fenced as a game preserve by Colonel Edwin S. George in 1927-28. Two years later, Colonel George gave the tract to the University of Michigan for the establishment of a natural history reserve, which is administered by the Museum of Zoology. It is being left in a natural state, fire being excluded and succession being permitted to take place without interference. The only somewhat artificial feature of its present management is the maintenance on the area of a herd of deer, which becomes so large from time to time that occasionally the size of the herd must be reduced. The deer browse on the shrubbery, and materially retard its growth as well as diminish the extent of the shrub habitats.

In a general way one may recognize the existence of two principal physiographic and vegetational subdivisions within the area of the Reserve-the dry uplands with their associated vegetational types, and the moist lowlands with their marshes, ${ }^{7}$ bogs, and swamps. The dry uplands cover approximately three-fourths of the Reserve and are about one-third woodland and two-thirds grassland. The woodland areas are occupied by an oak-hickory forest, occurring in patches of one or two acres to about 125 acres. These forest tracts cover the summits of hills, spread down the slopes, and occupy kettle holes and other areas which were more or less unfit for cultivation.

7 There is a considerable amount of variation in the use of these and other terms applicable to the different hydric types of environment, both on the part of ecologists and of the public. Many of the descriptive terms used vary in meaning from region to region, or are known only locally; others are used for quite different habitats in different parts of the country. As used in this paper, a bog is a leatherleaf-sphagnum association; a swamp is a low, moist area within which tree and heavy shrub growths are present; and marshes are all areas inhabited by sedges, grasses, and herbaceous plants. The distinction between my usage of the terms marsh and swamp is not sharp, nor is it essential for the purpose of this paper that it should be. 
Owing to the rough topography of the Reserve, the woodlots are scattered here and there over the entire area. The balance of the upland consists of areas suitable for cultivation, which were cleared early in the history of the region. They are now occupied by grass and herbaceous growths.

The lowlands are covered with a patchwork of bogs, marshes, and swamps. The bogs are in two areas, the big Cassandra, of about sixteen acres, and Buck Hollow, a small bog occupying about an acre. The marshes are much more extensive, and are scattered over most of the Reserve, generally in kettle holes, pockets, and low ground. The vegetation in the marshes varies and may consist of sedges and grasses, mixed herbaceous growths, shrubbery, or a mingling of two or more of these types. About one-half of the lowlands may be included under the head of marshes. The swamps, covering the balance of the lowlands, comprise a large part of the tract known as the big swamp, and two smaller areas of five and eighteen acres, respectively, in the western part of the Reserve. 


\section{THE ORTHOPTERAN HABITATS OF THE RESERVE}

\section{The Basis for Recognition and Classification of the Orthopteran Habitats}

The factors which determine the habitat selection and relative abundance of most orthopteran species are complex, and in large part unknown. It is, therefore, not possible in a field study such as this to base an interpretation of the occurrence of species upon their reactions to specific environmental factors. Instead, the only practicable basis for such work is to analyze the occurrence of each species in terms of correlations with recognizable and characteristic features of the environment. A criterion was sought by which the varied types of ecological situations present on the Reserve could be grouped into a relatively small number of orthopteran habitats. Such a criterion is found in the occurrence of similar assemblages of orthopteran species in situations that are, for the Orthoptera, a single habitat, and of unlike assemblages of species, or of assemblages differing in relative abundance of species, in situations which are considered distinct habitats.

Obviously, some initial classification into recognizable environmental units had to be adopted as a basis for field observations, and for this purpose phyto-ecological units, such as might be recognized by a botanist, were most useful. Records were kept of the occurrence of the Orthoptera in each such phyto-ecological unit, and after the work had progressed sufficiently these records were combined into a graph. On the basis of this graph, some of the original units were found to be nearly, or quite, identical in orthopteran populations present and were combined into a single orthopteran habitat; others had to be subdivided into strata or other divisions in order to fit the facts of orthopteran occurrence.

Isely's work (1937) on the distribution of soil types and of Acrididae in Texas has shown that, in that region, there is often close correlation between the two. This suggests that soil type might be taken as the basis for general classification of orthopteran habitats in other areas, but on the Reserve this was not the case. If one ignores the fact that orthopteran habitats differ so much that a soil-based classification would have little bearing upon the occurrence of many species, there are other sufficient reasons for discarding soils as an important factor on the Reserve. There is very little relation between the soil type and the vegetation of the uplands. The oak-hickory forest occurs indiscriminately on Bellefontaine and Miami soils and evidently was once present on at least a part of the areas occupied by Plainfield and Coloma. The distribution of the Orthoptera in the upland habitats is correlated with the vegetation rather than the soils. In the instance of the organic soils of the lowlands, the bogs occur only on the Greenwood peat; 
but the marshes and swamps, though situated for the most part on only two soil types, the Kerston and Carlisle, are varied when considered as orthopteran habitats.

It was recognized early in this study that the extreme diversity of habitats of the Orthoptera, and the mobility of many of the species, would make quadrat and transect studies comparatively useless. The methodl actually followed-study of stations representing ecological units selected on the basis of soils, water conditions, and the presence or absence of dominant indicator plants-has proved entirely practicable since clear-cut vegetational units differentiated by these criteria could be correlated with orthopteran populations. A classification of these units into orthopteran habitats was then derived from the correlations.

The orthopteran habitats of the Reserve fall into three main classes, xeric, xeromesic, and, a more numerous class, hydric. As explained below, the transitions from upland (xeric and xeromesic) situations to lowland (hydric) situations are so abrupt throughout the Reserve that no areas of mesic conditions are present of sufficient size to warrant separate consideration. Designation of these habitat classes as xeric, xeromesic, and hydric is based upon their phyto-ecological characteristics, together with the evidences furnished by soils, drainage, and other more obvious features of the environment.

The xeric associations of the uplands are divisible into two major orthopteran habitats - the sparsely vegetated sand and the mixed grass-herbaceous. The xeromesic associations comprise the wooded areas of the uplands and are likewise divisible into two major orthopteran habitats-the more open, sunny oak-hickory forest, and the denser, more shady oak-hickory forest. The hydric associations include a greater variety of environments which constitute distinct habitats for Orthoptera; within this class it was necessary to recognize eight habitats based on the characteristics of their orthopteran faunas.

In all of the major habitats of the Reserve except the floating vegetation it is possible to recognize minor habitats in the form of strata, with which many of the orthopteran species are definitely associated. Some of these strata, such as the sphagnum, the leatherleaf, and the coniferous-arboreal, are confined to a single major habitat. Other strata are common to two or more of the major habitats within a single class, and a few transcend class limits. A stratum may even occur alone, in a zone not included in any of the major habitats; thus the wet-terrestrial stratum may be present as a bare zone around the margins of bodies of water, though it extends beneath the sedges in the marshes, carrying with it its characteristic orthopteran species. In the light of this situation it has been necessary to develop a classification of orthopteran habitats based on a double concept of major and 
TABLE I

The Distribution of Strata (Minor Habitats) Within Recognized Orthopteran Habitats (Major Habitats)

\begin{tabular}{|c|c|c|c|c|c|c|c|c|c|c|c|c|c|}
\hline \multirow[b]{2}{*}{ Stratum } & \multicolumn{2}{|c|}{ Xeric } & \multicolumn{2}{|c|}{ Xeromesic } & \multicolumn{9}{|c|}{ Hydric } \\
\hline & 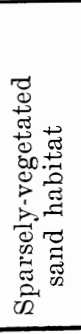 & 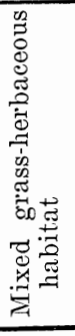 & 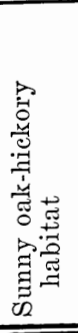 & 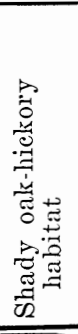 & 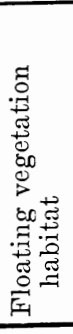 & 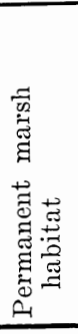 & 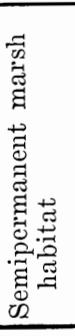 & 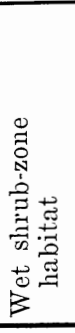 & 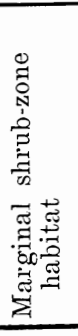 & 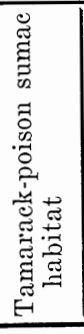 & 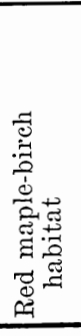 & 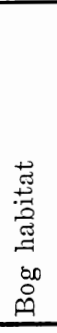 & 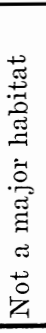 \\
\hline \multicolumn{14}{|l|}{ Deciduous-arboreal...... } \\
\hline \multicolumn{14}{|l|}{ Tall shrub } \\
\hline \multicolumn{14}{|l|}{ Low shrub-terrestrial } \\
\hline \multicolumn{14}{|l|}{ Upland hypogeic .......... } \\
\hline \multicolumn{14}{|l|}{ Coniferous-arboreal ... } \\
\hline \multicolumn{14}{|l|}{ Leatherleaf ........................... } \\
\hline \multicolumn{14}{|l|}{ 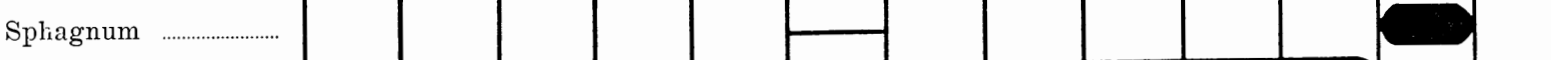 } \\
\hline \multicolumn{14}{|l|}{ Wet-terrestrial } \\
\hline Moist hypogeic zonal & & & & & & & & & & & & & \\
\hline
\end{tabular}


minor habitats, which in part coincide and in part overlap, and in which the distribution of the orthopteran species is related sometimes to the major habitat, sometimes to the stratum, and more often to both. Table I gives diagrammatic expression to the interrelationships of the major and minor orthopteran habitats of the Reserve. There follows a synopsis of the habitat classes, major habitats, and strata in the order in which they are later described and discussed.

\section{Summary of the Recognized Habitats}

\section{XERIC UPLAND ASSOCIATIONS}

1. Sparsely-vegetated sand habitat (Lichen-moss-Panicum associations)

2. Mixed grass-herbaceous habitat (Poa compressa-herb associations)

a. Upland hypogeic stratum. Common to 1 and 2

\section{XEROMESIC ASSOCIATIONS}

3. Sunny oak-hickory habitat (Quercus-Carya-Poa compressa association)

4. Shady oak-hickory (Quercus-Carya-Carex communis association)

a. Deciduous-arboreal stratum

b. Tall shrub stratum

These are more or less

c. Low shrub-terrestrial stratum common to both 3 and 4

d. Terrestrial-hypogeic stratum

\section{HYDRIC ASSOCIATIONS}

5. Floating vegetation habitat (Nymphaea advena association)

6. Permanent marsh habitat (Carex-Typha association)

7. Semipermanent marsh habitat (Carex-Calamagrostis-low shrub associations)

8. Wet shrub-zone habitat (Cornus-Cephalanthus-Salix associations)

9. Marginal shrub-zone habitat (Cornus association)

10. Tamarack-poison sumac habitat (Larix-Rhus vernix association)

11. Red maple-birch habitat (Acer rubrum-Betula association)

12. Bog habitat (Chamaedaphne-Sphagnum association)

a. Leatherleaf stratum

b. Sphagnum stratum

(Strata common to more than one of the hydric associations, or occurring alone)

a. Coniferous-arboreal stratum

b. Deciduous-arboreal stratum

c. Wet-terrestrial stratum

d. Moist-hypogeic zonal stratum 


\section{Description of the Habitats}

Cultivation, grazing, cutting of timber, fire, and the topography of the Reserve have caused the elimination of many of the stages of succession. Upland areas have been cleared of timber and cultivated so close to the remaining trees that shrub zones are almost nonexistent. The transition between the swamp lands and the woodlands or grasslands is abrupt, consisting at most of a narrow belt of hydrophytic shrubbery. Sharp transitions in soil type and soil moisture, and cultivation close to the swampland margins have combined to prevent the formation of well-defined ecotones.

\section{XERIC UPLAND ASSOCIATIONS}

When compared with the rest of the Reserve, the open upland areas, covered with grasses and herbaceous plants, form a decidedly xeric situation. Four successional stages may be recognized, which combine to form two orthopteran habitats.

\section{Sparsely Vegetated Sand Habitat \\ (Lichen-moss-Panicum Associations)}

(Pl. I, Figs. 1-2; Pl. II, Fig. 1)

1. The earliest stage of the xeric sere is represented by open, sandy areas which are sparsely covered with scattered plants. This vegetational type occupies areas ranging from as little as nine hundred square feet to as much as three or four acres. It occurs upon soils which may be Coloma loamy sand (the most restricted type), Plainfield sandy loam (the most extensive type), or Bellefontaine sandy loam (intermediate in extent of area covered). Extremes of light and temperature occur, and humidity is low. Shade is restricted to that offered by the plants themselves, particularly the grasses (Panicum spp.), which have a rosette of leaves often spreading several inches. The larger sandy areas are pitted with blow holes from one to thirty feet across, the smaller areas do not exhibit this condition.

Dominant plants of these sandy areas, listed in order of relative abundance are: lichens, mosses, panic grass (Panicum spp.), Canada blue grass (Poa compressa), goldenrod (Solidago sp.), mullein (Verbacsum thapsus), milkweed (Asclepias syriaca), fleabane (Erigeron ramosus), sand bur (Cenchrus carolinianus), a sedge (Cyperus filiculmis), and widely scattered clumps of low juniper (Juniperus communis var. depressa).

2. The sandy areas dominated by lichen and moss growth represent the second stage of the xeric succession on the Reserve. This stage differs from the preceding one in only a few respects. The soils are almost exclusively Bellefontaine sandy loam. Blow holes are absent, and vegetation has encroached over the open areas. The plant cover, except that the lichens and 
mosses now predominate and sand bur has dropped out, is very similar to that of the preceding stage in composition and proportion of area occupied.

\author{
Mixed Grass-herbaceous Habitat \\ (Poa compressa-herb Association)
}

(Pl. I, Fig. 2; Pl. II, Figs. 1-2; Pl. III, Fig. 1; Pl. IV, Fig. 1;

Pl. VII, Fig. 2 ; Pl. VIII, Fig. 1)

3. The next step in the xeric series may be called the short grass-lichen association. Poa compressa becomes much more abundant, and the mosses tend to drop out. As grass and herbs continue to increase in abundance, and lichens and mosses diminish, this association merges with the widespread grassy-herbaceous association described below.

4. The large expanses of grassy, herbaceous upland on the Reserve have been considered, for the purpose of this study, as one association. The following plants are found in various proportions with Poa compressa, the dominant plant: milkweed (Asclepias syriaca), goldenrod (Solidago nemoralis, S. altissima, and S. canadensis), pearly everlasting (Anaphalis margaritacea), everlasting (Antennaria neglectus and $A$. neodioica), fleabane (Erigeron ramosus), evening primrose (Oenothera sp. cf. muricata), hawkweed (Hieracium venosum), pinweed (Lechea minor), frostweed (Helianthemum canadense), a sedge (Cyperus filiculmis), panic grass (Panicum scribnerianum, $P$. tennesseense, $P$. addisonii, ${ }^{8}$ and $P$. huachucae), drop seed (Sporobolus neglectus), and triple-awned grass (Aristida purpurascens). The soil of this upland is Bellefontaine sandy loam, except for a small area of Coloma loamy sand.

The preceding four types of grassy upland have been discussed from the viewpoint of plant associations and physical factors. They constitute only two orthopteran habitats. The open, extremely xeric, sparsely vegetated areas and the lichen and moss association do not differ significantly in respect to their orthopteran faunas and must be considered as one-the sparsely vegetated sand habitat. Likewise, the short grass-lichen association and the tall, mixed grass-herbaceous association must, for the same reason, be accepted as one habitat - the mixed grass-herbaceous habitat. It is not possible to separate these two orthopteran habitats sharply, since they merge and grade into one another.

A third orthopteran habitat of the upland occurs as a stratum of both the sparsely vegetated sand and mixed grass-herbaceous habitats; this, the hypogeic habitat for Orthoptera, consists of the subterranean runways of small mammals. It is occupied by a single species, Ceuthophilus silvestris, and is discussed at length under that species.

8 Occasional. This is apparently the second known locality for the species west of the Atlantic seaboard, the only previous record being from northwestern Indiana. 
the habitat, one is sporadic, and the other twenty are erratics from near-by habitats.

Only two of the twenty species characteristic of xeric conditions are present in the sparsely vegetated sand habitat; the remainder are typical of the mixed grass-herbaceous habitat. Most of the other species which have been taken in xeric environments must be considered as erratics, since it is evident that they are not able to reproduce under these conditions. Among the erratics, sixteen ( 76 per cent) came from hydric environments, five (24 per cent) from woodland habitats.

\section{Upland Hypogeic Stratum}

A single species, Ceuthophilus silvestris-C, is known for this habitat.

\section{XEROMESIC ASSOCIATIONS}

On the Reserve, and in its immediate vicinity, there is practically no development of mesic environments. The closest approach to the theoretical regional climax forest (mesic beech-maple-birch) is in the assemblage of habitats which are here termed xeromesic. Two associations are included in this class-the oak-hickory woodland proper, and its marginal shrub zone. Both of these associations occur almost wholly on the Bellefontaine sandy loam, which is porous and permits water to drain readily. By late summer or during early fall this soil becomes so dry and compact that considerable effort is required to dig the ground. The good drainage and the comparative openness of the woodlots, as well as the fact that the oak-hickory association of the Reserve is situated on ridges, knolls, or slopes, produce a type of environment definitely drier than that of mesophytic forest. The contrast between the truly xeric environments of the Reserve and the oakhickory forest, however, is pronounced, and this habitat and its marginal shrub zone are therefore classed as xeromesic to indicate their intermediate status.

The oak-hickory marginal shrub zone, though present elsewhere in the general region, is almost nonexistent and certainly is of little importance as an orthopteran habitat on the Reserve, because of cultivation close to the margins of the woodlots. The oak-hickory association proper consequently forms the bulk of the xeromesic associations on the Reserve. The poor soil and good drainage will, at least for a very long time, prevent the development of the theoretical beech-maple climax forest cover.

The density of tree stand, density and composition of undergrowth, and amounts of down timber and leaf mold vary considerably within any one, and from one to another, of the several wooded tracts.

The woods in the southwest corner of the Reserve (Station 2) is, in many respects, the least disturbed. The predominant trees in order of abundance 
are: white oak (Quercus alba), pignut (Carya glabra), black oak (Quercus velutina), and shag-bark hickory (Carya ovata). The taller shrubbery is composed of sassafras (Sassafras officinale) and wild black cherry (Prunus serotina) occurring as young trees from one to two inches in diameter, and of frost grape (Vitis vulpina), witch hazel (Hamamelis virginiana), hazelnut (Corylus americana), and English hawthorn (Crataegus oxyacantha). The lower shrubbery consists chiefly of low-bush huckleberry (Gaylussacia baccata) and low-bush blueberry (Vaccinium canadense). Sedges, grasses, and herbs forming the woodland ground cover include: bracken (Pteridium latiusculum), panic grass (Panicum tennesseense), wild oat grass (Danthonia spicata), Canada blue grass (Poa compressa), brome grass (Bromus kalmii), bottle brush grass (Hystrix patula), sedge (Carex communis and C. convoluta), wild yam root (Dioscorea villosa), hepatica (Hepatica americana), cinquefoil (Potentilla pumila), bramble (Rubus flagellaris-marginal), agrimony (Agrimonia gryposepala), tick trefoil (Desmodium nudiflorum), vetch (Vicia caroliniana), bush clover (Lespedeza hirta), wild bergamot (Monarda fistulosa), northern bedstraw (Galium boreale), wild licorice (Galium circaezans), aster (Aster macrophyllus and A. laevis), plantain-leaved everlasting (Antennaria plantaginifolia), everlasting ( $A n$ tennaria neglecta), ox-eye (Heliopsis scabra), and common yarrow (Achillea millifolium).

This woodlot has suffered less from the operations of man or else has recovered more rapidly than most of the others. Tree cutting was apparently carried on judiciously, and there is, at present, little evidence of past overgrazing and fire. Aspen and juniper are not present, except for an occasional marginal aspen. These scattered aspens indicate that retrogression has occurred in the past. A heavy growth of young sassafras in the northeast corner of this woods shows that some cutting has been done there. In this part of the woodlot there are scattered tangles of frost grape, and invasion by sassafras has greatly reduced the abundance of herbage, so that little else than Carex communis grows on the ground. Sassafras, apparently unpalatable to the deer, is at present spreading to other parts of the southwest woods. Except in the northeast part of the woods, just described, the trees are far enough apart to permit the invasion of scattered individuals of a number of grassland plants, such as wild bergamot, common yarrow, bush clover, and everlasting; and in an area on the west edge of the woodlot the oaks and hickories are so widely spaced that the herbs of the ground stratum are more typical of the grass lands than of the woods. Here Canada blue grass replaces Carex communis as the dominant ground cover. To the north of this open part, on a northwest slope, the ground cover is composed of a heavy growth of low-bush huckleberry and low-bush blueberry. The forest floor of this woodlot, except where conditions are not typical, as indicated 
above, is everywhere covered with a moderate growth of the woodland sedge (Carex communis), with characteristic herbs and grasses scattered throughout. The ground is strewn with piles of leaves, sticks, and branches, and here and there is a decaying stump or log. The soil, predominantly Bellefontaine sandy loam, is literally honeycombed with the runways and burrows of mice and moles.

The woods in the northwest corner of the Reserve (Station 3) are in many respects similar to those of Station 2. There are, however, more small pockets in which leaves accumulate and become soggy. The soils and hypogeic conditions are very similar to those of Station 2. Red oak (Quercus rubra) is here an important tree, and sassafras occurs throughout, but is very scattered. Hazelnut and witch hazel are more frequently encountered. In the eastern part of the area, bracken (an indicator of openness) is a dominant plant crowding out most of the woodland herbs. Lowbush huckleberry and low-bush blueberry are widely scattered, and the herbaceous growths are greatly diminished. The tree density is variable from place to place. The trees are sometimes close enough together to prohibit herb growth; but elsewhere they may be scattered as a result of cutting, and there are occasional small openings among the trees. Aspen has invaded the more open situations, but is beginning to lose ground.

To the north of the esker is a small area of moderately dense secondgrowth forest composed largely of saplings and small trees. Although different in aspect from the other oak-hickory woods of the Reserve, it is probable that this tract will in time develop into a similar forest. A single mature beech is located in this woods, and it is possible that the climax tree may be able to shift the balance toward beech forest; but at present there are no indications of such a result. The orthopteran fauna of this dense stand does not differ significantly from that of the other woodlots of the Reserve.

The oak-hickory woods covering the esker, its slopes, and a considerable area to the north and west (Station 7 ) has about the same density of stand as Stations 2 and 3. In this station, as in both the others, there are open areas with scattered trees through which enough sunlight filters to maintain some grassland herbs and grasses. The presence in the more open places of living aspens three to six inches in diameter, of dead aspens and aspen logs, and of dead and dying clumps of juniper, indicates that this woods has, in parts, been more heavily cut over and more heavily grazed than the other woodlands of the Reserve.

The trees in Station 7 are predominantly black oak, white oak, a few scattered red oaks, shag-bark hickory, pignut, and wild black cherry. Sassafras saplings, attaining a height of about six feet, are more often sparsely distributed, but occasionally may occur in clumps. Witch hazel and hazelnut are few and widely scattered. The woody plants of the forest floor are 
few in kind and number, consisting of low-bush huckleberry, low-bush blueberry, dead, or nearly dead, junipers, and widely scattered wild black cherry seedlings. Owing to the steep slopes and resulting excessive drainage, the herbaceous growth is even more sparse than in Stations 2 and 3 . Woodland sedge is dominant, occupying all of the ground not covered by dead leaves and debris. Bracken, hepatica, cinquefoil (Potentilla pumila), frostweed (Helianthemum canadense), wild sarsaparilla (Aralia nudicaulis), spreading dogbane (Apocynum androsaemifolium), poke milkweed (Asclepias phytolacoides), common mullein (Verbascum thapsus), northern bedstraw (Galium boreale), bluebell (Campanula rotundifolia), daisy fleabane (Erigeron ramosus), and everlasting (Antennaria neglecta, $A$. munda, and $A$. plantaginifolia) are conspicuous in the herbage of the forest floor. Certain of these plants, particularly wild sarsaparilla, spreading dogbane, hepatica, and bluebell occur where the soil is moist. Down timber is more abundant and more rotted than in Stations 2 and 3, indicating that this forest was less used as a source of fire wood. The dead leaves and duff form a layer from two to four inches in depth, and here and there the leaves are heaped around the base of a dead juniper bush or some other obstruction.

The most open of the oak-hickory woods on the Reserve is a small patch of about two and one-half acres near the southeast boundary. Here the trees are quite scattered, permitting enough sunlight to reach the ground so that grassland herbs are maintained on most of the forest floor. Canada blue grass dominates for fully fifty feet within the margins, and then is partially replaced by woodland sedge. Common milkweed (Asclepias syriaca), common mullein, everlasting, daisy fleabane, and pearly everlasting (Anaphalis margaritacea) are common. The low juniper, Juniperus communis var. depressa, is common, and, although badly browsed and affected by rust, is still full and green. At the north and south margins of this tract, there are clumps of aspen seedlings.

From the above descriptions of different examples of the oak-hickory association on the Reserve, it is evident that, so far as their plant composition, type of soil, and ground and hypogeic strata are concerned, all the wooded tracts are very similar. With respect to density of tree growth, density of undergrowth, and the occurrence and abundance of herbaceous plants, differences are apparent within one woods and between different tracts. On the basis of orthopteran populations, the oak-hickory association may be divided into two general habitats-the sunny oak-hickory and the shady oak-hickory. Each is further divisible into four strata which are common to both major habitats : 1 , deciduous-arboreal ; 2 , tall shrub; 3 , low shrub-terrestrial and 4, terrestrial-hypogeic. One of these strata, the deciduous-arboreal, is recognizable wherever deciduous trees are present, throughout the xeric, xeromesic, and hydric associations of the Reserve. 


\section{Sunny Oak-hickory Habitat \\ (Quercus-Carya-Poa compressa Association)}

(Pl. III, Fig. 2 ; Pl. IV, Fig. 1)

The ecotone between grassland and oak-hickory woodland is so sharp that it fails to form an orthopteran habitat. Only those parts of the woods proper which are open enough to permit sunlight to reach the ground for several hours a day will maintain conditions favorable to the forms listed below. The numbers of sporadic and erratic Orthoptera in this type of habitat vary with the proximity to other orthopteran habitats. If close to grassland or swamp, erratics from these habitats naturally find their way into this association.

A Deciduous-arboreal Stratum

$\begin{array}{lll}\text { Diapheromera femorata } & \text { (C) } 10 \text { adults } & \text { *Oecanthus niveus C } \\ \text { Scudderia septentrionalis } & \mathrm{S} & \text { *Oecanthus angustipennis } \mathrm{C}\end{array}$

\section{B Tall Shrub Stratum}

*Diapheromera femorata (C) medium *Oecanthus angustipennis $\mathrm{C}$ juvenile and adults

*Oecanthus niveus $\mathrm{C}$

C Low Shrub-terrestrial Stratum

\begin{tabular}{|c|c|}
\hline $\begin{array}{l}\text { *Diapheromera femorata (C) eggs } \\
\text { and small young }\end{array}$ & $\begin{array}{l}\text { Melanoplus m. mexicanus } \quad \mathrm{E} \\
\text { Melanoplus keeleri luridus } \quad \mathrm{S}\end{array}$ \\
\hline${ }^{*}$ Parcoblatta pensylvanica $\mathrm{C}$ & Scudderia $f$. furcata $\mathrm{E}$ \\
\hline Parcoblatta virginica $\mathrm{S}$ & Amblycorypha rotundifolia $\mathrm{s}$ \\
\hline Acrydium subulatum $\mathrm{E}$ & Neoconocephalus ensiger $\mathrm{E}$ \\
\hline Tettigidea lateralis parvipennis $\mathrm{E}$ & Conocephalus strictus $\mathrm{E}$ \\
\hline${ }^{*}$ Chloealtis conspersa $\mathrm{C}$ & *Atlanticus testaceus $\mathrm{C}$ \\
\hline Encoptolophus s. sordidus $\mathrm{E}$ & Ceuthophilus brevipes $\mathrm{E}$ \\
\hline Dissosteira carolina $\mathrm{E}$ & Ceuthophilus meridionalis $\mathrm{E}$ \\
\hline${ }^{*}$ Spharagemon bolli $\mathrm{C}$ & Gryllulus assimilis $\mathrm{S}$ \\
\hline Spharagemon c. collare $\mathrm{E}$ & Nemobius fasciatus $\mathrm{E}$ \\
\hline Schistocerca alutacea $\mathrm{E}$ & ${ }^{*}$ Nemobius fasciatus tinnulus $\mathrm{C}$ \\
\hline Melanoplus bivittatus $\mathrm{E}$ & Nemobius c. carolinus $\mathbf{E}$ \\
\hline $\begin{array}{l}\text { Melanoplus confusus } \mathrm{E} \\
\text { Melanoplus } f-r . \text { femur-rubrum } \mathrm{E}\end{array}$ & $\begin{array}{l}\text { Oecanthus nigricornis quadripunc- } \\
\text { tatus } \mathrm{E}\end{array}$ \\
\hline
\end{tabular}

D Terrestrial-hypogeic Stratum

*Parcoblatta pensylvanica C

*Ceuthophilus meridionalis $\mathrm{C}$

* Parcoblatta virginica $\mathrm{C}$

*Ceuthophilus brevipes $\mathrm{C}$ Gryllulus assimilis $\mathrm{E}$

$10 \mathrm{D}$. femorata is characteristic of the three upper strata of the oak-hickory association and therefore cannot be classified under a single stratum. For further details regarding this species, see the Annotated List. 
Of the thirty-two species occurring in the sunny oak-hickory habitat, twelve are characteristic of one or more strata in this environment. Of these twelve forms, however, nine are also characteristic of the shady oakhickory habitat, and only three are typical of the sunny oak-hickory alone. Four sporadics occur, two of which have invaded from the shady oak-hickory and two from the grassland association. Of the nineteen erratics, reported, six come from hydric environment, eleven from the xeric upland, and two from the shady oak-hickory.

\section{Shady Oak-hickory Habitat (Quercus-Carya-Carex communis Association) \\ (Pl. IV, Fig. 2 ; Pl. V, Fig. 1; Pl. VI, Fig. 2)}

This orthopteran habitat forms the greater part of the oak-hickory association. The tree crowns overlap sufficiently to cut off most of the sunlight. leaving only very small areas, a few square inches or feet, which may get intermittent sunlight. Humidity is higher than in either the xeric grassy upland associations or the sunny oak-hickory habitat. The increase in moisture and shade permits the growth of much woodland herbage. The location of the woodlands upon hills, knolls, and slopes produces differences in the extent of drainage which are reflected in the density of the undergrowth, which may vary from abundant to scanty.

\section{A Deciduous-arboreal Stratum}

\begin{tabular}{|c|c|c|c|}
\hline \multirow[t]{2}{*}{$\begin{array}{l}\text { *Diapheromera femorata } \\
{ }^{*} \text { Scudderia septentrionalis }\end{array}$} & $\begin{array}{l}(\mathrm{C}) \\
\mathrm{C}\end{array}$ & adults & $\begin{array}{l}\text { *Oecanthus niveus C } \\
{ }^{*} \text { Oecanthus angustipennis }\end{array}$ \\
\hline & B & Tall Shrub & Stratum \\
\hline $\begin{array}{l}\text { Diapheromera femorata } \\
\text { juveniles to adults }\end{array}$ & (C) & medium & $\begin{array}{l}\text { *Oecanthus niveus C } \\
\text { *Oecanthus angustipennis }\end{array}$ \\
\hline
\end{tabular}

C Low Shrub-terrestrial Stratum

* Parcoblatta pensylvanica C

* Parcoblatta virginica C

* Parcoblatta uhleriana C

* Diapheromera femorata and small juveniles

Acrydium subulatum $\mathrm{E}$

Acrydium ornatum $\mathrm{E}$

Tettigidea lateralis parvipennis $\mathrm{E}$

Orphulella speciosa $\mathrm{E}$

*Chloealtis conspersa $\mathrm{C}$

Dissosteira carolina E

Spharagemon bolli $\mathrm{S}$

Spharagemon c. collare E

* Melanoplus islandicus C

Melanoplus bivittatus $\mathrm{E}$
Melanoplus f-r. femur-rubrum $\mathrm{E}$ Melanoplus fasciatus $\mathrm{S}$

Melanoplus m. mexicanus $\mathrm{E}$

Melanoplus keeleri luridus E

Scudderia c. curvicauda $\mathrm{E}$

Scudderia f. furcata $\mathrm{E}$

* Amblycorypha rotundifolia C

Conocephalus brevipennis $\mathrm{E}$

*Atlanticus testaceus C

${ }^{*}$ Ceuthophilus brevipes $\mathrm{C}$

*Ceuthophilus meridionalis $\mathrm{C}$

Gryllulus assimilis $\mathrm{S}$

Nemobius $f$. fasciatus $\mathrm{E}$ 


\section{Terrestrial-hypogeic Stratum}

*Parcoblatta pensylvanica C

* Parcoblatta virginica C

* Parcoblatta uhleriana $\mathrm{C}$
${ }^{*}$ Ceuthophilus brevipes $\mathrm{C}$

*Ceuthophilus meridionalis $\mathrm{C}$

Gryllulus assimilis $\mathrm{E}$

In the course of this investigation, thirteen characteristic, three sporadic, and fourteen erratic forms have been observed in the shady oak-hickory habitat. This environment has four species confined to it, but nine species are also characteristic of the sunny oak-hickory. Two sporadies have invaded the shady oak-hickory from the sunny oak-hickory, and one has moved in from the xeric grassland associations. Xeric and hydric environment each account for one-half of the erratics.

\section{HYDRIC ASSOCIATIONS}

In relation to hydrophytic conditions the orthopteran fauna of the Reserve is even less closely correlated with the recognizable phyto-ecological units than in the instance of the xeric and xeromesic associations. All stages of the hydrosere are found on the Reserve. Many local areas, however, do not represent any clear-cut stage in succession, but show a blending of two or more plant associations. Sedge may exist in pure stands, in association with grass, in association with grass and herbs, or in association with grass, herbs, ferns, shrubbery, and even trees. As a result, a given plant species may be well represented in several entirely different-appearing communities. The Orthoptera and Dermaptera, with rare exceptions, fail to be influenced by these different combinations; but their occurrence seems, instead, to be correlated with larger vegetational complexes which may comprise more than one stage in hydrophytic succession. These larger ecological units make up the hydric-orthopteran habitats.

The hydrophytic associations of the Reserve are confined entirely to areas occupied by one or more of four types of organic soils. These soils have developed in the larger kettle holes and pockets by the washing in of organic materials from higher areas, and by decay of marsh, swamp, and bog vegetation. Open water is retained in the larger depressions from seven to nine months each year. The small lake in the northern part of the big swamp represents the most permanent body of water. During the three years of this study, this lake has always retained water even when all of the other marshes and swamplands have dried out; its basin is shallow enough so that during times of extreme drought the water disappears, leaving expanses of bare, moist mud.

The relatively undecomposed and highly acid Greenwood peat occurs in the leatherleaf bogs and also in a small area along the east margin of the lake. The older, more fully decomposed and less acid Rifle peat occurs all through the big swamp, but becomes progressively more mature toward the 
southern end of the swamp, where it is almost indistinguishable from Carlisle muck. With the exception of a few small, shallow pockets containing Kerston muck, the remainder of the marsh and swamplands are occupied by the more alkaline and well-decomposed Carlisle muck. This soil is also found, in a belt of varying width, around the margins of the leather-leaf bogs and surrounding area occupied by Rifle peat. As indicated in the discussion of the grasslands, the organic soils give way abruptly at the margins of the depressions to the mineral soils characteristic of the uplands; the vegetation reflects this sharp demarcation, and the ecotone is correspondingly narrow or nonexistent.

Drainage is poor in the depressions, and each year for the past four years the water has stood higher in them and has remained later in the season. In 1938, probably because of obstruction of the artificial drainage channels, standing water persisted until about the middle of September. During 1939, several such depressions did not dry up at all.

Two swamps in the southwest corner of the Reserve present a rather atypical condition, owing to retrogression. Originally, these swamps drained by way of a small watercourse, southward into Patterson Lake. At that time they had reached a stage in which sugar maple and white ash invaded the area and became established. About 1872 a road was built across the outlet, blocking off the drainage. Water rose in the swamps until, in 1882, a tile drain was laid to carry the water eastward. Drainage by this means was incomplete, however, and open water is now present in these swamps during most of the year. This has had a profound retrogressive effect on the composition as well as on the distribution of the vegetation. The sugar maple and white ash are beginning to show the effects of this, for them, new and rigorous environment. Some trees are dead, and others are beginning to die. The vegetation of these swamps does not occur in typical concentric zones, but in blocks or units, indicating that ecesis has not progressed far enough for the establishment of well-defined associations.

Owing to the complexity of successional relations and the effects of disturbance in the hydric environments of the Reserve, it is not possible to treat these habitats from the phyto-ecological standpoint in the same manner as was done for the grassland and forest environments. Furthermore, the orthopteran populations of these environments fail to reflect the differences between the subordinate phyto-ecological units. Under these circumstances it is most feasible to discuss the hydric environments solely as orthopteran habitats.

The hydric orthopteran habitats are, with the exception of the floatingvegetation habitat, further divisible into four strata: 1 , the coniferousarboreal; 2, the deciduous-arboreal; 3 , the wet-terrestrial; and 4 , the moist-hypogeic zonal.

The coniferous-arboreal stratum is found only in the tamarack-poison 
sumac habitat and is confined to the trunks and branches of the tamarack trees. Certain species, notably Oecanthus niveus and $O$. angustipennis, inhabit the deciduous-arboreal stratum, made up of the foliage and branches of the deciduous trees of the red maple-birch habitat. These Orthoptera are also in the same stratum in the southeast swamp, where, as indicated above, many deciduous trees are still present. The wet-terrestrial stratum is made up of the muddy margins of the lowlands. As the season progresses and water recedes, this marginal zone may become broader and broader and finally often extends throughout a marsh or swamp. The amount and content of debris varies considerably from place to place and may be a layer several inches in thickness or be entirely lacking. Often a particular area or zone of the wet-terrestrial stratum may have permanently moist and mucky soil, in which Gryllotalpa hexadactyla makes its burrows. Such areas or zones are herein termed the moist-hypogeic-zonal stratum.

The various strata of the hydric habitats are indicated below each environment within which they occur, and their orthopteran species listed.

\section{Floating Vegetation Habitat (Nymphaea advena Association)$$
\text { (Pl. V, Fig. 2) }
$$

The association of floating vegetation is the most hydric habitat occupied by Orthoptera. Three distinct and quite different areas exhibit this type of environment. In the southwest swamp there is a small area, a fraction of an acre, in which water persists for long enough periods to permit Nymphaea advena and the scouring rush (Equisetum hyemale) to maintain themselves. In the spring and early summer the water surface is covered with a floating layer of a liverwort (Riccia) and duckweed (Lemna). The surface and margins of the lake constitute the second area in which there is floating vegetation. Here Nymphaea advena alone is scattered over the water and in the oozy mud of the margins. Floating vegetation, Nymphaea advena, has also been found in the ditches along an abandoned railroad grade on the south side of the big swamp. Here two depressions are filled with oozy mud in which the lily grows abundantly. Of these three situations, Orthoptera have been noted only in the second, from which I recorded only the songs of a few sporadic individuals of Orchelimum concinnum. Gryllotalpa hexadactyla is recorded, both by song and by specimens collected, as occurring in the moist-hypogeic-zonal stratum marginal to the first and third areas discussed above.

\section{Permanent Marsh Habitat \\ (Carex-Typha Association) \\ (Pl. V, Fig. 2)}

Around the lake, on a "quaking" mat, is an area covered with a mixture 
of cattail, sedge, ferns, grasses, herbs, and small shrubs. The most conspicuous of these plants are: shield fern (Dryopteris), common cattail (Typha latifolia), spike rush (Eleocharis sp.), swamp rose (Rosa sp.), water horehound (Lycopus rubellus), bedstraw (Galium sp.), joe-pye weed (Eupatorium maculatum), and bur marigold (Bidens sp.). Intermingled with these are scattered individuals of leatherleaf (Chamaedaphne calyculata), swamp birch (Betula pumila), dogwood (Cornus sp.), and small seedlings of poison sumac (Rhus vernix) and tamarack (Larix laricina) from one to two feet high. The soil, a fibrous muck, is hummocky and covered with a heavy layer of dead plant material. The hummocks themselves often support a dense growth of sphagnum or other mosses. The area is submerged until mid-August; after recession of the water the spongy soil remains saturated until, in early November, the water again rises and covers it until the following year. Three strata are recognizable in this habitat, the coniferousarboreal, the sphagnum, and the wet-terrestrial. Except for three species, Tettigidea armata, Paroxya hoosieri, and Orchelimum concinnum, the Orthoptera of this habitat are also typical of other hydric habitats having a less permanent water supply.

A Wet-terrestrial Stratum

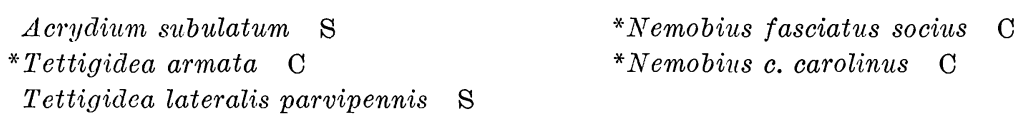

B Sphagnum Stratum

*Nemobius cubensis palustris $\mathrm{C}$

C Coniferous-arboreal Stratum

*Melanoplus p. punctulatus C

D Habitat Proper

*Chorthippus longicornis $\mathrm{C}$
Melanoplus bivittatus S
Melanoplus f-r. femur-rubrum S
*Paroxya hoosieri C
*Scudderia c. curvicauda C
${ }^{*}$ Scudderia f. furcata C
*Amblycorypha oblongifolia C

*Orchelimum gladiator $\mathrm{C}$

*Orchelimum c. concinnum C

${ }^{*}$ Conocephalus $f$. fasciatus $\mathrm{C}$

*Conocephalus brevipennis $\mathrm{C}$

*Conocephalus nigropleurum $\mathrm{C}$

*Anaxipha exigua C

It will be noted that sixteen of the species listed above are characteristic of the permanent marsh habitat. Two exceptions, Acrydium subulatum and Tettigidea lateralis parvipennis, are listed as sporadics, owing to their low frequency and low abundance in this habitat. The presence of high water for long periods probably prevents the hatching of the eggs of these 
two species. With the exception of Tettigidea armata, Paroxya hoosieri, and Orchelimum concinnum, all of the Orthoptera of this habitat are also typical of other hydric environments having a less permanent water supply.

\section{Semipermanent Marsh Habitat \\ (Carex-Calamagrostis-Low Shrub Association)}

(Pl. VI, Figs. 1-2 ; Pl. VII, Figs. 1-2 ; Pl. VIII, Figs. 1-2; Pl. IX, Fig. 1)

This orthopteran habitat is in every depression on the Reserve which is large enough to contain an organic soil, which has standing water during the spring and fall of the year, and which is not too greatly shaded to permit the growth of the characteristic vegetation. The herbage may exist as patches of almost pure stands of certain species of sedge or grass, as areas of mixed sedges and grasses, or as associations of sedges, grasses, and herbs. The more characteristic plants of the semipermanent marsh are the following: shield fern (Dryopteris palustris), sensitive fern (Onoclea sensibilis), regal fern (Osmunda regalis), water plantain (Alisma Plantago-aquatica), cut-grass (Leersia oryzoides), canary grass (Phalaris arundinacea), blue joint grass (Calamagrostis canadense), Dulichium arundinaceum, spike rush (Eleocharis sp.), bulrush (Scirpus atrovirens), wool grass (Scirpus cyperinus), sedge (Carex tribuloides, C. vulpinoidea, C. lanuginosa, C. riparia var. lacustris, C. lurida, C. pseudo-cyperus, C. intumescens, C. lupulina, and C. monile), large blue flag (Iris versicolor), false nettle (Boehmeria cylindrica), clearweed (Pilea pumila), knotweed (Polygonum muhlenbergii), lady's thumb ( $P$. persicaria), mild water pepper ( $P$. hydropiperoides), arrow-leaved tear-thumb ( $P$. sagittatum), water cress (Roripa islandica), cinquefoil (Potentilla norvegica hirsuta), Geum strictum, spotted touch-menot (Impatiens biflora), willow herb (Epilobium molle), water hemlock (Circuta bulbifera), spotted cowbane (C. maculata), mad-dog skullcap (Scutellaria laterifolia), water horehound (Lycopus rubellus, L. uniflorus, and $L$. americana), mint (Mentha arvensis), bittersweet (Solanum dulcamara), Culver's root (Leptandra virginica), bedstraw (Galium claytoni), boneset (Eupatorium perfoliatum), goldenrod (Solidago serotina and $S$. graminifolia), cocklebur (Xanthium italicum), bur marigold (Bidens discoidea), sticktight (B. cernua), tickseed sunflower (B. trichosperma), fireweed (Erechtites hieracifolia), and Canada thistle (Cirsium arvense).

As has been pointed out above, the vegetation of the southwest swamp does not present well-defined zones, but blocks or units in which one or several different plants are dominant. On the northern side of this swamp, the sedge, Carex riparia var. lacustris, occurs in an almost pure stand, merging on the eastern side of this area into a part of the swamp wherein bluejoint grass is the dominant plant. Other parts of this swamp are covered with 
an admixture of various sedges, grasses, and herbs. Two areas in the western and southern parts of the big swamp are characterized by having extensive growths of mixed sedge, grass, and herbs in which bluejoint grass is the dominant. On all other parts of the Reserve which exhibit the semipermanent marsh habitat, the plant cover is a general mixture of some, or all, of the plants listed above. In Buck Hollow, however, the ferns are more abundant.

There is, therefore, a great variation in the botanical aspects of this orthopteran habitat, and, excluding two restricted forms, the Orthoptera characteristic of any one particular type of sedge-grass-herbaceous swamp are characteristic of all the types. In addition to the exclusive herbage stratum which constitutes the marsh proper, four other strata are recognized in this habitat - the coniferous-arboreal, the deciduous-arboreal, the wet-terrestrial, and the moist-hypogeic-zonal.

\section{A Coniferous-arboreal Stratum}

*Melanoplus $p$. punctulatus C

*Oecanthus pini $\mathrm{C}$

B Deciduous-arboreal Stratum

* Diapheromera femorata C

*Oecanthus niveus $\mathrm{C}$

Melanoplus $p$. punctulatus $\mathrm{S}$

*Oecanthus angustipennis $\mathrm{C}$

C Wet-terrestrial Stratum

* Acrydium subulatum C

*Acrydium a. acadicum C

*Acrydium ornatum $\mathrm{C}$

* Acrydium arenosum angustum $\mathrm{C}$

* Tettigidea armata C

* Tettigidea lateralis parvipennis $\mathrm{C}$

Gryllulus assimilis E

*Paratettix c. cucullatus

*Nemobius fasciatus socius C

*Nemobius c. carolinus C

D Moist-hypogeic-zonal Stratum

*Gryllotalpa hexadactyla C

\section{E Herbag'e Stratum (Marsh Proper)}

*Doru a. aculeatum C

Diapheromera femorata $\mathrm{E}$

* Pseudopomala brachyptera C

*Chorthippus longicornis $\mathrm{C}$

* Stethophyma gracile C

Pardalophora haldemanii E

Dissosteira carolina $\mathrm{E}$

Schistocerca alutacea $\mathrm{E}$

*Melanoplus bivittatus C

*Melanoplus f-r. femur-rubrum C

Melanoplus m. mexicanus $\mathrm{E}$

Melanoplus keeleri luridus $\mathrm{E}$

*Phoetaliotes nebrascensis $\mathrm{C}$

${ }^{*}$ Scudderia c. curvicauda C
* Scudderia texensis C

* Scudderia f. furcata C

* Amblycorypha oblongifolia C

* Neoconocephalus ensiger C

*Orchelimum vulgare $\mathrm{C}$

* Orchelimum gladiator $\mathrm{C}$

Orchelimum nigripes $\mathrm{S}$ and $\mathrm{E}$

*Conocephalus f. fasciatus $\mathrm{C}$

*Conocephalus brevipennis $\mathbf{C}$

*Conocephalus nigropleurum C Atlanticus testaceus $\mathrm{E}$

Oecanthus n. nigricornis $\mathrm{S}$ and $\mathrm{E}$

Oecanthus angustipennis $\mathrm{E}$

Oecanthus niveus E 
Forty-one species are here listed as occurring in the semipermanent marsh habitat. Of these thirty-two are characteristic, seven are erratic, and two are sporadic. Many of the characteristic forms are also typical in other hydric environments. With the exception of Atlanticus testaceus (a woodland form), Oecanthus angustipennis, and $O$. niveus (both characteristic of the deciduous-arboreal stratum) all of the erratics come from the grassland habitats. The two sporadics are typical of the wet shrub-zone habitat.

\section{Wet Shrub-zone Habitat \\ (Cornus-Cephalanthus-Salix Associations)}

(Pl. VI, Figs. 1-2 ; PI. VII, Fig. 2 ; Pl. VIII, Figs. 1-2 ; Pl. IX, Fig. 1)

The wet shrub-zone habitat, as here considered, comprises all of the shrubs which occur within the marshes and swamps, but does not include the zone of shrubbery which may form the ecotone between swamp and grassland or swamp and woodland. The shrubs are commonly scattered throughout the other vegetation, but may exist as clumps and belts. The most abundant and most important of these shrubs from the standpoint of the Orthoptera are: dogwood (Cornus stolonifera, C. candidissima, and $C$. alternifolia), buttonbush (Cephalanthus occidentalis), high-bush blueberry (Vaccinium corymbosum), high-bush huckleberry, dwarf willow (Salix sp.), meadowsweet (Spirea alba), shrubby cinquefoil (Potentilla fruticosa), swamp birch (Betula pumila), and winterberry (Ilex verticillata).

The Orthoptera in this habitat are usually on shrubs exposed to a certain amount of sunlight and, hence, are more likely to occur on those species of shrubs which grow more or less isolated or in clumps along the margins. Many forms not typical of the shrubs have been taken from them, but in each case the species of Orthoptera was characteristic of the hydric association within which the shrubbery was growing.

A wet-terrestrial stratum is invariably present in this habitat, and the herbage stratum (marsh proper) occurs in varying extent in the areas of more open shrubbery. The orthopteran fauna of these strata is, for the most part, identical with the fauna of the same strata in the semipermanent marsh habitat. The Orthoptera of the wet shrub-zone habitat are:

${ }^{*}$ Scudderia pistillata C

*Orchelimum nigripes $\mathrm{C}$

*Conocephalus nigropleurum $\mathrm{C}$
*Oecanthus n. nigricornis $\mathrm{C}$

*Anaxipha exigua C

\section{Marginal Shrub-zone Habitat \\ (Cornus Association) \\ (Pl. VI, Figs. 1-2; Pl. VII, Fig. 1)}

Although the plants are largely the various species of dogwood named' above, many of the shrubs listed for the wet shrub-zone habitat are also in: this habitat. The marginal shrub zone is confined to the narrow ecotones: 
between the hydric and the xeric and xeromesic associations. It is, therefore, much less humid than the shrub habitat of the marshes and swampland proper. No characteristic Orthoptera, with the exception of Oecanthus $n$. nigricornis, have been found in this environment. Many other forms have been observed or collected, but all of them are erratics from other orthopteran habitats.

\section{Tamarack-Poison Sumac Habitat \\ (Larix-Rhus vernix Association)}

(Pl. V, Fig. 2 ; Pl. VII, Fig. 1)

The area occupied by this habitat on the Reserve is very extensive. Tamarack (Larix laricina) and poison sumac (Rhus vernix) commingle to form the tree growth. The undergrowth is exceedingly variable in content and abundance from one place to another. Certain areas are very moist, and in these places the trees grow close together, thus shutting out much of the sunlight and making an environment in which sedges, grasses, and herbs find it difficult to live. Such areas are almost barren of orthopteran forms. Individuals of Nemobius c. carolinus have sometimes been found among the ground litter. In the dense copses Melanoplus p. punctulatus and Oecanthus pini are apparently never present on the tamaracks, and no Orthoptera have ever been observed on poison sumac growing under any conditions. Other parts of the tamarack-poison sumac habitat are much more open, permitting the growth of sedges, grass, and herbage beneath the scattered trees. The undergrowth of such areas, although variable in plant species, is so similar to that of the semipermanent marsh habitat that the same species of Orthoptera are found in both. In these more open areas, Melanoplus $p$. punctulatus and Oecanthus pini commonly occur on the younger trees.

\section{Red Maple-Birch Habitat \\ (Acer rubrum-Betula Association)}

(P1. X, Figs. 1-2)

To the north of the lake is an area (Station 8), covered with a dense growth of yellow birch (Betula lenta) and red maple (Acer rubrum), which might best be termed a flood-plain forest. Inundated from a few inches to as much as two feet for several months each year, the floor of this floodplain forest is made up of rich, hummocky, organic soil which never becomes thoroughly dry. Many moist, decaying logs and limbs are strewn over the ground, and over these and the hummocks grow scattered clumps of regal fern, sphagnum, and other mosses. In some areas of this woodland, tall shrubbery is not present; in other places (particularly the margins) mountain holly (Nemopanthus mucronata), black alder (Ilex verticillata), poison sumac, high-bush blueberry, and high-bush huckleberry are common. Only three orthopteran strata are recognizable in this woodland, the ground being 
flooded during part of the year and so nearly saturated the rest of the time that the hypogeic stratum is unoccupied.

A Deciduous-arboreal Stratum

*Diapheromera femorata

*Oecanthus niveus $\mathrm{C}$

B Tall Shrub Stratum

*Diapheromera femorata

*Oecanthus niveus $\mathrm{C}$

C Low shrub-terrestrial Stratum

*Acrydium subulatum C (Marginal)

* Tettigidea armata C (Marginal)

*Tettigidea lateralis parvipennis $\mathrm{C}$ (Marginal)
*Oecanthus angustipennis $\mathrm{C}$

*Nemobius c. carolinus $\mathrm{C}$

*Ceuthophilus thomasi C

The three species characteristic of the upper strata of this woodland are also typical of the oak-hickory associations wherein they occur much more abundantly. Three of the five species of the low shrub-terrestrial stratum are present in the red maple-birch habitat, apparently because of the open areas around the margins. The fourth form, Nemobius c. carolinus, is found throughout the habitat amid the debris of the floor; but it also is not nearly so abundant as it is in the semipermanent marsh habitat. Ceuthophilus thomasi seems to be the only species which is definitely confined to this habitat. This camel cricket occurs in small numbers, but has been observed nowhere else on the Reserve. Erratics and sporadics have not been found.

\section{Bog Habitat \\ (Chamaedaphne-Sphagnum Association)}

(Pl. IX, Fig. 2)

Two typical leatherleaf bogs occur on the Reserve. Each of these has almost identical vegetation consisting of leatherleaf (Chamaedaphne calyculata), sphagnum moss (Sphagnum sp.), sundew (Drosera sp.), pitcher plant (Sarracenia purpurea), and bog rosemary (Andromeda glaucophylla). Two strata may be recognized: the leatherleaf and the sphagnum. A single species, Nemobius cubensis palustris, is characteristic of the sphagnum stratum, and a single species, Melanoplus borealis junius, of the leatherleaf stratum. Sporadics are sometimes common, and erratics often move into the habitat from the marginal grassland, woodland, or hydric environments.

\section{A Leatherleaf Stratum}

$\begin{array}{ll}\text { Chorthippus longicornis E } & \text { Scudderia c. curvicauda S } \\ \text { Melanoplus bivittatus E } & \text { Scudderia texensis S } \\ \text { Melanoplus f-r. femur-rubrum E } & \text { Scudderia } f \text {. furcata S } \\ \text { *Melanoplus borealis junius C } & \text { Conocephalus brevipennis E } \\ \text { Melanoplus m. mexicanus E } & \end{array}$




\section{B Sphagnum Stratum}

Acrydium subulatum $\mathrm{E}$

Atlanticus testaceus E

Tettigidea lateralis parvipennis $\mathrm{E}$

*Nemobius cubensis palustris

The three sporadics listed above are characteristic species of the semipermanent marsh habitat. Of the eight erratics, one comes from xeric environment, one from oak-hickory association, and the remainder are characteristic of the semipermanent marsh habitat.

\section{Some Environmental Peculiarities of the Reserve, and Their Influence on the Habitat Distribution of the Orthoptera}

In the foregoing account of the habitats of the Reserve a number of more or less peculiar or unusual conditions have been mentioned without having been particularly stressed. It seems desirable to give a little more consideration to certain of these local peculiarities that have a bearing on the composition of the orthopteran fauna of the Reserve and on the habitat relationships of the species which compose it.

THE REDUCTION OR ELIMINATION OF CERTAIN HABITATS TYPICAL OF THE GENERAL REGION.-The topography of the Reserve is characterized by high relief, with extensive uplands separated from basin-like depressions by steeply sloping hillsides. Furthermore, owing to the strong relief and porous soils, the drainage of the uplands and hillsides is good to excessive, resulting in relatively xeric conditions; while the water table in the depressions stands at, or near, the surface and varies but little. This results in a sharply drawn demarcation between wet and relatively dry environments, so that the ecotones are narrow and sometimes scarcely recognizable. There are no large areas of mesic forest or other types of mesic environment, and this results in the absence from the Reserve of a number of species of Orthoptera associated with such conditions which are present in surrounding territory. Among these may be mentioned Melanoplus viridipes eurycerus, Atlanticus davisi, Ceuthophilus divergens, and other species which in this region chiefly inhabit mesic woodland, as well as Melanoplus scudderi and $M$. gracilis, characteristic respectively of mesic forest-margin thickets and of the rank herbage and shrubbery that develops on mesic soils after cessation of cultivation. The influence of the deer and of former cultivation in reducing the extent of forest-margin thickets has already been mentioned.

EFFECT OF HABITAT PATTERN AND NARROWNESS OF ECOTONES ON OCCURRENCE OF THE ORTHOPTERAN SPECIES.-The knob-and-basin topography of the Reserve gives rise to a peculiarly patchy intermingling of habitats, in which each habitat type is brought into close proximity to many of the other types present on the area. This condition, together with the narrowness of, or 
absence of, ectones in many places, is conducive to widespread occurrence of erratics among the Orthoptera, which increases the difficulty of recognizing the true habitat relations of the species. A grasshopper of the oak-hickory forest, alarmed by the attack of some enemy, may, in a single flight, find itself in grassland or swamp, where it may remain for some time. Conversely, the absence of broad ecotones reduces the chance of establishment of sporadic colonies.

THE INFLUENCE OF RETROGRESSION IN PLANT COMMUNITIES ON THE OCCURRENCE OF CERTAIN ORTHOPTERAN SPECIES.-As already noted, drainage of parts of the lowlands of the Reserve was at one time more complete than in recent years. Succession in the direction of mesic forest had occurred in the southwest swamp, in parts of which a stand of sugar maple and white ash had developed. With the rise in water level, owing to the blocking of the drainage channels, retrogression has taken place, and both among the plants and the Orthoptera certain species which had become established are now being eliminated, while others which might soon have found suitable mesic environment have been prevented from entering. 


\section{SEASONAL RELATIONSHIPS OF THE ORTHOPTERA}

Without exception, the adults of the various forms of Orthoptera on the Reserve occur in greatest abundance during rather definite periods each season. Although a certain amount of overlapping is apparent, most of the forms reach maximum abundance during one of three periods-spring (May-July), summer (July-September), and fall (August-October). To indicate this time relationship of one species to another, as well as to show early and late records and periods of maximum abundance, and to give a summation of those forms characteristic of a given habitat, a series of tables, based upon adults, has been prepared (Tables II-XII).

TABLE II

The Seasonal Distribution of the Orthoptera Characteristic of the Sparsely Vegetated SANd Habitat

\begin{tabular}{|c|c|c|c|c|c|c|c|}
\hline & May & June & July & Aug. & Sept. & Oct. & Nov. \\
\hline Melanoplus angustipennis & & & & & ? & & \\
\hline 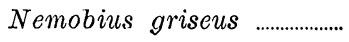 & & & & & & & \\
\hline
\end{tabular}

Whenever there is insufficient evidence, as for a few of the rare species, to determine comparative abundance, the records for these species are plotted as " $x$ 's", and no effort has been made to graph them quantitatively. With regard to other forms, the shape of the graph for each species indicates the earliest and latest record, the rapidity with which maximum abundance is attained, the diminution of abundance, and the seasonal range. The broadest part of the line, representing maximum seasonal abundance of the species in a habitat, is of the same width for all the species, regardless of their actual numerical abundance either relative to the other species occurring in the same habitat, or relative to the differences in abundance of any one species from habitat to habitat. This method of representation gives expression to the concept that in each habitat each species is as abundant during any season as the conditions in that habitat will permit; and hence, that the number of adults present at the time of maximum seasonal abundance represents 100 per cent of the possible population density under the existing conditions. 


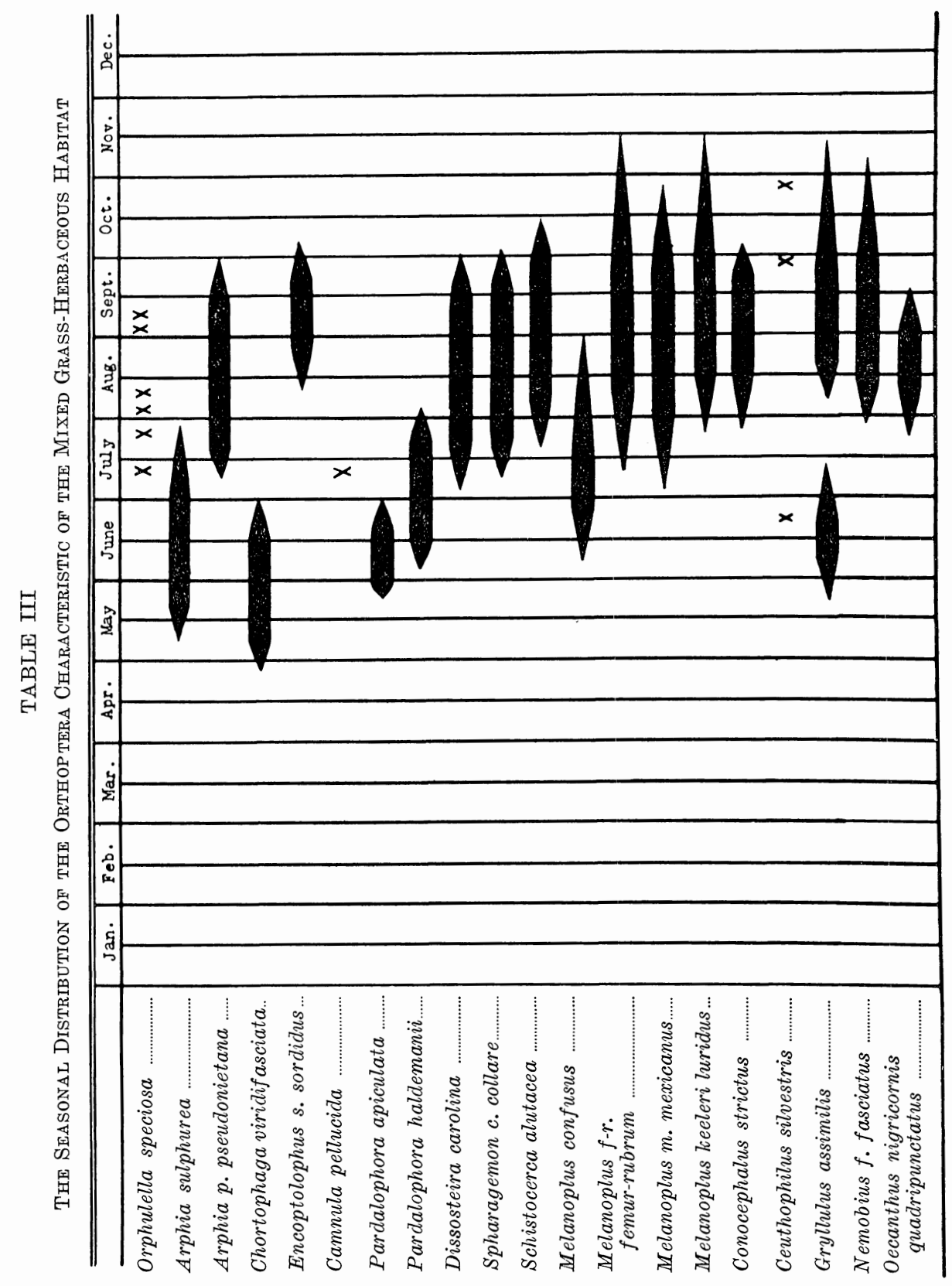




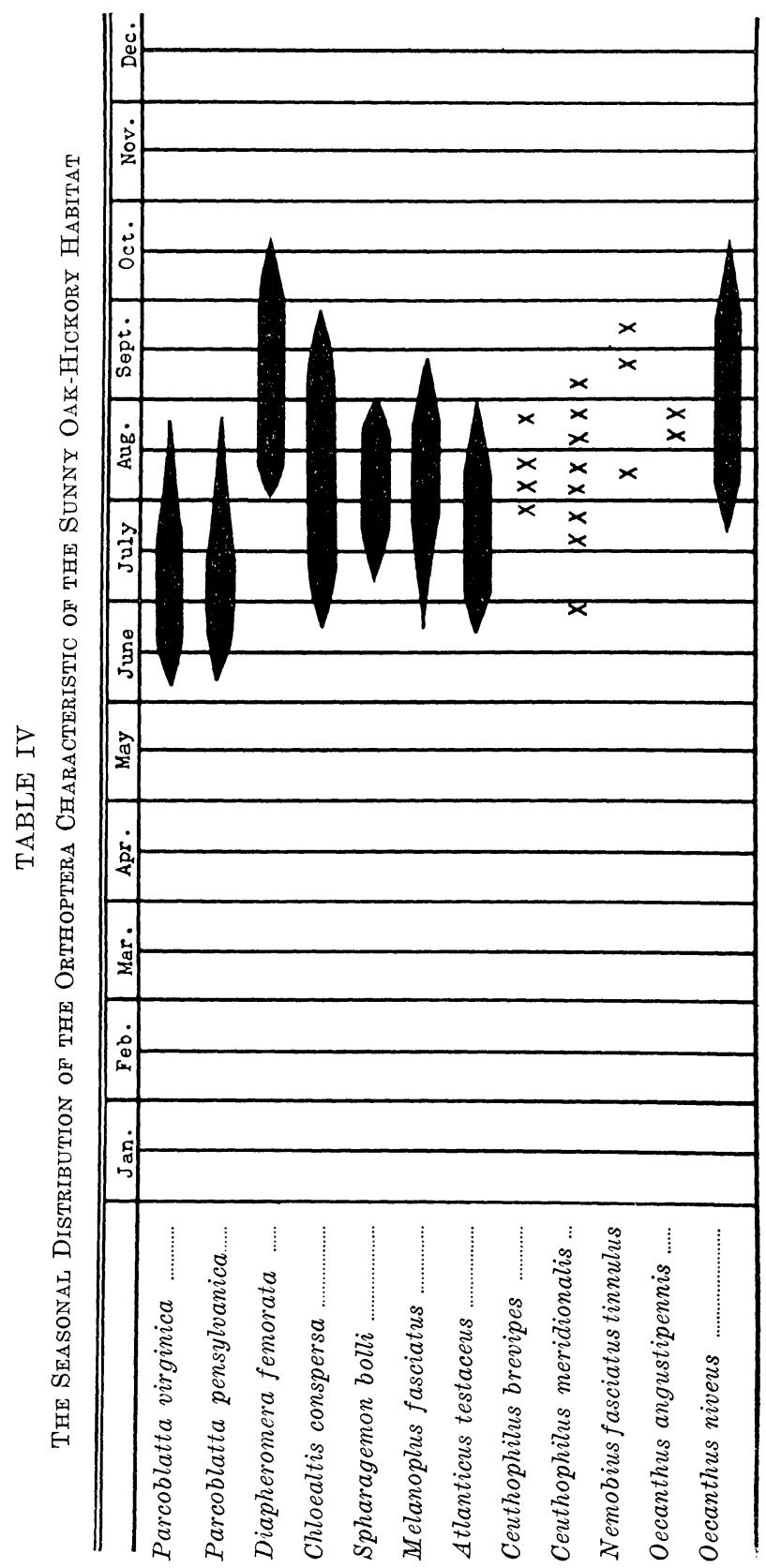




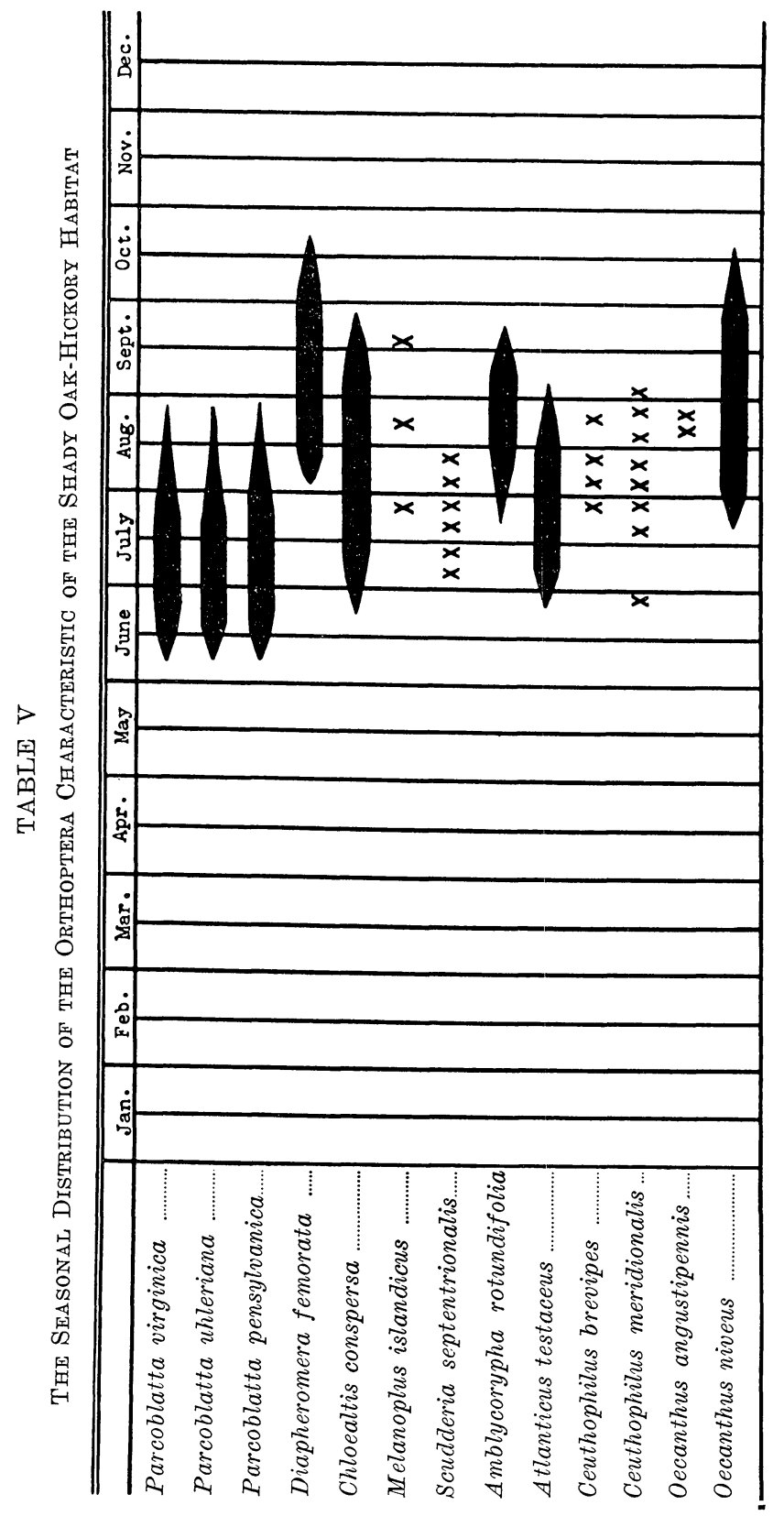




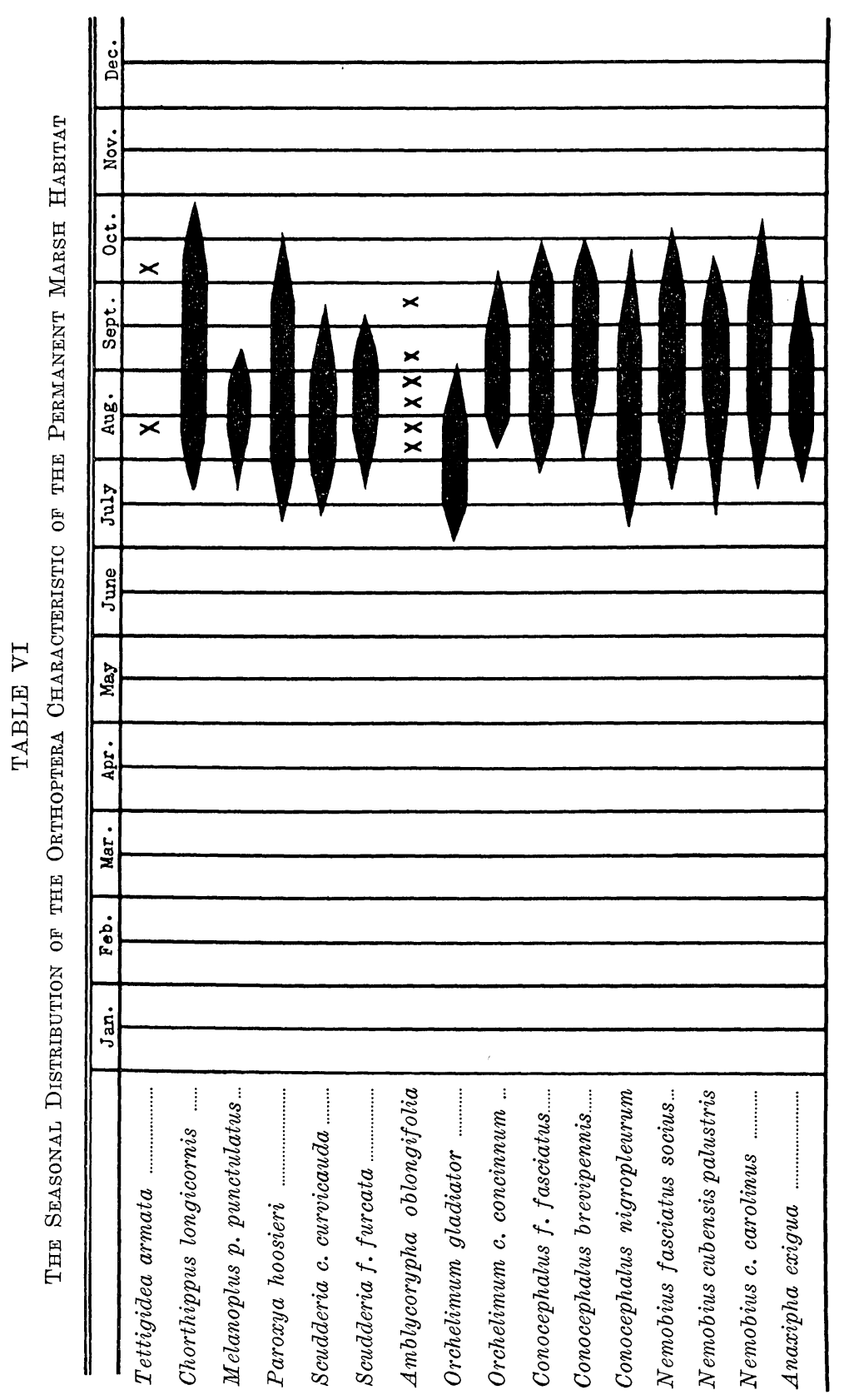


TABLE VII

The Seasonal Distribution of the Orthoptera Characteristic of the Semipermanent MaRsh Habitat

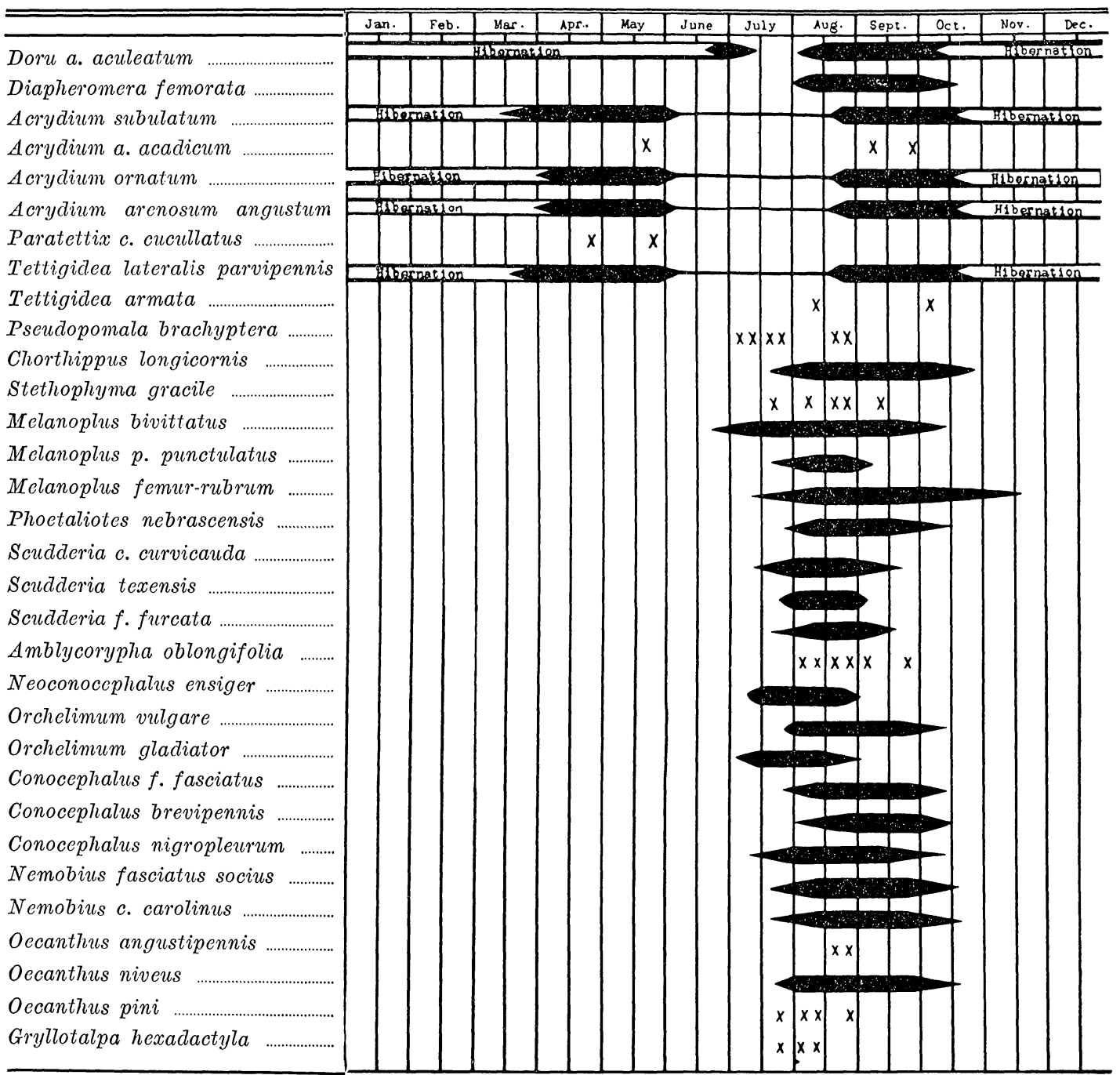



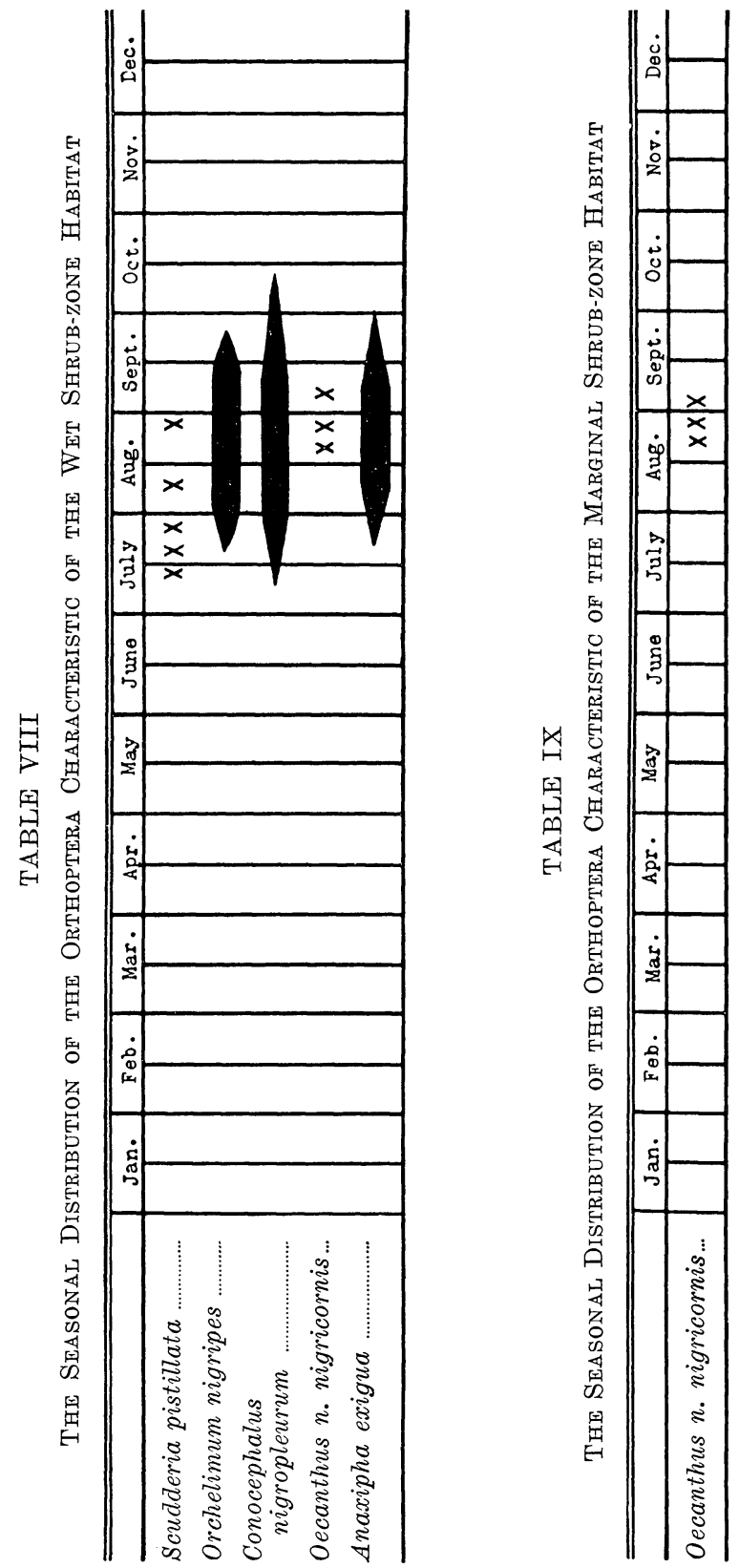


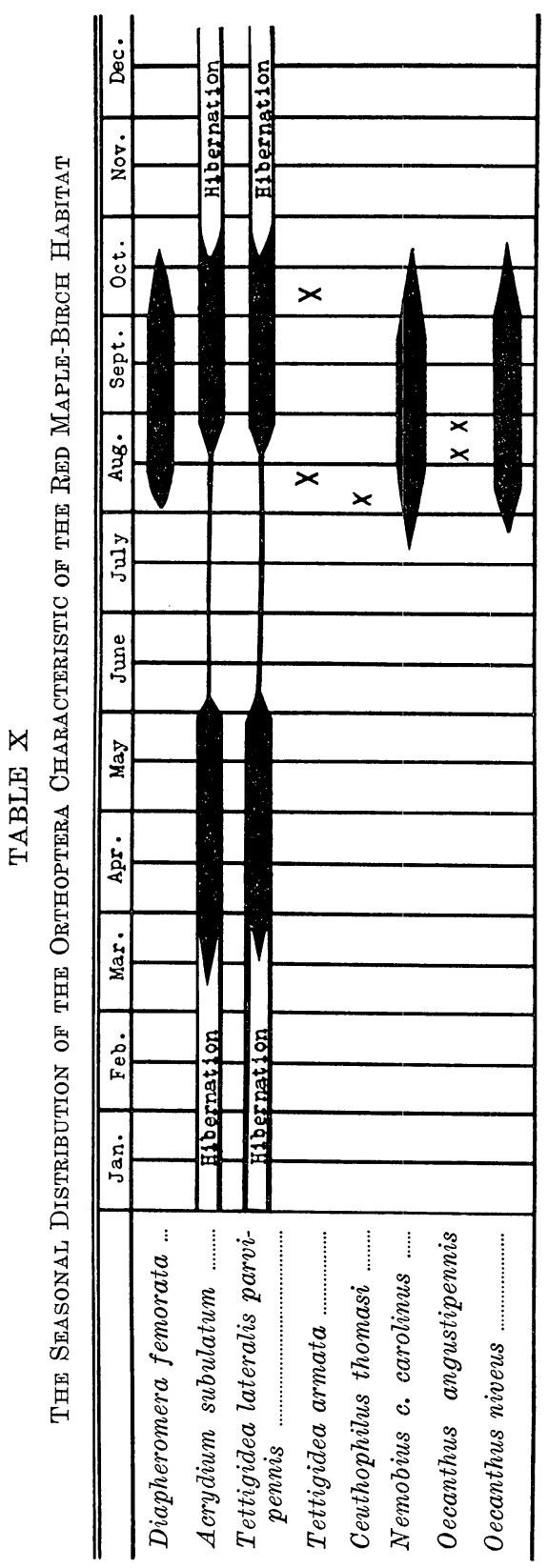


TABLE XI

The Seasonal Distribution of the Orthoptera Characteristic of the Tamarack-Poison Sumac Habitat

\begin{tabular}{|c|c|c|c|c|c|c|c|c|c|c|c|c|}
\hline & Jan. & Feb. & Mar. & Apr. & May & June & July & Aug. & Sept. & Oct. & Nov. & Dec. \\
\hline $\begin{array}{l}\text { Melanoplus p. punctulatus } \\
\text { Oecanthus pini }\end{array}$ & & & & & & & & $X$ & & & & \\
\hline
\end{tabular}

TABLE XII

The Seasonal Distribution of the Orthoptera Characteristic of the Bog Habitat

\begin{tabular}{|c|c|c|c|c|c|c|c|c|c|c|c|c|}
\hline & Jan. & Feb. & Mar. & Apr. & May & June & July & Aug. & Sept. & Oct. & Nor. & Dec. \\
\hline $\begin{array}{l}\text { Melanoplus borealis junius } \\
\text { Nemobius cubensis palus- } \\
\text { tris }\end{array}$ & & & & & & & $X$ & $\bar{x}$ & & & & \\
\hline
\end{tabular}


ANNOTATED LIST OF THE ORTHOPTERA AND DERMAPTERA

DERMAPTERA

FORFICULIDAE, FORFICULINAE

Doru aculeatum aculeatum (Scudder)

\section{Spine-tailed Earwig}

On the Reserve Doru aculeatum occurs in great abundance in a small expanse of sedge (Carex riparia var. lacustris) along the north side of the southwest swamp. The sedge forms a belt about thirty feet wide and one hundred feet long, bounded on the side toward the marsh by a zone of buttonbush. Along a part of the opposite margin of the sedge belt the Carex grades sharply into bluejoint grass; elsewhere the sedge zone borders upon a low, moist section of red maple-elm forest, within which the ground is strewn with old decaying logs, sticks, and dead leaves.

In 1936 and 1937 the marsh proper was inundated until about midAugust, with the greatest depth of water (about eighteen inches) occurring in June. During 1938 water stood in the marsh until mid-September; while from appearances in August, 1939, it seemed likely that the water might be present throughout the year. This increased persistence of standing water in successive seasons has had a very marked effect upon the habitat, for by late August, 1939, approximately three-fourths of the original stand of Carex had died. It is possible that the sedge will soon be completely killed out by the rising water level.

Doru aculeatum has never been taken elsewhere on the Reserve than in this small sedge patch in this particular marsh, with the exception of the two individuals collected by J. S. Rogers on August 3, 1936, about four hundred yards distant in the north end of Fishhook marsh. Subsequent collecting in Fishhook marsh has failed to reveal additional specimens, and the earwig must either be extremely rare in that situation, or (as seems more probable) the two taken by Rogers were erratics which had wandered from the Carex patch in the southwest swamp. On the Reserve this earwig is exclusively associated with this one particular species of Carex, which constitutes its normal habitat; it has never been taken from any of the other species of sedges that are abundant in other marshes on the Reserve. If the sedge disappears, owing to continued rise of the water in the southwest swamp, it is possible that Doru aculeatum will disappear with it and be eliminated from the fauna of the Reserve.

In Michigan the spine-tailed earwig is known from only a few localities, all in the southernmost three tiers of counties. The insect was recorded from Berrien County by Hubbell (1922); and specimens are in the collection of the University of Michigan Museum of Zoology from Washtenaw, Wayne, 
and Oakland counties. On the George Reserve this earwig is evidently living at very nearly the northern limit of its range, where relatively few situations are available in which one or more of the limiting factors do not at least occasionally exceed the limits of toleration of the species. It is therefore not surprising that on the Reserve, and in southern Michigan generally, the spine-tailed earwig is restricted to a much narrower range of ecological conditions than in regions to the south, where the environment is closer to the optimum for the species, and where it has a greater margin of safety in a larger number of habitats.

Along the northern fringe of its range it seems almost certain that low winter temperatures constitute the most important factor limiting the occurrence of the species. In this marginal zone, as is shown below, the species hibernates beneath cover and can probably only survive the winter in situations where suitable cover is available. All the evidence at hand concerning the occurrence of the species in southern Michigan indicates that it requires a sedge-marsh habitat during the remainder of the year. Thus, Hubbell (1922 : 29) stated that his specimens of Doru aculeatum from Berrien County were taken from Carex in a marsh; he also (MS) ${ }^{11}$ secured a female from Carex growing at the margin of a marsh bordering a shady, moist woods at Kent Lake, Oakland County, Michigan. In Section 14, Lima Township, Washtenaw County, I took a specimen from a tall sedge growing around the periphery of a huckleberry marsh in the center of a woods several acres in extent. It is to be noted that in two of these occurrences, as on the Reserve, proximity to woodland is mentioned.

Since, at the northern limits of its range, Doru aculeatum doubtless suffers high winter mortality, it appears that the species can maintain itself only where its optimum summer environment, a Carex marsh, lies adjacent to a situation affording suitable cover for hibernation. The optimum summer environment may be required to enable the species to build up a population sufficiently large to offset the probably high mortality among hibernating individuals. I am, therefore, of the opinion that in southern Michigan this earwig will rarely, if ever, be found in any other environment than a Carex marsh bordering upon a moist, low woodland.

South of Michigan, and nearer the center of its range, Doru aculeatum is less restricted in habitat, and occurs during the warmer months in any of several types of sedges and grasses, the axils of which afford it concealment. Furthermore, as one proceeds southward the species seems to be progressively less dependent upon the presence of humus and debris of forest floors as retreats for hibernation. These points are exemplified by the following published observations, arranged in order from north to south. Blatchley (1920: 55) stated that "in Posey Co., Ind., April 9, 15 specimens [were

11 Unpublished "Field Notes," eited in the Bibliography. 
taken] from beneath rubbish and leaves in woods along the north bank of the Ohio River. ...' The same author (1924: 127) found the species abundant below the surface of the ground between the bases of the leaves of skunk cabbage on May 1; and Cooper (1933: 216), writing concerning the occurrence of this earwig at Bayside, Long Island, stated that ". . . in the late fall it is very abundant under cover. It burrows in the soft debris beneath stones and $\operatorname{logs}$ at the approach of the hibernation period. Often one may take as many as fourteen or fifteen specimens from under a single log, where they are found clustered together." Somewhat farther south, Fox (1917: 206) in Virginia found Doru aculeatum to be "evidently frequent [sic] on tall reeds, Spartina cynosuroides, in tidal marshes, occasionally spreading to near-by timothy pastures. ..." Hubbell has informed me that in Florida, intermediates between Doru a. aculeatum and D. a. davisi R. and H. occur commonly in stands of saw grass (Cladium jamaicense) and maiden cane (Panicum hemotomum) which are often as much as one-half mile from the nearest woodland. The lack of dependency upon woodland adjoining marsh habitats in the southern parts of the range may be accounted for by the probable shortening, or complete omission, of hibernation in these regions.

During the spring and early summer of 1938 and 1939, semiweekly visits were made to the habitat of this earwig in order to determine as accurately as possible the exact date on which Doru, coming forth from hibernation, would appear on the sedge, Carex riparia var. lacustris. In 1938, the first individuals were found on June 23 in this sedge, very close to the low, moist woodland mentioned above. In 1939, the same conditions were noted on June 21. In both instances, no specimens were located more than ten feet from the margin of the woodland. On June 23, 1938, all specimens taken were adults, but on June 21, 1939, nine individuals of the first (smallest) size group and a single individual of the second size group were collected with several adults, indicating that the adults had appeared sufficiently prior to June 21 so that some eggs had been laid and had hatched. Adults may be readily found in late June, but become progressively fewer and fewer, until by the middle of July they are very difficult to locate, if they can be found at all. Of one hundred specimens taken July 15, 1937, only twelve were adults. About the first of August, the young from eggs laid in late June begin to mature; they may be found from this time until late September, or until cold weather forces the species into hibernation.

During the daytime the spine-tailed earwig has been observed only in the axils of the sedge, Carex riparia var. lacustris. Individuals almost invariably select the greenest leaves and never remain on dead plants. They are always head down and as deep within the axils as they can press themselves. The smaller juveniles are therefore lower down than the females, and the females in turn lower than the males. 
It was thought that this invariable position, head downward in the axil, resulted from the fact that the earwig always enters the leaf sheath head first; but specimens shaken into a collecting net always orient themselves in the same manner. Juveniles of the first and second size group do not have this trait, but pressing close to the inner side of the leaves arrange themselves, hit or miss, at various angles to the perpendicular. By the time the young have reached the third size group they react like adults.

Adults and young beyond the second class are not very gregarious during the summer. The general rule is to find a single specimen to a leaf, but occasionally two individuals may be found together. This may be due to the amount of concealment available in any single leaf. On four occasions females were observed apparently guarding young of the first size group (probably first instars).

When disturbed during the day, this earwig, about as often as not, will raise the abdomen in a threatening attitude. The forceps are never parted, and if the individual is touched it will quickly run in search of cover. If disturbed during the night, however, individuals will part the forceps and raise and lower the abdomen in a threatening manner. A piece of grass inserted between the forceps causes a hasty departure, and no attempts are made to use the forceps as pincers. Adults of both sexes exhibit this characteristic menacing behavior. An occasional late stage juvenile will sometimes demonstrate this activity, but it is quite rare and is never seen in younger juveniles.

Doru aculeatum is nocturnal, and at night may be seen scampering up and down over the sedge leaves. Individuals may often be observed in the near-by shrubbery on the tips of the highest branches, as much as ten feet from the ground. The beam of a headlight causes the earwigs to dodge quickly behind a leaf or twig or to run along the plant until they find a place of concealment.

During the day the spine-tailed earwig is rarely active and, except on one occasion, has been found only in the axils of the sedge leaves. On this occasion, a very cloudy afternoon about four o'clock, a specimen was observed running in a rather leisurely and somewhat jerky manner, first on top of a sedge leaf and then beneath it. Finally, the earwig stopped, bent the abdomen to the left, parted his forceps and proceeded to rub the left forcep with his left hind leg. The forcep was rubbed three times, then the hind leg was worked over with the mandibles. The right antenna was then cleaned by running it through the mouth parts. Any further activity was unceremoniously interrupted by sunlight suddenly breaking through a rift in the clouds. The earwig at once became very active and ran with great rapidity up a sedge until it disappeared head first into the axil of the leaf. 
Upon partly stripping away the leaf, I found the specimen lying snugly against it near the bottom of the plant.

Reference.-Blatchley, 1920 : 55 .

ORTHOPTERA

BLATTIDAE, PSEUDOMOPINAE

The Genus Parcoblatta Hebard

THE Wood RoAches

Three species of the genus Parcoblatta occur on the George Reserve: $P$. virginica (Brunner), P. uhleriana (Saussure), and P. pensylvanica (DeGeer). Since all have quite similar habits and are collected by the same methods, it will be advantageous to discuss at this point their common habits and characteristics.

The wood roaches of the Reserve are typical members of the woodland fauna. With the exception of $P$. pensylvanica, as pointed out under that species, they never appear in any other orthopteran habitat on the Reserve. Specimens may be collected under logs, loose bark, in spongy wood at the bases of rotting stumps, and under humus and piles of dead, decaying leaves. These situations when worked by hand, however, never yield the numbers of specimens secured by means of molasses traps, and it is highly probable that all of the species are more hypogeic than has generally been suspected. The woodlands of the Reserve are honeycombed with burrows and runways of small mammals, and in all probability the wood roaches find these suitable retreats.

All three of the species mentioned above are nocturnal. Their habits, as observed, are very similar. During the day a cockroach whose retreat has been uncovered will run rapidly in a zigzag manner until it disappears in the debris of the forest floor. The insect is not content with simply finding new cover, and unless quickly captured will slip through the dead leaves and humus until it can no longer be found. It is very likely that under these circumstances the cockroaches often take refuge in mammal runways. At night they emerge from concealment and may be observed sitting quietly on dead leaves on the ground, perched upon the top of a bracken fern or an herb, or even as high up as ten feet on the trunk of a tree. The beam of a headlight does not unduly disturb them at first, the only apparent reaction being a rapid whirling of the antennae. If the light is held on them for several seconds, however, they run a few inches away and then come to rest, or else dodge quickly under a leaf or ridge of bark. If touched with the fingers the reaction is the same as though they had been uncovered during the day.

On the Reserve the species of Parcoblatta all hibernate as juveniles in the same situations in which they are present as adults. Maturity is reached 
in late May and early June, and adults may then be found until late August; the females outlive the males by more than a month.

Molasses trapping is the best method of securing females. The males of certain species are not strongly attracted to this bait, but may be readily taken at a lighted sheet.

\section{Parcoblatta virginica (Brunner) Virginia Wood Roach}

The Virginia wood roach is the least abundant cockroach on the George Reserve. As in P. uhleriana, its favorite haunts are the deep, moist piles of dead and decaying leaves, humus, and the crevices beneath the bark of decaying logs. It is most abundant in, and characteristic of, the more mesic parts of the oak-hickory woodlands; but it occurs sparingly, possibly as a sporadic, in moist leaf-filled, xeromesic depressions. I have never taken this species as an erratic, and in view of its apparent requirements for mesic conditions, it is probable that $P$. virginica will never be found in this region except in the moister parts of the upland forests.

On the Reserve, the Virginia wood roach matures about the first of June and has been taken as late as mid-August; the earliest record is June 10 and the latest August 18. Adults are most abundant in June. The males diminish rapidly in numbers in late June and early July and are gone by the middle of the latter month; the females outlive the males by several weeks.

Hubbell (1922: 30) stated that in Berrien County, Michigan, he secured only females in molasses traps, and that males were taken only at light. On the Reserve, males were not secured at light, but were taken very sparingly in traps.

Reference.-Hebard, $1917: 96$.

\section{Parcoblatta uhleriana (Saussure) Uhler's Wood Roach}

Uhler's wood roach is as abundant on the George Reserve as is $P$. pensylvanica. An inhabitant of both the drier and moister parts of the oakhickory forest, it occurs both in open and in relatively dense woods. In the more open oak-hickory it is invariably associated with rotten logs and large piles of dead leaves. Like $P$. virginica, this species does not seem to wander widely, and erratic individuals have not been found in other habitats.

The males, like those of the other species of wood roaches present, mature about the first of June, reach their maximum abundance by the end of June, and are gone by the middle of July. Females begin to mature at about the same time as the males and attain greatest abundance near the first of July; some live on until the latter part of August. 
In Berrien County, Hubbell (1922: 30) secured this species in molasses traps, but no males were taken at light. On the Reserve, males were taken as readily at light as by trapping.

Hebard, in his revision of the genus (1917: 111), recorded 238 males as against 994 females of this species, or about 19.3 per cent males. Of 192 specimens taken on the Reserve 69 or 35.8 per cent were males. In spite of these figures, and of Blatchley's statement (1920:82) that females appear to be much the more abundant, the proportion of the sexes may be less unequal than has been supposed. The males of Uhler's wood roach, like those of $P$. pensylvanica, are not strongly attracted to molasses, and the coming of specimens to light seems to be definitely affected by meteorological factors. Thus, the number of specimens taken at light varies greatly from night to night in the same patch of forest. Better collecting methods and controlled breeding experiments may show that the sexes are nearly equal in number.

Reference.-Hebard, 1917 : 105.

\section{Parcoblatta pensylvanica (DeGeer) Pennsylvania Wood Roach}

Parcoblatta pensylvanica is environmentally the most plastic of the species of Parcoblatta occurring on the Reserve. A characteristic inhabitant of the low shrub-terrestrial and probably of the terrestrial-hypogeic stratum, this cockroach occurs throughout the upland forests. Sporadic groups have also been found, apparently established, in and under old, rotten, isolated logs as far as one hundred to two hundred feet from the nearest forest.

While trapping mammals, W. Frank Blair secured many juveniles of this species in traps scattered over large areas of mixed grass-herbaceous habitat. These traps had been thoroughly cleaned previous to being set, so that there was no possibility of the cockroaches having been introduced. Although the Pennsylvania wood roach has been taken many times as an erratic fifty to sixty feet from woodland, it is rather difficult to account for the young roaches traveling several hundred feet over a xeric area containing no semblance of their normal cover. Since the mammal traps were left in position for long periods, it is possible that, being attracted by the grain bait, and using the traps as retreats, the cockroach nymphs had progressed from trap to trap and had gradually spread over the area. These erratic juveniles apparently never reached maturity, since adults were not taken in these traps except when they were in close proximity to woodland; nor have adults ever been secured by ordinary collecting methods more than sixty feet from the characteristic forest habitats of the species. The only exception to this statement is the taking of a single male at light on June 23 about five hundred feet from woodland; but it is not unreasonable to believe that this specimen flew from the forest to the sheet. 
Dates of maturing and of attainment of maximum abundance, and the seasonal depletion of the population are as described above for P. uhleriana.

Males of the Pennsylvania wood roach have been taken at light more readily than by molasses traps.

Blatchley (1920: 87) has given a summary of the known habits of this wood roach. Rau (1940) has recently published on the life history of the species. He has determined that at St. Louis, Missouri, the Pennsylvania wood roach matures at the end of May. Adult females were found to live from thirty-five to one hundred and sixty days; adult males a considerably shorter time. Many interesting data are given regarding the number of egg cases dropped by females, the number of days between the production of egg cases, and the number of eggs contained in them. Most interesting are the remarks concerning the male's search for a female. Rau stated:

At about 7 : 30 P.M., which is about dusk in early June, [the male] comes out of hiding and may be seen flying swiftly in the air or running with lightning rapidity over wall or woodpile. Soon the search goes on in the crevices between the logs. He lands on the log-pile, and without a pause runs rapidly and excitedly in a very erratic manner, his antennae quivering nervously as he examines crevice after crevice. If his quest has been successful he disappears among the logs to remain there; if unsuccessful, he soon emerges and continues the search in the same agitated manner.

References.-Hebard, 1917 : 139; Rau, 1940.

\section{Blattella germanica (Linnaeus) \\ German Cockroach}

The German cockroach is an introduced, edificarian species and has not as yet appeared in the residences on the George Reserve. For obvious reasons, no great attempt was made to determine its presence. Since it is a pest in the homes of Michigan and is easily introduced, if the species is not now present in some of the buildings, it will be in the future.

Reference.-Hebard, $1917: 57$.

BLATTIDAE, BLATTINAE

\section{Blatta orientalis Linnaeus \\ Oriental Cockroach}

In July, 1938, several specimens of this roach were brought to the Reserve in a cardboard container used to transport dog food. This box was stored in a small unheated shed, and it is almost certain that the specimens did not live over the winter. Since the cockroach may have become established in near-by buildings, it is here recorded.

Reference.-Hebard, 1917 : 173. 


\section{PHASMIDAE, HETERONEMIINAE \\ Diapheromera femorata (Say) \\ Common Walking Stick}

This phasmid is of rather common occurrence in the oak-hickory woodland habitats. Specimens were present upon sassafras, low-bush huckleberry, bracken fern, and other plants of the low shrub-terrestrial stratum. The adults are characteristic inhabitants of the deciduous-arboreal stratum and have also been observed in the marginal shrub-zone habitat of the marshes and swamps adjoining woodland. A single male erratic was secured in the center of a semipermanent marsh about one hundred feet from the nearest oak-hickory woodland.

Juveniles begin to appear about the first of June, and are rather common in the low shrub-terrestrial stratum of the woodlands and along the adjoining shrubby-herbaceous margins of marshes and swamps. In these habitats, juveniles are less numerous as they become larger, partly as a result of the heavy mortality of the young demonstrated by Graham (1937), and partly because of upward migration into the arboreal stratum. Fifth instars have been taken as late as August 19. Adults appear about the first week of August, and may be found until the leaves drop from the trees.

Graham (1937: 17) has shown that, during outbreaks of the common walking stick, individuals wander from their normal habitat. Observations on the Reserve indicate that this is also true for populations of only average abundance. This species has been very thoroughly studied by many workers, and my observations on its habits and life history on the Reserve agree in all particulars with what has been recorded by Riley (1879), Morse (1920), Blatchley (1903, 1920), Severin and Severin (1911), and Graham (1937).

\section{ACRIDIDAE, ACRYDIINAE \\ The Acrydinae (Grouse Locusts)}

Three genera and seven species of grouse locusts occur on the George Reserve. All of these species characteristically occupy the wet-terrestrial stratum along the margins of ponds, swamps, marshes, and woodland pools. Mating and oviposition take place only in this type of environment, and here large numbers of these insects may be observed breeding in the spring and early summer.

Those species which occur on the Reserve in large enough numbers to permit critical observation all display a phenomenon of spring congregation which has not hitherto been described, and which, in some ways, suggests that found in certain Amphibia. This trait, which is treated below, has been observed in Acrydium subulatum, A. arenosum angustum, A. ornatum, and Tettigidea lateralis parvipennis. The species Acrydium a. acadicum, 
Tettigidea armata, and Paratettix c. cucullatus have been found in such small numbers on the Reserve that it could not be determined whether or not they exhibit similar behavior, though it seems likely that they do.

The assembling and dispersal of the grouse locust populations follow much the same pattern in all the species named above. In early April adult individuals of each species are scattered generally, to distances as much as two hundred feet from the margins of the marshes and ponds; there is at this time no indication of concentrations, nor are individuals confined to moist situations. As the season progresses and more grouse locusts emerge from hibernation, they begin to concentrate at definite points along the margins of marshes or ponds; the assemblages at these points grow in size, and, at the same time, the numbers of individuals present in the areas more remote from these spots become progressively diminished. By the end of April the greater part of the population has become concentrated at the focal points. These assemblages do not occupy all the areas of suitable habitat about the margin of a body of water, but only certain portions of it; and the exact site or sites of assembly on the margin of any particular marsh or pool will vary from year to year. During the period of study covered by this paper only one instance was noted of an assemblage occurring in the same place in successive years. After the assemblages have formed, a few scattered individuals still remain throughout the wet-terrestrial stratum where it borders bodies of water and where they are in their normal zone of permanent occupancy even though not part of the assemblage; but after the assemblages have grown to full size it is very rare to find erratics in adjoining habitats.

The congregations are fully formed by the end of May and maintain themselves until early summer, when dispersal begins. During the period of aggregation the grouse locusts breed and oviposit, and newly hatched young appear in late June and early July. These nymphs begin to mature by the first of August, and from then until the onset of cold weather adults are common. The details of the mating process, oviposition, feeding habits, and other activities have been described by Hancock (1902: 10-15).

In the fall the adults spread into habitats adjoining the assembly sites. They hibernate beneath dead leaves, twigs, mosses, grasses, under chips, rubbish, and the loose bark of logs, and in little crevices in the earth; these observations agree with those of Blatchley (1920: 151) and Hancock (1902: 10). By far the greater number of the hibernating grouse locusts are adults; but an occasional fourth or fifth size-group nymph is encountered. Adults collected in July have probably matured from such hibernating nymphs.

Grouse locusts sometimes hibernate in large groups (Blatchley 1920: 166), but this phenomenon was not encountered in my work on the Reserve, 
and in the majority of recorded instances the insects hibernated singly or in small groups. Another phenomenon occasionally exhibited by various species of grouse locusts is the mass flights sometimes seen, which occur in the fall, but are not observed every year. The spring and early summer assemblies, the occasional mass hibernation, and the irregularly recurrent mass flights of adults are apparently independent manifestations of the tendency shown by grouse locusts to mass behavior. It seems unlikely that either mass hibernation or mass flights have any bearing on the spring assembly, since they are exceptional occurrences; the latter is an annual phenomenon and has been observed to be preceded by a dispersed phase of the population.

Grouse locusts easily escape observation on account of their small size and inconspicuous coloration and are often considered as relatively rare insects. They are, on the contrary, often exceedingly abundant, and on the George Reserve form a large and very important part of the orthopteran fauna. Some of the species greatly outnumber and would outweigh the majority of the larger, more conspicuous, and more easily collected species of locusts, katydids, and crickets present in the same habitats.

Reference.-Hancock, 1902.

\section{Acrydium subulatum (Linnaeus) Slender Grouse Locust}

This species has for many years been recorded as Acrydium granulatum Kirby. Hebard (1935: 234) has recently shown that granulatum is a synonym of subulatum.

From late April through May adults of Acrydium subulatum occur in numbers in the wet-terrestrial stratum bordering the swamps and marshes of the George Reserve. Here the young may also be found throughout the summer. As the water level of the hydric associations drops lower and lower, this grouse locust invades the new territory thus made available, only to perish or be driven back as the water rises in the fall. Other individuals become erratic in their wanderings and may be taken, in late summer, from two hundred to three hundred feet away from any standing water. Isolated specimens have been captured in the mixed grass-herbaceous, sunny oakhickory, the shady oak-hickory, and the bog habitats.

Acrydium subulatum has been taken in the adult stage as early as March 13 and as late as October 14. Hibernating individuals are preponderantly adults, but an occasional late instar has been encountered in the spring. In late May and early June the adult population diminishes rapidly. This is largely due to death, but thinning of the population through spread of individuals into new habitat areas made available as the water level sinks probably causes the reduction to appear more rapid than it actually is. 
Juveniles, beginning to reach maturity in the last week of August, appear in numbers as the adults die out. The overwintering of late stage nymphs probably indicates the occurrence of more than one generation per year; but it is possible that such individuals were merely late in hatching or slow in developing. Adults found during the summer months may also be indicative of more than one generation per year, but have more probably developed from juveniles which hibernated. If two generations per year do occur, the first must be very small in relation to the second, and it would be impossible by ordinary field methods to determine whether or not such a generation exists.

Acrydium subulatum is the most active of the grouse locusts on the Reserve. Its flight is quicker and more vigorous than that of the other species, and it is much more easily flushed. An adult when startled reacts by a quick jump or hasty flight, depending upon the time of year. In the early summer congregations, fully winged individuals will almost invariably fly when flushed. The flight is quick and rapid; sometimes it carries the insect straight away from the source of annoyance, but more often in an arc to one side or another. The method of alighting varies. The insect may drop with a slight thud upon a dead leaf and then remain quiet until flushed again; it may alight noiselessly upon a sprig of vegetation; it may come down quietly then jump quickly from one to five times, a few inches at a jump, and then bury itself in the vegetation; or it may drop down, hop once or twice, and then take off on another extended flight of three to ten feet.

After the congregations have dispersed individuals are almost never seen to fly. Instead they jump vigorously; their leaps cover one to three feet and are often repeated several times, so that a particular individual is very difficult to follow. A. subulatum, being readily flushed, is easily taken in sweeping; it has seldom been observed to duck under a swinging net and then crouch close to the ground, after the fashion of $A$. ornatum and $A$. arenosum angustum.

The slender grouse locust has been taken a number of times at a lighted sheet at night; it is apparently more often so attracted than any of the other species of grouse locusts on the Reserve.

The species is normally caudate. Among the 265 specimens taken, three males have the pronotum and wings abbreviate, and two females have these structures intermediate between abbreviate and caudate. These specimens were taken in late April and late May along with numerous caudate individuals.

Reference.-Blatchley, $1920: 163$.

\section{Acrydium acadicum acadicum (Scudder) Acadian Grouse Locust}

The taxonomic status of the Acadian grouse locust is not certain, and my 
observations on material from the George Reserve have not helped to clarify the situation. Hebard (1925: 46) stated:

In the West, material of acadicum and ornatum is easily separated, the former being decidedly larger and more robust, with fastigium more projecting and pronotal crest somewhat more prominent. In the East, however, the differences are sometimes less conspicuous. As acadicum is often found in company with ornatum, it cannot represent a geographic race of that species, as has been indicated by Blatchley, being a distinct species as we believe, or a synonym, based on a mere phase. The constancy of its differentiation will require very careful analysis of very large series, with a view to discovering also other possibly useful features of difference, and some revision must be accomplished before the absolute validity of acadicum can be affirmed.

All material from the Reserve was taken, associated with ornatum, in the wet-terrestrial stratum. Three caudate males collected on May 20, September 17, and September 30 definitely fall into the category of acadicum; but two females, one a fully alate specimen taken on May 20 and the other taken on May 24, with wings and pronotum projecting little beyond the tips of the hind femora, approach ornatum to such an extent that they are assigned to acadicum with query.

Reference.-Blatchley, 1920: 167.

\section{Acrydium ornatum Say Ornate Grouse Locust}

The ornate grouse locust is an important and characteristic member of the orthopteran fauna of the wet-terrestrial stratum of the ponds, swamps, marshes, and woodland pools of the George Reserve. Although present around all bodies of water except the lake, it is most abundant along unshaded margins of ponds located in depressions of the grassland. In such habitats it is far more abundant than its associates, Acrydium subulatum and Tettigidea lateralis parvipennis; but along the more or less shaded margins of woodland pools and marshes it is surpassed in numbers by these two species and also by Acrydium arenosum angustum. The great majority of specimens were taken in the characteristic habitat. A single individual, which had wandered about one hundred feet away from the nearest typical habitat, was captured in shady oak-hickory forest. In the spring, other specimens were found in dry grassland from fifty to two hundred feet from the nearest pond margin. In early summer, when the congregations are being formed, scattered individuals gradually disappear, presumably moving toward the center of aggregation. This movement occurs about ten days later than that of $A$. subulatum and T. $l$. parvipennis; this is evidently due to the fact that, on the whole, this species emerges from hibernation later than the other two, although individuals have been taken as early as March 20.

A review of the literature, principally that of Fox (1915:307), Somes 
(1914: 12), Morse (1920: 533), Blatchley (1920: 166), and Hubbell (1922: 32 ), shows that this species has been taken in a variety of situations. Fox found it "moderately frequent in spring on dry hillsides and in stubble fields . . . ," while Morse stated that "the Ornate Pygmy Locust is found in wet meadows, but also quite as frequently in damp spots on drier upland soils." Somes indicated that the species is found less on banks and shores but almost anywhere on sandy soils. Blatchley observed it "usually along the edges of dry open woods and on gravelly hillsides, . . . occasionally . . . in company with Paratettix cucullatus (Burm.) about the borders of streams and ponds." Hubbell secured specimens on nearly bare, trampled areas of dried mud about the margins of water holes, on the moist, sandy margins of a river among the herbage of the mud bars, and on a wet springy hillside. Hubbell's catalogue notes state that his specimen taken "on a wet, sandy, clay road at the edge of a patch of second growth forest" was captured among moist leaves and mosses.

Fox (1915: 307) indicated that his material from xeric habitats was taken in the spring. Dates have not been given for other material recorded in literature from dry environments. In the light of my work on the Reserve, it seems probable that these specimens were taken in the spring prior to congregating, or in late summer and early fall when the species tends to wander. Furthermore, Hubbell (MS) noted the occurrence on April 3, 1921, of a migration or swarming, of hundreds of specimens of this species in company with Acrydium a. acadicum along a mile strip of road just south of Ann Arbor, Michigan. Therefore, although subsequent modification of the generalization may be necessary, it seems reasonable to assert that the characteristic habitat of this species is moist, bare, or sparsely vegetated soil bordering upon a body of water, and that the above records of material collected in dry situations are based upon erratics or wanderers.

Acrydium ornatum is not as active an insect as is $A$. subulatum. Individuals sit about on mud, dead leaves, and tiny clumps of moss sunning themselves, or else walk slowly and sedately over the ground. They are hard to flush, and one must work on hands and knees or walk and tramp back and forth over an area in order to disturb them to any extent. At first, most individuals leap only a few inches to avoid being stepped upon, but as the area is worked they become more and more restless and finally resort to leaps of two to three feet. These longer leaps generally occur one at a time, the individual remaining motionless after alighting; but a specimen may leap several times in quick succession.

Although all but one (118 of 119) of the adults of this species taken were fully alate the long-winged individuals seldom resorted to flight. If they did, the flight was quick, not flashy as in A. subulatum, and rarely carried the insect more than three or four feet. 
Leaping and flying are done with little, if any, sense of direction; the grouse locust simply moves away from the source of disturbance, a trait which sometimes causes the individual to land upon water. If this occurs, surface tension holds up about two-thirds of the body. The ability to leap from the surface is astonishing. Occasionally, the surface film is broken, and then the grouse locust sinks or swims to the bottom, grips a sprig of vegetation or dead leaf, rests a moment, and swims back to the surface, where it climbs up a stem out of the water and leaps away.

Reference.-Blatchley, 1920 : 165.

\section{Acrydium arenosum angustum (Hancock) Obscure Grouse Locust}

Over 90 per cent of the adults and all of the juveniles of this species taken on the George Reserve have been collected in and along the margins of a woodland depression which is full of water to a depth of about twelve to fifteen inches from October to early June. During the summer the water gradually recedes until, by the middle of August, all surface water has disappeared. Beneath the oaks and hickories surrounding the pool is a heavy layer of dead and decaying leaves, affording retreats within which angustum hibernates. The shrubs of the zone between the woodland and the pool are so few that the pool margins are not heavily shaded. As the water recedes the vegetation, consisting of Polygonum hydropiperoides and Bidens cernua, with a few scattered Carex lupulina and C. tribuloides, gradually spreads over the black muck of the depression. These plants never become so numerous as to cover all of the soil, and as a result bare patches occur here and there.

Hubbell (MS), on June 17, 1920, took angustum in a similar situation in Third Woods, near Ann Arbor, Michigan. His specimens were ". . . on the bare, moist humus areas . . . at the edge of an open area bounded by black locust bushes and a few trees. A considerable number was observed in a small area where the humus soil beneath grass and moss was quite moist." To the west, south, and east, angustum seems to have a somewhat higher ecological valence than was noted for the colony on the George Reserve. Somes (1914: 13) indicated that in Minnesota, Tettix obscurus Hancock (=A. arenosum angustum) is present ". . . in dry open places, varying from sandy banks of streams to the open prairie of the Red River Valley." In Illinois, Hart and Gleason (1907: 230) collected specimens on a ". . . sandy beach, moist at the water level"'; and Hancock (1902:90) stated that he collected this species near a dense woods which is swampy in the spring: "The soil is light clay covered with weeds, mosses, lichens and other usual flora common to damp situations." Later (1911: 419), Hancock gave the habitat of angustum as "swamp forest" and somewhat inadequately 
defined a swamp forest as "a tract of land saturated with water and covered with trees that have never been cultivated.' In Berrien County, Michigan, Hubbell (1922: 33) found angustum living in a variety of situations, such as sand and mud shores, margins of ponds, a dry sandy clay road at the margin of a second growth woods, mud-bar and sand-bar herbage, moist, muddy patches in flood-plain forest, and the mucky margins of a pool at the edge of a buttonbush swamp in the Galien River flood plain. Morse (1920: 534) stated that in New England, the obscure grouse locust inhabits "damp spots on fields of sandy loam, roadsides through springy land, and wet, sandy humus generally." In Georgia, Fox (1917: 207) noted that the species has a "marked preference for patches of bare, damp earth, occurring in open woodland and in open grassy pastures."

As I have pointed out in the introductory part of this paper, few attempts have been made by previous workers to ascertain whether or not the species collected in particular habitats were actually characteristic of them. Among the statements cited concerning the occurrence of Acrydium arenosum angustum, only that of Hancock (1911) represents an attempt to refer the species to its characteristic habitat. In the others no consideration has been given to the possibility that specimens found in many of the situations listed were erratics-a possibility that becomes a probability in the light of my observations on the fall dispersal of these insects. While this grouse locust may actually exhibit wider ecological valence in other regions than it does in the vicinity of the George Reserve, additional field evidence of this must be obtained before the species can be accepted as a characteristic inhabitant of many of the habitats to which it has been credited.

On the Reserve, Acrydium arenosum angustum was associated with Acrydium subulatum, A. ornatum, Tettigidea lateralis parvipennis, and Nemobius c. carolinus.

Reference.-Blatchley, 1920: 168.

\section{Paratettix cucullatus cucullatus (Burmeister) Northern Hooded Grouse Locust}

The several hundred specimens of Acrydiinae collected on the Reserve over a period of four years include only two specimens of Paratettix. The first of these, a fully winged male, was captured on April 25, 1939, on a mat of soggy, dead leaves beneath shrubbery in the narrow ecotone between an oak-hickory woods and a semipermanent marsh. When this specimen was first flushed, it was immediately recognized by its slower and more wavering flight as a species different from those usually encountered. After flying five or six feet, the insect came to rest, with a "splat," upon the leaf mat; immediately it hopped to the right a few inches and then about the 
same distance forward before it was taken. In the same area there were also present three other species of grouse locust-Acrydium subulatum (numerous), A. ornatum (rare), and Tettigidea lateralis parvipennis (common).

The second individual, also a fully alate male, was found on May 24, 1939, associated with Acrydium subulatum (rare), A. ornatum (common), and Tettigidea lateralis parvipennis (numerous) in a heavy growth of Poa pratensis. The stand of grass, about ten feet wide, was bordered on one side by upland, on the other by the wet, mucky, shrub-rimmed margin of the marsh mentioned above.

Careful work in this area prior to 1939 had failed to reveal this species; and it is evident that it must either have been overlooked because it is very rare on the Reserve, or else that it has recently invaded the area from a near-by colony. The latter hypothesis receives support from the observations on the wanderings of various grouse locusts on the Reserve, and from Hancock's statements (1894) concerning the migrations of Tettigidea lateralis. Furthermore, the specimens taken on the Reserve were not in what I should consider a typical habitat of the species. In Washtenaw County, Michigan, I have taken P. c. cucullatus at the bases of sedges and grasses along the sandy banks of the Huron River, and on the damp, sandy, shaded beach of Third Sister Lake. At Sand Point, Huron County, Michigan, Hubbell (MS) secured the species in scattered stands of Scirpus and Carex along a moist strand. In his Berrien County report (1922: 34) he recorded it as abundant in such habitats as the moist margins of streams and ponds, the sandy beach of Lake Michigan, and moist sand flats beside the mouths of two dune creeks; a single specimen was found in beach drift, and others were taken by sweeping in the margins of sandy reed and sedge marshes. Morse (1920:535) wrote that Paratettix cucullatus prefers "the immediate margins of lakes, ponds and streams ....," and Blatchley (1920:176) indicated its favorite haunts to be "the damp sandy or muddy banks of ponds, lakes and streams. . . ." Permanent bodies of water of this description have not been present on the Reserve prior to 1939 ; but with obstruction of drainage channels some of the depressions are filling with water, and it is probable that the northern hooded grouse locust is destined to become a common insect there.

Reference.-Blatchley, 1920 : 175.

\section{Tettigidea lateralis parvipennis (Harris) Sedge Grouse Locust}

The sedge grouse locust is ecologically the most plastic of the Acrydiinae occurring on the George Reserve, being approached in this respect only by Acrydium subulatum. It is characteristic of the wet-terrestrial stratum of 
the marshes, swamps, relict bogs, woodland pools, and bog lakes, and it has been taken as a erratic in the mixed grass-herbaceous and in the low shrubterrestrial stratum of sunny and shady oak-hickory and of the red maplebirch habitats. Conclusive evidence of its occurrence in sporadic colonies on the Reserve has not been found.

Blatchley (1920: 183) reported that "T. parvipennis is a very common grouse locust throughout northern Indiana, frequenting dry upland woods, fence rows, and low marshy tracts; . . . ." He failed, however, to indicate the season or habitat conditions in which the species was observed. In view of my findings on the Reserve, it seems probable that the material which he collected in the drier situations actually consisted of erratic individuals. Shull (1911: 223) found this species on an open grass-plot in the edge of damp woods, and on sand beaches with or without vegetation. Adams (1915: 57-58) recorded parvipennis from an upland oak-hickory forest in Illinois, which, according to his description, is similar to the moderately open oak-hickory of the Reserve. Although he failed to mention the presence near-by of a typical habitat of the species, his specimens were almost certainly erratics from such a situation. Morse (1920: 536-37), Hancock (1902: 149; 1911: 420), and Hubbell (1922: 34-35) have shown that $T$. lateralis parvipennis may be well distributed in an areal sense; but an analysis of their data, in addition to my observations on the Reserve, indicates that soil moisture is a potent factor controlling its local distribution. My own conclusions are in agreement with those of Morse (1920: 536-37), who stated that parvipennis is "in almost every place where there is a constant supply of moisture and bare soil for the growth of the minute veg'etable organisms on which it feeds."

The sedge grouse locust exhibits the same phenomenon of spring assembly as do Acrydium subulatum and $A$. ornatum. Beginning in late March and continuing through April, the insects congregate in large groups, probably for the purpose of breeding. By the beginning of May the number of adults diminishes rapidly, and during the remainder of the year the species never again attains the local abundance of the spring congregations. Adults probably become as numerous in late fall as they are in the spring; but at this time the population is dispersed over a wide area, and specimens are scattered and difficult to find. The spread of the grouse locust populations is doubtless, in part, due to the retreat of the water in ponds and marshes, making available an increased expanse of the normal habitat; but, in part, it probably also results from the increased tendency of the adults to wander in the fall, when they are not held together by the breeding stimulus.

Among 303 individuals of Tettigidea lateralis parvipennis collected on the Reserve (taken as nearly as possible at random and without conscious selection), 125 or 41 per cent, are of the abbreviate type; 178 or 59 per cent, 
of the caudate type. Both types were taken together at the same time and place, and in the spring they congregate and mate together, though some tendency was observed for caudate individuals to mate with caudate, and abbreviate with abbreviate. This last observation may, or may not, indicate conscious selection of mates; it may be largely the result of differences in activity, since the alate individuals appear to be attracted to each other while in flight. The inheritance of long-winged and abbreviate types in this and other grouse locusts is not well understood, in spite of the large amount of genetic research which has been based upon certain species of these insects.

The mating behavior of this grouse locust has been observed in caged specimens and in the field. In the cages the insects mated promiscuously. In one cage in which three pairs had been placed, each male mated with each female at least once during four days of captivity. In my observations the duration of copulation varied from twenty minutes to a maximum of thirty hours, though Hancock (1902: 178-80) recorded having seen a pair of this species in almost continual copulation for three days, except for intervals of a few hours. Owing to the small size of the insect it is difficult, to determine how much of the time that the male and female remain in contact is spent in actual coitus. In other Acrididae (cf. the account given below of Melanoplus punctulatus) I have observed that a male may mount a female and remain on her back in apparent coitus for long periods without actual coupling of the genitalia. Since the manner in which the male holds the female is very similar in all the subfamilies of the Acrididae, it seems probable that the prolonged periods of copulation among this and other grouse locusts do not actually represent the time required for insemination: this can only be determined by further observation and experiment.

The premating activities of $T$. lateralis parvipennis are quite similar to, and often identical with, those performed during mating. Both sexes wander about, perhaps leap a few inches here and there, and then resume their wandering until they chance upon another individual. If the wandering individual is a male, and another male is encountered, the two may merely cross antennae three or four times, or one or both may raise and vibrate the flexed hind legs in an apparently threatening manner, after which they move on. Either one of the males may, however, leap upon the back of the other, only to leap off again at once, or to be removed by the hind legs of the second male. A blow from the tibiae is quite effective in: dislodging one individual from the back of another. The grouse locust; desirous of removing an unwanted intruder raises the hind legs (folded as for jumping) straight up and down and then snaps them back, raking the mounted male and knocking him over backwards.

Should a wandering male encounter an unmated female, he may cross antennae and move away or leap upon her and attempt copulation. An 
unresponsive female is generally successful in removing a male by raking him off with the hind tibiae, though this often requires a great deal more effort than if the individual mounted had been another male. Occasionally, the male may leap upon an unresisting female and then not copulate immediately. In such cases both sexes have been observed to clean their forelegs, antennae, and eyes, and to work the mouth parts about. The male often appears restless and moves around on the back of the female, sometimes shifting position several times so that his head is directed now cephalad, and now caudad, to the body of the female; the female, meanwhile, grooms herself, feeds, or wanders slowly about. On one occasion a male was observed to nibble at the anterior end of the female's pronotum; he then defecated, kicking the feces away from his body with a deft stroke of one hind leg, and proceeded to copulate.

During copulation the male may bend the tip of the abdomen down on either the right or the left side of the female. The side to which the abdomen is turned seems to be determined by whichever hind leg the female swings away from her abdomen. The male's forelegs grasp the ventrocephalic angles of the female's pronotum, the middle legs grasp almost any portion of the pleura just at, or behind, the middle legs of the female, while the hind legs of the male may be permitted to dangle on the ground, may rest in jumping position on the female's abdomen or on the caudal part of her pronotum, or may be held out straight and rigid at an angle of about 45 degrees from the body. As copulation and insemination progress, the female often walks about, but at intervals she becomes quiet and the bodies. of both throb perceptibly. These movements are specially noticeable in the male's hind legs, which often quiver or jerk.

If a wandering individual should chance upon a mating pair, the mating male, and sometimes the female, will draw the hind legs up into warning position, and if necessary will strike out at the intruder. If the intruder and the mating pair approach head on, the mating male, holding his antennae straight out, will alternately snap them up and down. These movements of the antennae may consist of a full arc, a half are followed by a hesitation, or the arc may be divided into thirds with properly spaced hesitations, all in all giving a very jerky movement.

Although oviposition of the sedge grouse locust has not been observed on the Reserve, the egg's are almost certainly laid in the wet-terrestrial stratum, as very small juveniles are always found in such environment. Caged specimens oviposit freely in soil obtained from such a habitat.

Hancock (1902: 178-80) stated that females of Tettigidea parvipennis lay from seven to twenty-six eggs at one time. One of the females which he observed oviposited twenty-one eggs in one hour and five minutes, while .another required three and one-half hours to deposit twelve. Hancock also 
stated that the incubation period varies, according to the temperature, from fourteen to eighteen days. On the George Reserve, young begin to appear in late June, and start to mature by the middle of August. An occasional individual (only two out of a total of 303 which I collected) fails to mature in the fall, hibernates as a late stage nymph, and becomes adult in the spring. Hibernation occurs beneath sticks, stones, logs, and detritus; the insects simply crawl under any available shelter when the period of hibernation begins, usually in early November.

The sedge grouse locust has been observed on several occasions to feed upon the heavy black muck and the heads of mosses characteristic of the wetterrestrial stratum of the marshes and swamps.

The flight of $T$. parvipennis is slower and somewhat more labored than that of Acrydium subulatum. It generally carries the insect from three to five feet at a time, although badly frightened individuals may fly as far as ten feet. This insect almost always alights with a thud on the ground, or on vegetation within a few inches of the ground. My observations on the Reserve indicate that individuals rarely fly unless frightened and seldom fly at all except during the spring. The rest of the year this grouse locust seems to rely solely upon leaping, and upon its concealing coloration for protection. Cavorting, as indulged in by Acrydium subulatum in the spring, seems to be absent in this species; however, since subulatum is more abundant and flashier than parvipennis and occurs with it, this type of flight may have been overlooked in the latter. The sedge grouse locust leaps only two to four feet at a time, seldom more than once, sometimes twice, and rarely three times.

During the fall parvipennis, like the other species of grouse locusts which were abundant enough on the Reserve to demonstrate the phenomenon, begins to wander. An occasional individual has been found as far as two hundred yards from the nearest characteristic habitat. Hancock (1894) has recorded large, active migrations of the species into Chicago in 1893, and Rehn (1902: 310) observed a similar phenomenon at Philadelphia on September 24, 1902. No such migrations were noted on the Reserve, during the period of this investigation.

Tettigidea lateralis parvipennis, being a common insect of the wetterrestrial stratum, has been noted in association with all of the other species of grouse locusts known to occur on the George Reserve.

In this region members of the genus Tettigidea may be separated at a glance from any of the other grouse locusts by the small white spot at the caudal end of the tegmina of both sexes. The smaller size and white face of the male enable one to distinguish the sexes in the field with ease.

Reference.-Blatchley, 1920 : 183. 


\section{Tettigidea armata Morse Armored Grouse Locust}

On the Reserve Tettigidea armata is a rare insect, only two alate females (taken August 13 and October 4, 1936) and a few nymphs having been captured. The nymphs and the female taken in August were secured amid growths of Eleocharis and moss on the black, oozy mud of the lake margin. The other female was taken on dead leaves about five feet from the muddy soil of the ecotone between the oak-hickory of Station 7 and the red maplebirch forest of Station 8 .

The species is apparently rare and very local in distribution not only on the Reserve, but also throughout southern Michigan. Populations of sufficient density to warrant the term "numerous" have seldom been encountered in this region, specimens usually being secured one or two at a time. In Berrien County, Michigan, Hubbell (1922: 35-36) found this species numerous about a dune pond:

[It occurred] especially on the area of exposed muck and on small mossy patches around the margin, but also among the herbaceous growths of the sandy shore. . . . All specimens taken here during both seasons were found in an area of perhaps thirty square yards; none were found on other apparently similar parts of the pond margin. On one occasion forty-five minutes' search for this species yielded fourteen specimens; at no other time were they so numerous.

He further stated that other specimens were taken in and around the drier margins of a lizard's tail marsh. Blatchley (1920: 185) wrote that "Morse's types were taken by me in Vigo County [Indiana], where [they] occurred in small numbers along the wooded margin of a large lowland pond. In the northern counties it [armata] frequents woods about the margins of lakes and is usually found closer to water than is T. lateralis." On May 7, 1922, Hubbell (MS) found this species fairly numerous around the margin of a shallow (probably temporary) pond in the edge of an open oak woods near Francisco, Jackson County, Michigan:

This pond is filled with sedges and other semi-aquatic plants, and on the side within the woods is bordered by a narrow shrub zone. The ground around the pond margins, within the grove, is covered in many places with a thick growth of moss, sodden and water soaked, near the water's edge. Among the shrubs the ground is bare, thinly covered with a sprinkling of dry leaves. This species was found close to the margin of the pond, on the side toward the woods, on the mossy areas and among the clumps of bushes.

I found late instars of the armored grouse locust on July 23 near Mud Lake, Washtenaw County, Michigan. The species was rare and occurred on a rather open, muddy area sparsely covered with mosses and the liverwort Marchantia. This area was formerly a part of a tamarack swamp which had been burned over. 
Reviewing the above observations on the occurrence of Tettigidea armata, one notes that at least two factors are common to all situations in which the species has been found in fair-sized colonies. These are the presence of heavy, mucky, organic soil, and a sufficiency of sunlight. If these actually constitute the requirements of the species they afford an explanation of its scarcity on the Reserve. Here the water level in the lowlands fluctuates sufficiently so that the lake margin and the floor of the red maple-birch flood plain forest are inundated for several months each year; furthermore, only the lake margin is sufficiently sunny to afford the second of the two requirements, the floor of the wet forest and the ecotone between it and the oakhickory forest being densely shaded in most places. Since the lake margin and the floor-plain forest are the only habitats present on the Reserve which approach the types of situations where the species has been found elsewhere, and since these are rendered uninhabitable for the species by the conditions described above, it is not surprising to find this grouse locust of rare occurrence in the area.

In reference to certain habits of this species, at Francisco it was also noted by Hubbell (MS) that in the open places specimens were fairly easy to capture, as they often jumped out into the water and clung to some submerged object, after a time leaving it and swimming vigorously toward the shore. While in the water they were easily caught, although, if near the surface, they could leap for some distance even though hampered by the surface film. Among the bushes they were considerably harder to capture. None was seen more than ten feet from the water margin. They were more numerous than Acrydium subulatum and Tettigidea lateralis parvipennis, with which they were associated.

Reference.-Blatchley, 1920 : 185.

\section{ACRIDIDAE, ACRIDINAE \\ Pseudopomala brachyptera (Scudder) \\ Bunch Grass Locust}

On the Reserve the characteristic habitat of Pseudopomala brachyptera remained unknown for several years. The rarity of the species and the fact that it had been taken both in extreme xeric conditions and in hydric environments, combined to present a puzzling situation. Intensive collecting failed to reveal additional specimens from the drier habitats, but occasional individuals were found from time to time in the marshes.

On July 19, 1939, males of a colony were heard stridulating ${ }^{12}$ amid a

12 The term "stridulation," as used in this paper, is restricted to sounds produced by the movements of caudal legs against the tegmina as well as those made by rubbing the bases of the forewings together, these being produced while the insect is not in flight. For the sounds produced by shuffling the hind wings against the fore wings while in flight, the term "crepitation", is used. 
dense growth of sedge and regal fern in a marsh. It was impossible to capture a specimen by tracing the notes, so the trampling method was employed to locate individuals. An area forty feet in diameter, in what seemed to be the center of the colony, was selected and worked. Not a single specimen was observed until only a small circle of vegetation containing about ten square feet was left standing. A male then leaped from the untrampled sedges and ferns, landed upon a stem, turned slowly about, and then jumped about a foot back into the standing plants, where it was picked up with the fingers. A few minutes later, a female was observed sluggishly squirming her way up from beneath the matted vegetation, and was also picked up with the fingers. An hour and a half was required to secure this pair, although several other males were heard near-by.

The areas on the Reserve where this species has been taken are all included within the semipermanent marsh habitat, except for the few specimens taken in xeric situations, where they were probably erratics. Although the species must be listed as characteristic of these habitats, so far as the Reserve is concerned, it is probable that true optimum habitats are not represented in the area. In Berrien County, it was found by Hubbell (1922: 36) in an environment similar to that in which I have taken it on the Reserve-a marsh with tall lush vegetation. At Milford, Oakland County, Michigan, Hubbell (MS) encountered it in greater numbers in tall dense grass in a hillside orchard. I have observed it in moderate numbers in a similar situation near Ann Arbor, Michigan, and both Hubbell and I have collected this species in the heavier growths of mixed grass and bracken fern near Oscoda, Iosco County, Michigan. Shull (1911:223) reported $P$. brachyptera in Huron County, Michigan, as occurring in open woods, in patches of tall grass, and on grassy sand dunes; and Morse (1896: 382) stated that in New England the bunch grass locust "is not uncommon locally on the coarser grasses found in waste lands, especially upon a species of bunch grass (Andropogon scoparius Michx.). ...' In Illinois it is recorded by Hebard (1934: 173) from tall grass, and from fields of bluegrass and timothy. The true home of the species is probably on the tall-grass prairies of the Middle West; in Oklahoma it was abundant, according to Hubbell (MS), in areas of untouched beard grass (Andropogon furcatus) prairie, though it has disappeared from most cultivated land. Its discontinuous occurrence eastward from the prairie region probably indicates that in this part of its range it is a relict form, maintaining itself where conditions are tolerable, but not always occurring in optimum habitats. The transition from hydric to moderately xeric environments on the Reserve is too abrupt to permit the development of rank prairie-like growths of grass and herbage, and the marshes where it is present are probably the closest approach to these which the Reserve affords. 
Adult specimens of this species have been secured on the Reserve from July 10 to August 21. Hubbell (1922: 37) took last-stage nymphs and teneral adults on July 16 in Berrien County, Michigan, but on the Reserve $P$. brachyptera evidently becomes adult about the first week of July. In this area the species is believed to pass the winter in the egg stage.

Reference.-Blatchley, 1920 : 200.

\section{Orphulella speciosa (Scudder) Pasture Locust}

The rarity of Orphulella speciosa (only fifteen specimens were taken in four collecting seasons) and the diversity of the habitats in which it was found on the Reserve, make it impossible to state with certainty the most characteristic habitat.

The pasture locust was first encountered during 1936 in a small depression, about sixty feet long and fifteen feet wide, in which Poa pratensis grew luxuriantly. Surrounding this depression were extensive areas of the mixed grass-herbaceous habitat. Intensive search failed to reveal a single specimen in the latter habitat, all being secured in the grassy swale. Work during the next three seasons revealed an entirely reversed situation. Specimens were found, one or two at a time, in the mixed grass-herbaceous habitat, although none could be located in the swale, or any other similar tract, on the Reserve.

In July, 1937, a single female was taken in a sparsely vegetated sand area, the most xeric type present on the Reserve. Continued search in this same area during the rest of that year and during the 1938 season failed to reveal additional specimens. In 1939, however, an hour and a half's search yielded four males from identically the same area. It is probable that these were members of a small sporadic colony maintained by specimens moving out from a near-by mixed grass-herbaceous habitat. A single juvenile and a few other specimens have been collected in the latter. I have formed a strong impression, although it is not proved, that the pasture locust normally occupies the more open parts of the mixed grass-herbaceous habitat. This suggestion is strengthened by the fact that both Hubbell (1922: 37) and Morse (1920:435-36) are agreed that the species lives on dry, sandy, grassy upland. I have also taken $O$. speciosa commonly at Oscoda, Iosco County, Michigan, in the dry, sandy, jack-pine plains of the Au Sable delta.

When alarmed the pasture locust generally either attempts to conceal itself among grass stems or leaps vigorously away from the collector and crouches on the ground. It will fly after being flushed several times. The flight of the male is rapid and straight and carries the insect from six to eight feet. The act of alighting, although very rapid, is not a dive, as in certain Oedipods, nor is it accompanied by a fluttering movement, as in 
Melanoplus mexicanus mexicanus. Specimens have neither been heard to stridulate nor to crepitate.

The capture of a last instar male on July 6 indicates that on the Reserve the species probably matures around the tenth of the month. Adults have been secured from July 12 to September 3.

Reference.-Blatchley, 1920 : 228.

\section{Chloealtis conspersa Harris Sprinkled Locust}

On the George Reserve, the sprinkled locust is a characteristic inhabitant of the low shrub-terrestrial stratum of both the sunny and the shady oakhickory habitats. The species is common in all of the woodlands of the area that are not too dense in stand and in which dead wood suitable for oviposition is present.

Within a given oak-hickory woods the distribution of individuals varies with the time of year. This is, in large part, owing to their peculiar requirements for oviposition and their fondness for diffuse sunlight. Blatchley (1920 : 216-18) has summarized the literature dealing with the unusual egglaying habits of this species. Although I have not observed the oviposition of conspersa on the Reserve, the invariable occurrence of small to mediumsized juveniles in colonies near down timber is explained by the fact that the eggs are laid in the soft or decaying wood of fallen limbs. As the season progresses, individuals move away from the places where they hatched, and by the time maturity is reached they have become fairly well distributed within a given woodlot. They also are very likely to remain about the more open places in the woods, where individuals may be observed from time to time sunning themselves.

Specimens of the third, fourth, and fifth size groups of the sprinkled locust have been taken on June 24 and 26. Adults were also secured on the latter date, although last stage juveniles were three times as abundant. At this same time two males were heard singing-proof that they had reached maturity at least twenty-four hours earlier. Juveniles of the fifth size group have been taken as late as July 13, and teneral females as late as July 21. The species is susceptible to cold; the population dies off very rapidly in early September and is probably completely gone by the latter part of the month. September 1 is the latest date on which a specimen has been taken. On the Reserve the species undoubtedly passes the winter in the egg state.

About 10:00 P.M. on July 2, a teneral male was observed feeding upon the leaves of Canada blue grass (Poa compressa). Like other individuals of the species observed at night, this male was very sluggish in its movements. At night each step is so slowly executed that it appears to be calculated, and specimens are easily picked up by hand. Individuals observed 
one night, when the temperature was $66^{\circ} \mathrm{F}$. one foot from the ground, moved with grace and deliberation almost equaling that of Scudderia. At this same time near-by individuals of Neoconocephalus ensiger were very active.

During the day conspersa is extremely alert and active. Males walk about upon the leaves with quick, spry steps. When flushed, they leap with a snap and elasticity that suggests the activity of Acrydium subulatum, and upon alighting, immediately leap again. Several jumps usually follow in sequence, each one seemingly carrying the insect in a different direction. After four or five such jumps, the male quickly crawls beneath the vegetation, where its somber hues effectively conceal it. Once hidden in this manner, a male can be flushed again only after much trampling. Females are much more sluggish than males. They are more difficult to alarm, and leap but once or twice for distances of one to two feet-about half as far as the males. The females are much readier to burrow beneath grass and dead leaves than are the males, but are flushed again as easily as that sex.

Stridulation is performed only during the warmer hours of the day. The song is made up of a series of notes, which may be expressed as "zeeeek", or "eeeeek," varying from time to time in intensity, sharpness, and number of sounds. A male was observed on August 1, 1936, walking about on the old, dead, browned leaves on the floor of an oak-hickory wood. Each time it approached grass it turned away. It seemed to take pains not to walk directly into sunshine nor into dense shade, but stayed on leaves which were illumined by diffuse light. While I watched, this male walked quickly along for about four inches, and then stopped and began to stridulate. The body was raised slightly, and then the hind legs were lifted synchronously until they were well above the tegmina. Both hind legs were then brought down simultaneously against the tegmina, producing a sound which may be represented as "eeek." On the upward stroke the legs were swung outward in an are so that they did not touch the tegmina nor produce any sound. The sounds were given slowly and softly at first, but after the first few their loudness and tempo increased, until at the end of the song they came about three times as fast, and had several times the volume of the early ones. This male was heard to sing five times. The first time nineteen notes were struck, the second time eighteen, and the third, fourth, and fifth times sixteen each. The notes were produced at the average rate of four per second. After each song the male moved forward a few inches.

On July 19, 1939, five stridulating males of C. conspersa, were studied. In all of these the activity accompanying stridulation was as described above, except that an individual might remain in one place and stridulate for several minutes before moving about. On this occasion, with the temperature about $82^{\circ} \mathrm{F}$. one foot above the ground, the usual rate of note production was about four per second, but often dropped below that frequency. The notes, furthermore, decreased in sharpness and volume toward the close 
of the song, instead of continuing crescendo to a climax. It is possible that the songs heard on this occasion were not carried to their normal completion, since none of them consisted of more than ten notes. The number of notes struck in a consecutive series of separate songs by one male was $9,1,2,9,9,4,10,5,6,7,3,2,4,3,5,2,2,6$. The interval between notes in each song was merely a slight pause, that between songs three seconds to many minutes.

References.-Blatchley, $1920: 215$.

\section{Chorthippus longicornis (Latreille) Meadow Locust}

The meadow locust is one of the commonest grasshoppers of the marshes of the George Reserve. Characteristic of the permanent marsh and semipermanent marsh habitats, it has been found wherever these environments exist. Erratics and sporadics have never been observed.

Chorthippus longicornis passes the winter in the egg stage and begins to hatch in late May and early June. Adults were first noted on July 18, in company with late instars. Teneral adults have been taken as late as August 13, while maximum abundance of adults is reached in late August. It is one of the hardiest Orthoptera of the area studied and can survive a number of light frosts; in 1936 individuals were still common on October 14. For this reason the abundance curve drops suddenly from time to time in the fall, each drop following a freeze and proportional to its severity, until but a few survivors are left. These succumb to the still more severe freezing weather of late October and of early November.

The meadow locusts are most active and dodge behind vegetation with the agility of Orchelimum vulgare. When flushed, meadow locusts leap and tumble through the grass and sedges, finally dropping to the ground, where they work their way along under the vegetation. Trampling, however, causes them to emerge soon, and they are then readily captured. They normally cling close to the tops of the vegetation, and by moving along and sweeping rapidly one may easily collect many individuals before they can drop to the ground. At night many often sleep motionless on the tops of grass and sedge stems. This behavior is only occasional, and appears to be a response to special meteorological conditions, which are, however, as difficult to analyze as those responsible for the "good lighting nights" well known to collectors of Lepidoptera.

Morse (1920: 441) has observed that macropterous individuals of Chorthippus longicornis fly readily. I have never observed individuals of this species in flight on the Reserve, but this may be owing to the lack of long-winged specimens. Of the material collected on the area, 97.7 per cent is brachypterous and but 2.27 per cent macropterous; all of the latter are females.

Reference.-Blatchley, $1920: 234$. 


\section{Stethophyma gracile (Scudder) \\ Northern Sedge Locust}

One of the most beautiful Orthoptera on the George Reserve is the northern sedge locust. It is, however, a secretive species, and hours of laborious trampling are often rewarded with only a single specimen. A characteristic inhabitant of the heaviest mixed growths of sedge, meadowsweet, swamp birch, and bluejoint grass in the semipermanent marsh habitat, it has been observed in all the swamps and marshes that have sufficiently lush growths of vegetation. The species does not appear to wander much, as specimens have never been taken in any other habitat. Drier parts of marshes and swamps, with less heavy vegetation, are avoided as much as are areas that remain constantly inundated throughout the year.

Stethophyma gracile is a wary and shy grasshopper. Males cease to stridulate as the collector nears them and often will not resume their calls for as long as twenty minutes. The closer a male is approached, the longer the waiting period becomes, so that it is virtually impossible to track down an individual by its call note. If the collector runs toward the spot where a male has just been heard stridulating the insect will often fly up with a rather awkward, heavy wing beat. Its flight is not sluggish, however, and rapidly carries the locust to a distance of twenty to forty feet. At the end of the flight it dives with a quick plunge into the vegetation, burrows beneath the grass and remains quiet, admirably concealed by the green and brown plant stems which match its own coloration. If the collector makes a gradual approach instead of rushing up, males remain in their customary positions, clinging to the stem of a sedge at a height of two feet or so, until they become thoroughly alarmed. They may attempt to hide themselves by sidling around the stem to the side away from the intruder; but more often they drop to the ground and quickly burrow from sight.

Females are even more difficult to collect than males, as they have not been heard to call, seldom if ever fly, remain low in the vegetation, and burrow out of sight at the first indication of danger. When alarmed, they remain motionless in concealment for long periods. On one occasion a part of a marsh, about fifty feet in diameter, was worked continuously by the trampling method for nearly three hours before a female hidden beneath the vegetation was finally forced out into the open. Her leap from concealment was lubberly, not at all graceful, and carried her only two feet; upon alighting she literally dropped and tumbled about until she could grasp a plant stem and right herself, whereupon she crawled beneath the vegetation to hide again.

Trampling will flush all the males from an area approximately fifty feet across in from twenty minutes to an hour, and if one terminates his endeavors at this stage his collections will contain three or four times as many 
males as females. The proportions of the sexes are, in fact, probably nearly equal; but even prolonged working of an area will never reveal more than a fraction of the females which are undoubtedly present.

The stridulation of the male of Stethophyma gracile is louder and clearer than that of any other acridian in this region, in this respect approaching the calls of some of the katydids. The notes, generally repeated four times but occasionally more often, are audible to the average person for a distance of about seventy feet. An impression of the sound of the rasping notes is conveyed by the phrase "Zeeeek! —_Zeeek! -Zeeeek!-Zeeeek!" The first note is not so loud as those which follow, and gives the impression that the male is testing to see if it is safe to continue his song. This first note is generally followed by a pause of about half a second; the remaining notes of the song are given clearly, sharply, and with uniform duration and brief, equal pauses between notes. The call may be repeated several times at intervals of four or five seconds, or, once given, may not be repeated until fifteen or twenty minutes later. The call of one male does not seem to stimulate other males to stridulate in answer, as it does in certain other singing Orthoptera.

Adults of Stethophyma gracile have been taken from July 18 until September 14, but are gone by the time of the first autumn frosts. The species probably passes the winter in the egg stage.

Nemobius fasciatus socius, N. carolinus, Chorthippus longipennis, Pseudopomala brachyptera, Orchelimum vulgare, O. gladiator, Conocephalus brevipennis, and $C$. nigropleurum are characteristically associated with the northern sedge locust.

Reference.-Blatchley, $1920: 240$.

ACRIDIDAE, OEDIPODINAE

Arphia sulphurea (Fabricius)

Spring Yellow-winged Locust

The flash of the sulphur-yellow wings of Arphia sulphurea is a common sight in the mixed grass-herbaceous habitat on the Reserve during late spring and early summer, and the crackling flight stridulation is a familiar sound. Characteristic of the above habitat, the species is also sporadic in the sparsely vegetated sand habitat of the uplands. It has often been encountered as an erratic along the margins of woods, swamps, marshes, and ponds adjacent to the characteristic habitat.

Passing the winter as juveniles, the spring yellow-winged locusts emerge from hibernation as soon as the ground thaws and soon reach maturity; adults begin to appear the first week in May. The adult population reaches its peak in about ten days, maintains maximum abundance until the end of June, and then diminishes rapidly. The last specimen observed in 1939 was 
captured on July 10. In the previous year the species was occasionally encountered as late as July 21.

The activities and behavior of sulphurea are similar to those of Arphia $p$. pseudonietana, and comparisons are made under that species.

Reference.-Blatchley, 1920 : 252.

\section{Arphia pseudonietana pseudonietana (Thomas) Red-winged Locust}

As Arphia sulphurea dies away in mid-July, the red-winged locust takes its place in the uplands, occupying the same habitat as that in which sulphurea gamboled but a short time before. The earliest recorded adults were taken on July 10. Maximum abundance is reached in the brief period of eight to ten days after the appearance of the first adults, and the species does not diminish much in abundance until fall frosts begin to take their toll. The species is quite tolerant of cold, and individuals have been collected as late in the fall as October 3 . This northern race of pseudonietana passes the winter in the egg stage.

The activities of Arphia sulphurea and A.p. pseudonietana are very similar. The statements made below apply to both species except where otherwise indicated.

The red-winged locust is not quite so wary as are Spharagemon c. collare and certain members of the genus Trimerotropis. It does not turn about and face an approaching object as do those grasshoppers, but instead it remains closely crouched to the ground, or flies. When not in flight pseudonietana invariably remains close to the ground, never climbing about on the fallen vegetation. It walks quickly about from the base of one plant to another, or lies close to the soil, sunning itself. At night individuals hide under leaves, or amid the bases of plants and in grass clumps.

Males that have not been alarmed by an intruder may often be seen performing anties in the air. Rising slowly, a male flies almost straight up from the ground to a height of about four feet; then it flutters and glides slowly back down. It never plummets down in a dive on these occasions, but drops slowly with fluttering wings which flash brilliantly red in the sunlight. As the level of the vegetation is reached, the wings are closed and the male then drops to the ground. This performance is accompanied by a strong, sharp crackling or crepitation of the wings, audible for fifty yards or more. At the end of the flight the male is generally not much more than four feet from its starting point. This odd flight behavior is exhibited only when the sun is shining brightly. The reason for the crackling and display of color is obscure; it has been variously interpreted as a form of play, as a means of maintaining assemblages, or as a form of courtship; the latter explanation appears most probable. 
The flushed males generally fly ten to thirty feet. When accompanied by crepitation the flight is uneven, zigzagging, and somewhat undulating, but it is even and smooth when the male is too badly frightened to make this sound. In the flight in which crepitation occurs the crackling notes are begun after the first third of the flight and are continued until the sound ends abruptly with a crashing finale as the male zooms up in preparation for alighting. In alighting, males whirl quickly and sharply to one side, close the wings, and dive into the grass. The shift in direction is nearly 180 degrees as a rule and causes the individual to land facing the direction from which it came.

The flight of the female is somewhat longer than that of the male, individuals traveling from five to fifty or sixty feet. In alighting, the females do not turn sharply to one side, and quite often drop straight down along the line of flight. Disturbed females crepitate, but not nearly so loudly as do the males, the notes being audible for only ten to fifteen feet. Crepitation by females lasts only about a second and occurs during the middle of the flight. Badly frightened individuals of both sexes do not crepitate, and usually fly farther.

The above description of the activities of Arphia p. pseudonietana applies equally well to Arphia sulphurea, except that in sulphurea both sexes crepitates less loudly; the flight sounds of the male are audible for about thirty yards.

Somes (1914: 36) has described the stridulation of males of pseudonietana. I have not observed stridulation in either pseudonietana or sulphurea, but it is undoubtedly performed by both, as Chortophaga viridifasciata and Dissosteira carolina have been seen and heard to produce faint sounds by rasping the caudal femora on the closed tegmina. It is probable that males of most species of Oedipodinae exhibit this form of sound production.

Reference.-Blatchley, 1920 : 251.

\section{Chortophaga viridifasciata (DeGeer) Green-striped Locust}

With the exception of the grouse locusts, the first grasshopper to mature on the Reserve in the spring is the green-striped locust. It passes the winter in the juvenile stage of the fourth and fifth size groups, and the adults begin to appear in late April, having been taken as early as April 22. Maximum abundance is reached in May, and numbers diminish rapidly in June. During the last ten days of June only two specimens, taken June 27 and 29, were observed, and by the end of the month the species is gone. The young hatch in August and September, and nymphs are abundant in the fall until freezing weather comes, and again in the spring during late March and April. 
On the Reserve, viridifasciata occurs characteristically in the mixed grass-herbaceous habitat, but early in the season it is always in areas of this habitat, in or near the moister swales and marsh margins, where Poa pratensis grows luxuriantly. Juveniles have invariably been found in numbers only in such moist situations. As the season progresses, individuals fly out into the upland, but none have ever been observed in the marshes or swamps. The species, although upland or campestrian, is definitely associated with, and limited by, the occurrence of areas of moister environment than that typical of the grassy upland habitats of the Reserve.

C. viridifasciata crepitates on the wing as do the species of Arphia. The crepitations, however, are not so sharp as those of Arphia sulphurea, but instead have a more rasping, buzzing quality. Females crepitate on the wing, producing a low, short buzz, audible for about ten feet. Flight slows down noticeably during crepitation, as would be expected from the mechanics of the sound production. Individuals of either sex when thoroughly frightened do not crepitate, but fly with the straight even flight otherwise characteristic of the females. The species is slightly more sluggish than Arphia and flies in the same undulating, zigzag manner, although without, such marked deviations in direction. Males normally fly about ten to thirty feet, while the females fly twice that far. Upon alighting the insects half dive, half flutter to the ground. On the whole, the species is not as good a flier nor as loud in its flight crepitation as is Arphia sulphurea. All of the males and 81 per cent of the females taken on the Reserve were of the green color phase, and 19 per cent of the females represented the brown phase.

Reference.-Blatchley, 1920 : 255.

\section{Encoptolophus sordidus sordidus (Burmeister) Dusky Locust}

A member of the fall grasshopper fauna and characteristic of the mixed grass-herbaceous habitat of the upland, the dusky locust is one of the latest to mature on the Reserve. Although generally in dense vegetation, the species is often taken in areas of sparser growth within the mixed grassherbaceous habitat. A few individuals, probably erratics, have been found in the sparsely-vegetated sand habitat; but otherwise the dusky locust does not wander far from its typical environment.

Appearing in mid-August (August 13), adults of sordidus become abundant by the end of the month, and begin slowly to decrease in numbers during late September. With the advent of freezing weather this sombercolored insect quickly disappears. Nymphs, hatching from overwintering; eggs, become abundant in late June and in July.

$E$. sordidus is not a flashy insect. Most of its life is spent upon the ground, where, with its dull hues matching the soil, it wanders about, or 
simply sits sunning itself for long periods of time. When flushed, males fly with a slightly zigzag motion, for about thirty to forty feet. Flight of the males is usually accompanied by crepitation, which does not have the snap and crackle of an Arphia, but is more of a buzz. The sound is produced after the insect attains the highest point of its flight and continues until just before the individual dives into the vegetation at the end of the flight. Badly frightened males do not crepitate, but fly as do females-straight, without zigzagging, and without noise. Although females have not been heard to crepitate, they possibly may do so sometimes. Individuals of this sex commonly fly about fifty feet before alighting. In both sexes the flight usually ends in a straight-ahead landing that does not turn noticeably to either side and is accomplished by a dive combined with a fluttering movement of the wings. Morse (1896: 19) observed stridulation in captive males of this species.

Reference.-Blatchley, $1920: 259$.

\section{Camnula pellucida (Scudder) \\ Clear-winged Locust}

On the George Reserve, the clear-winged locust is rare, specimens having been taken only twice. On July 10, 1936, a single female was captured by sweeping in a typical mixed grass-herbaceous habitat. Three years later, also on July 10, a colony was located in a similar area which had been combed several times each season without the species having been encountered. It is possible that in both cases individuals flew into the Reserve from some outside colony. The group discovered in 1939 contained approximately thirty to forty individuals and was probably established by a single fertilized female.

Females of the clear-winged locust are rather difficult to flush; males fly up rather readily. The flight of both sexes is rapid, straight, and not accompanied by crepitation. Males fly twenty to forty feet, and females about twice that far. Alighting is much more graceful than in Pardalophora, individuals coming down rapidly but with good control. Parker (1924, 1930) has written extensively on the ecology of this species.

References.-Blatchley, 1920 : 261 ; Parker, 1924, 1930.

\section{Pardalophora apiculata (Harris) Coral-winged Locust}

On the Reserve the adults and juveniles of this species occur characteristically in the mixed grass-herbaceous habitat. When flushed in this environment, however, the strong powers of flight will often carry individuals into adjacent areas of the sparsely vegetated sand habitat; here they may hide beneath a Panicum clump or in some other place of concealment, or 
more often, resume flight and move on to an area where the plant cover affords more protection. The coral-winged locust has never been seen or taken in any other habitat than the two mentioned.

The winter is passed, in this species, by hibernating juveniles of about the fourth instar, which have crawled beneath the masses of dead rosette leaves of Panicum (a favorite hibernation site), beneath other plant debris, or into crevices and holes in the ground. The last week in April these nymphs begin to come forth from their winter retreats; the earliest date on which I have observed them is April 25. By the end of May adults begin to appear, May 24 being the first date on which adult males have been seen. Maximum abundance of adults is attained within three or four days after their first appearance, is maintained until toward the middle of June, and then drops off very rapidly. By the end of June the species is scarce and practically impossible to locate, because $P$. haldemanii, which it closely resembles and which occurs in the same habitats, reaches maturity at this time. The activities and behavior of apiculata are described under haldemanii.

For some reason Pardalophora apiculata is scarce on the Reserve. The species is common to abundant in the jack-pine plains of the northern part of the Lower Peninsula of Michigan in early June, and in the vicinity of the Reserve has been observed in numbers near Portage Lake and at various other points. Pardalophora haldemanii, a species of prairie and plains affinities, is far more abundant on the Reserve than is apiculata-a fact which simply adds to the puzzle.

Reference.-Blatchley, 1920: 264.

\section{Pardalophora haldemanii (Scudder) Haldeman's Locust}

In early June (June 4), when the daisy fleabane begins to flower and the coral-winged locust is most abundant in the uplands, adults of Pardalophora haldemanii begin to appear. At first sight this addition to the number of flashy red-winged grasshoppers suggests a secondary increase in the population of the coral-winged locust, and not until one sees the occasional yellowwinged variant found in haldemanii, but rarely or never seen in apiculata, does it become apparent that a second species has come on to supplant the first.

$P$. haldemanii, hibernating as juveniles of the third and fourth size groups, begins to mature a little later than apiculata, and is somewhat slower in reaching its peak of adult abundance. From the first appearance of adults six or seven days is the average time necessary for attainment of maximum abundance. This brings the greatest abundance at the time that apiculata is declining in numbers (the end of June); the falling off in abundance of apiculata thus is somewhat obscured. 
Haldeman's locust does not begin to decrease in abundance until toward the end of July, but when the decrease once sets in, it is rapid, and apparently few stragglers are left. The latest date on which a specimen was taken on the Reserve is August 5.

Characteristic of the mixed grass-herbaceous habitat, Haldeman's locust is almost always found in masses of Panicum, heavy stands of Erigeron and Anaphilus, thick growths of Poa, or wherever the vegetation is heaviest. When flushed, these insects forsake the clumps and dense patches and fly for some distance, usually alighting in other heavily vegetated areas. Gradually, as the habitat is worked, the specimens become more and more scattered, until they are dispersed over the whole area. A day or two later, however, these specimens have again congregated in their original locations. Erratics of this species have never been taken on the Reserve, but haldemanii occurs in the sparsely vegetated sand habitats as a sporadic. Juveniles and adults are seldom seen in this very xeric environment, but sufficient numbers of both have been taken in large areas of this type of habitat far enough distant from the nearest mixed grass-herbaceous habitat to make it seem highly probable that the nymphs had hatched near where they were found. The juveniles are exceedingly sluggish and are not readily flushed. When flushed they leap but once or twice, for a distance of a few inches only, and then try to conceal themselves beneath Antennaria or Panicum leaves. Generally, they may be secured only by carefully searching the ground, while crawling on the hands and knees. Flushed females fly in a heavy, lubberly manner for distances of fifty to one hundred feet. They frequently rise to a height of fifteen to twenty feet, and on windy days fly down wind. In alighting, females close their wing's and drop to the ground with a thud. One was observed to drop three feet in front of me, where she tumbled down through the grass, catching her left hind leg on a stem, and tearing it completely from her body. Both the leg and the bleeding specimen were collected. Males fly up in one of two ways. If approached cautiously, a male simply flies away for about five feet, but if one walks rapidly through the vegetation, the male will fly away in a zigzag, dancing fashion for a distance of fifty to seventy-five feet. Males never fly as far as females, and they flutter their wings more while alighting, so that the force of their fall is somewhat broken. In flight neither sex crepitates, but they both produce a whirring noise similar to that made by a hummingbird. Haldeman's locust has never been observed to fly except when flushed.

An interesting observation may help to explain the absence of erratics in the species. A female was flushed and flew down wind toward a moist depression. Upon approaching this area she started to alight, dropping downward toward the very center of the depression; but when she was about three feet from the ground, she apparently judged the area not to her liking, 
righted herself, and flew on to land in a typical mixed grass-herbaceous habitat.

So far as I was able to determine, this account of the activities of haldemanii applies equally well to $P$. apiculata.

Reference.-Blatchley, $1920: 268$.

\section{Dissosteira carolina (Linnaeus) Carolina Locust}

The Carolina locust is probably the best known of all our grasshoppers. Its flashy black wings are often seen in the roadways, and occasional specimens are observed in the hearts of large cities. On the Reserve this species is characteristically in the mixed grass-herbaceous habitat, where it commonly walks briskly about or simply sits quietly in the sunlight for long periods of time-apparently a favorite occupation of the species. Probably for this reason carolina is almost always on bare areas, which range in size from a few square inches to large exposed tracts such as roads. It is typical of the group which Morse designated the "bare-ground locusts."

$D$. carolina seems able to select these sunny spots as it flies along. Specimens have been seen many times to fly over grassland, suddenly turn one way or another, and then drop down upon exposed soil. This habit of continuing flight until a suitable landing spot is found probably accounts for the occurrence of the species as a common erratic in all of the marshes, swamps, and woodlands of the Reserve. Each of these vegetational types offers many sunlit, bare spots where a wandering individual may alight. The aerial performances described below tend to attract other individuals to the same spot, so that several may be present in such an area. However, regardless of how far the adults wander, juveniles are invariably only in the characteristic habitat.

On the Reserve the Carolina locust matures about the first week of July. Teneral individuals were taken on July 4 and 5, 1939, and on July 2, 1938. At this time juveniles of the fourth and fifth size group are common in the upland. Maximum abundance is reached in about two weeks, and adults are present until frost kills them in the fall. The latest specimen observed was a female, seen on October 3. The species hibernates in the egg stage.

The Carolina locust has the most interesting type of flight of any of the grasshoppers that occur on the Reserve. Individuals fly along with only a slight whir; the flight is slightly undulating, wavering and fluttering from side to side, and very similar to that of a butterfly. An individual may hesitate and appear ready to alight, but as often as not flies on. When preparing to alight, carolina flutters to within six inches of the ground and then swings back and forth from one side to another. If bare ground is not available, the insect will fly on ahead and repeat the procedure until a 
suitable spot is located. The grasshopper then closes its wings and drops to the ground.

D. carolina is gregarious. When one specimen is observed, a reconnaissance of the area will generally reveal the presence of others near at hand. Single individuals seem restless and fly up more often than when associated with others of their kind. Individuals are readily attracted to one another. Should one flutter down a roadway, it will soon be followed by others. This attraction of one individual for others of either sex has often been noted, and has been explained both as a manifestation of play instincts and as related to courting activities. Two types of reaction between individuals have been observed in this study. Males often rise four to six feet straight up in the air and then hover, with fluttering wings, as nearly as possible in one position. The wings move rapidly, producing a whirring noise similar to the beat of flying hummingbird's wings. Suddenly, the wings appear to be tilted at an angle, the rate of movement is slowed down, and the fore and hind wings move up and down in opposite directions. This produces a clear sounding "chick-a—chick-a_chick-a." The note produced may be easily imitated by holding the hands extended, palms down and fingers together, and then brushing them past one another so that the forefingers strike in passing. By moving the hands at the rate of about five double strokes per second one may produce a series of sounds rather like those made by the Carolina locust.

One male was observed to give eight "chick-a's" and then drop to exactly the same place from which he arose. Two minutes later the performance was repeated by the same, or a near-by male. Two males were captured in this same spot, and it is possible that both were performing. Townsend (1884: 167, 168), Scudder (1893: 77), Morse (1920: 234), Blatchley (1920: 274), Somes (1914: 53), and others have observed this same phenomenon and have tried to explain its meaning. No one has yet been able to demonstrate either that the activity constitutes play or is a form of mating behavior.

On August 22 another type of activity was observed. Eleven males and one female ( $\mathrm{I}$ was able to get close enough to determine the sexes with certainty) were present in a bare, sunny spot at one end of a dried-up woodland pool. Occasionally, a male, wandering about on the ground, saw and recognized another individual. Recognition appeared usually to be dependent upon movement, and in no instance was another individual recognized at a distance of more than eighteen inches. The fact of recognition was immediately evident, since the individual under observation at once walked hurriedly toward the other grasshopper he had spied, often tripping over debris in his eagerness to investigate. Soon the second male observed the first and started to approach rapidly. When the two were about six 
inches apart, they slowed their impetuous gait and began to move their hind legs as though stridulating. The legs were rapidly lifted and dropped either alternately or at the same time. Often one leg was moved several times while the other was held motionless against the body. There did not seem to be any consistency in the way in which these leg movements were performed, the procedure varying haphazardly. It is doubtful if this represents stridulating behavior, for not the slightest sound could be heard, and the legs often did not touch the tegmina; it is, however, interesting to speculate as to whether it represents degeneration of a former interesting procedure, or whether it could be regarded as an activity representative of that from which stridulatory behavior developed in the past.

The two males danced and pranced around one another, sometimes crossing antennae, sometimes actually walking upon each other. Often they became so excited that the hind legs were moved up and down with great rapidity, sometimes causing the tibiae to be thrust out straight behind. Often other males spotted the cavorting pair and walked hurriedly over to join them. When this occurred they all tumbled over one another. The whole procedure lasted only a few seconds, or until one individual flew away for a few feet. The others did likewise, and following the first, alighted beside him, whereupon the whole performance began again.

Only twice have I observed females to be at all involved in this activity. On the first occasion, a female was walking slowly along the ground, testing a piece of grass here and there with her palpi. A male near-ky observed her and immediately began to vibrate his hind legs and hurry toward her. When he was only about four inches from her, the female took flight, alighting about fifteen feet above the ground on a twig of a tree. The male did not follow. On the second occasion a female flew along a roadway for about ten feet and then dropped to the ground. A male perceived her flight and, flying close, dropped six inches behind her. The male began to wander aimlessly about, but soon saw the motionless female. With his hind legs twitching and jerking he walked toward and around her. The female then began to vibrate her hind legs in the same manner as did the male. The antennae of both individuals meanwhile were rapidly moved up and down or whirled around and around. The male then moved around to the left side of the female and began walking backward and forward beside her. The performance ended as the male walked over the female and placed his right fore tarsus upon her tegmina, causing her to fly. In making this set of observations I saw the up-and-down movements of the hind legs very clearly. The legs did not touch the tegmina, but moved with a clearance of at least three millimeters.

On August 4, a mating pair was observed in the grass about twenty feet from a roadway running through an area of mixed grass-herbaceous habitat. 
My field notes on this pair are here given verbatim. The notes show clearly how inactive these insects are while in copula; most of the actions recorded are of only seconds' duration, most of the intervals being spent in quiescence :

5: 20 P.M. - The day has been cloudy and smoky, and the sun did not shine until 4: 00 P.M. All forms are much slowed down and show less than normal activity.

The mating pair is resting, about one-half inch above ground on a mat formed by the criss crossing of several blades of grass. Both sexes have their heads pointing in the same direction; the bodies are parallel, with the male's to the right of the female's. The left fore tarsus of the male rests upon the vertex of the female's head; his left middle leg clasping her tegmina at a point shortly behind her left coxa. The male's left hind leg is resting upon the female's right hind leg; the balance of the body of the male is to the right of the female, his right legs gripping the dextro ventro portion of her body.

5: 24-Male kicked the female's right tegmina three times with his left hind leg.

5: 27-Moving about one-sixteenth of an inch each time, the female's left hind leg jerked four times.

5: 34-Male perceptibly moved twice the cephalic end of body from side to side. Repeated.

5: 38-Male again moved body from side to side. The pair seem oblivious to everything. A large carabid beetle just raced through the grass beneath them. Neither moved.

5: 44-The female shifted to the right about ninety degrees but the male did not move; simply rode along.

5: 46-The male rapidly kicked the female's right tegmina three times.

$6: 16$ - The female turned to the right about sixty degrees and then made a weak jump of about two inches. Jumped again. Seems restless. She moves back and forth and lifts her legs. The male remains motionless.

$6: 18$ - The female started up as though she were going to walk away, but settled back in her original position. She just now took a single step forward.

6:22-Female took a sudden step back and then two forward. Now two more forward. Has moved about five inches forward.

6: 25-Female moved twice and shook her head as though to dislodge the tarsus of the male.

6: 27-Male regripped vertex of female with his left tarsus.

$6: 28-F e m a l e ~ m o v e d$ forward three steps.

Continuous observation was interrupted at this time but at 10:00 P.M. the pair were still in the same position as at $6: 28$ P.M. They were so cold that they could not move when I touched them. At 7:50 A.M. the next morning, the pair had moved about two inches from the point where last seen the night before and had turned about 180 degrees. The male had loosened the grip of his fore and middle legs and these had slipped farther back and more on top of the female. As I watched they both jumped and separated. Both were collected.

$D$. carolina spends the night on the ground beneath plants and debris. It has never been observed high up on the vegetation at night.

Reference.-Blatchley, 1920: 272. 


\section{Spharagemon bolli Scudder Boll's Locust}

A characteristic member of the low shrub-terrestrial stratum of the sunny oak-hickory orthopteran habitat, Spharagemon bolli has been found as a sporadic in the same stratum of the shady oak-hickory which borders upon its normal habitat. Erratics have been taken in both the mixed grassherbaceous and the sparsely vegetated sand habitats, but only where these habitats adjoin woodland occupied by Boll's locust.

Normally an inhabitant of open areas, such as partial clearings, roadways, and trails, this species is also present around the margins of the more open woodland. From these marginal areas specimens wander as erratics into the dry upland habitats.

Passing the winter in the egg stage, bolli begins to mature at the same time as does S. collare, early in July. The earliest record is that of a male taken July 6 ; the latest that of a pair taken September 3. Maximum abundance and decline therefrom take place at the same time as in collare. Spharagemon bolli does not, however, seem able to stand cold weather as well as collare, and hence is more quickly destroyed by frosts in the fall.

Although flight crepitation is as loud in bolli, in other respects the present species seems to act like a less vigorous copy of collare. In many of their behaviors, such as the length of flight, method of alighting, manner of jumping, and mating activities the two species are almost identical, but bolli is larger and heavier, and hence flies more slowly, and does not have the agility of the mottled sand locust. Individuals are more difficult to flush and are more easily collected because of the slower reactions of the species.

Superficially, Spharagemon bolli resembles Arphia sulphurea rather closely in general facies, and erratic individuals occurring in the habitat of the latter might be confused with it in field observations were it not for the conspicuous black ring on the hind tibiae and for the deeply notched pronotal keel.

Reference.-Blatchley, 1920: 276.

\section{Spharagemon collare collare (Scudder) Mottled Sand Locust}

The mottled sand locust is one of the most sprightly and abundant of the grasshoppers on the Reserve. Characteristic of the mixed grass-herbaceous habitat, it occurs sporadically so often in the sparsely vegetated sand habitat that it might almost be considered also characteristic of that environment. Erratics have been taken in the low shrub-terrestrial stratum of both the sunny and shady oak-hickory woodlands.

This species matures early in July (July 6) and reaches its maximum abundance in about two weeks. During the middle of September collare is 
still common, but it diminishes rapidly in numbers as the fall frosts come on. The latest specimen recorded was taken on October 3.

The mottled sand locust winters in the egg stage, and the young hatch during May and early June. The presence of juveniles in various stages of development in early July indicates that the eggs hatch over a period of several weeks. The young are generally present on the ground among the bases of the plants characteristic of the mixed grass-herbaceous habitat. Nymphs have also been taken several times in the more xeric areas of the upland, but the places where they have been found in such environments are not the same from year to year, indicating that these individuals are sporadics.

Spharagemon collare seldom leaps when disturbed, but takes to wing with dispatch. It rivals members of the genus Trimerotropis in agility. Flight is rapid, but does not carry the insect far, males usually flying from fifty to one hundred feet. As in other members of the Oedipodinae, the females usually fly much farther. Crepitation is not loud, but is rather a sharp, crackling rattle.

Individuals are wary, and on warm days are difficult to capture. They invariably fly before one has come closer than six feet to them. The early morning and just before sundown are the best times for collecting this insect, since individuals are then much less active than during the heat of the day. Like other oedipods, collare hides beneath plants and debris at night; it has never been observed asleep on the tips of plants.

The mating position, observed several times, is similar to that of Dissosteira carolina. One pair mating in a rather abnormal position was observed one hot afternoon in September. The male was facing in the opposite direction from the female, the tip of his abdomen was bent at a right angle in order to maintain the mating clasp. The pair remained in this position for an hour and a half, and then separated and flew.

Reference.-Blatchley, 1920 : 281.

ACRIDIDAE, CYRTACANTHACRINAE

\section{Schistocerca alutacea (Harris)}

\section{Rusty Locust}

Known from as far north as Midland County, in Michigan, the rusty locust is very local in its distribution in this state. On the Reserve, certain parts of the xeric uplands afford ideal conditions for the species. In the mixed grass-herbaceous habitat, wherever the heavier growths of Cyperus filiculmis, Anaphilus margaritacea, Solidago, and Lespedeza, occur, the rusty locust is common in the late summer. These areas constitute its characteristic habitat on the Reserve, but it is also present in other situations. Rarely it occurs in heavy growths of dewberry, although in the 
less dense dewberry thickets, where herbs are mingled with the briars, the species is often abundant. Sporadic groups have been encountered, both as adults and as nymphs, in the less heavily vegetated parts of the mixed grass-herbaceous habitat and in the sparsely vegetated sand habitat.

Schistocerca alutacea is a strong flier; when it is flushed on a windy day it may be carried for distances of several hundred feet. As a result, erratics are common, and the adults become more and more scattered as the season progresses. Erratics have frequently been taken in late summer and fall in the low shrub-terrestrial stratum of the sunny oak-hickory habitat, and even more often in the semipermanent marsh habitat.

Overwintering eggs hatch in early summer, and by the first of July many half grown nymphs may be found in the characteristic habitat. The earliest adult seen was observed in flight on July 18. During the last third of July adults slowly become more numerous, maximum abundance being reached about the end of the first week in August. This abundance is maintained until the coming of cold weather and fall frosts. The last specimen observed on the Reserve in the fall was a female taken on October 15.

The rusty locust is completely diurnal in its activities. At night individuals usually lie close to the ground hidden beneath the bases of plants, in dead leaves, and in debris. Occasionally, however, they may be seen in numbers asleep on the tops of tall weeds; this does not happen regularly, nor often, and is probably caused by some as yet undetermined combination of weather conditions. At such times specimens are easily collected, often being so sluggish that an individual can be held on the palm of the hand without its making any effort to escape.

During the day alutacea is quite active, wary, and easily flushed. It flies up before one can approach it closer than ten feet. The flight is strong, steady, and accompanied by a whir, which is not, however, a crepitation. On still days females normally fly about one hundred feet; males half that distance. If there are trees near-by, flushed individuals often fly up to one of the lower branches and roost there until their alarm is forgotten; ordinarily they alight upon the ground, with a combined flutter and dive at the end of the flight.

On one occasion notes were made on a female observed feeding. At 4:30 P.M. this individual was slowly walking along on the ground, now testing a grass blade, and again the leaf of an herb with her palpi. Finally, she stopped and fed upon a leaf of Lechea minor for about two minutes, after which she settled down upon the grass and became immobile for fifteen minutes. At the end of this time she was captured.

Oviposition has been seen many times on the Reserve. It agrees in all respects with the process as described below for Melanoplus bivittatus. Both the striped and the unstriped phases of the rusty locust have been observed 
on the Reserve, and no differences have been noted between them in respect to their habitat distribution. The brownish, unstriped phase is commonly regarded as being associated with more xeric situations, the greenish, striped phase with more mesic conditions. On the Reserve both have been taken in the same habitats on scores of occasions, and copulation between the two phases has frequently been noted.

Reference.-Blatchley, $1920: 314$.

\section{Melanoplus islandicus Blatchley Forest Locust}

Melanoplus islandicus is the rarest of any of the locusts on the Reserve. Intensive search continued throughout three field seasons revealed in all only nine specimens. Eight of these were taken in a small area (about 400 square feet) situated in a rather heavy stand of oak-hickory forest. The undergrowth of this part of the woods consists largely of low-bush huckleberry; the forest floor is covered with a carpet of dead and decaying leaves, six to eight inches deep, which is unbroken except by an occasional specimen of Carex communis. The ninth specimen was taken on the top of a low-bush huckleberry growing in the woods about fifty feet from the area where the main colony was.

I am convinced that on the Reserve the species occurs only in the limited area where it was found. A most prolonged and careful search for this insect was made, not only of the remaining parts of the woods where my specimens were secured, but also in all other apparently favorable locations on the Reserve. Why islandicus should be restricted not only to this one piece of forest, but even to a particular small area within the forest, is a matter of conjecture. Other parts of the woods where the species was not found were apparently similar to the area occupied. So far as its distribution within this one woods is concerned, it is possible that the ground fire that ran through this part of the Reserve in 1926 may have nearly destroyed the population, and the species may be having difficulty in becoming reestablished. It is likewise possible that this is an example of a relict colony on the verge of extinction.

The second hypothesis seems less likely than the first, since Melanoplus islandicus, though a boreal form, has been observed locally at other points in extreme southern Michigan, and is often common where it occurs in this region.

The rarity of this species on the Reserve has made it impossible to determine its seasonal relations in detail. Adults were taken from July 27 until September 15. Two late instars were collected July 12 in the same area where the eight adults were found, showing that the species actually breeds there, and indicating that maturity is reached about the third week of July, and that winter is passed in the egg stage. 
Melanoplus islandicus is agile and alert. Males leap quickly for distances of two to four feet, and either alight upon the huckleberry shrubs or upon the leaf-covered ground. Two to three leaps are usually taken, and then the individual burrows down into the ground litter. Females do not leap as far as do males, and they are prone to burrow sooner. Both sexes may easily be flushed again after they have gone into hiding.

Reference.-Blatchley, $1920: 388$.

\section{Melanoplus bivittatus (Say) Two-striped Locust}

The two-striped locust, a very common species of the hydric habitats, is the largest and most conspicuous member of the genus Melanoplus that occurs on the George Reserve. The species is characteristic of the semipermanent marsh habitat, in which it occurs abundantly. Variations in density of plant growth and in composition of the vegetation apparently have no effect upon its occurrence. Permanently wet habitats such as the permanent marsh, however, seem less favorable for bivittatus, as large numbers of individuals have not often been observed to develop in them. Many specimens have, nevertheless, sometimes been taken in just such situations, and it seems certain that bivittatus can exist as a sporadic under an exceptionally wide range of environmental conditions. The two-striped locust has a strong tendency to spread, and by August individuals are often present as erratics in all the other orthopteran habitats of the Reserve except the floating vegetation and the red maple-birch habitats.

The species is so little responsive to variations in environment that it often oviposits in xeric areas, as indicated below. It is however, highly probable that eggs so laid rarely hatch and seldom, or never, give rise to a new generation of adults, since on the Reserve neither young nor teneral adults have ever been found in any other than the hydric habitats.

Although adults begin to appear as early as June 23, juveniles and teneral specimens have been collected as late as September 14. This may indicate the occurrence of two generations a year on the Reserve, or may be the result of great variability in time of hatching and duration of development. Maximum abundance of adults is not reached until late July, but is maintained until the middle of September. The latest record is that of a pair collected on October 14.

Melanoplus bivittatus is a sluggish species with slow reactions and spends most of its time resting or wandering about in the vegetation. Generally, it prefers to stay about halfway between the ground and the tops of the plants. At night it is often in this same situation, but it sometimes climbs up to the tips of shoots and stems to sleep.

When disturbed, females take a single lubberly leap and then tumble 
through the vegetation to the ground. Here they remain motionless, and if found, can be picked up with the fingers. Males are somewhat more active; sometimes they dodge behind a stem, but more often they leap away in a series of short jumps each of which covers no more than eight to twenty inches. The leaps are made at random, and the insect generally ends on the ground.

A food preference for the blossom of Spirea alba has been noted several times. The heart of the flower is generally eaten, but occasionally an individual will eat the entire flower down to the receptacle. The two-striped locust has also been noted feeding on Carex riparia var. lacustris and on Calamagrostis canadense. Feeding has been observed to occur in the late afternoon (4: 30 P.M.) and at night (10:00 - 11:00 P.M.).

The mating clasp is typical of the Melanopli. The male's fore tarsi grasp the cephalic edge of the female's pronotum, the middle tarsi the sides of the abdomen just back of the female's hind legs, and the hind legs are free or rest upon the female's tegmina or abdomen. The male's abdomen is twisted either to the right or to the left. The only exceptional thing noted was that the female's abdomen is lifted much higher than in any other members of the genus Melanoplus found on the area. This may be necessary to offset the great difference in size between the two sexes.

On August 5, 1936, an ovipositing female was watched. The sequence of activities is taken from my notes:

2: 10 P.M.-A female $M$. bivittatus has her abdomen in the ground as far as the second segment. The abdominal segments are stretched to such a degree that the coria are taut. The female's hind legs do not touch the ground, but are held up almost perpendicular to the body and are bent inwardly so that they slightly pass one another above the abdomen. She slowly raises and lowers the whole caudal end of her body. This movement is not regularly timed, but is persistent and has been repeated forty-one times in two minutes. During these two minutes the abdomen has entered the ground a full sixteenth of an inch. Each time the female dips, her abdomen raises and lowers one thirty-second of an inch.

3: 15-A female straightened and flexed her left hind leg three times in succession and then moved her right hind leg once in the same manner. She has now moved her forelegs forward a little and has raised the abdomen so that the fourth segment is free of the ground.

3: 19-An ant walked up the dorsal side of the female's abdomen, and she very deftly kicked it away. Another came in front of her, and she shook her front legs, frightening it away. The coria do not now seem to be so stretched, and the abdomen is being slowly withdrawn from the ground.

$3: 24$ - The female is again pumping her whole body up and down, meanwhile flexing her legs. She moves the front and middle legs as if trying to get a better grasp on the ground.

3:30-The abdomen has now been removed, and remaining in the same position, the female is using the ovipositor valves to cover the hole. Tiny particles of dirt are pinched up with the valves and then dropped in the hole.

3 : 32-The hole is now full, and the female has leaped twice. She is fully ten feet away. Captured. 
The eggs were laid in a sandy clay hillside near the edge of an oak wood. Here the sun shines on the ground for most of the afternoon, but the spot is shaded by trees in the morning. The hill slopes gently downward in three directions: to the east to a grassy flat; to the north to an herbaceous marsh with heavy growths of Iris, Solidago, Cornus, Spiraea, and other herbaceous plants (the female probably came from this marsh); and to the south through the open end of the oak woods and into tamarack swamp about 150 feet away. Up the slope for about seventy feet the grass is largely replaced by moss, primrose, and lichen; beyond lies the oak woods.

The burrow passes at an angle of 45 degrees through, and beneath, a mat of dry moss. The upper end of the egg pod is one-half inch below the surface, and the pod itself reclines at about a 45 degrees angle between two small pebbles.

The finding of this female ovipositing in this type of environment bears out my belief that members of this species oviposit wherever they may be when the time for laying eggs overtakes them.

Reference.-Blatchley, 1920 : 446.

\section{Melanoplus punctulatus punctulatus (Scudder) Grizzly Locust}

The coniferous-arboreal stratum of the Reserve has only two characteristic species of Orthoptera-Oecanthus pini and Melanoplus p. punctulatus. Adults and young of the grizzly locust have been found in this area almost exclusively on tamarack trees, but all tamaracks do not seem acceptable to the species. Only the younger trees, ten to twenty feet in height and in the open margins of the swamps, where sunlight falls on them all day, harbor this insect. In such trees it sits on the tips of the branches, sunning itself for long periods, and moving only to keep in the sunshine.

The only specimens of this species not observed on tamaracks are three adults that were collected beneath a mixed clump of American elm, red maple, and red and white ash, near the margin of a semipermanent marsh. These trees are fully five hundred yards from the nearest tamaracks, and it is unlikely that three individuals of so sluggish an insect should have wandered to such a distance and have chanced to arrive at and be in the same spot. The fact that they were taken in successive years increases the probability that here a small colony of punctulatus exists in the deciduous-arboreal stratum on the Reserve. Elsewhere in Michigan this species has always been taken by myself and others in conifers, with the exception of four specimens recorded from Berrien County by Hubbell (1922: 56), which were taken on hawthorn shrubs and in deciduous dune and ravine forests. Blatchley (1920: 451) stated that in southern Indiana the species is found on oak, beech, and maple.

Hibernation occurs in the egg stage. Adults, often teneral, have been collected as early as July 19. Maximum abundance, however, does not occur until mid-August. The latest date on which a specimen was taken on the 
Reserve is September 4, but Morse (1920: 512) stated that in New England the species was present throughout September and October.

The grizzly locust is inactive and difficult to flush. Individuals cling closely to the tips of branches, where their somber hues so match the color of the tamarack needles and bark that they are very difficult to see. It is possible to approach within a foot of an individual without causing the slightest movement on the part of the grasshopper. To collect this species one must carefully scrutinize the limbs of trees until an individual is seen. Then, by moving from side to side while observing the locust from all angles, a mental impression of its appearance can be obtained which materially aids in locating others. The first specimen is difficult to find, but each additional one is more easily seen. As many as twenty-four specimens have been collected from a single tree during a period of two hours. Often they are so hidden that only the lifting of a tarsus or the movement of an antenna reveals their presence. Although the locusts are at all heights from the lowest to the topmost branches, they are nearly always on the side of the tree exposed to the sunlight. During the day, as the direction of the sun shifts, the insects move around the tree to a more suitable location. Often this is the first indication the collector has of the presence of the insect. With great care the locusts may be picked up with the fingers, but it is generally safer to collect them with a quick snap of the net. This does not always succeed, for they cling most tenaciously to the twigs, and their grasp sometimes causes them to be thrown away from the trees and into the vegetation below, when the net strikes. By waiting a few minutes these individuals may be seen returning with their feeble leaps covering twelve to twenty inches, to the base of the nearest tree. When this is reached they calmly walk up the trunk, turn on the nearest branch, and walk out along it until they are again in the sunlight.

On very warm days activity is more pronounced, and males may then leap out of the tree when approached. Females very rarely do this, even on the hottest days. On the Reserve $M$. punctulatus has never been seen to fly; but at Oscoda, Michigan, where the species was abundant on the trunks and branches of pine trees, as the collector approached, the males occasionally flew from one tree trunk to another.

During August, males were sometimes noticed beneath the trees in the swamp vegetation, but they invariably soon climbed back into the trees. These males probably leaped or were thrown from the trees, as they attempted to mate.

In order to observe mating activities, a cage was built around several limbs of tamarack. On August 18, three females were captured and placed in the cage, and on August 23, four more females and five males were introduced into the cage. 
As the first male entered the cage he walked the length of it and then without any preliminary courtship leaped upon a female, seized her, thrust his abdomen to the left side, and began to copulate. The female offered no resistance. As the male seized her, and before he began to copulate, he thrust his hind legs straight out behind and slightly above his tegmina, and then jerked them very perceptibly. The female also jerked her hind legs rhythmically, but they were held in jumping position and not extended. Following attachment both sexes remained nearly motionless as long as I watched them (one and one-half hours). Once the female walked about four inches, carrying the male. Whenever another individual, male or female, approached within two inches of the mating pair, the copulating male would vibrate his hind legs, and the intruder usually left. On four occasions, however, other males leaped upon the pair, only to be dislodged immediately by the mating male by means of violent thrashing movements of his hind legs.

I expected that this pair would remain in coitus until the following morning, since mating pairs observed at Oscoda had been observed to do so, but when I returned to inspect the couple at 11:05 P.M., six hours after the beginning of copulation, they had separated. The duration of copulation in this instance was, therefore, somewhere between one and one-half to six hours. A second pair which I watched, and which exhibited the same behavior, was in coitus less than five hours.

Females are not always so receptive, nor males so impetuous as in the instance described above. The caged males spent much time in wandering restlessly up and down the cage. Whenever they came near a female they would raise and rhythmically jerk their hind legs, usually in the flexed position; only when the male is very excited are the tibiae thrust out straight. Occasionally, a male maneuvered around a female and attempted to leap upon her; if she was not receptive she either evaded the embrace by jumping away, or kicked the male from her back. In a single instance a male was seen to try to mount a female head on; he was rewarded for this attempt by a deft kick which sent him tumbling. The males often jumped upon other males, but they either jumped off immediately of their own accord, or were kicked off.

A single example of very active resistance to copulation was observed on the part of one of the caged females. She lacked a hind leg and was therefore hampered in her efforts to repulse males. One male succeeded in getting a very secure hold upon her. He immediately twisted his abdomen to the left, and clasped the ventro-caudal part of her abdomen, after which he began to jerk his hind legs back and forth so violently that both individuals fairly rocked. The female did not permit copulatory attachment to be completed and tried to unseat the male by leaping and twisting about. 
When this failed, she attempted to rake him off with her remaining hind leg, bringing it far forward and snapping it back so that the spines and calcars of the tibiae jabbed into the body of the male. After a little of this treatment the male stopped shaking his hind legs and loosened his clasp on the abdomen of the female; he then swung his abdomen to the right of her body and clasped from that side. The female, apparently tired after her fiveminute struggle, became quiescent and began to vibrate her hind leg, whereupon the male began again to jerk his legs and tried to shift the end of his abdomen into copulatory position. This stimulated the female to renewed resistance, and the struggle was resumed so furiously that in attempting to rake the male loose, she broke her remaining caudal tibia at mid-length; thus hampered, she was unable effectively to resist the male. He might have succeeded in mating with her had he not been interrupted by the advent of a second male, which jumped upon the pair so forcibly that both males were jarred off. The female escaped and crawled into a corner of the cage, apparently much exhausted by the twenty-five minute struggle; there she remained unmolested in hiding. The next day she was observed to accept a male without resistance.

Caged specimens ate with avidity the tamarack needles on the limbs enclosed by the cage. An uncaged male was also observed feeding upon tamarack. This male selected only the more tender terminal needles which were sought out and then eaten from the distal end down to the base.

Shortly after noon on August 6 a female was observed to molt to maturity. When first seen she was hanging upside down clasping the bark of a tamarack with her fore and middle tarsi, and was already free except for the tip of her abdomen. Five minutes later the abdomen was extracted, and she slowly turned about until she rested head up. Her swollen and stretched abdomen pulsated slowly as the wings gradually unfolded. Twenty-five minutes later the wings were completely expanded, and the female stroked them from cephalic to caudal end with her hind tibiae, forcing them to fold and fall into position as they dried. In a few minutes the wings were plaited, the abdomen was of normal size, and the female climbed upon a twig and lay horizontally in the sunshine. Upon collecting her, it was noted that the tegmina and the wings were clear green, as yet showing not the slightest sign of brown pigmentation.

The grizzly locust has been shown by Walker (1901: 22) and Morse (1920: 513) to oviposit in the borings made in stumps, logs, and trees by various insects, principally wood-boring beetles. On the Reserve specimens were caged in order to observe whether or not they would oviposit in soil, but all such experiments were negative.

Reference.-Blatchley, 1920: 450. 


\section{Melanoplus confusus Scudder \\ Little Locust}

One of the most characteristic locusts of the mixed grass-herbaceous habitat in the early summer is Melanoplus confusus. Occurring commonly in that habitat, it has also been taken as a sporadic in the sparsely vegetated sand areas of the upland and rarely as an erratic in the low shrub-terrestrial stratum of the oak-hickory.

Maturing early in June (June 7), it reaches maximum abundance toward the end of the month. A gradual decline in numbers then sets in, and the species is gone by early September. The latest specimens recorded for the Reserve were ragged individuals taken on August 25. As the season progresses and the upland becomes drier, the species tends to congregate around the edges of the marshes. During each of the three seasons the last specimens collected were in this situation.

For several years it seemed that the pinkish red coloration of the ventral surface of the caudal femora was a good field mark; but I have since found that an occasional Melanoplus m. mexicanus exhibits this characteristic. Furthermore, not all individuals of confusus are colored in this way, the caudal femora of some females being yellowish beneath like those of $\boldsymbol{M}$. mexicanus. Partly for this reason and partly because the season of adult occurrence of confusus considerably overlaps that of mexicanus, it is difficult to make field observations on the relative abundance of confusus during July and August. Although it is as active as mexicanus, the little locust seldom flies more than eight or ten feet at a time and alights with a motion that is a half dive and half flutter. These features of behavior, together with the usual differences in femoral coloration between confusus and mexicanus, will enable a close observer to separate the two species in the field. One must take care not to mistake Orphulella speciosa for Melanoplus confusus on the basis of flight behavior, which is quite similar in the two.

Reference.-Blatchley, 1920 : 434.

\section{Melanoplus femur-rubrum femur-rubrum (DeGeer) Red-legged Locust}

This species is one of the more common of the locusts on the Reserve, where it is more nearly ubiquitous than any of the others, having been collected in a wide variety of habitats. The semipermanent marsh is the optimum and most characteristic habitat, large populations being present in this environment each year. On the uplands, femur-rubrum likewise fares well, being about as numerous there as are Melanoplus keeleri luridus and $M$. angustipennis. Upland populations are nearly always in the mixed grassherbaceous habitat, although small sporadic colonies are present in the more 
xeric sparsely vegetated sand habitat. At the opposite end of the humidity scale the species occurs as a sporadic in the permanent marsh habitat, while erratics have been taken in the bog habitat and in the low shrub-terrestrial stratum of the oak-hickory forests. Such wide ecological range must indicate that the species can tolerate a considerable amount of variation in temperature, humidity, and other environmental factors.

The red-legged locust matures early; adults have been taken on July 12. On the other hand, juveniles remain common until late August and early September, and on account of this spreading out of the time when maturity is reached the maximum abundance of adults is not attained until mid-August. M. femur-rubrum is a very hardy species, surviving frosts and occasional longer periods of freezing weather until late November. The latest record for the Reserve is furnished by a female taken on November 18 .

Being somewhat less active and alert than mexicanus, the red-legged locust is harder to flush and is less ready to take wing. Flushed individuals are most likely to fly, but not infrequently merely leap away three or four feet. The flight of this species is strong, even, and swift, and generally carries the insect thirty or forty feet. Individuals fly three or four feet above the vegetation, or about twice as high as is usual in mexicanus.

Reference.-Blatchley, 1920 : 419.

\section{Melanoplus borealis junius (Dodge) Northern Locust}

The northern locust is the only characteristic orthopteran inhabitant of the leatherleaf stratum of the bog habitat. Sporadics and erratics of this species have not been taken on the Reserve. In this area the species gives the impression of being very rare; in my three years of collecting I have been able to obtain only three adults and two nymphs-a number too small to permit any generalizations to be made concerning the seasonal distribution of the species.

It is very probable that $M$. borealis junius is much more numerous in the bog habitat than would appear, and that it is actually represented on the Reserve by many more individuals than is Melanoplus islandicus, with which it ranks so far as collections are concerned. Its secretive habits, and the difficulty of working in the dense bog thickets in which it lives, make the task of locating specimens extremely difficult even when individuals are abundant. During the season of 1939, a single juvenile individual was secured as the result of four two-hour periods spent in searching and beating the leatherleaf stratum of the bogs.

When first seen, individuals of this species are usually resting on the upper surface of the leatherleaf growths. They are most alert and agile, however, and before the collector can approach close enough to sweep them 
into his net they make a number of short, quick leaps that carry them down through the leatherleaf tangle to the sphagnum beneath ; into this they burrow and remain motionless. In trying to find such hidden specimens it was often necessary to tear up leatherleaf and practically denude the area about the spot where they were last seen, and then to feel about among the sphagnum for them.

Late stage nymphs have been collected on June 24 and July 4. Adults were taken on July 20 and August 12. The species appears to be an early summer form in this area and probably does not live much beyond the first of September. Hibernation occurs in the egg stage; the eggs are probably laid in the sphagnum.

Reference.-Blatchley, $1920: 422$.

\section{Melanoplus fasciatus (F. Walker) Huckleberry Locust}

On the Reserve the huckleberry locust prefers low bush blue- and huckleberry shrubs. Its name, the "huckleberry locust," is slightly misleading, however, since the species is not found wherever these shrubs grow, but only in the more open sections of woodland. Furthermore, the species does not occur in all parts of the Reserve where conditions would seem to be suitable for it. Melanoplus fasciatus is one of the less common of the locusts of the area and has been taken in too small numbers to furnish a clue to these pecularities of local distribution. One factor which is certain to be involved in the problem is the preference, perhaps the requirement, that the species exhibits for sunlit areas of the forest floors.

M. fasciatus becomes adult in late June. The earliest captures of adults were made on June 24. The species is most numerous in late July, and has been taken as late as September 1. On the latter date thirteen specimens were secured, indicating that individuals probably live on into October. Winter is passed in the egg stage.

An inactive insect, the huckleberry locust is difficult to flush; long-continued trampling is often required to obtain a very few specimens. When flushed this locust executes only one or two short leaps of one to one and one-half feet; thereafter, the insect relies for concealment upon its camouflage and burrowing ability.

M. fasciatus is best collected on the occasional nights when it climbs upon low bush blue- and huckleberry shrubs and bracken fern to sleep.

Reference.-Blatchley, $1920: 400$.

\section{Melanoplus mexicanus mexicanus (Saussure) Lesser Migratory Locust}

First acquaintance with the lesser migratory locust on the Reserve would lead one to believe that this species is completely ubiquitous. More detailed 
study, however, shows that it is partial to, and characteristic of, the mixed grass-herbaceous habitat. So commonly sporadic as to be almost characteristic in the sparsely vegetated sand habitat, its strong tendency to wander carries it, as a common erratic, into the bog and semipermanent marsh habitats. It has also been collected in the low shrub-terrestrial stratum of both the sunny and shady oak-hickory habitats.

Adults appear on the Reserve early in July (July 3) and maximum abundance is attained by the end of that month. This abundance level is maintained until late in September, and individuals were still numerous on October 24. Hubbell (1922: 52) stated that mexicanus was common in Berrien County, Michigan, as early as June 20; and Blatchley (1920:415) observed that the species begins to mature in Indiana during the latter part of May. Both of these dates are early for the species as observed on the Reserve. In view of the late date to which abundance is maintained, and of the fact that teneral individuals have been taken on September 8 as well as mating pairs on October 24, these early records of adults strongly suggest that the species goes through two generations a year in southern Michigan. The possibility that the seasonal range of adults is to be explained by overlapping of generations (such as apparently occurs in Gryllulus assimilis) seems negligible, since the species hibernates only in the egg stage.

Spreading of adults does not become noticeable until maximum abundance is attained, and that has first been detected about the end of July.

On August 24 three females were observed ovipositing in a bare, sandy area located between clumps of Gerardia at the edge of a very open section of oak-hickory forest adjacent to the characteristic habitat of mexicanus. At 12 : 39 P.M. the first female was noticed walking about the ground. Here and there, bending her ovipositor down, she seemed to test the ground. Five times her tests were made upon a dead leaf, twice upon sand loosened by my boot heel, and three times upon packed sand. Each time her abdomen struck bare soil she drilled down for about two millimeters, and then removed her abdomen from the hole she had made. After each attempt she walked a few inches farther, or until she seemed to become uncomfortable. Her hind legs then twitched and she immediately started to drill again regardless of where she was. Her tenth attempt was made on packed sand, and this time she sank her abdomen deep into the ground. Within five minutes all but the first two segments were inserted in the soil, and the intersegmental membranes were stretched to their full extent. Drilling was accompanied by both lateral and vertical movements. The body swayed from side to side and moved up and down. The vertical movement was produced by "hammering." In "hammering," the abdomen is shoved hard into the ground, thus raising the head and thorax. The muscles of the abdomen are then relaxed, the fore part of the body resumes its nomal position, and the 
abdomen is raised a millimeter or two; the sequence of movements is then repeated. Thirty-nine minutes after the female started to drill the hole to receive her eggs, she withdrew her abdomen. Still standing in the same place she caused the ovipositor valves to open, close, and move about over the mouth of the hole. In this way, small grains of sand were picked up and dropped or pushed into it. These movements were performed in a very haphazard manner, and the valves often failed to come in contact with anything. At the end of two minutes of this activity the hole was well covered, and the female hopped away.

A second female oviposited for thirteen minutes in the sand loosened by my boot heel. Her abdomen was inserted only about two-thirds of the maximum amount possible; however, she covered her burrow after finishing her egg laying.

While the first female was busy ovipositing, a male spied her and came hurriedly toward her. His hind legs quivered, twitched, and occasionally lashed out behind him. At times the legs were stretched out straight up and down at right angles to the body. When the legs were suddenly kicked out straight the action produced a distinctly audible snap. As the male approached he assumed a prancing manner, lifting the fore and middle legs high while he vibrated the hind legs and caused his body to weave from side to side. Continuing this dance, the male completely circled and then climbed upon the female and was promptly kicked off. He repeated his dance and leaped on her again, only to be ruthlessly removed by a well-aimed kick. This ended the display, and the male walked away. The entire performance lasted two minutes.

The lesser migratory locust seldom jumps, but when occasion arises it can leap strongly and to a distance of three or four feet. The insect more often takes wing when alarmed, its flight being strong and even; however, it flies only about two feet above the top of the vegetation, lower than, and not so far as, $M$. f.-r. femur-rubrum, which may fly as far as forty feet. $M$. $m$. mexicanus is easily flushed, but may readily be taken by walking along while sweeping a net rapidly through the vegetation.

Reference.-Blatchley, 1920 : 414.

\section{Melanoplus keeleri luridus (Dodge) Broad-necked Locust}

This species and $M$. femur-rubrum, have a broad range of tolerance in habitat requirements. $M$. $k$. luridus is characteristic of and most abundant in the mixed grass-herbaceous habitat. Common in the low shrub-terrestrial stratum of those sunny oak-hickory woodlands which contain bracken fern in the understory, it must be considered as a characteristic species of this habitat also. Juveniles have been collected in both of the above mentioned 
vegetational areas. Sporadics have been found in the sparsely vegetated sand habitat of the upland. Erratics have been taken in the shady oakhickory bordering upon the woodland habitat indicated above. A single erratic was collected forty feet from the margin of and within a semipermanent marsh.

The broad-necked locust matures in late July and is commonly found from then until mid-November. The earliest record for the Reserve is a teneral male taken on July 26, and the latest record is that of six males and five females collected on November 7. The winter is passed in the egg stage.

Reference.-Blatchley, $1920: 437$.

\section{Melanoplus angustipennis (Dodge) \\ Narrow-winged Locust}

Characteristic of the sparsely-vegetated sand association, Melanoplus angustipennis is also rather common as a sporadic in the mixed grass-herbaceous habitat. It never occurs in heavy stands of upland vegetation, and is present only in those areas which are sandy and open, or which border upon sparsely vegetated sand areas. In comparison with Melanoplus confusus the species cannot be rated as more than numerous. This is only to be expected, for the extent of its typical habitat on the Reserve is very limited.

The narrow-winged locust passes the winter in the egg stage. The earliest adults collected were taken on June 13, and maximum abundance is reached in July and August.

Observation on the abundance and seasonal relations of angustipennis on the Reserve were made very difficult by the great abundance of Melanoplus m. mexicanus in the area. The similarity of the two species is so close that often I did not realize that angustipennis had been taken until material was examined in the laboratory. The extent of this masking of the less abundant angustipennis by mexicanus may be illustrated by the fact that on one occasion, working in a single station on August 29, out of eighty-nine specimens of almost identical appearance that were taken by sweeping and flushing, eighty-two proved to be mexicanus, while seven were angustipennis.

Reference.-Blatchley, $1920: 425$.

\section{Phoetaliotes nebrascensis Thomas Large-headed Locust}

Except for a single male, taken by Morse at Needham, Massachusetts, August 23, 1908, the material collected on the George Reserve and specimens taken by Hubbell near Milford, Michigan, represent the easternmost records of this Great Plains species. Found in the semipermanent marsh habitat on the Reserve, nebrascensis is partial to, and observed only in, those areas of 
hydrophytic environment that are covered with heavy growths of commingled Calamagrostis canadense and Carex. Only two marshes on the Reserve are of this type, and the species occurs abundantly in both.

The large-headed locust winters in the egg stage. Juveniles of the fourth and fifth size groups are very numerous in late July (July 24) and early August (August 4); adults become abundant about the first of August. The species is hardy and capable of withstanding light freezes; adults are still numerous as late as September 30.

During the day males remain within two or three inches of the tops of plants. They are wary and agile, and as one is approached, it either drops straight to the ground and burrows, or before doing so executes a series of quick jumps each covering six inches to three feet. The insect leaps apparently at random, this way and that, so rapidly that it is most difficult to follow its movements. The outburst of activity is invariably terminated when the insect drops to the ground and seeks shelter beneath debris.

Females normally remain lower in the vegetation, usually about a foot above the ground, where they sit motionless for long periods of time. If disturbed they seldom attempt to leap, but immediately drop to the ground and hide. Because of their behavior they are quite difficult to find or capture.

Both sexes usually spend the night on the ground concealed beneath debris, but occasionally many of these locusts may be observed asleep at night clinging high up on the tips of the grasses and sedges. At such times, these sleeping individuals can be picked up with the fingers; they offer no resistance and seldom move even after being put into the killing jar.

Reference.-Blatchley, 1920 : 356.

\section{Paroxya hoosieri (Blatchley) Hoosier Locust}

The Hoosier locust is the third least abundant member of the Cyrtacanthacrinae on the George Reserve. Only Melanoplus islandicus and borealis junius are less numerous. P. hoosieri, Tettigidea armata, and Orchelimum c. concinnum are the species most restricted to the permanent marsh habitat. $P$. hoosieri occurs on the Reserve only in a small part of this habitat-an area bordering on the lake. Individuals normally stay well within this area, but an occasional specimen has been taken from ten to twenty feet away in typical semipermanent marsh habitat. These individuals are probably erratics, or at most, sporadics. All juveniles secured were in the characteristic environment.

Nymphs of the fourth and fifth size groups have been collected on July 2 ; adults were first seen a week later (July 11). Maximum abundance of adults is attained in late July and early August, and numbers decline in 
September. The latest record for the species is that of a male collected on October 17. Winter is passed in the egg stage.

The Hoosier locust is surprisingly inactive for so graceful a grasshopper. Individuals usually attempt to escape by merely sidling around the cattail stems upon which they commonly rest. Sometimes, however, they drop down into the matted vegetation beneath, and there remain quiet, their coloration aiding materially in their concealment.

Reference.-Blatchley, 1920 : 349.

\section{TETTIGONIIDAE, PHANEROPTERINAE \\ Scudderia septentrionalis (Serville) \\ Northern Bush Katydid}

A review of the literature shows that the northern bush katydid has been regarded as a rare, or at best, scarce insect. Although this may be true in parts of its range, on the Reserve this katydid is common, though difficult to capture. It probably owes its reputation for rarity in large part to our former ignorance of its habits and habitat.

Scudderia septentrionalis is a characteristic inhabitant of the deciduousarboreal stratum of the shady oak-hickory woodland, and is rarely observed in any other situation. The only occasion on which I have ever taken it in another habitat was on the night of July 20, when a male was found in the top of a dogwood growing on the edge of a semipermanent marsh. This individual had probably flown from a clump of American elms about twenty feet away, in which I had noted the presence of a small colony of the species. The chances are that it would soon have rejoined its fellows. I have never seen or heard this katydid in any other situation than oak-hickory forest, with the exception of the colony in the elm clump and the individual on the dogwood just mentioned. In the oak-hickory woodland this species seems to occur in groups or colonies, which shift their location in the forest from time to time. Sometimes a group of these katydids will move out into the arboreal stratum of the sunny oak-hickory habitat. Whether or not septentrionalis can maintain itself in these more open woods is not known; but the presence of a small colony in the isolated elm clump mentioned above suggests that it can survive in open forest, at least for a time. In the sunny oak-hickory habitat the species is therefore listed as a sporadic rather than an erratic.

The northern bush katydid matures early. An adult male was first seén on July 8, and one was captured on July 13. The arboreal and secretive habits of the species have made it practically impossible to determine either the period of maximum abundance or how late in the fall the insects survive. On August 12, the latest record, seven males were secured. Adults are probably present much later than this. 
Although oviposition has never been observed, the egg-laying habits of this species are probably similar to those of other species of Scudderia, which oviposit in the parenchyma of deciduous leaves. The eggs drop to the ground with the leaves in the fall, and there pass the winter. It is not known whether they hatch in the following spring or, like the eggs of Amblycorypha oblongifolia, pass a second or even a third winter on the ground before the young emerge. Small Scudderia nymphs are found in late June and early July in the lower shrub-terrestrial stratum of the oak-hickory woods, and since no other species of the genus is of more than erratic occurrence in the habitat these have been regarded as the young septentrionalis.

The most beautiful, graceful, and active of all the species of Scudderia on the Reserve, septentrionalis is the most difficult to secure. So long as the individuals remain in the trees they are almost impossible to locate, and they rarely leave the treetops. Almost all of the specimens taken on the Reserve came to light at night; but only the males are attracted to a lighted sheet, and this happens only on occasional nights. I have spent dozens of nights lighting for these and other insects in the margins of the oak-hickory woods, or in clearings, or along trails through the forest, more often than not without taking a single specimen. Even on occasions when no individuals came to the sheet the males could be heard calling in the surrounding trees and could often be followed by their notes as they flew from branch to branch, coming closer to the light and stopping to sing from time to time, but remaining out of reach in the trees. On such occasions the insects approached within thirty to one hundred feet of the sheet, and there remained singing and prancing about on the leaves. On other nights males flew in to the sheet, and as many as seven specimens have been taken in three hours. It has been found by experience that the initial use of a brilliant light will attract the insects to the general vicinity of the sheet, and that by dimming it gradually they may often be brought closer until they finally fly to the sheet itself. No females have ever been taken at light, and none have been seen on the Reserve.

The song of Scudderia septentrionalis is more complicated and more interesting than that of any of the other four species of the genus in this region. It begins with a series of short, sharp, clear notes that may be represented as "tick-tick-tick." These notes are usually repeated six to eight times, but are sometimes continued in an indefinitely long series. Their volume and spacing are variable and seem to reflect the mood of the insect; commonly, they are loud enough to be heard about one hundred feet away. Following this introductory part of the song a series of clear brisk notes is produced, which may be represented as "dee-dee-dee-dee-dee-dee." These are given evenly and with only a slight hesitation between the notes; their number is usually six to eight, and when eight notes are sounded this part of the song 
lasts about three seconds. As the notes are uttered they increase in volume but not in rate, so that the song as a whole is a crescendo ending abruptly with the last note.

On two occasions males were seen to accompany their song by a sort of dance. As the introductory "ticks" began, the male quickly lifted and set down one foot with a sort of stamping motion. This procedure was then repeated with his other feet, particularly the fore and middle ones, the rate and amplitude of the motions increasing and keeping time with the increasing tempo and volume of the "ticks," so that soon the male was stamping and prancing as he turned about. After about a minute of this performance he seemed to become even more excited, and sounded the final "dee-dee-dee" notes of his song. Although this may have been a courtship procedure, no female was seen in the vicinity. None of the other katydids of the Reserve have so specialized a song, and none have been seen to indulge in such rhythmic, dancelike antics as those described above.

Scudderia septentrionalis is rarely dislodged from its perch even by high winds which whip the foliage about. The following observation may indicate how they are able to maintain their hold so securely. On July 12, 1938, I observed a young nymph of this species perched upon a hazelnut leaf about two and one-half feet above the ground, in an oak-hickory woods. Although the identity of this nymph could not be determined with certainty, it was in the habitat of S. septentrionalis and was surely that species. This nymph had the claws of its right hind tarsus hooked over the edge of the leaf, but the distal segment of each of the other tarsi was bent upward so that the claws did not touch the leaf and played no part in holding the insect in place; only the tarsal pulvilli were pressed against the leaf surface. A rather brisk wind was blowing, and the leaf fluttered rapidly down as much as half an inch. Occasionally, the young katydid slowly lifted a foot and as slowly set it down again; otherwise it did not stir. It was evidently held firm in position on the leaf solely by the adhesion of the tarsal pulvilli.

During the day the northern bush katydid apparently seeks a place of seclusion in the foliage of the treetops, and becomes inactive. It has never been heard to sing in daylight, even on very cloudy days when the notes of other species of the genus are frequently to be heard.

Reference.-Rehn and Herbard, 1914 : 277.

\section{Scudderia pistillata Brunner Broad-winged Bush Katydid}

This species is the rarest of the bush katydids on the Reserve. It is characteristic of the wet shrub-zone habitat, and rarely occurs elsewhere as an erratic. A single male was taken in the mixed grass-herbaceous habitat. Sporadic colonies have not been found. Typically a thamnophilous insect, 
during its nocturnal period of activity it is generally on marsh and swamp shrubbery.

The species matures about mid-July, and adults probably persist until sometime in September. The earliest specimen taken was captured on July 13, the latest August 29. The time of maximum abundance has not been determined, owing to the rarity of the insect on the Reserve.

S. pistillata, like texensis and curvicauda is slow-moving and inactive. These three species are so similar in behavior, except in regard to song, that it was impossible to distinguish them in the field unless they could be inspected closely or heard singing.

During the day the broad-winged bush katydid seeks concealment in heavy growths of grasses and sedges. At this time it is difficult to flush, and can often only be discovered by trampling. At night individuals climb to the tips of shrubs, where they sit quietly or very slowly move from leaf to leaf; the males then call from time to time. When the beam of the approaching collector's headlight is focused upon them they sometimes fly, but more often remain on their perches until they can be caught with a quick sweep of the net. Flight is rather slow, clumsy, and seemingly laborious; it may be level or slightly undulating.

The day song of pistillata is the same as that of texensis and curvicaudaa sharp, short "tsick," sounded but once with long intervals between such notes. The night song is simply the day song given rapidly six or seven times at a speed which makes it just possible to count the notes. The intervals between songs at night vary from two minutes to an hour or more; but in favorable weather the song is repeated at an average frequency of once in every twenty minutes.

Reference.-Rehn and Hebard, 1914: 278.

\section{Scudderia curvicauda curvicauda (DeGeer)}

This species, which is partial to hydrophytic environments, is the commonest bush katydid on the Reserve. Characteristic of both the semipermanent and permanent marsh habitats, it is much more abundant in the former. During August erratics have been taken in both the sunny and shady oak-hickory habitats. Sporadics occur only in bog environment.

Like the other Scudderia of this region, curvicauda passes the winter in the egg stage. Maturity is reached about mid-July, but maximum abundance of adults is not attained until early August. By September the population is greatly diminished, a few stragglers lasting until the first frosts come in late September. The earliest record is that of a male heard singing on July 13; the latest specimen was captured on September 21.

S. curvicauda, like texensis and pistillata, is relatively inactive. It is somewhat more diurnal than pistillata, although it usually spends the day- 
light hours in concealment in heavy marsh vegetation. An occasional male has been observed perched upon low shrubbery during the day. Such individuals are more active, and when flushed will often fly, slowly and rather evenly, to a distance of about twenty feet. At night curvicauda is less startled by collecting activities, and specimens climbing about upon the shrubbery can readily be approached and picked up without the aid of a net.

The day song is a short, sharp "tsick," given but once and generally at long intervals. Rarely, a male will strike the song during cloudy days. The night song is essentially the day song with two added notes, "tsick-tsicktsick." The pause between the first and the second notes is twice as long as that between the second and third, and the third note is slightly louder and much sharper than the others. The entire song is sounded in about one-half second. The interval between songs may be a few minutes or an indefinite period. One male usually answers another's call.

Reference.--Rehn and Hebard, 1914: 283.

\section{Scudderia texensis Saussure and Pictet Texan Bush Katydid}

Scudderia texensis occurs with pistillata, curvicauda, and the much more abundant furcata in hydrophytic environment. It is a characteristic species of the semipermanent marsh habitat. Sporadic colonies are not numerous, and have been noted only in the bog associations. A female taken one hundred yards from semipermanent marsh in a mixed grass-herbaceous habitat is the only erratic individual that has been found.

The Texan bush katydid matures in late July. As in curvicauda, maximum abundance occurs in early August; the population diminishes rapidly in early September and is gone by late September. The earliest record was secured on July 24, and the latest on September 4.

S. texensis and curvicauda are so similar in appearance and behavior that in the field they cannot be distinguished at any distance except by their songs. As far as observed, they are practically identical in flight, thamnophilous habits, and activities during the day. Males of the two species can easily be distinguished when in the hand, but even under close inspection females are discouragingly similar in appearance.

The day song of texensis may be represented by "zzzeeck-tseek," or better yet as "skee-deeck!" The notes are somewhat sharper, louder, and given more slowly than those of pistillata or curvicauda; the complete song lasts three-quarters of a second. The day song is given at very irregular intervals, and may be heard but once or twice in an afternoon.

The night song is an amplification of the day song and is a "zzeektseek-tseek-tseek" or "skeee-deee-deee-deeek." Pauses between notes are very brief; the whole song requires only about one and one-quarter 
seconds for its delivery. This song is generally sounded by individuals perched upon the tips of grasses and sedges or on shrubs. It is given at very irregular intervals and is often answered by near-by males. The notes are audible only about fifty yards.

Two females bearing spermatophores were taken between $9: 00$ and 10:00 P.M. on August 7, indicating that copulation occurs during the height of activity in the evening.

Reference.--Rehn and Hebard, 1914: 293.

\section{Scudderia furcata furcata Brunner Fork-tailed Bush Katydid}

This species is very common on the Reserve, where it is surpassed in abundance only by curvicauda. Both sexes are easily recognizable in the field by means of the swollen lobes of the anal plate of the male and the reddish, sharply upturned ovipositor of the female. All the other Scudderia observed in the region have green ovipositors.

Characteristic of both the permanent marsh and the semipermanent marsh habitats, $S$. furcata is most abundant in the latter. In late August, when the species is most numerous, individuals tend to wander. At this time erratics have been noted in the mixed grass-herbaceous habitat and in the low shrub-terrestrial stratum of both the sunny and the shady oakhickory habitats, but never more than fifty yards from the nearest characteristic hydric environment. Sporadic groups occur in the bog habitat.

S. furcata matures later than the other bush katydids of the Reserve. Although adults have been taken in late July, their maximum abundance is not reached until late August. This delay in attaining maturity is not compensated by a longer period of life in late fall than is found in other Scudderia; the frosts of late September silence this species as well as the others. Specimens have been taken or observed from July 20 until September 30.

The fork-tailed bush katydid is more active than texensis, curvicauda, or pistillata. It is more easily flushed and takes wing more readily than any of those species. Its flight is wavery, somewhat undulating, and reminiscent of that of Dissosteira carolina. Individuals alight as readily upon the limbs of trees as upon shrubbery.

Both the day and the night calls have been heard many times, and so far as I can tell are identical. The song consists of a sharp, clear "tsick" given but once. C. V. Riley (1874: 169) reported that the song "consists of a . . . zeep, zeep, zeep, sometimes uttered singly, but generally thrice in succession." I have never heard furcata sing in this way on the Reserve. The insects usually call more often in mid- and late afternoon than at night.

Late on the afternoon of September 30, 1936, a male uttered a call which 
I have never heard before or since in any Scudderia. This male was perched on top of a dogwood shrub and from this vantage point issued a series of slow, lispings which sounded like "tsips." These were only a fraction of a second in length and were given once every two and one-half seconds. The notes were barely audible five feet away.

Reference.-Rehn and Hebard, 1914 : 297.

\section{Amblycorypha oblongifolia (DeGeer) \\ Oblong-winged Katydid}

The oblong-winged katydid is the largest Tettiginiid on the Reserve. In spite of its size and consequent conspicuousness, only sixteen adults have been observed during four seasons. The species is characteristic of the permanent marsh and semipermanent marsh habitats. Only a single erratic has been taken, an adult from the mixed grass-herbaceous habitat.

Juveniles occur only in the characteristic marsh habitats. They reach maturity about mid-August. Adults have been taken sparingly from this time until late September. Several specimens were collected on August 11; only a single one on September 21. Hancock (1916: 74-76) has shown that the eggs are laid in the ground and that they must pass through two, or sometimes three winters before they are ready to hatch. Neither adults nor young hibernate.

In its movements $A$. oblongifolia is typical of the Phaneropterinae. It is slow in its reactions, and is generally quietly perched on top of a bush or sedge. It walks about slowly and sedately; each foot is carefully lifted and as carefully set down before another is moved. Flight is leisurely and cannot be distinguished from that of Scudderia texensis. When forced to take flight this katydid invariably alights upon a shrub or bush if there is one not more than ten or fifteen yards distant.

The song is generally sounded only once at long intervals, but occasionally it is quickly repeated. Allard's representation (1910:36) is excellent. He said that its song "consists of a single brief phrase. . . When heard close by, it is apparent that this note begins with a very rapid crepitation, which may be likened to the sudden rasping of an object across the teeth of a comb. This terminates sharply with a sound remotely like "itzick." The entire song may be likened to the syllables, z-z-z-z-itzick. . . ."

Reference.--Rehn and Hebard, 1914: 319.

\section{Amblycorypha rotundifolia (Scudder) \\ Short-winged Katydid}

This species is far more common on the Reserve than is A. oblongifolia. Decidedly characteristic of the shady oak-hickory habitat, it is also in much smaller numbers as a sporadic in the sunny oak-hickory habitat. Only one 
possibly erratic individual has come to my attention. This male was brought to me on August 26, and the collector informed me that he had taken it in an area of mixed grass-herbaceous upland fully two hundred yards from the nearest patch of woods. In view of the inability of this insect to fly, its deliberate walk, and its apparent reluctance to leave its favored haunts, it is quite possible that the collector was in some way mistaken as to where he obtained the specimen.

Statements in literature regarding the habitat preferences of this shortwinged katydid seem, in part, contradictory. Morse (1920:339) said that, in New England, "it is frequently captured by sweeping the net over lowgrowing shrubs and dense grass in moist fields near shrubbery." Blatchley (1920 : 483-84) reported that, in Indiana, "it is more of a terrestrial species than oblongifolia, being often seen on the ground, or on the clumps of tall grass and weeds, which grow in damp ravines. . . ." In Virginia, Fox (1917: 226 ) indicated that it is "taken in shrubbery and undergrowth in or close to open deciduous woods. Apparently confined to the mountain sections of the state," whereas Allard (1911: 30), writing of the species at Oxford, Massachusetts, stated that "this Amblycorypha occurs everywhere in the grass, weeds and shrubbery of fields and pastures. It is especially abundant among the shrubby pasture growths, consisting mainly of species of $V a c$ cinium, Gaylussacia, Kalmia angustifolia, and the two species of Spirea, i.e., tomentosa and salicifolia."

On the Reserve large nymphs of rotundifolia are common in the oakhickory woodlands during July. The earliest record of adults is July 18, the latest September 15. The largest number of adult individuals is present during the second week of August, but the species remains plentiful all through that month, and does not become scarce until the first of September, at which time it falls off rapidly in abundance. Extensive search on September 15 revealed only one female. The species is evidently very susceptible to the frosts of late September, and in this region has probably entirely disappeared by October 1 in normal years.

The short-winged katydid is the most sedate and slow-moving of the Tettigoniidae occurring on the Reserve. During the day it sits motionless in the grass, usually close to the ground and well concealed, though occasionally one is seen resting near the top of the grass stems. It seems to make little difference to this species whether it is well concealed or not, and several times I have nearly stepped on specimens without causing the slightest movement on their part. They can invariably be picked up with the fingers. In the evening these insects crawl slowly to the dead twigs, grass blades, and low shrubbery upon which they sit at night. The males devote much of their time to giving their intermittent song; females seem as a rule merely to rest immobile. I have never seen them eating. 
A. rotundifolia has never been seen to fly, but when disturbed at night will sometimes jump. The leap is very feebly and slowly executed, being more of a slow shove than a quick springing movement. At most the leap carries the insect only two to three inches; often it causes the katydid merely to trip and fall over the vegetation. When this happens the insect slowly but carefully rights itself, moves into a satisfactory new position, then remains quiet.

This species is as meticulous in cleaning and grooming its body as are the other Tettigoniidae of the Reserve. One afternoon a female engaged in these activities was watched for some time. When first seen she was resting on the grass; when picked up she offered no resistance of any sort. Her identity was verified, and she was replaced upon her original perch. She did not jump, but walked slowly down to the ground, continued about a foot, and stopped upon a dead oak leaf. She then lifted her right front tarsus to her mouth and carefully cleaned it by working the mandibles back and forth along its length. Setting this foot upon the ground, she proceeded to treat her other fore and middle legs in the same manner, first the left middle tarsus, then the right, and finally the left front tarsus. She had difficulty in maintaining her balance during these cleaning operations as she often found it necessary to push a front leg forward and hold it in position with the aid of a middle tarsus. After her front and middle tarsi were cleaned to her satisfaction, the female lifted a front leg, hooked it over one of her antennae, and pulled the antenna down to her mouth. The mouth parts were then moved rather rapidly, and the antenna gradually moved through the mouth. As the mouth parts worked along toward its distal end, the antenna formed a larger and larger loop and, acting as a spring, snapped back into normal position when the cleaning was finished. When the other antenna had been similarly treated, the female walked slowly over to a clump of grass, drew her hind legs up so that they projected upward and backward at an angle of about thirty degrees from her body, otherwise arranged herself in normal position, and then became motionless. When, after fifteen minutes, there had been no signs of renewed activity the specimen was collected. The cleaning operations described required five minutes for completion.

The song of rotundifolia, as I have heard it on the Reserve, is not sharp, and it totally lacks the slight tinkly sound that is present in the songs of Scudderia. The notes are dull and lisping, but not at all unpleasant. They usually continue ten to eleven seconds, and may be expressed as "thrrrpthrrrp-thrrrp-thrrrrrrrrrrrrrrrp-thrp-thrp." The whole song may be repeated several times, but is variable in duration and the frequency with which it is given. The first notes may be repeated once or as many as five 
times, although three times is usual. The long note may be long or cut off short, but is always the longest of the series, generally lasting several seconds. The last notes are short and somewhat staccato, they may be sounded once or twice, or be completely omitted. The entire song is even, without crescendo, and, except for the abrupt closing notes, does not change pitch. Males do not sing in chorus, but the song of one usually brings an answer from another until all of the males in a colony are singing. Most of the singing is done at night, but once in a long while a song may be heard during the day.

Published descriptions of the singing habits of rotundifolia are strongly at variance. Scudder (1893:68) stated that the insect "stridulates both by day and by night, and without variation. . . The song consists of from two to four notes-sounding like 'chic a chic'-repeated rapidly so as to be almost confounded, and when three requiring just one-third of a second; the song is repeated at will, generally once in about five seconds, for an indefinite length of time." This gives such a different impression of the song that one is tempted to suppose that Scudder confused the stridulation of $A$. rotundifolia with that of some other katydid. Allard (1910:37) said that around Washington, D. C., "its song is brief, faint, and of the same lisping character as that of Amblycorypha uhleri, but entirely unlike it in delivery. Each phrase is a soft, shuffling noise repeated at intervals, '- - sh-sh-shsh-sh-sh-sh-sh-sh-sh-sh-sh-sh.', Regarding the song of this species at Oxford, Massachusetts, Allard (1911:30) indicated that "its notes are soft and lisping and continue indefinitely. They may be expressed thus: 'tsip-i-tsip-i-tsip-i-tsip-i-tsip.',' Later this author (1912:462) contradicted himself and stated that "the stridulations of Amblycorypha rotundifolia may consist of brief, soft shuffling phrases, 'sh-sh-sh-sh-,' repeated at intervals." Subsequently (1929: 577), he reiterated that the song is given at intervals. (I have italicized the phrases in which the discrepancy lies.)

There is no indication in Allard's work as to whether or not his later interpretation regarding the frequency of song repetition is a correction. It is possible that his 1910 statements were based upon too few observations. As recorded above, my observations on the song of rotundifolia, other than tone and quality, are different from the songs recorded for eastern populations of this species. This is by no means astonishing, since the songs of several other Orthoptera, which are considered as distinct species, are known to vary from place to place. Examples of these forms are Pterophylla camellifolia, Nemobius ambitiosus, and Gryllulus assimilis. The differences in song between eastern and Michigan populations of the species, and the differences in observed habitat preferences, probably indicate at least incipient development of physiological races.

Reference.-Rehn and Hebard, 1914 : 335. 
TETTIGONIIDAE, COPIPHORINAE

\section{Neoconocephalus ensiger (Harris)}

\section{Sword-bearer}

This graceful and wary insect is common on the Reserve. During August its song dominates the nocturnal insect chorus. The characteristic inhabitant of the semipermanent marsh habitat, it is numerous in the heavy growths of vegetation along the margins of the marshes and swamps. Young have been commonly found in such environments, but occur in the marsh proper as well.

The males of this species mature abruptly; on one night not a single individual may be heard, whereas on the following night the marshes ring with their songs. In 1938 the males matured on July 18; the next year they were first heard in numbers on July 11. Females develop less rapidly and do not become adult until one or two weeks after the males. In spite of the sudden appearance of large numbers of males, maximum abundance of adults is not reached until five to seven days later. In late August the population dies away rapidly, and only a few stragglers remain in September. The latest record is that of a female taken September 4.

As maximum abundance is reached, the species slowly begins to spread. Individuals become more and more common in the mixed grass-herbaceous habitat, until by mid-August erratics may be heard all through the uplands that border upon the marshes. The only other erratics noted on the Reserve were in a section of sunny oak-hickory close to a marsh. Juveniles have never been collected in either of the two environments into which the species spreads as an erratic.

Literature records and observations made in other parts of southern Michigan indicate that ensiger can and does live in other less moist habitats than that of which it is characteristic on the Reserve. The unmistakable song has been heard in the heart of large cities, including Detroit, and also in heavily vegetated, slightly moist areas of upland. The xeric conditions of the Reserve upland apparently constitute too rigorous an environment for the young of the species, and the sharp intergradation. of upland and hydrophytic environment on the Reserve eliminates the mesic situations in which the species might otherwise occur.

During the day ensiger remains hidden at the bases of grass clumps and low down among heavy growths of herbage. At night, males crawl up the plant stems until they are within a few inches of the tips, and there sit quietly, head up, singing for indefinite periods. Females sometimes climb to this height on the plants, but more often move up only a foot or eighteen inches above the ground. Individuals of both sexes may be easily approached at night if one uses a dim light, but a strong light usually causes them first to dodge behind the stem on which they rest, and then to drop 
to the ground, where they hide by burrowing in the vegetation. Males invariably cease singing when the beam of the headlight falls upon them.

The song of ensiger is usually heard at night, although on cloudy days occasional males can be heard singing. The song is a continuous series of rapidly repeated notes which may be expressed as "zick-zick-zick-zick . . . ." and is accompanied by a definite whirring sound that can only be heard when one is close to the singer. The individual notes are sharp and resonant and on sultry nights are given so rapidly that they cannot be counted. The song begins about dusk and is continued until late at night, possibly sometimes until dawn.

Only three specimens of the pink color phase were taken during four collecting seasons. All of these were females; those taken August 10, 1936, and August 10, 1938, are pinkish brown, and the specimen taken on September 4, 1938, is a clear, bright pinkish color.

Reference.-_Rehn and Hebard, 1915 $a$ : 384.

\section{CONOCEPHALINAE \\ The Meadow Grasshoppers}

The Tettigoniid subfamily Conocephalinae is represented in Michigan by two genera, Orchelimum and Conocephalus, which together include eight species found on the Reserve. In many respects the behavior and activities of these eight species are so similar that they may best be presented in summary form, as follows. Peculiarities characteristic of individual species are discussed separately.

The meadow grasshoppers (with the exception of the upland-inhabiting Conocephalus strictus) are characteristic of the hydric associations of the Reserve. Juveniles of the seven species characteristic of hydric situations are invariably in such environment and nowhere else. The young of $C$. strictus alone occur in the uplands. Adults of the various forms are sedentary in habit and seldom wander far during the course of a season. For this reason erratics are rare and are usually not far from the characteristic habitats. All of the forms overwinter in the egg stage.

All of the Conocephalinae are agile and wary insects. During the day individuals of both sexes of all eight species are usually perched within two to twelve inches of the tops of the sedges, grasses, and shrubs in their favorite haunts. Here they cling, sometimes head up, sometimes head down. The hind legs are stretched out behind, the antennae project forward, and both are held close against and parallel to, the plant stem upon which the insect is resting. Disturbed individuals often whirl the antennae about, as though attempting to feel, or in some other way detect, the cause of their misgivings. If approached closely they sidle quickly around the stem and thus partly hidden and by means of their somber browns and bright greens 
seem almost to become a part of the stem. If followed still closer, they quickly leap away in a series of short or long jumps that carry them close to the ground, where they hide in the matted vegetation. The length of each leap depends both upon the size of the individual and upon the proximity of the stem or leaf toward which it jumps. Meadow grasshoppers jumping from a resting position head down on a stem have often been seen to turn completely over in the air and land head up.

Active as these species are, none of them has ever been observed to fly during my work on the Reserve. The wings of Conocephalus brevipennis, nigropleurum, and strictus are normally so strongly abbreviate that flight is impossible for them. Orchelimum vulgare, gladiator, and nigripes possess fully developed wings, but they are relatively small in comparison with the size of the body, and these species probably do not make much use of them. Orchelimum concinnum, Conocephalus fasciatus, and occasional macropterous individuals of Conocephalus brevipennis and strictus are strongly alate, and are capable of flying considerable distance; Conocephalus fasciatus is sometimes attracted to street lights in cities in large numbers, and in moist meadows and marshes where it is abundant will fly up underfoot like some of the locusts. That these forms have not been observed in flight on the Reserve is probably the result of lack of opportunity to make numerous observations on their activities.

All of the Conocephalinae of this region are primarily diurnal and are most active in the heat of the day, although 0 . gladiator has been heard on warm evenings to sing during twilight and dusk. Feeding, mating, and singing are mostly daytime activities. At night individuals of these species retire to the protection of the matted vegetation on the ground, or on rare occasions remain in their daytime posture, asleep on the vegetation.

Males are able to sing in their resting position with the hind leg's stretched out straight behind, but they were nearly always observed to relax the legs and allow them to sag a little away from each side of the body, thus giving more room within which to shuffle the tegmina. Only when startled do the males keep the hind legs stiffened straight out behind, and under such conditions the song decreases in tempo and volume, or when it is one of those made up in part of "tick's" only the latter type of note is sounded.

The meadow grasshoppers are dainty and clean. Hours are spent each day in repeatedly cleaning first one appendage and then another. The bases of the antennae are cleaned by brushing them with the tarsus of a foreleg, after which the tarsus is manipulated by the mandibles. The procedure is repeated again and again, until the insect evidently feels satisfied with the condition of that part of its body. The other parts of the antennae are cleaned as described for Amblycorypha rotundifolia. All of the feet are cleaned directly by the mouth. Many of the positions assumed by the 
meadow grasshopper during the cleaning process seem rather droll, and it often appears that an appendage will surely be torn from the body before the process is finished. Some of the odd postures are attained by pushing the hind tibiae far forward to the mouth aided by the fore and middle tarsi, which hook, pull, or push the hind leg into position. Tegmina are cleaned by rubbing them with the hind femora, which in turn have been moistened by the middle tarsi. Allard (1929a) has written a very interesting account of the cleaning habits of Orchelimum agile DeGeer, with which my own observations on other species of the genus are in full agreement.

\section{Orchelimum vulgare Harris Common Meadow Grasshopper}

The common meadow grasshopper occurs in the same habitats as $O$. gladiator and completely replaces it in late summer. It is characteristically in the semipermanent marsh habitat from late July until mid-October. $O$. vulgare is partial to drier situations than is gladiator and has not been observed in the permanent marsh habitat. A distinct tendency to wander becomes apparent soon after maximum abundance is reached, and the species is then occasionally found as an erratic in the mixed grass-herbaceous habitat. Dense growths of vegetation and moderate amounts of moisture seem to be the requirements for optimum development.

On July 24, the first mature individuals were noted with many juveniles. By the first week in August adults are as abundant as it is possible for this species to become. This is the hardiest member of the genus Orchelimum on the Reserve, several frosts being required to destroy the adult population. Males have been heard singing as late as October 14 .

The song of vulgare is somewhat like that of gladiator. It is preceded by from one to several short, staccato "tick's," breaking quickly into a buzzing trill that can be represented by "zzzzzz." The first part of this trill rises rapidly in a crescendo which is only about one-half second in length. The rest of the trill is even and steady, and at the finish does not rise or fall, but ends abruptly. O. vulgare invariably sounds at least two preliminary "tick's" before the trill, while gladiator often omits them.

Reference.--Rehn and Hebard, 1915b : 38.

\section{Orchelimum gladiator (Bruner) Gladiator Meadow Grasshopper}

Orchelimum gladiator is as common on the George Reserve as is $O$. vulgare. Occurring in the same habitats, these two species overlap considerably in their seasonal appearance. The former is the earlier, showing much the same seasonal relation to vulgare as Pardalophora apiculata does to $P$. haldemanii. 
The species is characteristic of both the semipermanent marsh and the permanent marsh habitats, but is far more abundant in the first. It is unpredictable in abundance; areas which appear to be very similar may differ greatly in the number of individuals present. Only a single female erratic has been taken on the Reserve.

Maturity is reached early in July, the first adults having been taken on July 3. Maximum abundance is attained in the short time of about one week; the species maintains its numbers until mid-August, and then declines rapidly. The latest record for adults is September 4.

The singing of gladiator may be heard throughout the day, and until dusk on warm evenings, although, owing to temperature changes, the night song differs radically from the day song. Individual males sing with no attempt to synchronize their performances with those of other individuals, either by day or night.

The day song is probably best recorded as "tick-tick-tick-tickzzzzzzzzip!" The preliminary notes are short and sharp and may be heard for a distance of twelve feet. Disturbed individuals become wary and reduce the volume of their songs, so that the "tick" is difficult to hear three feet away. These preliminary notes are given a variable number of times. Undisturbed males often repeat the "zzzzzzzzip" part of their song without interpolating the ticking notes. In forty-nine songs produced by two males, the numbers of "tick's" between each "zzzzzzzzip" were as follows : none, 23; one, 4 ; two, 3 ; three, 5 ; four, 1 ; five, 6 ; six, 3 ; seven, 3 ; and eight, 1 . When a male is disturbed, the number of "tick's" increases and they are given in an irregular, haphazard fashion as many as twenty to thirty times. One can roughly estimate his proximity to a male that is singing by the number of "tick's" sounded between songs. The continuous "zzzzzzzzip" part of the song is clear, ringing, and somewhat buzzing in quality. It is also variable in length and sound. An undisturbed male, performing continuously, sang this part of his song for the following different periods of time : $1,2 \frac{1}{2}, 3,3,2$, $3,3,1 \frac{1}{2}, 1,3,4,4$, and $3 \frac{1}{2}$ seconds. The sound is also modified by the manner of ending the song. The "zzzzzzzzip" starts with fairly low volume and speed, picks up after about two strokes of the tegmina to a much louder and faster rate, continues to build up to a maximum which is held for over half the length of the phrase, and finally ends abruptly, either dropping a trifle, or with no change in tone or volume, or rising at the finish to a quick sharp "zip."

The night song is begun about dusk and generally ceases just after dark. This song has the same buzzing quality as that sung during the day, but is slower and more drawn out. In tone, quality, and volume the night song is very similar to that of Atlanticus testaceus, but the buzzing effect instantly marks it as different. The preliminary notes are struck as usual, but follow 
rather than precede the main body of the song. As darkness descends and the air becomes cooler they are completely eliminated.

In order to determine the variation in the night song, the notes of a single male were recorded at 8:20 P.M. on July 20. At this time the temperature four feet above the ground was $68^{\circ} \mathrm{F}$. The periods of time required for the "zzzzzzzzip" portion of the song in a consecutive series were $8 \frac{1}{2}, 2,4,8,5,7$, $5,7,6,3,5,5,15,10,15$, and 12 seconds. The intervals between consecutive notes were $5,6,3,2,4,3,5$, and 13 seconds. The numbers of "tick's" given during these intervals were $2,5,3,4,5,7,7,4$. Later in the evening the song was somewhat shortened. Intervals between notes became longer and the "tick's" were gradually eliminated. The male finally ceased singing altogether.

Reference.--Rehn and Hebard, 1915b : 44.

\section{Orchelimum nigripes Scudder Black-legged Meadow Grasshopper}

This species, the most handsome Orchelimum occurring on the Reserve, is a thamnophilous form characteristic of the tall shrubbery of the wet shrubzone habitat. It has been found, however, only on the dogwoods and buttonbush. Less than a mile from the Reserve, on the shore of Patterson Lake, Orchelimum nigripes is abundant in a zone of mixed dogwood and buttonbush. It is, therefore, possible that in this region buttonbush may in some way be necessary for the occurrence of the species, or at least may.indicate suitable conditions for it. In Berrien County, Michigan, Hubbell (1922: 63) found nigripes common in buttonbush swamps, but he also recorded it from numerous other situations along the margins of woods and in floodplain forest. There is no way of determining how many of these occurrences were based on erratics which might have spread from the buttonbush swamp.

On the Reserve Orchelimum nigripes begins to mature about the third week in July; individuals become scarce in late September and probably disappear about the first week in October. The earliest record of an adult is that of a male heard singing on July 18; the latest capture recorded is that of two males and one female taken September 21.

The black-legged meadow grasshopper has the most distinct song of any of the Conocephalinae on the Reserve. It is not as loud or coarse as the songs of vulgare and gladiator, but is clearly audible for thirty or forty yards. The song is invariably introduced with two preliminary notes, quickly followed by the main trill. It may be written as "tee-dee-tseeeeeeeeea, tee-dee-tseeeeeeeea." The first preliminary note and the "ts" of the trill are struck sharply. The very brief pause between the first and second notes is only about one-half as long as that between the second note and the trill. The trill seems to drop a trifle at its completion, as indicated by the "a" of 
"tseeeeeeeeea." The complete song is given repeatedly with scarcely a pause between songs. All males do not sing at the same rate. Of four males that were timed one afternoon for a five-minute period, one sang twenty-eight complete songs in thirty seconds; the second, twenty-one; the third, sixteen; and the fourth, eighteen. Although the songs are not at all synchronized, for brief periods those of two males may seem to be so, since the song of one may overtone that of another singing at a different rate, and several complete songs may be sounded almost in unison.

My observations indicate that nigripes does not normally sing after dark. One night, however, the beam of a headlight chanced to fall upon a male, and he immediately began to sing, at about one-half the daytime rate. Soon many males joined in the chorus, but all stopped abruptly as soon as the light was snapped off.

Reference.--Rehn and Hebard, $1915 b: 56$.

\section{Orchelimum concinnum concinnum Scudder (Orchelimum campestre Blatchley) ${ }^{13}$}

A rare species on the Reserve, campestre is characteristic of the permanent marsh habitat. Since on the Reserve this habitat is restricted to the margins of the lake, where the roots and matted debris of the vegetation form a weak mat underlain with an unknown depth of oozy mud, the species has not been too enthusiastically collected. Only fourteen specimens have been secured; other observations and records are largely based on data obtained by listening to the song. O. campestre occurs as a sporadic upon the water lilies (Nymphaea advena) of the lake's surface.

Most abundant in mid-August, individuals have been collected, seen or heard from August 5 until October 3. On the latter date, the species was still numerous. The capture of a last instar taken on July 2 indicates that maturity is reached before the middle of that month.

The complete song of campestre is audible for about thirty feet. Beyond this distance the introductory notes cannot be heard. In its entirety it may be written as "zick-tick-tick-z-z-z-z-z-z-z-z-z." The first note or "zick" is always struck once and the "tick's" are sounded from two to seven times. The remainder of the song is steady and buzzing in quality and lacks the "zing" and sharpness of the notes of 0 . gladiator. This part may be sounded without interruption for from four to forty-eight seconds.

Reference.-Rehn and Hebard, 1915b : 60.

13 E. S. Thomas, of the Ohio State Museum, Columbus, Ohio, has accumulated evidence which strongly suggests that Orchelimum concinnum concinnum Scudder and concinnum delicatum Bruner may be good species and not races. O. campestre may also need to be reinstated as a good species. Mr. Thomas has examined my material and informs me that the specimens taken on the George Reserve will represent the entity which, should he make the above mentioned changes, may probably be known as Orchelimum campestre Blatchley. 


\section{Conocephalus fasciatus fasciatus (DeGeer) Slender Meadow Grasshopper}

On the Reserve this is the rarest species of the genus Conocephalus. This is difficult to understand, for in southern Michigan fasciatus rivals and often surpasses brevipennis in numbers; throughout the Lower Peninsula it is generally abundant in damp situations which maintain growths of lush and rank-growing grasses. Not more than six miles from the Reserve, the slender meadow grasshopper occurs in great numbers in the heavy growths of grass and sedge at the east end of Little Portage Lake. On the Reserve, fasciatus is found throughout the semipermanent marsh and the permanent marsh habitats; in the former, however, it could never be classed as more than frequent, nor as more than numerous in the latter. One might attempt to attribute the rarity of this species on the Reserve either to the number of the herbaceous and shrubby plants as opposed to grasses and sedges, or to the necessity for a more humid environment. An unfavorable type of plant growth does not seem a very plausible explanation, since the denser growths are generally isolated, separated by large areas of pure sedges, grasses, or a combination of the two. If more humid environment is required it may be the absence of lush, mesic meadows and wet grassland that renders the slender meadow grasshopper so surprisingly scarce on the Reserve. If such is the case, the species should become more abundant in the future, with continued rise of the water table.

Maturity is reached late in July, and maximum abundance of adults is attained in about two weeks. Little change in abundance occurs until the heavy frosts of early October destroy all stages of the insect except the eggs. On July 24 several late stage nymphs were observed. The next night fifteen adult specimens of both sexes were collected from the freshly painted sides of the laboratory. These individuals, the earliest adults seen, were attracted from a semipermanent marsh about one hundred yards away, probably by the lighted windows of the laboratory. I have, however, wondered whether the odor of the fresh paint might not have attracted them; the species sometimes comes to light in other localities, but in all my collecting at lighted sheets on the Reserve not a single specimen has ever flown to the sheet. The latest record for the species is that of an individual observed on October 4 .

The song of fasciatus is very faint and, owing to interference by the songs of other katydids and crickets, is audible to me in the field for only five or six feet. Caged specimens have been heard up to ten feet away, but at this distance the preliminary notes are inaudible. The song in its entirety may be written as "tic-tic-tic-tseeeeeeeeeee." The preliminary "tic's" are very short and faint and are clearly audible for only about two feet. They may be struck from one to many times, at no definite intervals, and are uneven in volume and quality. Males have been heard to do nothing but "tic" slowly, 
for periods of from ten to fifteen seconds. Piers (1918: 324) stated that the "tic" notes follow the main body of the song, whereas Allard (1911: 31-32) stated that "the staccato lisps nearly always precede the phrase "tseeeeeeeeeeeeee." I have observed that both writers are correct; the "tic's" being given indiscriminately before or after. The "tseeeeeeeeeeeeee" is variable in length. This part of the song was timed in the instance of one male which was singing continuously, and in consecutive songs, was found to vary in duration as follows: $\frac{1}{4}, \frac{1}{2}, 3,4,1,1 \frac{1}{4}, 1 \frac{1}{2}, 1 \frac{3}{4}$, and 2 seconds. Sometimes the song of one of these insects sounds as though the male was too busy or hurried to execute the performance properly. I jotted down one such song as "Thrrrp-tic-tic-thrrp-thrrp-tic-tic-tic-tseeeeeeeeeeeeee." This particular song was heard at 12:00 o'clock noon with the temperature at $88^{\circ} \mathrm{F}$.

Reference.-Rehn and Hebard, 1915c: 170.

\section{Conocephalus brevipennis (Scudder) Short-winged Meadow Grasshopper}

The most abundant member of the genus Conocephalus on the Reserve, this species is present throughout the hydric environments, which I have classified as the semipermanent marsh and the permanent marsh habitats. So generalized are its habitat requirements that populations distinguishable as sporadic have not been recognized. Erratics have been observed on several occasions in the mixed grass-herbaceous, the shady oak-hickory, and the bog habitats; but individuals have never been collected more than one hundred feet from their characteristic marsh environments.

Conocephalus brevipennis is adult on the Reserve from the first of August until mid-October. A teneral male, taken on August 1, constitutes the earliest record. Juveniles and teneral individuals are common until the last week of August. Maximum abundance of adults occurs in late August and early September. In mid-October adults are still fairly numerous, and four females and one male were collected October 14. The species is able to withstand freezing weather much longer than any other member of the Conocephalinae present on the Reserve.

The song of the short-winged meadow grasshopper is virtually impossible to hear in the field, being the least audible of that produced by any katydid of the Reserve. Furthermore the species is rather wary and usually will not sing when one approaches to within five feet of it. At a greater distance the song is submerged in the incessant calling and singing of other katydids and crickets. It was necessary to cage specimens in order to study their song. I cannot describe the song better than has been done by Allard (1911: 33), with whose observations my own agree fully. Allard wrote: 
The notes of Xiphidium [Conocephalus] brevipenne are very brief and much more hurried in their delivery than those of $X$. fasciatum. ... In the song of $X$. brevipenne usually only one or two almost inaudible staccato lisps precede one, two, or even three of the brief, faint phrases, "tseeeeee-tseeeeee." The phrases "tseeeee" are of much longer duration in the song of $X$. fasciatum, and are rarely heard without the preceding staccato lisps, which are of indefinite number.

On August 27 a pair of brevipennis was observed mating halfway up a sedge leaf, about two feet above ground. The insects were clinging to opposite edges of the sedge leaf, the male facing upward and the female downward. Their abdomens lay on the same side of the leaf, with the ventral surfaces facing one another. The abdomen of the male was curved ventrad and cephalad in such a way that copulatory attachment was made from beneath the female's abdomen. At the time observations were begun the pair was already mating, and the male was seen repeatedly to push the tip of his abdomen toward the female in such a way that the female's ovipositor was forced up each time the movement was made. This was done fourteen times in twenty-five seconds. The female then began to move away and the male, lifting his hind legs straight up over his back and offering no resistance nor making any attempts to walk or cling to the leaf, retained his hold on the female and was carried along. In this manner the pair moved about two inches. The male then broke away and dropped to a sedge leaf, and the female leaped away. Upon capturing the female, a bilobate spermatophore was seen to be affixed to the genital chamber. It was semitransparent and jellylike in consistency, but immediately turned white when placed in alcohol.

Reference.--Rehn and Hebard, 1915c: 182.

\section{Conocephalus strictus (Scudder) Straight-lanced Meadow Grasshopper}

The straight-lanced meadow grasshopper is the only member of the Conocephalinae present on the Reserve which is not characteristic of hydric environments. The favorite haunt of this species is a mixed grass-herbaceous habitat, although it occurs not uncommonly in sporadic colonies in the clumps of panic grass scattered through the sparsely vegetated sand habitat. Erratics have been collected only in the sunny oak-hickory, and then only when an area of favorable habitat was close at hand.

The song, given by males hidden in clumps of panic grass (Panicum) or Danthonia, may be heard from late July until the heavy frosts of early October. It is a clear, ringing monotone, "zzzzzzzzzzzzzzzzzzzzzz," which may be given for several minutes without interruption. Staccato notes are not sounded. The song is much louder than that of any other Conocephalus in the area, but is audible for only about thirty feet. At this distance it 
blends so well with the calls of the ground crickets and tree crickets that especial attention must be expended to hear it at all. The song has been heard only during the day.

Teneral males were taken on July 27, and adults of both sexes have been collected as late as October 3. Maximum abundance is attained about midAugust and is maintained until the frosts of September begin to take their toll.

Reference.-Rehn and Hebard, 1915c: 193.

\section{Conocephalus nigropleurum (Bruner)}

Black-sided Meadow Grasshopper

This species, the most handsome of the George Reserve Orthoptera, is characteristic in the wet shrub-zone, the permanent marsh, and the semipermanent marsh habitats. A semithamnophilus insect, nigropleurum is usually in the lower shrubs which are commingled with the sedges and grasses, but it is also commonly seen on the main trunks and limbs of taller shrubbery such as dogwood, buttonbush, and high-bush huckleberry, in moist environment. Notwithstanding the brilliant color composite of black, green, or brown with which it is adorned, the species is difficult to locate. Males are often heard singing cheerily and continuously for many minutes before they can be seen.

Adults of the black-sided meadow grasshopper have been collected from July 9 until September 21. Maximum abundance is attained slowly; nymphs and teneral individuals are common until the end of the first week in August. On September 21, adults were still frequent, indicating that the species probably survives until mid-October.

The song of nigropleurum-a steady, even, rhythmic, lisping "tic-tic-tictic-tic" - is not preceded by introductory staccato notes. Males have been heard singing continuously for over twelve minutes. The song has a clear, buzzing, or whirring undertone when heard at close range. Only this undertone is heard when a singing male sidles around to the side of a stem or twig opposite the observer. The notes are given so rapidly that it was found impossible to time them by tapping a pencil upon a paper pad for a measured period, as could be done with most of the other singing Orthoptera.

Of the males collected, 25 per cent were of the brown, 75 per cent of the green color phase. All females collected or seen were of the green phase.

Reference.-Rehn and Hebard, 1915c : 205.

TETTIGONIIDAE, DECTICINAE

Atlanticus testaceus (Scudder)

Short-legged Shield-bearer

Atlanticus testaceus is the only member of the subfamily Decticinae occurring on the Reserve. Although quite common in the wooded areas, it 
is a seclusive, nocturnally active species, and hence is comparatively seldom seen.

The short-legged shield-bearer is characteristic of both the sunny and shady oak-hickory habitats, but is much more abundant in the former. Its predilection for the more open woodlands probably results from the fact that only these situations combine the unlike conditions sought by the species in different stages of its life history. Very small juveniles are nearly always in or around sunny spots in the forest, while the adults seem to require shade, humidity, and a minimal density of undergrowth.

During mid-April and May the young have been observed not only in the characteristic habitats, but also in the mixed grass-herbaceous upland. Juveniles in the upland are seldom more than ten to twenty yards from neighboring woodland, and have probably always migrated from there. As maturity is reached, the adults developed from these erratic nymphs rapidly disappear. They must either die or move back to the wooded areas, for they are never found in the upland a fortnight after maturity is reached. Erratic adults have also been taken early in the season in the bog and semipermanent marsh habitats. It is highly probable that these individuals were also derived from wandering juveniles, and that they too must either find a more favorable environment or die.

A. testaceus matures early; songs have been heard as early as June 20. The adults appear rapidly and soon the forest rings with their calls. Greatest abundance is reached about a week after the first adult appears, or about the end of June. Numbers of the species were seen on the night of June 4. Blatchley (1920: 591) reported that individuals may be found in Indiana until after heavy frosts, but on the Reserve most of the population is gone by the first of September; the latest record is that of a specimen taken on that date.

During the day the short-legged shield-bearer hides beneath dead leaves and debris, under logs and around the bases of woodland plants; at night it crawls on the nearest herb, shrub, or tree trunk it can find and mounts as high as it can go if the plant is not over four or five feet in height, or at most to a height of ten or eleven feet on a tree trunk. There it sits quietly twirling its antennae in typical katydid fashion. Individuals disturbed by the beam of a headlight or by movements of the collector either dodge beneath a leaf or to the far side of a stem, or else drop to the ground. In any event the insect becomes immobile after this first activity and can be picked up with the fingers. If not handled with care, however, it will inflict a severe bite upon the nearest finger. Individuals that have been alarmed and have dropped to the ground from a favorite perch on a bracken fern or low-bush blueberry, and that have been prodded with the end of a net handle without causing any further movement on their part, have bitten me severely when they were picked up. When flushed from their hiding places during the 
day $A$. testaceus usually hops once or twice and then attempts to burrow beneath the nearest debris.

The song of the short-legged shield-bearer is a clear ringing buzz which can be expressed as "zzzzzp-zzzzzp-zzzzzp." Preliminary notes are not sounded. At a distance the song sounds as though it were continuous, but when one is within twelve feet of a singing male a very slight pause can be detected between each "zzzzzp." At very close range the song dissolves into a series of extremely rapid "tic's," accompanied by a decided whirring undertone. Although Atlanticus testaceus sings much more loudly than Conocephalus nigropleurum, a very close similarity otherwise exists between the songs of these two species. A. testaceus does not sing for very long periods of time. As a single male begins to sing, others answer, until within a minute or two, numbers of males are singing, each apparently striving to outdo the others. Finally, after four or five minutes, one by one they cease singing until all have stopped. At the height of their burst of song the effect of a definite chorus is produced; but it is not a synchronized performance. The pauses between songs of the different individuals do not coincide, but these hesitations are so short and the song is of so even a timbre that unless one listens carefully all the insects may seem to be singing in unison.

This species is nearly or quite omnivorous. Males which I kept caged ate with avidity all except the hard parts of disabled specimens of Melanoplus m. mexicanus. Davis (1893) found that a caged male ate various fruits, berries, and melon. He kept a male alive seventy-six days on such a diet.

Reference.--Rehn and Hebard, $1916: 47$.

\section{GRYLLACRIDIDAE, RHAPHIDOPHORINAE \\ Ceuthophilus brevipes Scudder}

On the Reserve this species is second in abundance only to Ceuthophilus meridionalis; it may well be termed rare on this area. It has been found only in five places on the Reserve, all in the bottoms of rather large kettle holes, or in low mesic areas which afford a moist, usually forested environment with shelter on the ground. In all probability the scarcity of individuals may be traced directly to the small extent and rather wide separation of these patches of mesic environments. The areas occupied vary from forty to one hundred feet in width by one hundred to three hundred feet in length; the shortest distance between any two is about one-quarter mile. Three of these small, mesic patches are located in the midst of oak-hickory forest; a fourth is the margin of the red maple-birch habitat; and the fifth is a small tamarack island near the center of a leatherleaf bog. It is not surprising to find this boreal species located on such a relict island.

The above data are in line with Hubbell's contention (1936: 120) that 
"toward the southern edges of its range this northern species is more restricted to cool, moist situations." The mesic environment in which brevipes was observed on the Reserve fulfills these requirements.

Ceuthophilus meridionalis, being a more plastic species than brevipes, has always been taken in the same traps and on the same days as has the latter species. Size groups of juveniles and appearance of brevipes has followed very closely the same chronological sequence as that determined for meridionalis (Table XIII). Nymphs of the third size group were taken on June 9 and very small individuals were trapped on September 30 . It is evident, therefore, that brevipes hibernates over winter both as juveniles and in the egg stage.

Reference.-Hubbell, 1936 : 114.

\section{Ceuthophilus meridionalis Scudder}

Ceuthophilus meridionalis is the most abundant camel cricket on the Reserve and is a characteristic inhabitant of the terrestrial-hypogeic stratum of the shady oak-hickory habitat. The prevalence of suitable retreats in which to hide during the day appears to be the principal factor limiting the abundance of the species in any given area of forest. Small depressions, piles of dead twigs and limbs, bushes, and, in short, any object in or upon which dead leaves pile may be a potential retreat. These leaf piles must be permanent enough to permit humus formation. As this stage of decay is reached, fungus mycelia spread through the walls of small runways and tiny crevices in which, along with Parcoblatta pensylvanica, $P$. virginica, and P. uhleri, Ceuthophilus meridionalis seeks concealment. As many as twenty-five specimens have been secured at one time from a single such leaf pile. Small piles of leaves in which this state of decay has not been reached have never yielded the species. The underground runways and burrows formed by small mammals are probably also used as retreats, since specimens have sometimes been taken in traps set in woodland areas lacking in heavy accumulations of decaying humus. The crevices of old rotten stumps and decaying logs also harbor meridionalis.

Only three records of meridionalis are at hand which do not agree with the above generalizations. A single male was noted beneath a wood pile behind the custodian's house. This specimen was probably brought in along with the wood. On May 11, 1937, Mr. Lawrence Camburn found a halfgrown female of this species on the eastern edge of the southwest swamp; this individual undoubtedly wandered from the oak-hickory woods about two hundred feet away. The edge of the swamp in this area is sufficiently covered with debris to offer shelter when needed. In August, 1936, five specimens were trapped in the middle of a tamarack island in a leatherleaf bog: The colony was apparently established by migrants from near-by oak- 
hickory, and the insects found concealment among the masses of moss and fallen tamarack needles beneath the trees.

Information (Table XIII) secured on the Reserve seems to bear out the statement of Hubbell (1936: 171) that "meridionalis probably passes the winter both as small hibernating nymphs and as eggs." Depending upon the stage in which they hibernate, nymphs mature at various times during the summer; the larger nymphs become adult by the latter part of June. Eggs laid by these adults hatch during July and August, and the nymphs hibernate. Overwintering eggs probably hatch early in June, the juveniles therefrom maturing in late summer and depositing eggs which in turn hatch late the next spring.

TABLE XIII

Seasonal Distribution of Ceuthophilus meridionalis

\begin{tabular}{|c|c|c|c|c|c|c|c|c|c|c|c|c|c|c|c|}
\hline \multirow{7}{*}{$\begin{array}{l}\text { Adult ............. } \\
\text { Size group } 5 \ldots \\
\text { Size group } 4 \ldots \\
\text { Size group } 3 \ldots \\
\text { Size group } 2 \ldots \\
\text { Size group } 1 \ldots\end{array}$} & \multicolumn{3}{|c|}{ May } & \multicolumn{3}{|c|}{ June } & \multicolumn{3}{|c|}{ July } & \multicolumn{3}{|c|}{ August } & \multicolumn{3}{|c|}{ September } \\
\hline & $\ldots \ldots$ & $\ldots \ldots$ & $\ldots \ldots$ & & $\ldots \ldots$ & $x$ & & $\ldots \ldots$ & $X$ & $X$ & $\mathrm{X}$ & $\mathrm{X}$ & $x$ & $\ldots \ldots$ & $\ldots \ldots$. \\
\hline & $\ldots . .$. & $\ldots \ldots$. & $\ldots$ & $\mathrm{X}$ & $\ldots . .$. & $\mathrm{X}$ & $X$ & $\ldots \ldots$. & $\mathrm{X}$ & $\mathrm{X}$ & $X$ & $\ldots . .$. & $\ldots . .$. & ....... & $\ldots . .$. \\
\hline & & ........ & $\ldots . . .$. & & $X$ & $\bar{X}$ & $\ldots . .$. & $\ldots . .$. & ........ & $\ldots . .$. & $\mathrm{X}$ & ....... & $\ldots . .$. & $\ldots \ldots$ & $\ldots \ldots$ \\
\hline & $\mathrm{X}$ & $X$ & $\ldots \ldots$ & $X$ & $X$ & $\ldots \ldots$ & $\ldots \ldots$ & $\ldots . .$. & $\ldots \ldots$ & $\ldots \ldots$. & & ....... & $x$ & $\mathrm{X}$ & ....... \\
\hline & $\ldots . .$. & $\ldots .$. & $\ldots \ldots$ & $\ldots . .$. & $\bar{X}$ & $\ldots \ldots$ & $\ldots . .$. & $\ldots . .$. & $\ldots \ldots$ & $\ldots \ldots$ & $X$ & $\ldots . .$. & $\ldots . .$. & $\ldots \ldots$ & ....... \\
\hline & $\ldots \ldots$ & $\ldots . .$. & $\ldots . . .$. & $\ldots . . .$. & $\ldots . .$. & $\ldots \ldots$ & $\ldots . .$. & $\ldots \ldots$ & $X$ & $\ldots . .$. & $\mathrm{X}$ & $\ldots . .$. & $\ldots \ldots$ & $\ldots . . .$. & $\ldots . .$. \\
\hline
\end{tabular}

Individuals of meridionalis, when disturbed, leap a few inches to three or four feet. One or several jumps may be made, depending upon how soon the individual can find shelter. Under these conditions, leaping is aimless, and the camel cricket, after several jumps in quick succession, often lands where it began.

Only a single specimen has been observed in my night work with a headlight. This was a small juvenile which remained motionless, apparently blinded by the headlight beam, and was picked up with the fingers.

Reference.-Hubbell, 1936: 166.

\section{Ceuthophilus thomasi Hubbell}

On the Reserve, thomasi is one of the least common species of Ceuthophilus. A single female and a last instar male, taken August 6, 1936, and July 1, 1937, respectively, are the only specimens secured. Both were taken from molasses traps set in the margins of the red maple-birch habitat. Additional traps placed throughout the habitat at various times failed to capture specimens. Furthermore, traps set at the same time in the adjoining oak-hickory habitat and in the ecotone between the red maple-birch and oakhickory habitats yielded negative results.

The red maple-birch habitat corresponds to a flood-plain forest, and is inundated for several months each year. The area in which thomasi can oviposit and develop is therefore restricted to the margins. 
Hubbell (1936: 422) stated that he took thomasi at Mendon, Ohio, associated with meridionalis in a situation, which, from his description, was much more xeric than the habitat which thomasi occupies on the Reserve. In an areal sense, much of this more xeric habitat is available on the Reserve, but so far it has never yielded thomasi.

Associated with this species in the same habitat were found $C$. brevipes, Acrydium subulatum, Tettigidea lateralis parvipennis, T. armata, and Nemobius carolinus.

Reference.-Hubbell, $1936: 419$.

\section{Ceuthophilus silvestris Bruner}

Ceuthophilus silvestris is undoubtedly the least abundant of the four species of Ceuthophilus known to occur on the Reserve, although fewer specimens of $C$. thomasi have actually been taken there. Long and diligent searching has failed to reveal $C$. silvestris, a subterranean species, except in one place-on and around a small knoll which has a relief of about ten feet and lies between a marsh and an oak-hickory woodland. Here the species has been found in the runways of the mole Scalopus aquaticus machrinus. The soil of the upper part of the knoll consists of fine sand, becoming progressively darker and heavier down the slopes. A moderately dense growth of Poa compressa, Anaphilus margaritacea, Cenchrus carolinianus, and an occasional goldenrod make up most of the vegetation on the sand, with here and there small patches of mosses and lichens. In the spring and early summer Erigeron ramosus is a prominent plant. The mole burrows ramify in all directions through this habitat, many being only an inch or two beneath the surface. Deer have trampled a number of the shallower tunnels, exposed them to the air and desiccation. Other tunnels are two to five inches below the surface. $C$. silvestris was found only in these deeper, moister burrows.

It was discovered that the most satisfactory way to secure this species was to break into the burrow, exposing a few feet of it, then to trace the surface ridge, marking the position of the tunnel, for a distance of ten or twenty feet and to make a new opening. From this point the tunnel was gradually exposed while working back toward the original opening. Since the insects are negatively phototropic and retreat from the opening, they move ahead as the tunnel is exposed, keeping well within the undisturbed part. When only two or three inches of the tunnel were left intact, specimens were observed to cling to the roof. As the remnants of the tunnel were uncovered, the individuals present leaped about sluggishly, their jumps covering two to fourteen inches. If one of the camel crickets chanced to move away from the moist sand of the tunnel, it immediately hopped back and attempted to hide itself beneath any small lump of soil offering concealment. It was then readily captured by placing a forefinger upon it. 
Owing to the lack of very great differences in the depth of the tunnel, it was difficult to determine in exactly which sections the species was most abundant. The question was cleared up by the discovery of a colony of silvestris about six miles west of Toledo, Ohio. There, along the upper edge of a ditch formed by road grading operations, mole runways were abundant. On the lower side of the ditch the runways were close to the surface, and no specimens of silvestris were found. Farther up the bank, runways were three to eight inches below the surface. It was soon discovered that silvestris is gregarious, and that its small colonies preferred the deeper, moister parts of the tunnels. Since the loose sand of the surface of the soil acts as a mulch, these sections of the burrows are moist even under the driest surface conditions.

The finding of silvestris on the George Reserve as well as at Toledo, Ohio, is of much interest, since Hubbell (1936: 439) has recorded the geographic distribution as being "within the limits of the prairie belt west of the Mississippi River." The very close similarity of the females of $C$. silvestris and $C$. occultus has caused Hubbell, lacking males from this part of the country, to confuse the ranges of the two species. This matter and its taxonomic significance will be discussed at greater length in another paper.

In order not to deplete the small colony of silvestris occurring on the Reserve, relatively few specimens were collected, and their number is too small to permit determination of the number of generations per year. Since nymphs belonging to various size groups have been secured with adults in June, September, and October, it is evident that the species must pass the winter both in the egg stage and as nymphs; there appear to be indications of the occurrence of at least two generations per year on the Reserve.

Reference.-Hubbell, 1936: 437.

\section{GRYLLIDAE, GRYLLINAE \\ Gryllulus assimilis (Fabricius) \\ Common Field Cricket}

The classification of the common field crickets has been one of the most difficult taxonomic problems faced by students of American Orthoptera. Literally dozens of species were described by the earlier workers, but as collections grew larger it was found that the supposed distinctions between them did not hold. In their revision of the North American forms of the genus Gryllus (= Gryllulus), Rehn and Hebard (1915) finally came to the conclusion that, in America, only one extremely variable native species exists. They found it impossible to correlate, except to a minor extent, the numerous variants of this species with either ecological conditions or geographic areas. The variants were in their opinion so inconstant and unistable that they finally fell back upon a system of symbols instead of names, 
whereby the principal characteristics of individual specimens as well as of the so-called "standard" (named) variants might be expressed.

On the Reserve, as elsewhere in southern Michigan, Ohio, Indiana, and probably the northern states generally, there exist two populations of Gryllulus assimilis, a "spring" population present in the spring and early summer, and a fall population. It has been maintained by Blatchley (1920: 705-6) and others that the spring population constitutes a variant distinct from that occurring in the fall, recognizable by differences in appearance, habitats occupied, behavior, and song. Blatchley has described this supposed "spring" variant under the name vernalis. One of the most difficult problems which I have encountered in my work on the Reserve has been to determine the actual status of these two populations, for the problem had to be solved before I could arrive at any satisfactory interpretation of the habitat relations of the field crickets. Two possibilities were considered: first, that the two populations might actually represent two different variants each having an annual cycle but maturing at different times; and second, that the two populations were merely successive generations of a single variant which was two-brooded. This problem was attacked by two methods: by analysis of the characteristics of large numbers of specimens collected throughout the year, and by field studies and rearing experiments.

Analysis of the collections was begun by classing all of the specimens according to the symbols devised by Rehn and Hebard (1915). The data thus obtained were tabulated by date (Table XIV), and by percentage dispersal of variant values (Table XV), to determine whether the spring and fall populations actually differed absolutely or in the proportions of different variant types composing them. According to Blatchley's description of his vernalis its typical condition should correspond to class I of Tables XIV and XV, though the range of variation described also would include classes II to IV, and overlaps the characteristics of the "standard" variant neglectus (AUax4), which was not taken on the Reserve, and hence is not assigned a class in the table. The commonest "standard" variant in the northeastern United States, and the one which Blatchley apparently thinks of as the principal fall form, is pennsylvanicus (AVabx3, variable), the closest approach to which in the population of the Reserve is represented by class III. Blatchley also mentioned certain additional characteristics by which vernalis may be distinguished, such as the more polished appearance of the tegmina, which I have been unable to recognize and have consequently ignored.

The first thing that one observes on inspection of Table XIV is the well marked break between the spring and fall populations. The second is that all of the principal classes are as well represented in the spring as in the fall. It will be noted (Table XV) that in the spring specimens the preponderance 
TABLE XIV

Seasonal Dispersal of "Variant" Values for Gryllulus assimilis

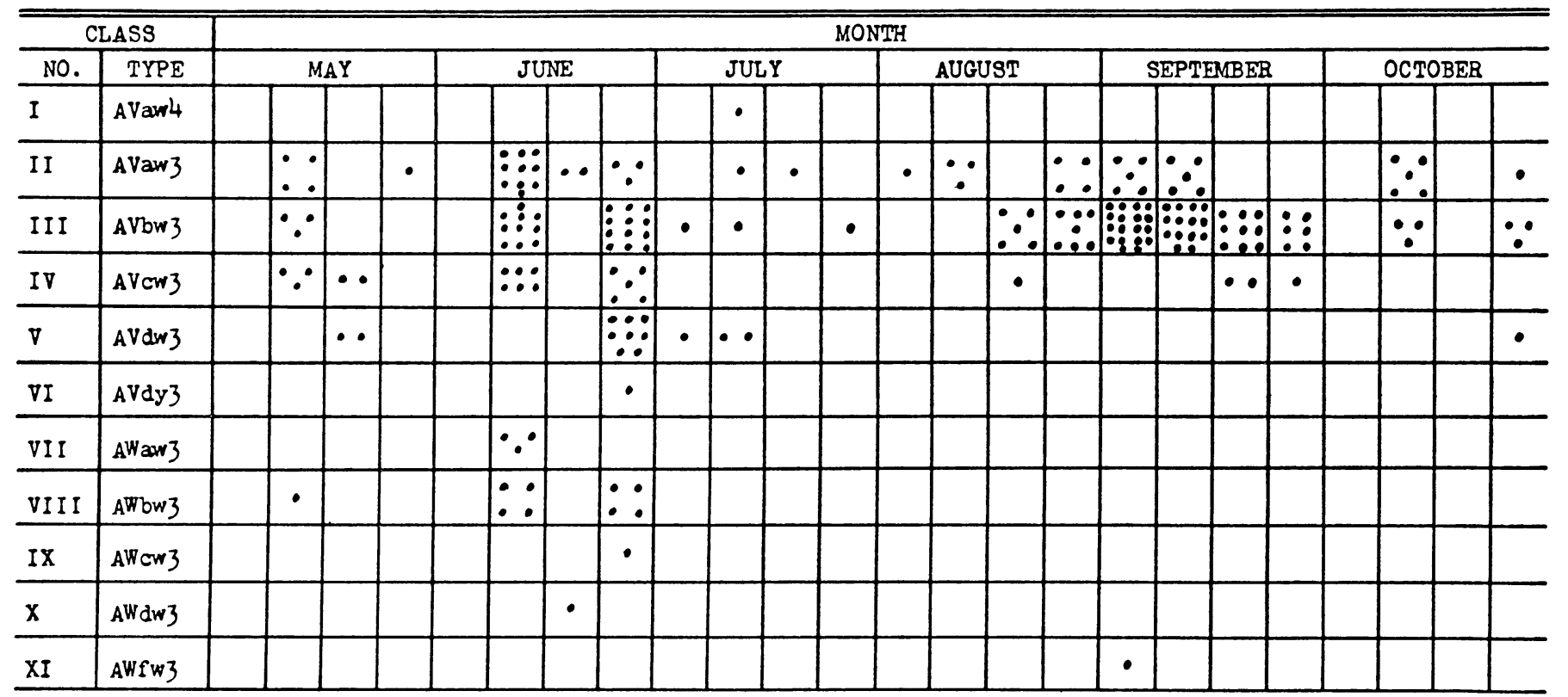


(55 per cent) of the material falls equally into classes II and III. Another point of interest is the fact that class II of the spring population contains about six times as many males as females and that class III contains about four times as many females as males. This acquires greater significance when we note that in the fall population class II contains seven times as many males as females and class III about six and one-half times as many

TABLE XV

Percentage Dispersal of "Variant" Values for Gryllulus assimilis

\begin{tabular}{|c|c|c|c|c|c|c|c|c|}
\hline \multicolumn{2}{|c|}{ Class } & \multirow[b]{2}{*}{ Sex } & \multicolumn{3}{|c|}{$\begin{array}{c}\text { Spring Population } \\
\text { (April-July) } \\
102 \text { Specimens : } 33 \text { Males, } \\
69 \text { Females }\end{array}$} & \multicolumn{3}{|c|}{$\begin{array}{c}\text { Fall Population } \\
\text { (August-November) } \\
112 \text { Specimens: } 33 \text { Males, } \\
77 \text { Females }\end{array}$} \\
\hline No. & Type & & $\begin{array}{l}\text { Num- } \\
\text { ber of } \\
\text { Speci- } \\
\text { mens }\end{array}$ & $\begin{array}{l}\text { Percent- } \\
\text { age of } \\
\text { Males } \\
\text { and } \\
\text { Females } \\
\text { in Class }\end{array}$ & $\begin{array}{l}\text { Percent- } \\
\text { age of } \\
\text { Total } \\
\text { Speci- } \\
\text { mens } \\
\text { in Class }\end{array}$ & $\begin{array}{l}\text { Num- } \\
\text { ber of } \\
\text { Speci- } \\
\text { mens }\end{array}$ & $\begin{array}{l}\text { Percent- } \\
\text { age of } \\
\text { Males } \\
\text { and } \\
\text { Females } \\
\text { in Class }\end{array}$ & $\begin{array}{l}\text { Percent- } \\
\text { age of } \\
\text { Total } \\
\text { Speci- } \\
\text { mens } \\
\text { in Class }\end{array}$ \\
\hline I & AVaw4 & $\begin{array}{l}\hat{0} \\
\hat{+}\end{array}$ & $\begin{array}{l}1 \\
0\end{array}$ & $\begin{array}{l}3.03 \\
0.00\end{array}$ & 0.98 & $\begin{array}{l}0 \\
0\end{array}$ & $\begin{array}{l}0.00 \\
0.00\end{array}$ & 0.00 \\
\hline II & AVaw3 & $\begin{array}{l}\hat{O} \\
\text { o }\end{array}$ & $\begin{array}{r}21 \\
7\end{array}$ & $\begin{array}{l}63.63 \\
10.15\end{array}$ & 27.44 & $\begin{array}{r}21 \\
3\end{array}$ & $\begin{array}{r}60.00 \\
9.30\end{array}$ & 21.43 \\
\hline III & AVbw3 & $\begin{array}{l}\hat{o} \\
\grave{+}\end{array}$ & $\begin{array}{r}3 \\
25\end{array}$ & $\begin{array}{r}9.09 \\
36.25\end{array}$ & 27.44 & $\begin{array}{l}11 \\
70\end{array}$ & $\begin{array}{l}31.43 \\
90.91\end{array}$ & 72.32 \\
\hline IV & $\mathrm{AV}$ ew 3 & $\begin{array}{l}\hat{O} \\
\stackrel{+}{o}\end{array}$ & $\begin{array}{r}4 \\
12\end{array}$ & $\begin{array}{l}12.12 \\
17.40\end{array}$ & 15.68 & $\begin{array}{l}1 \\
3\end{array}$ & $\begin{array}{l}2.86 \\
3.90\end{array}$ & 3.57 \\
\hline $\mathrm{V}$ & AVdw3 & $\begin{array}{l}\hat{O} \\
\stackrel{+}{+}\end{array}$ & $\begin{array}{r}2 \\
12\end{array}$ & $\begin{array}{r}6.06 \\
17.40\end{array}$ & 13.72 & $\begin{array}{l}1 \\
1\end{array}$ & $\begin{array}{l}2.86 \\
1.30\end{array}$ & 1.78 \\
\hline VI & $\mathrm{AVd} y 3$ & $\begin{array}{l}\hat{o} \\
\hat{q}\end{array}$ & $\begin{array}{l}0 \\
1 .\end{array}$ & $\begin{array}{l}0.00 \\
1.45\end{array}$ & 0.98 & $\begin{array}{l}0 \\
0\end{array}$ & $\begin{array}{l}0.00 \\
0.00\end{array}$ & 0.00 \\
\hline VII & AWaw3 & $\begin{array}{l}\hat{0} \\
0 \\
+\end{array}$ & $\begin{array}{l}2 \\
1\end{array}$ & $\begin{array}{l}6.06 \\
1.45\end{array}$ & 2.49 & $\begin{array}{l}0 \\
0\end{array}$ & $\begin{array}{l}0.00 \\
0.00\end{array}$ & 0.00 \\
\hline VIII & AWbw3 & $\begin{array}{l}\hat{o} \\
\stackrel{+}{+}\end{array}$ & $\begin{array}{l}0 \\
9\end{array}$ & $\begin{array}{r}0.00 \\
13.05\end{array}$ & 8.82 & $\begin{array}{l}0 \\
0\end{array}$ & $\begin{array}{l}0.00 \\
0.00\end{array}$ & 0.00 \\
\hline IX & AW cw 3 & $\begin{array}{l}\hat{o} \\
\stackrel{+}{+}\end{array}$ & $\begin{array}{l}0 \\
1\end{array}$ & $\begin{array}{l}0.00 \\
1.45\end{array}$ & 0.98 & $\begin{array}{l}0 \\
0\end{array}$ & $\begin{array}{l}0.00 \\
0.00\end{array}$ & 0.00 \\
\hline$X$ & AWdw3 & $\begin{array}{l}\hat{O} \\
\text { Q }\end{array}$ & $\begin{array}{l}0 \\
1\end{array}$ & $\begin{array}{l}0.00 \\
1.45\end{array}$ & 0.98 & $\begin{array}{l}0 \\
0\end{array}$ & $\begin{array}{l}0.00 \\
0.00\end{array}$ & 0.00 \\
\hline$X I$ & AWfw3 & $\begin{array}{l}\hat{O} \\
\stackrel{+}{+}\end{array}$ & $\begin{array}{l}0 \\
0\end{array}$ & $\begin{array}{l}0.00 \\
0.00\end{array}$ & 0.00 & $\begin{array}{l}1 \\
0\end{array}$ & $\begin{array}{l}2.86 \\
0.00\end{array}$ & 0.89 \\
\hline
\end{tabular}

females as males. It is therefore apparent that the males of both populations tend to be somewhat darker than the females. Specimens of the fall population tend on the whole to be slightly lighter than those of the spring population, since 72 per cent of the material is of class III. By combining classes II and III it is evident that 55 per cent of the specimens of the spring population and 94 per cent of the specimens of the fall population are representative of this combination. 
By plotting the combinations of "variant" symbols against the successive weeks of the collecting season (Table XIV), it is apparent that classes II and III are evenly dispersed through the period of maturity of both the spring and fall populations. Although the two populations differ somewhat in behavior, as is pointed out below, it may be concluded from the morphological data that two generations of a single predominant variant class of Gryllulus assimilis are found on the Reserve. These populations fall best into the "standard" variant pennsylvanicus, which as indicated by Rehn and Hebard (1915 : 302) has the characteristics "AV (normally a or b but ranging to $f, x$ but often $\mathrm{u}$ ), 3." These authors stated of pennsylvanicus that "great variability is exhibited and every integradation with the variants termed neglectus and luctuosus is to be found." The sixteen individuals of classes VI to XI represent a trend toward the "standard" variant termed luctuosus.

During 1939, a cage experiment was conducted in order to determine whether or not members of the spring population could give rise to individuals of the fall population. A piece of coarse-mesh wire (to prevent the possibility of ground squirrels digging into the cage from beneath and liberating my captives) was laid in the bottom of a three-inch hole covering an area of four square feet of the typical habitat of the spring population. Into this hole there was inserted a covered cage, two feet by two feet by one foot, made of No. 40 mesh brass wire. The soil removed while digging the hole was boiled for twenty minutes in order to kill any cricket eggs or other organisms which might have been present and was then placed in the cage. Four holes were excavated in the soil as retreats for the crickets. On June 9 seven pairs of the spring population of Gryllulus were introduced into the cage.

Except for the absence of vegetation, conditions in the cage were made to simulate the natural environment as closely as possible. Food, in the form of meat, seeds, bran, and other items of diet which the crickets relish was supplied in amounts greater than were consumed by the captives and their progeny. Innumerable young hatched in the cage; but, although they flourished, not one reached maturity that fall. On December 16 the contents of the cage were carefully checked, and only half-grown, hibernating juveniles were found.

It may be argued that had the adults been caged earlier during the spring the young might have matured late in the fall. Folsom and Woke (1939) have shown that in Louisiana the common field cricket requires from seventeen to thirty-one days for incubation, and that sixty-three to one hundred and eight days elapse before the young reach maturity. In 1939 the first adults of the spring population were heard singing on May 21. If one assumes that eggs are laid as soon as the females become adult and allows the 
minimum time for incubation and growth, young hatched from eggs laid on May 21 would develop into adults by about August 8. Folsom and Woke stated that in Louisiana overwintering young mature in late April, and that young hatched from eggs laid by this generation reach maturity about the last week in July (about two weeks prior to the appearance of the fall population on the Reserve). These authors further stated that the periods of incubation and development are definitely lengthened by lower temperatures. Since Michigan is so much farther north than Louisiana and has definitely lower daily average temperatures and a shorter growing season, one would naturally anticipate that more time would be required for the development of each generation in this region. This conclusion is supported by the results of Severin's studies (1926, 1935) on Gryllulus assimilis in South Dakota. Severin found that in that state the species requires a full year to complete its life cycle; and this is in agreement with the results of my own observations and experiments on the Reserve. Severin's further conclusion-that since in South Dakota (and hence in Michigan) the spring and fall populations would appear to constitute separate "breeding groups," they may also represent two distinct "biological races"-is one which may be justified, but with which I am not yet ready to concur without reservation, in the light of the morphological data presented above. Further investigation is evidently called for, and the possibility of there being sufficient overlapping of the two generations to ensure intermingling of their characterisitics must not be overlooked. It is, furthermore, still uncertain how much the apparent differences in behavior between the two populations may be owing to differences in density of population and other environmental effects.

SEASONAL APPEARANCE.-The spring population begins to mature about the last week of May. In this population appearance of adults is sudden and often occurs overnight. Many males were heard on the night of May 21, 1939, although not a single song had been noted up to that time. Maximum abundance of adults, however, is not attained for about two weeks. About the last week of June the adults begin to die off; and by the middle of July few are left. It is possible that a few may survive until, or even for a short time after, the fall population makes its appearance. The fall group begins to mature in the first week of August, and the adult population reaches its maximum rather rapidly, in about ten days. Maximum abundance is maintained until the end of September, at which time the onset of cold weather causes a rapid drop in numbers. .Each frost kills a part of the remaining individuals, and all adults disappear before the end of November. The smaller number of individuals that make up the spring population is probably due to the high mortality of hibernating nymphs, demonstrated by Folsom and Woke (1939). 
Habitat Relations.-The common field cricket is strongly affected by high temperatures. Chapman (1926: 421) stated that specimens of this cricket, when placed in the direct rays of the sun, die in a few minutes. In very hot weather Gryllulus sings almost entirely at night, in the early hours of the morning and again in the evening; only an occasional well-protected male will sing during the heat of the day. Extremes of humidity have also been observed to limit choice of environments. This is indicated by the fact that caged specimens cease to sing and exhibit other symptoms of distress when exposed to a very dry atmosphere, while on the other hand, although occurring typically very close to the margins of swamps and marshes, these crickets very rarely enter hydric habitats. Those which take shelter in piles of dead leaves always occur in greatest abundance around the periphery of the piles, where the leaves are not wet or soggy. Oviposition is apparently limited to the sandy soils of the upland, juveniles having been found nowhere else on the Reserve.

Owing to these habitat requirements, Gryllulus is confined to such dry situations as afford plenty of shelter. It is found characteristically in the mixed grass-herbaceous habitat, but only where either mammal burrows or mats of dead vegetation are present. It occurs as a sporadic in areas of the sparsely vegetated sand habitat which have enough retreats to offer sufficient protection.

In the fall, the common field cricket becomes very abundant on the Reserve; so much so that individuals are forced to move about seeking places of concealment. As a result large numbers are found along the margins of the forests where the individuals hide under piles of leaves and dead branches. The crickets seldom penetrate far into the woods, however, except in the sunny oak-hickory habitat. The spring and early summer population is much less numerous, and the abundance of available retreats makes it unnecessary for them to move about in search of unoccupied places in which to hide. Probably for this reason in spring and early summer this insect has never been found elsewhere than in the mixed grass-herbaceous habitat.

HABITs.-Gryllulus assimilis is omnivorous and probably should rank as a scavenger. Caged specimens of the spring population eat moist bran avidly and will eat a molting field cricket with just as much relish. Individuals have been observed feeding upon dead field mice and dead insects.

This species is active both day and night, but especially so in late afternoon and early evening, when the temperature has begun to fall, but before the chill of night has set in. On warm nights inging is probably continued most of the night, as the chirping has been heard as late as 1 A.m. and as early as 5 A.m. As the temperature rises during the morning, activity of the species gradually lessens, and the crickets retire to places of protection. On 
a hot day most of the singing has ceased by ten o'clock in the morning, but an occasional muffled call of a well hidden individual may be heard until the temperature begins to drop in the afternoon and general singing and activity are resumed. Individuals of the spring population placed in cages well protected from the sun behave in the same way, their activity decreasing through the day and becoming marked in the evening.

Members of the spring population are quite solitary when compared with those of the fall population. Males more often seek out the entrance to a mammal burrow in which to hide. The burrows or refuges of the males are comrnonly situated from six to fifteen feet apart. Their spacing and distribution present a picture suggestive of the home ranges of certain birds and mammals, and I believe that future studies will show that these insects exhibit the same phenomenon of territoriality in a primitive form. The males of the spring population are very aggressive, as demonstrated by observation of caged specimens. Whenever one male approaches another to within two to four inches, one or both will raise the tegmina at about one-half the angle used for normal singing, give forth a shrill, continuous, highpitched call, and dash to attack. The challenged male turns to meet the aggressor, and the two then feint at each other with the mandibles, pull and tug, and bite. Two males were observed on one occasion to cross mandibles and then rear back and pull, all the while giving their ringing battle cry. Occassionally a male may recognize the superiority of the challenger and retreat at once, emitting only a few sharp, "angry" chirps. Such a retreating male is sure to get a few sharp nips on the abdomen, wings, or hind legs, spurring on his flight. Caged females have never been observed to charge or bite either males or other females, and males have never been observed to attack females.

The only occasion on which a member of the spring population was watched in the field without disturbing it was on a cloudy day in June; a female was seen to crawl from under a mass of dead grass, walk with a steady regular gait for about fourteen inches and then disappear under another mass of dead grass. In the laboratory, caged individuals of this population seem to wander about much as do the members of the fall population.

Individuals of the fall population are for the most part gregarious, although many specimens have been taken without others being found near-by. As menny as twenty-six have been captured in a small pile of leaves. I have never observed individuals of this population assuming an antagonistic attitude toward other individuals. In watching the normal movements and activities of the species the females are seen much oftener than are the males. During periods of activity both sexes run from place to place in a haphazard way. An individual will run in a jerky fashion for a few inches, investigate 
some feature of its surroundings, perhaps go on a little farther, and then may even turn around and retrace its steps. When disturbed, it usually leaps one to four times, covering one to four feet at each leap, and then burrows down into the grass or debris. In jumping it displays no sense of direction, and after several leaps the cricket may be in exactly the same place from which it started.

Except for the loud, clear, ringing "shrill" of an angry male of the spring population, I have been unable to detect any difference between the songs of the two populations. The song is a clear, sharp note which, given at regular intervals, might be represented as "geee geee geee geee" or as "deee deee deee deee." The rate at which these notes are emitted varies considerably both from individual to individual and with changes in temperature. Three males were timed within a period of ten minutes about 4 P.M. One was singing at the rate of 128 notes per minute, the second at 156 , and the third at 188 . At $79^{\circ} \mathrm{F}$. (six inches above ground) a male was timed at 120 notes per minute. Another male was observed wandering about near-by at this same time. His song was alternately jerky and rhythmical, the jerky notes being produced whenever he was running from place to place, and the rhythmical notes when he was standing still. The first count on this male gave 130 notes per minute. Abruptly this rose to such a rapid rate that I was unable to count the beats. The song then dropped to 153 notes per minute. The average number of notes per minute was between 120 and 130 . At a temperature of $53^{\circ} \mathrm{F}$. (six inches above ground) a male was timed at 88 notes per minute.

The following account of mating behavior applies to both the spring and fall populations. A male and female of the fall population were caged, the male having been taken five days before the female. When observations were begun the female was cleaning her left hind femora. She was lying on her abdomen and right hind leg and was chewing on the tibia of the left hind leg. Suddenly she stood up, rocked back, and with her mouth parts extracted a spermatophore ( the first of the series here recorded) from the genital chamber. Meantime the male was singing in a normal way. After eating the spermatophore, the female walked up behind the male, which ceased singing, and backing in under her, immediately started copulation. The female stood slightly to the right of the male so that the legs on the right side of her body were resting on the ground. Her left front leg rested upon the male's pronotum, her left middle leg was on the ground between the male's left hind leg and abdomen, her left hind leg was on the ground to the left of the male. During transfer of the spermatophore the male's right antenna whirled in clockwise motion, his left antenna counterclockwise; his cerci waved up and down. Aside from these movements neither individual stirred. The transfer of the spermatophore (the second 
in this series) required one minute. Following this the female remained motionless for fourteen minutes; the male, after moving out from under the female, also remained still. Four minutes after copulation I noted a new spermatophore at the tip of the male's abdomen. Twenty minutes after copulation the male raised his subgenital plate and concealed the new spermatophore. At the same time he began to chirp at very irregular intervals and to sidle up to the female. Occasionally he leaped at and upon her. Twenty-five minutes later the male began to sing normally, and the female at the same time tipped her abdomen forward, bent down, and seized the spermatophore, which had been lodged in her genital chamber for fortyfive minutes. In so doing she fell over backwards; righting herself, she walked to the center of the cage and ate the spermatophore. The male, still singing, backed up to her, turned about a little, stopped singing, leaped straight up in the air for about one-half inch, resumed his preceding position, backed under the female, and copulated. Transfer of this third spermatophore required one minute and three seconds; as soon as it was accomplished the male crawled out from beneath the female. Four minutes later he extruded his genitalia and worked the parts about. A pair of appendages was exposed, so placed that a hollow groove was formed. In this groove a white mass appeared, and by working of the appendages it was molded into a spermatophore. At the end of six minutes this structure was complete, and ten minutes later the male concealed it within his genital chamber. About an hour later the female was seen with the third or a fourth spermatophore attached to her. To judge from what had previously occurred it appears likely that this spermatophore was a new one; so that during a period of two hours and ten minutes at least three and possibly four spermatophores were transferred.

Reference.--Rehn and Hebard, 1915.

GRYLLIDAE, NEMOBIINAE

\section{Nemobius fasciatus (DEGEER) AND ITS RACES}

The small ground cricket, Nemobius fasciatus, is of more than usual interest because it presents one of the most clearly demonstrated instances of a species that is differentiated into physiological races. The classical studies of Fulton $(1931,1933,1937)$ have not only brought this out, but have also left relatively little to be learned concerning the habits and ecological distribution of these races. All three of them, fasciatus fasciatus, fasciatus socius, and fasciatus tinnulus, have been observed on the Reserve, the two latter being here reported for the first time from Michigan.

Morphologically, these races are very similar, being distinguished only by average differences; the range of variation in each is sufficient to cause wide overlapping of characteristics, so that only the extremes of structural 
and colorational features of each race can be certainly recognized. The real distinctions between the races lie in their very different songs and habitat preferences. Further evidence of the reality of these races has been presented by Fulton (1933) in a study of their genetic behavior. He found that while individuals of any one race would mate (sometimes only reluctantly) with those of the others, fertile eggs were obtained only from the fasciatus $\times$ tinnulus cross; males produced from these eggs in a few cases possess an intermediate type of song which is easily recognizable as different from that of either of the parents. Since socius can apparently breed with neither of the other two races, and since during long continued field observations none of the students familiar with the songs of fasciatus and tinnulus has ever heard an intermediate type of song, it appears that in nature the three races never or at most very rarely intergrade. My own observations show that on the Reserve they are quite distinct entities.

Individuals of all the races are active, and in most of their activities are very similar. All are active both by day and by night. They react positively to a white net held close to them and when "herded" toward it will leap into the net bag. Unlike N. griseus, when the collector's hand is clapped down over them they will attempt to escape by crawling up between the parted fingers, where they may easily be caught. During the hottest part of the day they seek concealment beneath debris at the bases of plants, whence they can be flushed readily by simply kicking the plant. An individual thus disturbed will leap away in a series of rapid, aimless leaps. These jumps, each covering twelve to fifteen inches, carry the individual along a zigzag course for a distance of ten to fifteen feet, after which the cricket crawls beneath a plant. It may be flushed a second time by merely brushing the top of the plant with a net handle. This time the leaps rapidly become shorter and slower, and the cricket, soon tiring, may often be picked up with the fingers. In singing, males of all three races hold their tegmina at an angle of about 45 degrees over the back. Features in which differences in behavior were noted between typical fasciatus, tinnulus and socius, or which have been observed only in some one of the three are treated under the individual races.

\section{Nemobius fasciatus fasciatus (DeGeer) Striped Ground Cricket}

On the Reserve this race is decidedly an inhabitant of the xeric uplands. It is one of the most abundant characteristic species of the mixed grass-herbaceous habitat, but also occurs as a sporadic in the sparsely vegetated sand habitat. In the latter environment, together with Nemobius g. griseus it seeks shelter beneath the bases of plants, and is active only in the late afternoon and at night except on cloudy days. Certain individuals found in the 
sunny oak-hickory habitat have been puzzling to treat, since their songs were not heard; because of the nature of the habitat they could scarcely be socius, but they might represent either isolated individuals of tinnulus or erratics of fasciatus. No colonies of the former were found near-by, and hence the second determination is believed to be correct. Fulton (1933: 369) stated that whereas socius in the northern states is confined to low ground and wet situations, and tinnulus is a woodland race characteristic of the more open types of forest and of forest margins, fasciatus is intermediate in its habitat preferences: "It is associated with grass, but may live in open woodland or under trees where there is enough light to permit a good growth of grass ... [In the] northern states it is the most common race and occurs in both open and partly shaded places, but is scarce or absent on poorly drained ground where socius lives." My observations on the Reserve accord well with these generalizations.

Winter is passed in the egg stage. The young are abundant in the uplancls during late June and July. The earliest record of adults is July 28. $N$. $f$. fasciatus does not attain maximum abundance until the first week of August. From that time on until late September the species is abundant in its favorite habitat. The frosts of September and October cut down its numbers, but individuals are fairly numerous as late as October 25 .

The song of this race when sung at full speed is a high-pitched, steady tinkling, slightly bouncing trill. At close range, (within one or two feet) it is accompanied by an undertone of low, rasping, scarcely audible notes. Occasionally a sharp "teek" is emitted, as though the tegmina moving at such a rapid rate had suddenly slipped. The song is broken by a very slight pause at varying intervals. A male was heard to introduce these pauses in his song four times in fifteen seconds, and one minute later five times in fifteen seconds. Individual notes are given so rapidly that I have found it impossible to count them, or even to form an accurate estimate by the method of pencil tapping. Fulton (1931: 221) estimated the normal rate under average temperature conditions at twelve to fifteen per second. Later (1983: 373), by means of an ingenious vibrator combined with a kymograph, which could be synchronized with the songs of caged specimens, he determined that, for the North Carolina individuals tested, the chirping rate ranged from about five per second at $50^{\circ} \mathrm{F}$. to about fifteen per second at $80^{\circ} \mathrm{F}$., and averaging between seven and eleven per second in the temperature range from $60-70^{\circ} \mathrm{F}$. During cold weather and on damp, chilly days and nights the song rate is very noticeably slowed down in the field, and at such times the song is almost indistinguishable from the normal song of tinnulus. As in the instance of Gryllulus assimilis, in exceptionally warm weather $N$. fasciatus almost ceases to sing during the hotter parts of the day.

One day in early October, while bending over to collect a plant, I heard 
a cricket song with which I was not familiar. Upon investigation the singer was found to be a male of fasciatus. He was very excited, and raced back and forth in all directions over a distance of from two to four inches. Hurrying to one spot, he would then stop and turn about in all directions. His antennae moved rapidly, and the tip of his abdomen, bearing a spermatophore, was continuously raised up and down. The tegmina were held in singing position and were shuffling as though in normal song, but I could hear only an occasional "teek." I timed this note for three-quarters of a minute and heard only two "teeks" in the first fifteen seconds and two more in the last thirty. After two and one-half minutes in the excited state, the male became quieter, finally stopped under a tiny canopy of grass blades, rocked back on his hind legs, bent his abdomen down and forward, grasped and ate the spermatophore. He then broke into the fast trill characteristic of fasciatus. A female was then noticed near-by, running by fits and starts, up to various tiny fragments of vegetation, which she investigated, but did not eat. The male, observing her, immediately changed his song to the almost inaudible type described above and rushed toward her. The female appeared startled, and hastily retreated behind a clump of grass about six inches away. The male, thus, evaded, increased his song a trifle in loudness and began to cast about here and there. The female turned around and hastily retracing her steps, moved toward the male, whose song became totally inaudible to me. The pair crossed antennae; the female then resumed her previous occupation of examining plants, stones, and particles of dirt, while the male retreated to his canopy and again burst into the typical song. On the basis of these observations there is every reason to believe that the almost inaudible type of song represents a mating or courting performance, and that the loud, ringing trill is a calling song.

$N$. f. fasciatus has been observed to feed upon the dead body of a deermouse (Peromyscus) in an upland field, and also upon a dead female Melanoplus f-r. femur-rubrum.

Of the many specimens of this race taken on the Reserve, only 5 per cent are of the long-winged phase.

References.-Fulton, 1931, 1933, 1937.

\section{Nemobius fasciatus socius Scudder Marsh Field Cricket}

This small black cricket is first heard on the Reserve during the latter part of July. Adults were found as early as July 20, and were still common on October 14. In spite of the relatively early appearance of adults, the bulk of the population of this race matures slowly, and maximum abundance is not reached until mid-August. There is no reason to suppose that in southern Michigan this insect is double-brooded, although Fulton (1933: 
368) has found it to be in North Carolina. In that region its seasonal relations are quite different from those of the other two races, which seem to be single-brooded and mature in late fall. My observations on the Reserve suggest that even in Michigan, with its shorter season, something of this difference in seasonal behavior between socius and the others may be detected.

On the George Reserve Nemobius $f$. socius is characteristic of the wetterrestrial stratum of the permanent marsh and the semipermanent marsh habitats. In the hydric environments it occurs on almost every type of wet soil except acid soils such as the Greenwood peat of the bog habitat. The race is inclined to stay close within its favorite habitat, and has been taken as an erratic but once, when, in 1938, several specimens were found in moist crevices between the concrete wallks and the sod on the lawn back of the custodian's house. Mr. Camburn informed me that he had spread heavy, black, marsh soil over this portion of his lawn; eggs of socius were probably carried in with the muck, and the insects were able to survive through one season in the crevices along the walk. This same situation was examined for socius several times during 1939, but the species had disappeared.

In general, the habits of this race are the same as those described for typical fasciatus. The song, however, is totally different. It consists of a clear, loud series of notes which may be written as- "zeeep! zeeep ! zeeep!" and is much lower in pitch and far slower in delivery than the songs of either fasciatus or tinnulus. Fulton (1933: 368) said concerning the song of socius: "Its notes are produced by a rapid vibration of the tegmina as they are brought together. This vibration only becomes apparent when movernent is retarded by low temperature. The notes have a slower frequency and a more buzzing, less musical quality than the other two races." I have observed that the rate of singing varies from one minute to the next, and from individual to individual; different males in the same colony may sing from three notes per second to fourteen per five seconds. One male may sing slowly for a while, then speed up and again slow down at will. The intervals between the notes are about one-half as long as the "zeeep." The song is continued for indefinite periods of time.

On September 8, a male of socius was heard singing. Suddenly he gave forth two or three loud, clear, ringing, "angry" notes, which were about a second in length. The typical song was then resumed. These harsh notes reminded me of the fighting calls of the spring population of Gryllulus and may represent the same type of call.

Three long-winged males were taken on the Reserve, two on August 9 and one on September 13, 1938. All other specimens from this area are brachypterous.

References.-Fulton, 1931, 1933, 1937. 


\section{Nemobius fasciatus tinnulus Fulton}

Because of the small area of suitable habitat on the Reserve tinnulus is far less common than either fasciatus or socius, although it is abundant in the three locations in which it has been found. This race is characteristic of the sunny oak-hickory habitat, and has not been found with certainty in any other environment. A few specimens which may possibly represent erratics were collected in a strip of mixed grass-herbaceous upland within ten feet of a known colony of tinnulus. Although typical fasciatus also occurred near-by, the suspected erratics are slightly lighter in color than fasciatus and probably belong to the woodland race.

Adult individuals were taken in company with late instars on August 9. The last actual record of specimens taken on the Reserve is September 23, but the insect was quite common on that date, and undoubtedly occurs until sometime in October. Hibernation takes place in the egg stage.

The song of tinnulus as heard on the Reserve is identical with that of typical fasciatus, except that the notes are given only about one-half as fast. Fulton (1931: 221) estimated that rate as usually six to nine notes per second. Later (1933: 373), in connection with his study of the inheritance of song in crosses between tinnulus and fasciatus, he actually measured the rate (as described under the typical race), and found it to range from four per second at $50^{\circ} \mathrm{F}$. to seven per second at $80^{\circ} \mathrm{F}$., averaging about six per second at around $70^{\circ} \mathrm{F}$. He describes the songs of fasciatus and tinnulus as sharp, single-stroke chirps, in contrast to the buzzing, multiple-stroke chirps of socius.

All definitely determined specimens of tinnulus from the Reserve are brachypterous.

References.-Fulton, 1931, 1933, 1937.

\section{Nemobius griseus griseus E. M. Walker Gray Sand Cricket}

Surpassed only by Nemobius c. palustris in specificity of habitat requirements, the gray sand cricket is of very restricted occurrence on the Reserve. In this area it has been found only in the sparsely vegetated sand habitat. Here griseus conceals itself during the day beneath the debris and dead leaves that collect about the panic grass rosettes. Not all clumps of Panicum harbor the species, but only those in which the rosettes and associated debris measure eight inches or more in diameter. As will be seen by what follows, the smaller clumps evidently do not give the necessary amount of shelter. Small groups of this species have also been found in the same habitat beneath seedling oaks three to six feet high. Taller oaks usually have their branches farther from the ground, so that the accumulations of dead leaves and debris in which griseus hides do not form beneath them. 
It is evident that Nemobius griseus cannot tolerate high humidity, since it is restricted to the most xeric environment on the Reserve. On the other hand it cannot withstand the very high temperatures reached during the day on the exposed sands of its characteristic environment, and is probably equal y adapted to the high evaporation rates prevailing in this habitat. An experiment was tried, in which individuals of griseus were placed in a one-giallon glass container with an inch of sand in the bottom, left uncovered in the sun on an exposed area in the habitat. The temperature of the soil in this jar, and that of the surface soil outside, reached $110^{\circ} \mathrm{F}$., and the crickets placed in the jar at this temperature died in less than three minutes. At the same time the temperature beneath the dead leaves under the small oaks and under panic grass rosettes was only $84^{\circ} \mathrm{F}$.

The earliest record which I have of adults of the gray sand cricket is July 28. However, the adult population is rather slow in appearing, and maximum abundance is not attained for about two weeks. Young have been collected as late as August 9. The species is hardy and can successfully withstand a number of fall frosts. A single female was collected as late as October 7. Winter is passed in the egg stage.

$N$. griseus is less active than $N$. fasciatus. It will not flush until the collector has removed a large part of the clump of leaves and debris in which it is hiding. When it is finally forced to leave, it may do any of several things. Sometimes it will give a quick leap covering six to ten inches that carries it directly away from the source of disturbance; this may be followed by a second leap that brings it back to the original hiding place, where it then attempts to burrow beneath the remaining debris. On other occasions the cricket will jump one or two inches and then try to hide. Unlike all the other species of Nemobius on the Reserve, griseus is not at all attracted by the net bag. Instead of leaping into the net it tries to crawl under the rim and take shelter beneath the cloth. This species also reacts differently when a cupped hand is clapped over it. Instead of attempting to escape between the fingers, the cricket works back in under the hollow of the palm and quietly accepts it as a retreat.

The gray sand cricket is inactive during the day unless the sky is heavily clouded. Then, as at night, it comes out of hiding and wanders about the sand of its habitat. I have never succeeded in hearing the song in spite of many attempts. Caged specimens did not sing, and no songs attributable to the species have ever been heard in the field. Walker (1904) said that "the shirp of the male is a feeble continuous trill, more high pitched and much shorter than that of fasciatus."

All the material of griseus from the Reserve is brachypterous.

Reference.-Blatchley, 1920 : 678 . 


\section{Nemobius cubensis palustris Blatchley Sphagnum Cricket}

This dainty little cricket is the smallest, and to me the most interesting, member of the genus Nemobius present on the Reserve. Extremely abundant in its characteristic haunts, it would easily be the most abundant orthopteran on the area if its habitat were more extensive. The sphagnum cricket, found only in and on sphagnum moss, occurs on the Reserve wherever this plant grows. This restricts it to the bog habitat and to a small area (containing only a few square feet) in the permanent marsh habitat at the east end of the lake.

Nemobius c. palustris hatches late in June. On June 24, countless numbers of very small young were on and in sphagnum. Most of these juveniles were hidden in the nooks and crannies of the hummocks of moss and were found only by kneading and pressing the plants about. Gradually the tiny crickets worked their way up to the top of the moss and were easily captured by means of an insect aspirator. Another method of catching them was to place a hand on the moss, whereupon several of the crickets would jump into the palm and could then be readily transferred to a net. About the second week of July the crickets begin to mature. The adults are more active and are harder to capture. They seem to be strongly attracted by the white cloth of the net bag, however, and are easily "herded" into the bag where they are then captured. The method of escape of adults, when alarmed, is to leap quickly several times, two or three inches at a jump, and then quickly burrow into the sphagnum.

Juveniles are common until the middle of August, at which time greatest abundance of adults is reached. The earliest record of an adult is July 12; the latest October 4. All material examined is brachypterous.

The song of the sphagnum cricket is a feeble, high-pitched, continuous trill, and is sounded both by day and by night.

Reference.-Fulton, 1931.

\section{Nemobius carolinus carolinus Scudder Carolina Ground Cricket}

This species is one of the most abundant members of the genus Nemobius on the Georg'e Reserve. It occurs commonly in every hydric environment of the area except the floating vegetation and the bog habitats. Its absence from the latter may be owing to the acidity of their peat soils. Only twice has the species been taken as an erratic-once in the mixed grass-herbaceous habitat and once in the sunny oak-hickory habitat. A single male was taken in each of these, both times within ten or fifteen feet of the margin of an area having the moist, black soil to which it is partial.

The Carolina ground cricket passes the winter in the egg stage. Hiber- 
nating young have never been found on the area. Juveniles, hatching in the spring, mature during the latter part of July. On the nineteenth of that month a few males were heard singing. A week later adults were common: and by the middle of August, abundant. Large numbers of young representing nearly all instars are found throughout July and August. The presence of nymphs in various stages of development during this period may be taken as evidence either that the eggs of carolinus hatch all through late spring and the early part of the summer, or that two broadly overlapping generations occur on the Reserve. I am inclined to think that the first supposition is correct, since carolinus is one of the last species to die away in the fall; specimens have been taken as late as October 25, following several severe freezes. Furthermore, these lagging individuals certainly lay eggs which do not have time to develop very far before cold weather sets in. Eggs laid so late in the fall would presumably hatch much later than those which were laid during the summer.

The Carolina ground cricket exhibits much the same behavior as the races of fasciatus. Flushed individuals leap quickly several times, usually in zigzag fashion, covering one to three feet at each jump. After several such leaps they burrow down beneath dead leaves and debris. They are attracted by a white net bag and will readily leap into it if they are slowly "herded" toward the net.

Only a single macropterous female is present among the many brachypterous specimens collected.

The song of carolinus is a clear, continuous, slightly "bouncing," highpitched trill. The best transcription seems to be "eeeeee-dee-dee-eeeeeedee-deee-deeee." The "eeeeeee" is carried as an undertone throughout the song. Speed and loudness of the song are increased as the "deee" portion is reached; the " $d$ " of the "deee" is sharp and resounding; the whole expression is slightly jerky, giving the "bouncing" effect. The entire song (i.e., the part written as "eeeeeee-dee-deeee") is repeated without break about twenty-four times per minute.

Fieference.-Fulton, 1931.

GRYLLIDAE, OECANTHINAE

\section{Oecanthus angustipennis Fitch Narrow-winged Tree Cricket}

T'his tree cricket is characteristic of the deciduous-arboreal stratum of the Reserve. It has been seen and heard on American elm, white oak, black oak, sassafras, sugar maple, and white ash. In the upland woods, the species also occurs characteristically in the tall shrub stratum, but it is not present in the low shrub-terrestrial stratum. Patches of low shrubbery near the Reserve were examined for the species, but it was not found. 
Owing to its strictly arboreal habits I was able to secure only three adults. A male was swept from beneath a tree in a marsh on August 17, 1936, and on August 25, 1938, two males were secured in a similar place. A single third size group female was swept from an oak-hickory forest floor on July 18. Aside from these specimens (all of which undoubtedly fell from trees) all of my records of angustipennis are based on song. To judge by the number of singing males the species was abundant on August 6 and still common September 21.

The song of the narrow-winged tree cricket is a series of low, plaintive phrases, and can be written as "crrreeeee-reeeee-reeeee." The "creeeee" is sounded only at the beginning of the song. Each phrase continues from one to six seconds. Males occasionally sing slowly and with intervals of from one to many seconds or even minutes between phrases. At such times the song is begun over again and again with the "creeeee" phrase-as "creeee__creeee__creeee." One male was noted to sing the individual phrases seventeen times in forty-five seconds. The songs are not synchronized into a chorus; they are usually heard only at night or on cloudy days. Males, however, were twice heard singing in perfectly clear weather, about 2 P.M., during the hottest part of the day.

Reference.-Fulton, 1915.

\section{Oecanthus niveus (DeGeer) Snowy Tree Cricket}

On summer nights from late July until mid-October, the chorus of many singing males of the snowy tree cricket may be heard in the deciduousarboreal stratum. Unlike angustipennis, niveus is often found in low shrubbery and tangles of vines. However, on the Reserve niveus is seldom taken in such situations owing to the scarcity of such environment and to the fact that most of the shrubbery is in or around the marshes and swamps. This tree cricket does not usually occur in these moist situations, except in the tree tops, where humidity is lower. The tall shrub stratum of the oakhickory woodland, however, harbors the species as abundantly as does the deciduous-arboreal stratum.

The snowy tree cricket matures on the Reserve late in July. It was first heard there on July 24, although several males were singing in Ann Arbor on the night of the twenty-first. Maximum abundance is rapidly reached, and within a week the song may be heard throughout the woodlands. The last specimens collected were taken on September 17, but the song is often heard in early October, and does not completely die away until after several heavy frosts have caused the leaves of the trees to begin dropping. Light freezes often so chill these insects that they fall from the trees. As the temperature rises the next day they become active again, and may be seen crawling up the tree trunks. 
The song of niveus is a clear, melodious "keeeee-keeeee-keeeee," repeated indefinitely. It is sung in synchronized chorus, each male being capable of lengthening or shortening the phrases of its own song so that it can join in with the rest. The individual phrases or trills of the song are much shorter and somewhat louder than those of angustipennis, and often drown out the song of that species. Singing occurs both during cloudy days and at right, and individual males have been heard to chirp occasionally on clear, hot days.

Much has been written of the song of niveus. It has been claimed that the number of beats per minute is correlated so closely with variations in temperature that by counting the beats and applying a formula to the result one may calculate the temperature. This has earned for Oecanthus niveus the sommon name of "temperature cricket."

Reference.-Fulton, 1915.

\section{Oecanthus nigricornis nigricornis F. Walker Dusky Tree Cricket}

This species seems to be no more abundant on the Reserve than $O$. pini, probably on account of the absence of large areas of plants suitable for its oviposition needs. Fulton (1915: 38) stated that it oviposits almost exclusively in plants that have a central pith surrounded by a woody outer layer. When found on the Reserve it was generally associated with dogwoods and shrubby Salix in the wet shrub-zone habitat. Occasional sporadic or erratic individuals have been found in the semipermanent marsh habitat, but always in close proximity to shrubby growths. The uplands, in which grow various species of Solidago, said by Fulton to be one of its choices for oviposition, have never yielded a specimen of nigricornis but instead, only quadripunctatus.

'The dusky tree cricket probably matures on the Reserve about midAugust. The collections made on the area contain no juveniles and few adults, and no accurate statement concerning seasonal relations of the species can therefore be made. On August 21, the earliest record for the area, the species was found in some numbers, while a single male taken September 4 represents the latest date of capture. The adults probably persist, like those of quadripunctatus, until the first frosts in middle or late September. Hebard (1937-38: 102) recorded nigricornis as becoming adult in Pennsylvania in early August, and Blatchley (1920 : 720) gave the seasonal occurrence of this race in the eastern United States as August and September.

The song is a clear, high-pitched, continuous trill, and in my experience is not separable in the field from that of quadripunctatus. It is sung both by day and by night.

In terms of the classification based on antennal markings that was pro- 
posed by Fulton (1926: 44), the specimens collected on the George Reserve fall into the following classes : class $6^{\prime}, 6.66$ per cent; class $7^{\prime}, 53.28$ per cent; class $8^{\prime}, 26.64$ per cent; class 9', 13.32 per cent.

References.-Fulton, 1915, 1926.

\section{Oecanthus nigricornis quadripunctatus Beutenmuller Four-spotted Tree Cricket}

The four-spotted tree cricket is by far the most abundant of the members of the genus Oecanthus on the Reserve. It is a characteristic and common species of the mixed grass-herbaceous habitat. Sporadics have been found in the sparsely-vegetated sand habitat, but in far smaller numbers. This is probably due to the scarcity of herbaceous plants suitable for oviposition. Very few erratics of quadripunctatus have been observed; all of these occurred in the sunny oak-hickory habitat, and only in such parts of it as are adjacent to the mixed grass-herbaceous habitat.

Although scattered males have been heard singing in the upland as early as July 24, the adult population does not reach maximum abundance until about the first week of August. The species dies away rapidly in early September, and after the middle of the month specimens can no longer be found. The latest record for the Reserve is that of a male and two females taken September 8.

The song of quadripunctatus is a clear, shrill, continuous note, in my experience inseparable in the field from that of nigricornis. The song is continued for several minutes at a time; it may be heard both at night and during the day. However, many more males are heard at night and on dull days than in bright sunlight, and when the songs are at their height the effect of a chorus may be produced.

Eggs are laid in the pith of herbaceous annuals. On the Reserve the plant which seems best suited is Anaphilus margaritacea. To determine the extent to which this herb is used for oviposition, twelve plants were collected on August 24 and examined for eggs (Table XVI). Four of the stems gave a negative result, but the other eight had been punctured by quadripunctatus. The work of this insect was easily recognized, since the punctures were always in a single row running parallel with the axis of the stem. Some of the stems had several such rows of punctures, each representing the number of punctures a single female made during one period of egg laying.

These results do not suggest that any selection between large and small stems, or even with regard to the part of the plant in which the eggs are laid, is exercised by the female. The eggs are bright lemon color, with the micropyle end white. This white cap is pointed toward the opening of the puncture. The body of the egg is slightly curved and projects upward into 
TABLE XVI

Holes Per Row, Rows Per Plant, Location of Each Row on the Plant, AND THE NUMBER OF EMPTY HOLES

\begin{tabular}{c|l|c|c}
\hline \hline Plant & \multicolumn{1}{|c|}{ Location of Row } & $\begin{array}{c}\text { Number of Holes } \\
\text { in Row }\end{array}$ & $\begin{array}{c}\text { Number of Holes } \\
\text { without Eggs }\end{array}$ \\
\hline 1 & & & \\
2 & Near base of stem & 6 & 3 \\
3 & Near crown & 4 & 1 \\
4 & Mid-stem & 9 & 0 \\
5 & Near base of plant (row 1) & 10 & 0 \\
6 & Mid-stem (row 2) & 10 & 1 \\
& Near crown (row 3) & 8 & 0 \\
7 & Lateral stem (row 1) & 5 & 1 \\
8 & Mid-stem (row 2) & 4 & 0 \\
9 & Mid-stem (row 1) & 7 & 0 \\
10 & Near crown (row 2) & 2 & 0 \\
11 & Mid-stem & & 0 \\
12 & Near base & 28 & \\
\hline
\end{tabular}

the pith. If the pithy center of the stem is small the eggs are placed in the pith parallel to the stem and with the white cap downward, facing the opening. Each opening, if an egg is present, is sealed with a tiny, mucilaginous plig.

At the time these stems of Anaphilus were studied, several other herbaceous annuals were examined for eggs, but none were found in which quadripunctatus had oviposited. One of the important limiting factors to the occurrence and abundance of this species thus appears to be the presence or absence of suitable ovipositing sites. Were Anaphilus absent from the Reserve, quadripunctatus would be at least much less abundant than it is.

The proximal joints of the antennae of the material of quadripunctatus collected on the Reserve show some variation in extent of pigmentation. When assigned to Fulton's classes the specimens collected were found to be distributed as follows: class 3, 3.7 per cent; class 4, 29.5 per cent; class 5, 66.4 per cent.

References.-Fulton, 1915, 1926.

\section{Oecanthus pini Beutenmuller ${ }^{14}$ Pine Tree Cricket}

Because of its lack of abundance and arboreal habits, published records of this species are not numerous. Almost all of these records refer to pini as occurring in the eastern states, where it is said to inhabit pitch pine (Pinus rigida) and scrub pine (Pinus virginiana). Hebard (1937-38:

14 The identification of the material of this species collected on the George Reserve has been verified by B. B. Fulton. 
102) gave the range as follows: "Northern limits are Gloucester, Massachusetts; Windham, Connecticut; Karner, New York, and Columbiana and Erie counties, Ohio ... while a southern limit is Raleigh, North Carolina." Hart and Gleason (1907: 235) have recorded the pine tree cricket from near Havana, Illinois. Regarding this record, Blatchley (1920: 724) said : "Hart has recorded it from Northwestern Illinois but (MS) reports that his specimens were not from pine and their identification uncertain." Hebard (1934) in his report on the Orthoptera of Illinois did not list the species for that state nor does he comment on Hart's record. Regardless of the doubt cast on the record, pini has been found in numerous places in Ohio and in two localities in southern Michigan. Hubbell (MS) has taken it at Milford, Michigan, and it occurs commonly on the George Reserve.

Both on the Reserve and at Milford the pine tree cricket is characteristic of the coniferous-arboreal stratum of swamps. It has never been found in either place except in tamarack. Specimens are very difficult to secure, as the species seems to prefer the upper portions of vigorous, young trees twenty to forty feet in height. Only those individuals which chance to wander low enough can be beaten from the trees and captured.

Two last instar females were collected on July 24. Since males mature slightly before the females in most of the Orthoptera, it is probable that males were already present, although none were heard. O. pini was collected and recorded (based on song) as common on August 3. The species probably lives until late September. This supposition is based on the taking of a last instar juvenile on August 14, and on songs heard as late as September 14.

The song of the pine tree cricket is shrill and continuous. Very similar to those of both nigricornis and quadripunctatus, it can be distinguished by its lower pitch as well as by its source in a tamarack; no other tree cricket occurs in this tree in Michigan.

Reference.-Fulton, 1915.

GRYLLIDAE, TRIGONIDIINAE

Anaxipha exigua (Say)

Striped Bush Cricket

Heretofore unreported from Michigan, the striped bush cricket was found to be a characteristic species of the wet shrub-zone habitat on the George Reserve. In this environment it is invariably seen or heard upon shrubby plants, its favorite being the buttonbush (Cephalanthus occidentalis), though much less often it is present on the marsh inhabiting species of dogwood (Cornus). This bush cricket has been taken in only four places on the Reserve, but each of these areas is extensive and has an abundance of the shrubs favored by this species. Other similar situations in which it 
has not been observed seem to be unsuitable in not possessing the optimum corabination of humidity and shrub growth.

A few individuals mature about the end of July, the earliest record being that of a male heard singing on July 20. Abundance of adults slowly increases to a maximum about the end of the first week of August. Juveniles remain common until about August 7. Adults of exigua are still abundant dus:ing the first week of September, but thereafter rapidly diminish until by late September the species is gone.

Anaxipha exigua sometimes appears to be an inactive insect, but on occasions it is as active as any of the species of Nemobius. It is typically thamnophilous and unless disturbed has never been seen or heard in any other but shrubby environment. Individuals seek out shady locations upon the stems and twigs of the shrubs, and as the day progresses they shift their positions so as never to become exposed to the sun's rays. They sit quietly with their antennae held straight forward, parallel to the axis of the twig upon which they rest. The hind femora and tibiae are held parallel to the surface of the twig, diverging at about a forty-five degree angle from one to another. On one occasion two females and a male were observed quietly resting in such a position. All three were on the same twig; one female an inch in front of the male and the other an inch behind him. Not the slightest movement was noted for a period of ten minutes. I then slowly moved the tip of a pencil toward them. When the pencil was about four inches away, they slowly sidled about the stem to the opposite side. Subsequently these individuals slowly moved back and forth through a distance of about two inches, meanwhile turning around once or twice as though trying to find a more comfortable position. About a minute later one of the females leaped to another twig fully a foot away. The male now became quite active. He ran up and down the twig and began to sing, although at fourteen inches distance I could not hear a single note. The male made no attempt to leap to the stem upon which the one female now rested, nor did he pay any attention to the other female sitting only an inch away from him. He soon ceased singing, stretched out and again became quiet. The striped bush cricket clings to its perch with great tenacity and is best dislodged by the beating-cloth method.

Singing is done both during the day and at night. Males do not sing in an exactly synchronized chorus, but when many are singing the result is a continuous, clear tinkling, bell-like cadence. This medley is high-pitched, and unless especially listened for will be completely missed by the collector; the songs of other crickets and katydids are lower in tone and louder, and hence are heard to the exclusion of the songs of exigua. Individual males $\sin$ g with a faint, continuous, tinkling trill that sounds like "ti-ti-ti-ti-ti." It is not audible at distances of more than ten to fifteen feet.

Reference.-Blatchley, 1920 : 730. 


\section{GRYLLIDAE, GRYLLOTALPINAE}

\section{Gryllotalpa hexadactyla Perty American Mole Cricket}

The American mole cricket is a rare insect on the Reserve. It is characteristic only of the moist hypogeic zonal stratum. From 1936 until 1939, the only place in which hexadactyla was found was a low, heavily vegetated seepage area kept constantly moist by the flow of spring water. Here in the mucky organic soil a small colony was located but not more than three or four males were ever heard singing at any one time.

During 1939 G. hexadactyla was heard singing in the muddy margins of two marshes and a pond in the southwest corner of the Reserve. On July 24 three males were heard singing in the oozy mud of the ditches along the railroad embankment. Here the mud is very soft and saturated with water. Nymphaea advena grows in a narrow belt running down the middle of the ditches. The song of the mole cricket was always traced to the edge of the ditch where organic and mineral soils met and merged. Unsuccessful attempts were made to collect all of these males. On August 7 a single male was captured. As the mud was dug away with a trowel, this male went lower and lower until, when finally located, it was fully a foot beneath the soil surface in mud from which water trickled and oozed.

This male has very abbreviate tegmina and wings. The tegmina reach only to the end of the first abdominal tergite and the wings only to the middle of the third. The presence of a juvenile about one-half inch long with the male indicates that the species has probably occupied this place prior to 1939 .

Because of the distinct possibility of destroying the colonies on the Reserve by excessive collecting, too few specimens have been taken to give any indication of the time of maximum abundance or in what stage the species hibernates. Individuals have been collected or heard from July 24 until September 14, but Hebard (1937-38: 103) stated that hexadactyla is " present from early spring until late fall."

The song of hexadactyla is heard only at night or during cloudy days. It is sounded in the confines of the cricket's burrow, and hence has a muffled, growling tone. It may be written as- "grrrr-grrrr-grrrr,"' although Morse (1920:418) recorded these notes as "querr, querr," or "gruu, gruu," and Scudder (1893: 63) stated that they sound like "grii or greeu.' Scudder also said that these notes are "repeated in a trill indefinitely, but seldom for more than two or three minutes and often less time." On the Reserve I have found that the notes are very brief, in tone and timing like those of Oecanthus niveus, although much lower in pitch. On the night of August 6 , at an air temperature of $86^{\circ} \mathrm{F}$., I noted that a male G. hexadactyla and a colony of $O$. niveus were synchronized exactly in their singing. Had it 
not been for the low-pitched, muffled tone of the mole cricket it would have been impossible to distinguish one from the other. The number of notes per second given by a male varies from one minute to another, but has been found to lie within the limits of from three to five per second.

Hebard (1934:257) suggested that G. hexadactyla may be parthenogenetic in the northern portions of its range. He based this inference upon the scarcity of males in series of the insect that he has seen from northern localities. He stated that the northernmost males he ever saw were one, of four specimens, from Kansas and one, in eleven, from Nebraska. All the specimens he examined from Illinois (31) and the northernmost record in this part of the range (a single female from Osceola, Wisconsin) are females. Hebard has overlooked the fact that of the four adult specimens recorded by Hubbell (1922: 68) from Berrien County, Michigan, three were males. Furthermore, in the Museum of Zoology at Ann Arbor there are cilmost as many males as females represented in collections from various localities in southern Michigan, and I have frequently heard the singing of males on the Reserve as well as in several localities about Ann Arbor. Since we have reason to believe that $G$. hexadactyla will not be found much farther north in Michigan than we know it at present, I am of the opinion that Hebard's supposition is erroneous, or only true in part.

Rieference.-Blatchley, 1920 : 644. 


\section{SUMMARY AND CONCLUSIONS}

1. A three-year study was made of the Orthoptera of the Edwin S. George Reserve, a tract of approximately two square miles situated on the edge of an interlobate moraine region in Livingston County, Michigan. This study was designed to form a part of the general program of investigation of the biota of the Reserve which is being undertaken under the auspices of the University of Michigan Museum of Zoology. The major purposes of my work were: (1) to obtain a complete list of the Orthoptera present on the Reserve; (2) to determine the habitats of the species and to analyze their occurrence in terms of established correlations with environmental features; (3) to develop a satisfactory classification of the orthopteran habitats of the area; (4) to determine the seasonal relations of the species present; and (5) to obtain as much incidental information on the natural history of these forms as could be gathered without interfering with the attainment of the other objectives.

2. One species of Dermaptera and seventy-five species and races of Orthoptera were found to inhabit the area. (The total list for Michigan is one hundred and thirty seven species and races.) Four of the forms taken on the Reserve had not previously been recorded from Michigan, and the first definite state records for two others were obtained. The absence of a number of species that occur in neighboring territory is attributed to the absence or poor development of their characteristic habitats on the Reserve.

3. The habitat relations of all of the species were studied in detail, and a classification of their occurrence in different situations was worked out, based on the concepts of "characteristic," "sporadic," and "erratic" occupancy of habitats. The environments of the Reserve were studied in terms of physiographic, pedologic, and phytologic characteristics and were correlated with the ecological distribution of the orthopteran species. From these data the classification of orthopteran habitats presented in this paper was derived. This classification recognizes the presence on the Reserve of three major types of environment, each with its own series of orthopteran habitats-a xeric series that includes two grassland habitats of the uplands; a mesoxeric series that includes two forest habitats of the uplands; and a hydric series that includes eight marsh, swamp, and bog habitats. It was necessary to bring into the habitat classification the concept of strata, some confined to a single major habitat and others extending through several habitats; the occurrence of the orthopteran species proves in some instances to be correlated with the major habitats, in other instances with particular strata wherever they may occur.

4. Some of the species of Orthoptera were found to be at all times restricted to particular habitats or strata, while others exhibit a changing 
relationship to habitat as the seasons progress. Spread of certain species as erratics into noncharacteristic habitats was a common occurrence, particularly in the autumn. Among the grouse locusts a hitherto undescribed phenomenon of seasonal aggregation was discovered, most of the species forming breeding assemblies in restricted areas during the spring, followed by dispersal later in the season.

5. Critical consideration of the various methods that have been proposed for determining relative abundance of populations of Orthoptera led to their being discarded as highly inaccurate and misleading; it was concluded that estimates based on long-continued observation of the species in the field, detailed knowledge of their individual peculiarities of behavior, and experience with the results of different collecting methods gave the closest approach to accuracy obtainable at present. This method of estimate was therefore adopted in this study.

6. A review of the literature on the species occurring on the Reserve showed that little of value had been recorded concerning the habitat relations and habits of most of them; such relevant information as there was has been summarized in the treatments of the individual species.

7. A large amount of data on the life history, seasonal relations, breeding habits, songs and other features of the species dealt with was obtained, and has been incorporated in the Annotated List.

Adams;, Charles C.

\section{REFERENCES}

1915 An Ecological Study of Prairie and Forest Invertebrates. Bull. Ill. Nat. Hist. Surv., 11: 33-280, 63 pls.

ALLARD, H. A.

1910 The Stridulations of Some Katydids. Proc. Biol. Soc. Wash., 23: 35-40.

1911 The Musical Habits of Some New England Orthoptera in September. Ent. News, $22: 28-39$.

1912 Variations in the Stridulations of Orthoptera. Ibid., 23: 460-62.

1929 Our Insect Instrumentalists and Their Musical Technique. Ann. Rept. Smithson. Inst., Wash., pp. 563-91, 16 pls.

$1929 a$ The Cleaning Habits of a Katydid. Amer. Nat., 63: 283-88.

BEALL, G.

1935 Study of Arthropod Populations by the Method of Sweeping. Ecology, 16: 216-25.

Bei-Bienko, G. J.

1630 Zonal and Ecological Distribution of Acrididae in the West Siberian and Zaisian Plains. Bull. Plant. Prot. U.S.S.R., Ser. 1, 1: 51-90.

BLATCHLey, WiLuis S.

1903 The Orthoptera of Indiana. An Illustrated Descriptive Catalogue of the Species Known to Occur in the State, with Bibliography, Synonymy and Descriptions of New Species. 27th Ann. Rept. Ind. Dept. of Geol. and Nat. Resources, pp. 123-471, Pls. I-II, Figs. 1-122.

1920 Orthoptera of Northeastern America, with Especial Reference to the Faunas of Indiana and Florida. Indianapolis, Ind.: Nature Pub. Co., 1920. Pp. 1-784, Pls. I-VII, Fig. 1-246. 
1924 Notes on the Orthoptera of the Eastern United States. Journ. N. Y. Ent. Soc., 32 : 127-32.

BUCKELL, E. R.

1922 Notes on the Ecological Distribution of Some Orthoptera from the Chilcotin District of British Columbia. Proc. Ent. Soc. Br. Col., No. 18: 32-38.

CANTRALL, IRVING J.

1939-40 Notes on Collecting and Studying Orthoptera. Ward's Combined Ent. and Nat. Sci. Bull., 1939-40, 13 (3-7).

1941 Notes on Collecting and Preserving Orthoptera. Part II of Compendium of Entomological Methods. Rochester: Ward's Nat. Hist. Est. Pp. 1-25, illus.

CARPenter, John R., and J. Ford

1936 The Use of Sweep Net Samples in an Ecological Survey. Journ. Soc. Br. Ent., Southampton, 1: 155-61, 2 figs.

Chapman, R. N., C. E. Mickel, J. R. Parker, G. E. Miller, and E. G. Keliy

1926 Studies in the Ecology of Sand Dune Insects. Ecology, 7: 416-26, 2 figs.

COOPER, KENNETH W.

1933 Observations on Doru aculeatum Scudder (Dermaptera). Bull. Brook. Ent.

CRIDDLE, NORMAN Soc., 28 (5) : 216, Pl. XVI.

1915 Some Inhabitants of a Sand-plain in June. Can. Ent., 47: 24-30.

1922 Manitoba Grasshoppers. Can. Field Nat., 36: 41-44, 66, 68.

1925 Field Crickets in Manitoba. Can. Ent., 57: 79-84.

1932 The Life-history of Schistocerca lineata Scud. Ibid., 64: 98-102, 3 figs.

Davis, William T.

1893 The Song of Thyreonotus. Can. Ent., 25: 108-9.

DeLong, Dwight M.

1932 Some Problems Encountered in the Estimation of Insect Populations by the Sweeping Method. Ann. Ent. Soc. Amer., 25: 13-17.

FAURE, JACOBUS C.

1932 The Phases of Locusts in South Africa. Bull. Ent. Res., 23, Pt. 3 : 293-405, Pls. XIV-XXXVIII, 1 map.

Folsom, Justus W., and P. A. Woke

1939 The Field Cricket in Relation to the Cotton Plant in Louisiana. U. S. Dept. Agr. Tech. Bull., 642: 1-28, Figs. 1-11.

Fox, Henry

1915 Notes on Orthoptera and Orthopteran Habitats in the Vicinity of Lafayette, Indiana. Proc. Ind. Acad. Sci., 1914, pp. 287-321.

1917 Field Notes on Virginia Orthoptera. Proc. U. S. Nat. Mus., 52 (2176) : 199234.

Fulton, Bentmey B.

1915 The Tree Crickets of New York: Life History and Bionomics. New York Agr. Exp. Sta. Tech. Bull., 42: 1-47, Pls. I-VI, 21 figs.

1926 Geographical Variation in the Nigricornis Group of Oecanthus (Orthoptera). Iowa State College Journ. Sci., 1 (1) : 43-62, 1 fig.

1931 A Study of the Genus Nemobius (Orthoptera: Gryllidae). Ann. Ent. Soc. Amer., 24 (2) : 205-37, Figs. 1-5.

1933 Inheritance of Song in Hybrids of Two Subspecies of Nemobius fasciatus (Orthoptera). Ibid., 26 (2) : 368-76, Fig. 1.

1937 Experimental Crossing of Subspecies in Nemobius (Orthoptera: Gryllidae). Ibid., 30: 201-17, Figs. 1-2. 
GaUsi, G. F.

1930 Studies on the Ecology of the Orthoptera. Ecology, 11 (2): 307-25, Figs. $1-6$.

1932 Ecology of Populations. Quart. Rev. Biol., 7 (1) : 27-45.

Graham, Samuel A.

1937 The Walking Stick as a Forest Defoliator. Univ. Mich. School For. and Conserv. Circ., 3 : 1-28, frontis., Figs. 1-5.

Grassé, P. P.

1929 Etude écologique et biogéographique sur les orthoptères français. Bull. biol. fr. belg., 63 (4) : 489-539.

Gray, H. E., and A. E. Treloar

1933 On the Enumeration of Insect Populations by the Method of Net Collection. Ecology, 14: 356-57, illus.

HANCOCK, JOSEPH L.

1894 Unusual Flights of the Grouse Locust (Tettigidea lateralis Say) in North Eastern Illinois. Amer. Nat., pp. 483-87, Pl. XIII.

1902 The Tettigidea of North America. Chicago. Pp. vii +188, Pls. I-XI.

1911 Nature Sketches in Temperate America. Chicago. Pp. 1-451, illus.

1916 Pink Katydids and the Inheritance of Pink Coloration (Orth.). Ent. News, 27: 70-82.

Hart, Charles A., and Henry A. Gleason

1907 On the Biology of the Sand Dune Areas of Illinois. Bull. Ill. State Lab. Nat. Hist., 7 : 137-272, Pls. VIII-XXIII.

Hebard, Morgan

1917 The Blattidae of North America, North of the Mexican Boundary. Mem. Amer. Ent. Soc., No. 2: i-vi +1-284, Pls. I-X, 1 text fig.

1925 Orthoptera of South Dakota. Proc. Acad. Nat. Sci. Phil., 77 : 33-155.

1934 The Dermaptera and Orthoptera of Illinois. Ill. Dept. Reg. Educ., Bull. Div. Nat. Hist. Surv., 20 (3) : iv + 125-279, frontis., 5 pls., 167 figs.

1935 Notes on Acrydium and the Actual Status of Three Supposedly American Species (Orthoptera, Acrididae, Acrydiinae). Ent. News, 46 (9) : 231-35.

1937-38 Where and When to Find the Orthoptera of Pennsylvania, With Notes on the Species Which in Distribution Reach Nearest This State. Ibid., 48: 219-25, 274-320; 49 : 33-38, 97-103, 155-59.

HuBbeLL, THEODORE H.

M.S Field Notes Dealing with Portions of Southern Michigan and Oklahoma (1920$34)$.

1922 The Dermaptera and Orthoptera of Berrien County, Michigan. Occ. Pap. Mus. Zool. Univ. Mich., No. 116: 1-77.

1932 [Raphidophorinae], pp. 46-51, in: M. Hebard, The Orthoptera of Minnesota. Univ. Minn. Agr. Exp. Sta., Tech. Bull., 85: 1-61, 1 map.

1936 A Monographic Revision of the Genus Ceuthophilus (Orthoptera, Gryllacrididae, Raphidophorinae). Univ. Fla. Pub., Biol. Sci., Ser. II (1) : 1-551, Pls. I-XXXVIII, 3 figs.

ISELY, F. B.

1937 Seasonal Succession, Soil Relations, Numbers, and Regional Distribution of North-eastern Texas Acridians. Ecol. Monogr., 7 (3): 317-44, 6 text figs., 3 tables.

1938 The Relations of Texas Acrididae to Plants and Soils. Ibid., 8: 551-604.

JANNCINE, GIUSEPPE

$1 \subseteq 36$ Nuovi contributi alla conoscenza della fauna delle isole italiane dell'Egeo. V. 
Studio bio-ecologico e sistematico dell'ortotterofauna con notizie sui Blattoidei e Fasmoidei. Boll. del lab. di zool. generale e agraria del R. InstiMorse, Albert P. tuto Superiore Agrario in Portici, 29: 47-248, Pl. I, Figs. I-XLVIII.

1896 Notes on the Acrididae of New England. Parts I-VII. Psyche, 7 : 232-327, 342-44, 382-84, 402-3, 407-11, 419-22, 443-45, Pl. 7.

$1896 a$ Some Notes on Locust Stridulation. Journ. N. Y. Ent. Soc., 4: 16-20.

1899 The Distribution of New England Locusts. Psyche, 8: 315-23, Pl. 8.

1904 Researches on North American Acrididae. Carnegie Inst. Wash. Publ., 18: 1-55, Pls. 1-8.

1907 Further Records on North American Acrididae. Ibid., 68: 1-54, Pls. 1-9.

1920 Manual of the Orthoptera of New England. Proc. Boston Soc. Nat. Hist., 35 : 197-556, Pls. 10-29, 99 figs.

NEFEDOV, N. I.

1933 Uber die Phanologie der Wichtigsten Heuschreckenarten in den Umgebungen von Kustanaj (N. W. Kasakstan). Bull. Inst. Rech. Biol. Perm., 8: 189204. [In Russian.]

$1933 a$ Uber die Oekologie der Eikapela der Heuschrecken (Locustodea) und die Methode zur Abundanzbestimmung der-selben. Ibid., pp. 205-22, 5 figs. [In Russian.]

1936 Contribution to the Ecology of Acrididae of Some Districts Adjacent to the Urals. The Acrididae of the Troitsk Forest-Steppe Reserve. Ibid., 10 (4) : 151-78. [In Russian.]

PARKER, J. R.

1924 Observations on the Clear-winged Grasshopper (Camnula pellucida Scudder). Univ. Minn. Agr. Exp. Sta. Bull., 214: 5-44, 6 figs.

1930 Some Effects of Temperature and Moisture upon Melanoplus mexicanus mexicanus Saussure and Camnula pellucida Scudder (Orthoptera). Univ. Mont. Agr. Exp. Sta. Bull., 223 : 5-132, 25 figs.

Piers, H.

1918 The Orthoptera of Nova Scotia; with Descriptions of the Species and Notes on Their Occurrence and Habits. Proc. and Trans. Nova Scotia Inst. Sci., 14 : 201-354, 4 pls.

RAU, PHIL.

1940 The Life History of the Wood-roach, Parcoblatta pennsylvanica DeGeer (Orthoptera: Blattidae). Ent. News, $51(1,2): 4-9,33-35$, Tables I-V.

ReHN, JAMES A. G.

1902 Records of New Jersey and Pennsylvania Orthoptera. Ent. News, 13: 309-16. Rehn, James A. G., and Morgan Hebard

1914 Studies in American Tettigoniidae (Orthoptera) I. A Synopsis of the Species of the Genus Scudderia. Trans. Amer. Ent. Soc., 40 (4) : 271-314, Pls. IX-XII.

$1914 a$ Studies in American Tettigoniidae (Orthoptera) II. A Synopsis of the Genus Amblycorypha Found in America North of Mexico. Ibid., 40 (4) : 31544, Pls. IX-XII.

1915 The Genus Gryllus (Orthoptera) as Found in America. Proc. Acad. Nat. Sci. Phil., 47 : 293-322.

$1915 a$ Studies in American Tettigoniidae (Orthoptera). III. A Synopsis of the Species of the Genus Neoconocephalus Found in America North of Mexico. Trans. Amer. Ent. Soc., 40 (4) : 365-413, Pls. XV-XVI. 
$1915 b$ Studies in American Tettigoniidae (Orthoptera). IV. A Synopsis of the Species of the Genus Orchelimum. Ibid., 41 (1): 11-83, Pls. II-IV.

$1915 c$ Studies in American Tettigoniidae (Orthoptera). V. A Synopsis of the Genus Conocephalus (Xiphidium of Authors) Found in North America North of Mexico. Ibid., 41 (2) : 155-224, Pls. XV-XX.

1916 Studies in American Tettigoniidae (Orthoptera). VII. A Revision of the Species of the Genus Atlanticus (Decticinae). Ibid., 42 (1): 33-99, Pls. VI-VIII.

Riliz, Charles V.

1874 Katydids. In: Sixth Ann. Rept. on the Insects of Missouri. Pp. 150-69.

1879 The Thick-thighed Walking-stick. Rept. U. S. Dept. Agr., 1878, 241-45, Pl. III.

ROG:IRS, J. SPEED

1942 The Craneflies (Tipulidae) of the George Reserve. Misc. Publ. Mus. Zool. Univ. Mich., No. 53: 1-128, 8 pls., 1 map.

SALJ!I, M.

1924 Osservazioni sulla ecologia di alcune species di Locustidae e Phasgonuridae. Boll. Soc. Nat. Napoli, 36, ser. II, XVI: 129-52.

SCUJDER, SAMUEL H.

1893 The Songs of Our Grasshoppers and Crickets. Ann. Rept. Ent. Soc. Ont., 23 : $62-78$.

SEvirin, HaRry C.

1926 The Common Black Field Cricket, Gryllus assimilis (Fab.), and Its Control. Journ. Econ. Ent., 19: 218-27.

1935 The Common Black Field Cricket a Serious Pest in South Dakota. S. Dak. Agr. Exp. Sta. Bull., 295: 1-51, illus.

Sevirin, Henry P., and Harry C. Severin

1911 The Life-history of the Walking-stick, Diapheromera femorata Say. Journ. Econ. Ent., 4: 307-20, 3 figs.

SHuli, A. Franklin

1911 Thysanoptera and Orthoptera. In: A. G. Ruthven. A Biological Survey of the Sand Dune Region of the South Shore of Saginaw Bay, Michigan.

Somes, M. P. Mich. Geol. and Biol. Surv., Publ. 4 (Biol. Ser. 2) : 177-231.

1914 The Acrididae of Minnesota. Univ. Minn. Agr. Exp. Sta. Tech. Bull. 141: 1-100, 4 pls., 11 figs.

STRCHECKer, H. F.

1937 An Ecological Study of Some Orthoptera of the Chicago Area. Ecology, 18 (2) : 231-50, Fig. 1, Tables I-II.

THORNTHWAITE, C. WARREN

1931 The Climates of North America According to a New Classification. Geog. Rev., 21 (4) : 133-655, Figs. 1-13, 1 map (Pl. III).

Townsend, Charles H. T.

1884 On the Courtship of the Sexes in Oedipoda carolina. Can. Ent., 16: 167-68. Trei.oAR, A. E., and H. E. Gray

1935 Note on the Enumeration of Insect Populations by the Method of Net Collection. Ecology, 16: 122 .

United States Department of Agriculture

1938 Soils of the United States. In: Soils and Men. Yearbook, Soil Survey Div., Bur. Chemistry and Soils. Pp. 1019-1161, 57 figs., map. 
URquHART, F. A.

1941 An Ecological Study of the Saltatoria of Point Pelee, Ontario. Univ. Toronto Studies, Biol. Ser., No. 50: 1-91, Pls. I-XXVII.

Uvarov, B. P.

1932 Ecological Studies on the Morocean Locust in Western Anatolia. Bull. Ent. Res., 23 (2) : 273-87, Figs. 1-6, map.

1932 a Bioclimatograph, an Improved Method of Analyzing Bioclimatic Relations of Insects. Ecology, 13: 309-11, 1 fig.

1933 Ecology of the Morocean Locust in Iraq and Syria and the Prevention of Its Outbreaks. Bull. Ent. Res., 24: 407-18, 3 figs., 1 pl.

Vestal, Arthur G.

1913 Local Distribution of Grasshoppers in Relation to Plant Associations. Biol. Bull., 25 (3) : 141-180.

Vinokurov, G. M., and J. A. RUBtov

1930 Studies on the Ecology of Grasshoppers in Irkutsk District. Bull. Irkutsk Plant Prot. Station 2, pp. 3-86.

WALker, Edmund M.

1901 Notes on Some Ontario Acrididae. Part IV. Can. Ent., 33: 20-23.

1904 The Crickets of Ontario. Ibid., 36: 142-44, 181-88, 249-55, Pl. 4.

WHEETING, L. C., and S. G. BeRgQUist

1928 Soil Survey Livingston County, Michigan. U. S. Dept. Agr., Bur. Chem. and Soils, Series 1923, No. 37: 1203-22, Fig. 40, map. 
PLATES 
PLATE I

Fig. 1. Station 11. An area of sparsely vegetated sand habitat.

Frg. 2. Station 5. Mixed grass-herbaceous habitat with an area of lichen-clad sand in the center. Oak-hickory woodland is visible in the background. 


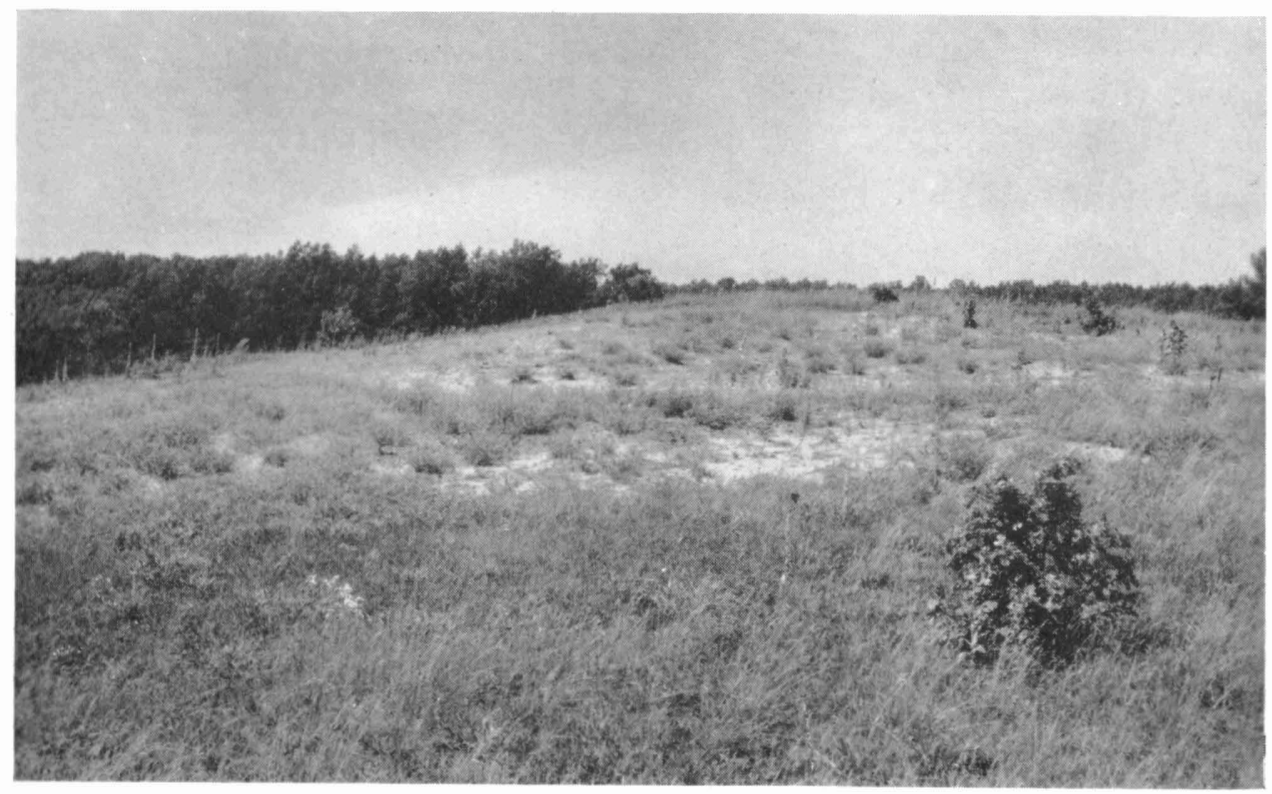

FIG. 1

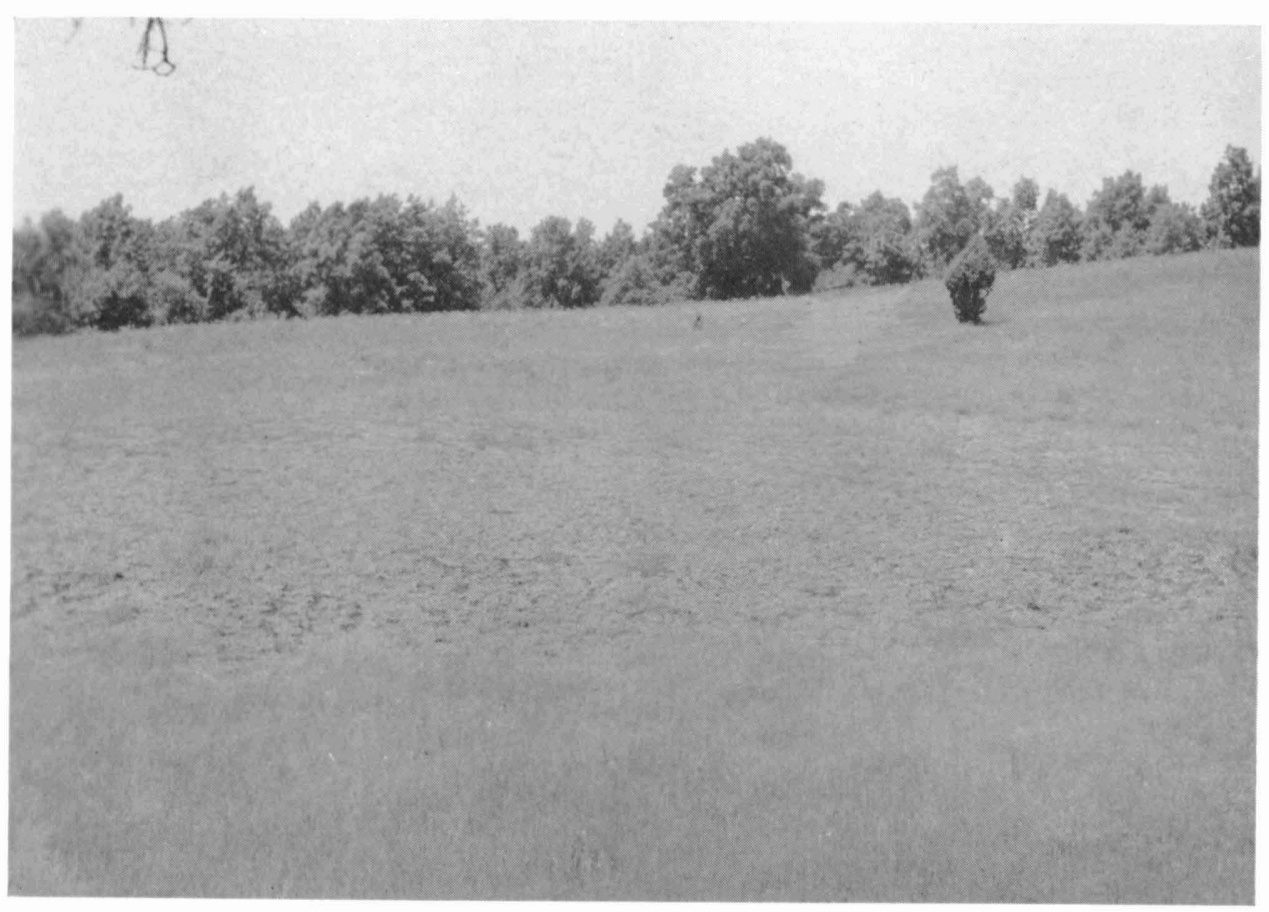

FIG. 2 
PLATE II

Fig. 1. Station 5. An area just to the right of that shown in Fig. 2, Plate I. Poa compressa is the dominant plant covering the gentle slopes.

FIG. 2. Station 11. An area of intergradation between the sparsely vegetated sand and the mixed grass-herbaceous upland. Oak reproduction in the center serves as protection for Nemobius griseus. Old fence rows on the Reserve are often marked by a row of oaks. The lack of shrubbery in such situations is striking. 
PLATE II

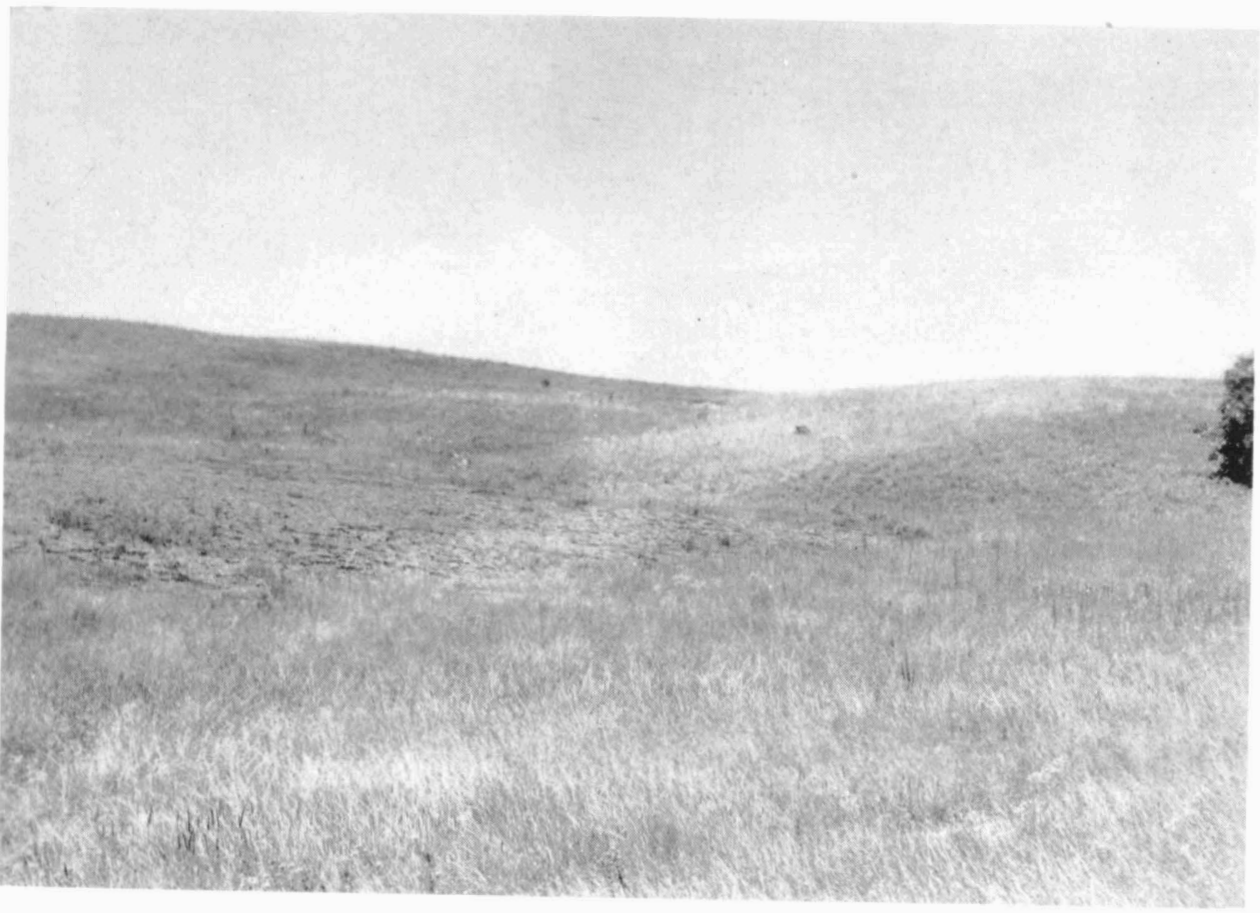

FIG. 1

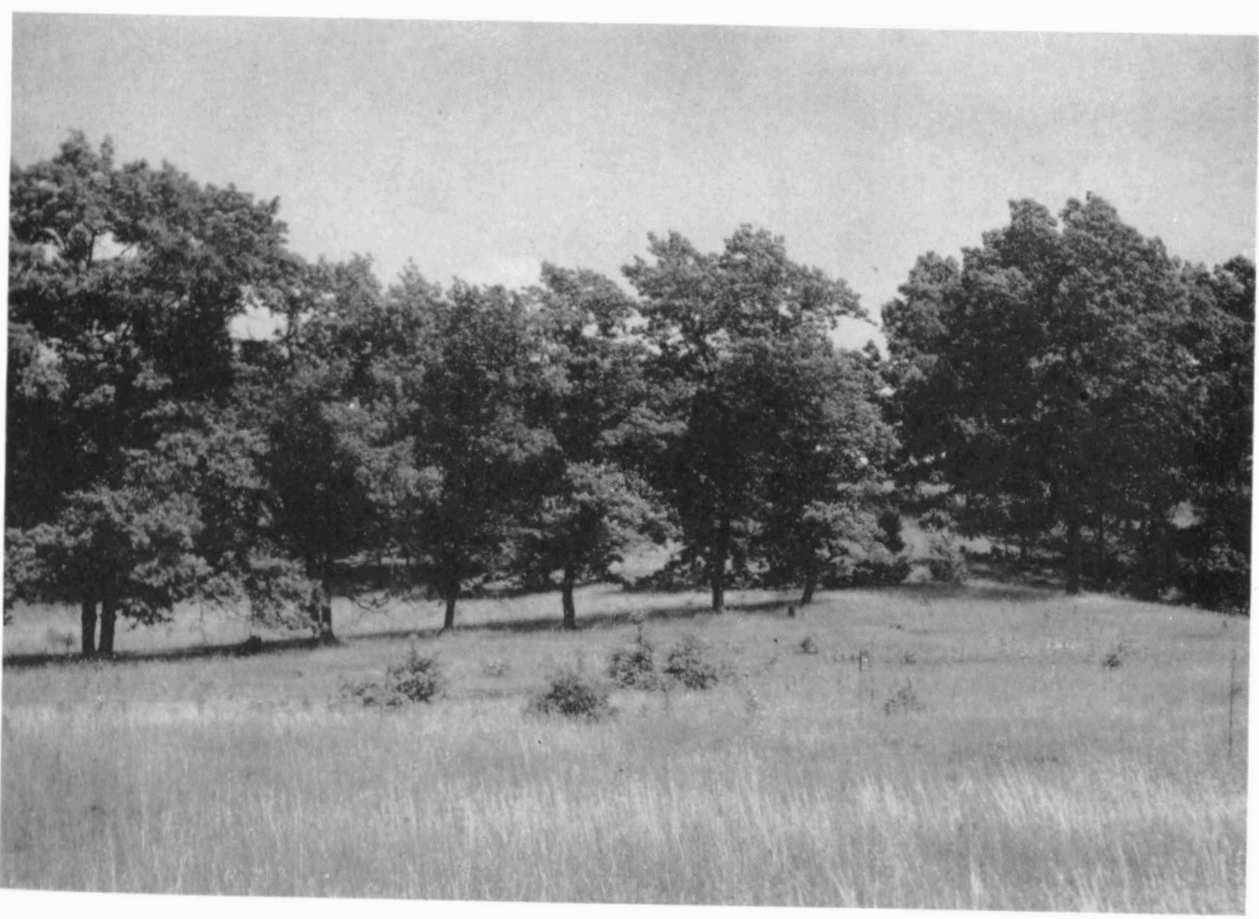

FIG. 2 


\section{PLATE III}

FIG. 1. Station 9. A heavy growth of mixed grass-herbaceous habitat in the foreground. The trees of the background are largely red maple and birch. Two dead tamaracks appear in the upper left hand corner.

FIG. 2. Station 3. An area of sumny oak-hickory habitat. Grassland approaches this habitat, but ends abruptly in an almost nomexistent ecotone indicated by the line of bracken in the extreme foreground. The deciduous-arboreal and the low shrub-terrestrial strata are apparent. 


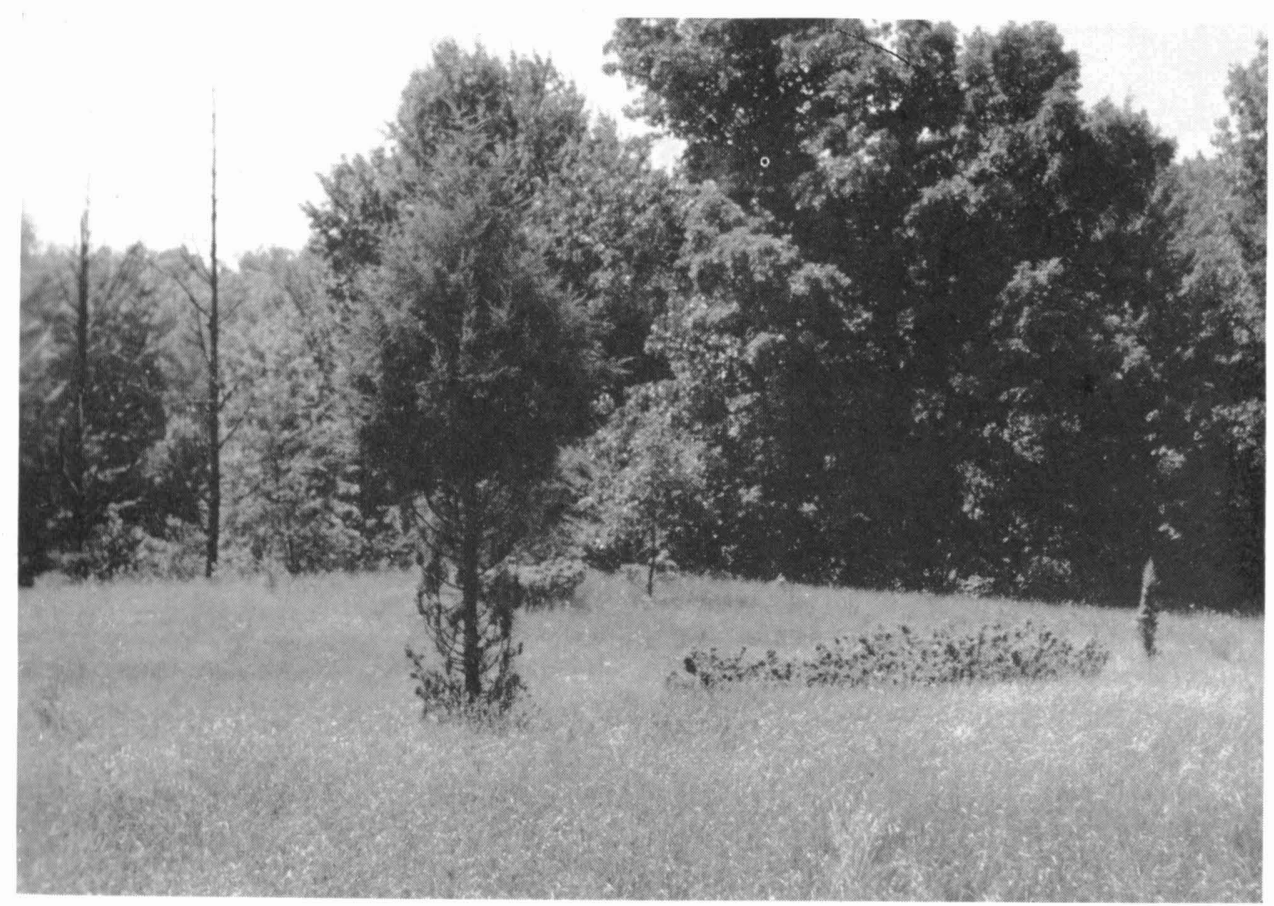

FIg. 1

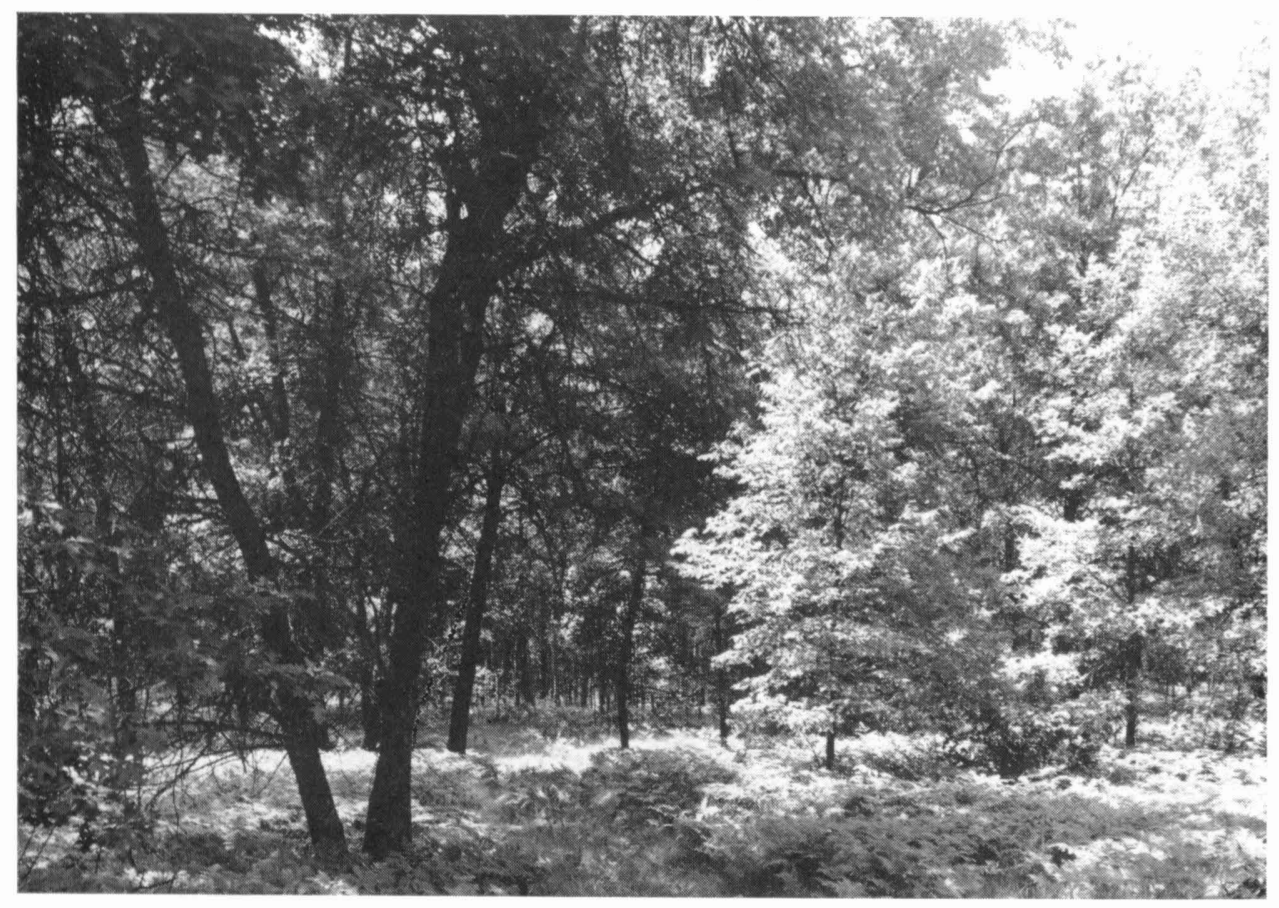

FIG. 2 


\section{PLATE IV}

Fig. 1. Station 2. Poa compressa, characteristic of the mixed grass-herbaceous habitat, is the dominant grass of the low shrub-terrestrial stratum of this area of sunny oakhickory habitat.

FIG. 2. Station 2. An area of shady oak-hickory habitat in which the deciduousarboreal, the tall shrub, and the low shrub-terrestrial strata are clearly indicated. Spharagemon bolli is a characteristic inhabitant of the woodland roadways in the center of the foreground. 


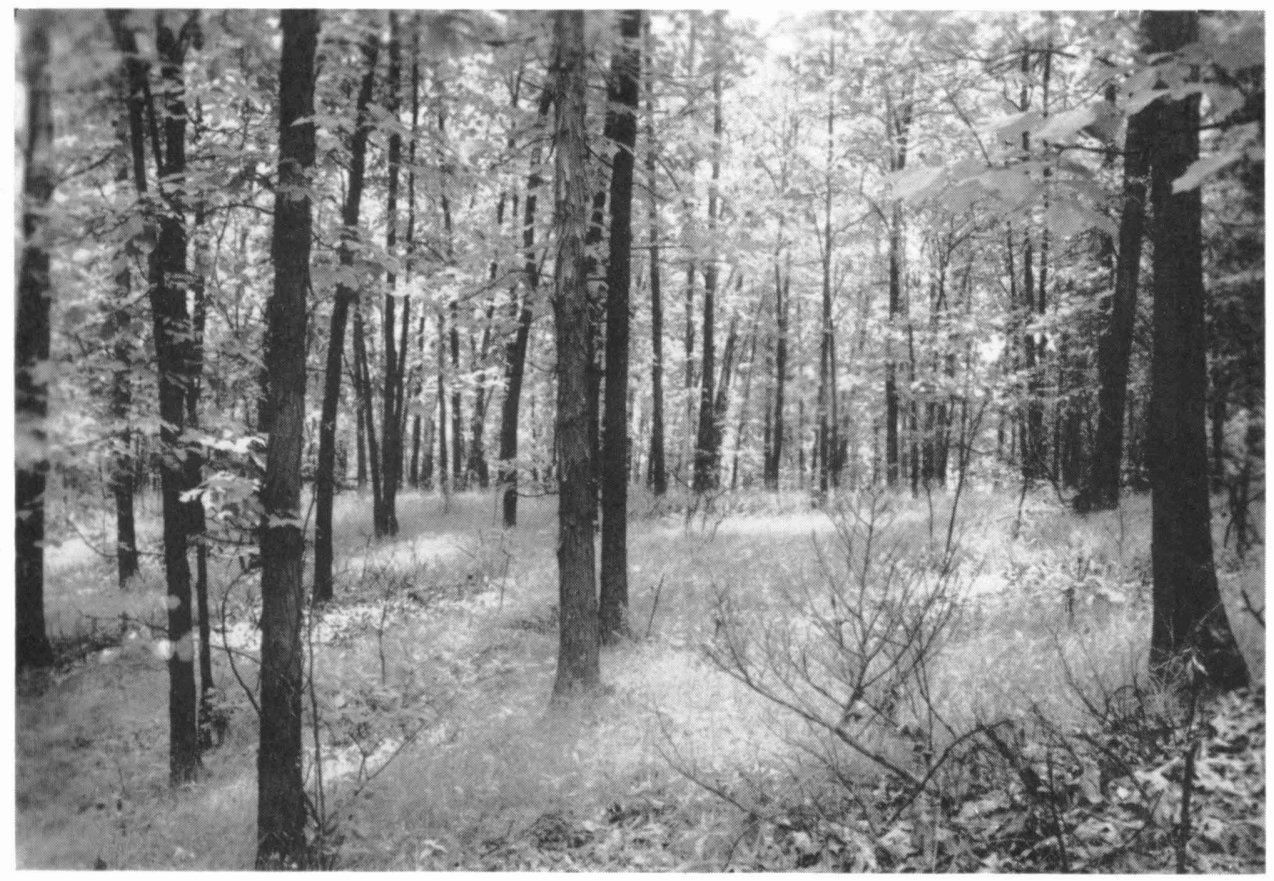

Fig. 1

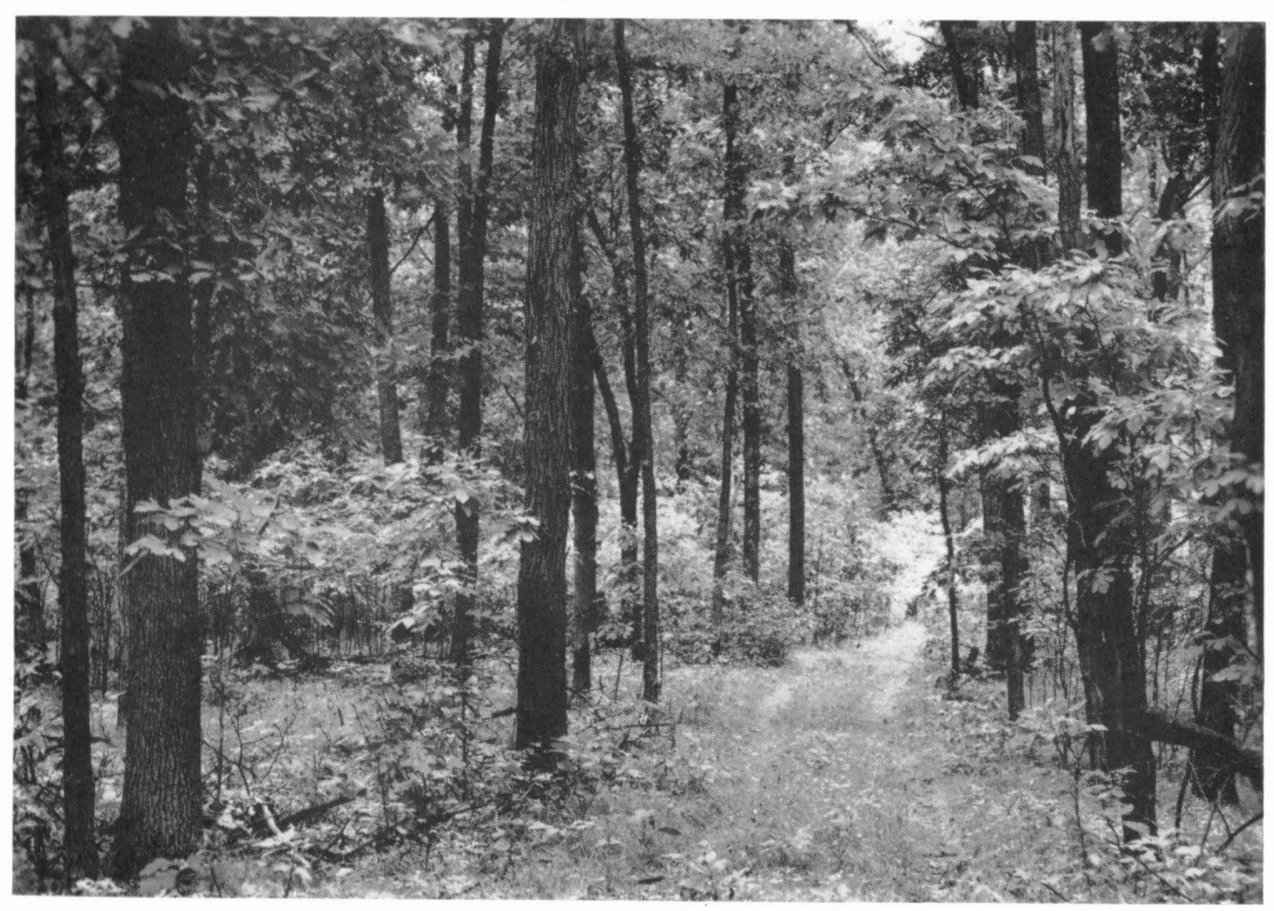

FIg. 2 
PLATE V

FIG. 1. Station 2. Heavy growths of sassafras have invaded parts of the shady oakhickory habitat, forming the tall shrub stratum. Piles of decaying leaves accumulate about fallen timber and there give shelter to cockroaches and camel crickets.

Fig. 2. Station 10. The permanent marsh orthopteran habitat on the far side of the lake. In the background may be seen a part of the tamarack-poison sumac habitat. 


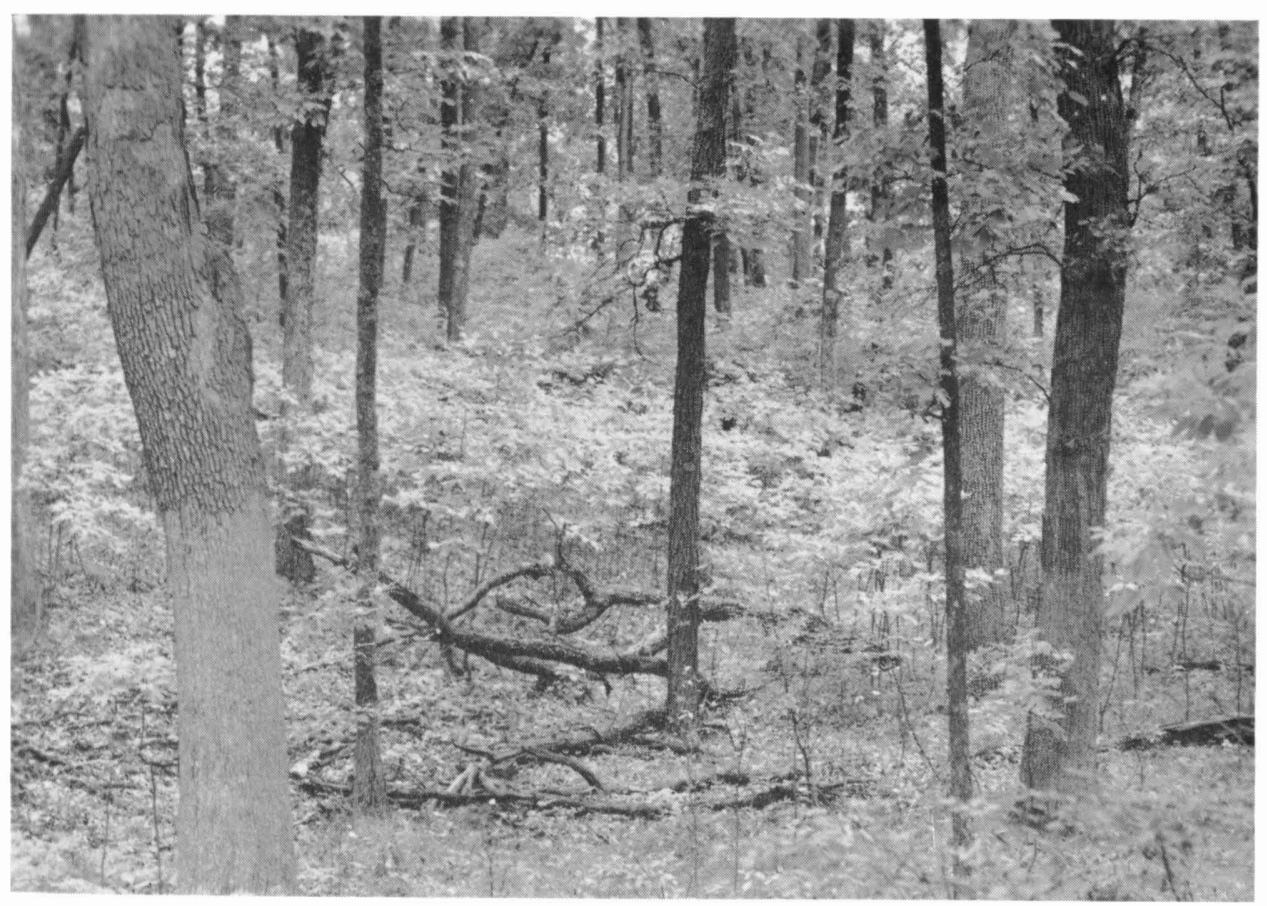

FIG. 1

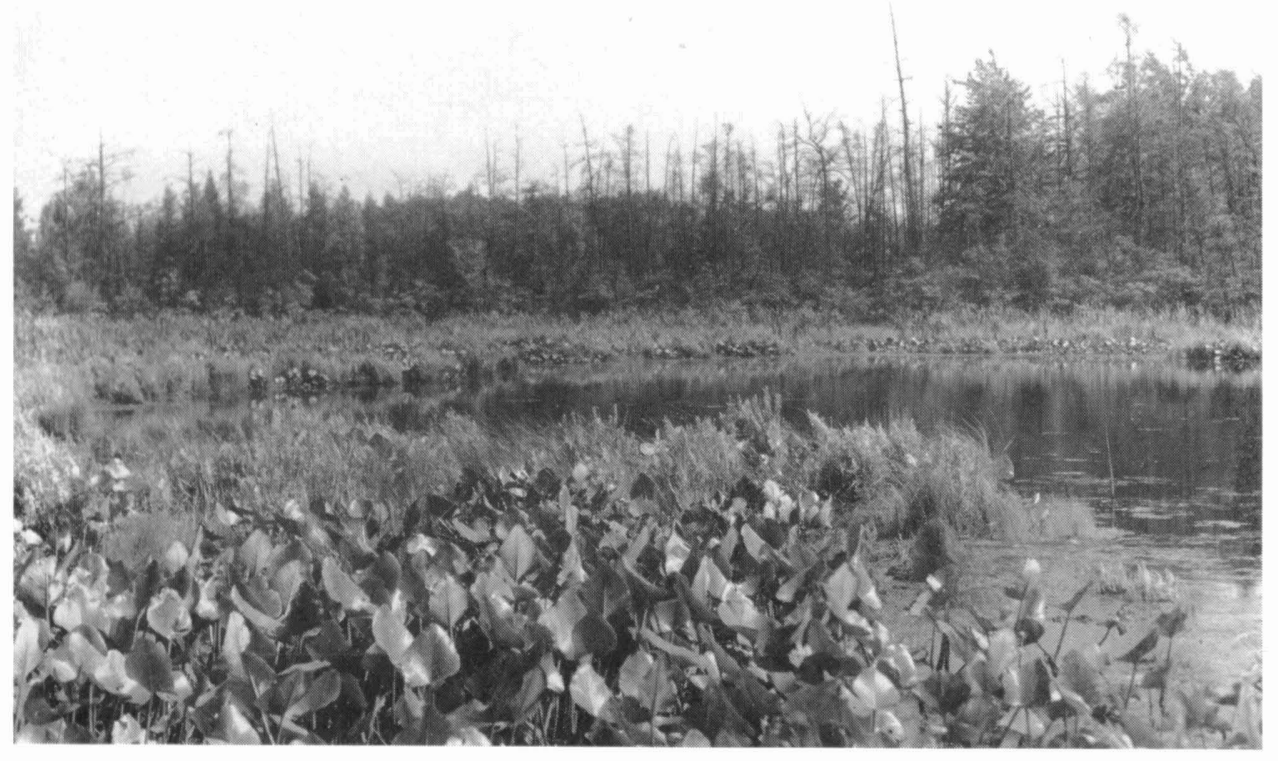

FIg. 2 


\section{PLATE VI}

FIg. 1. The narrow ecotone between grassland and woodland (in the upper center). Overly moist conditions are killing certain of the trees (center). Below these trees may be seen an area of wet shrub-zone habitat beneath which parts of the wet terrestrial stratum develop in the fall.

FIg. 2. Station 1. This area (just to the right of Fig. 1) is illustrative of the semipermanent marsh habitat. Marginal shrub-zone habitat (lower right hand corner) is generally limited to the narrow ecotones between grass and marshland. 


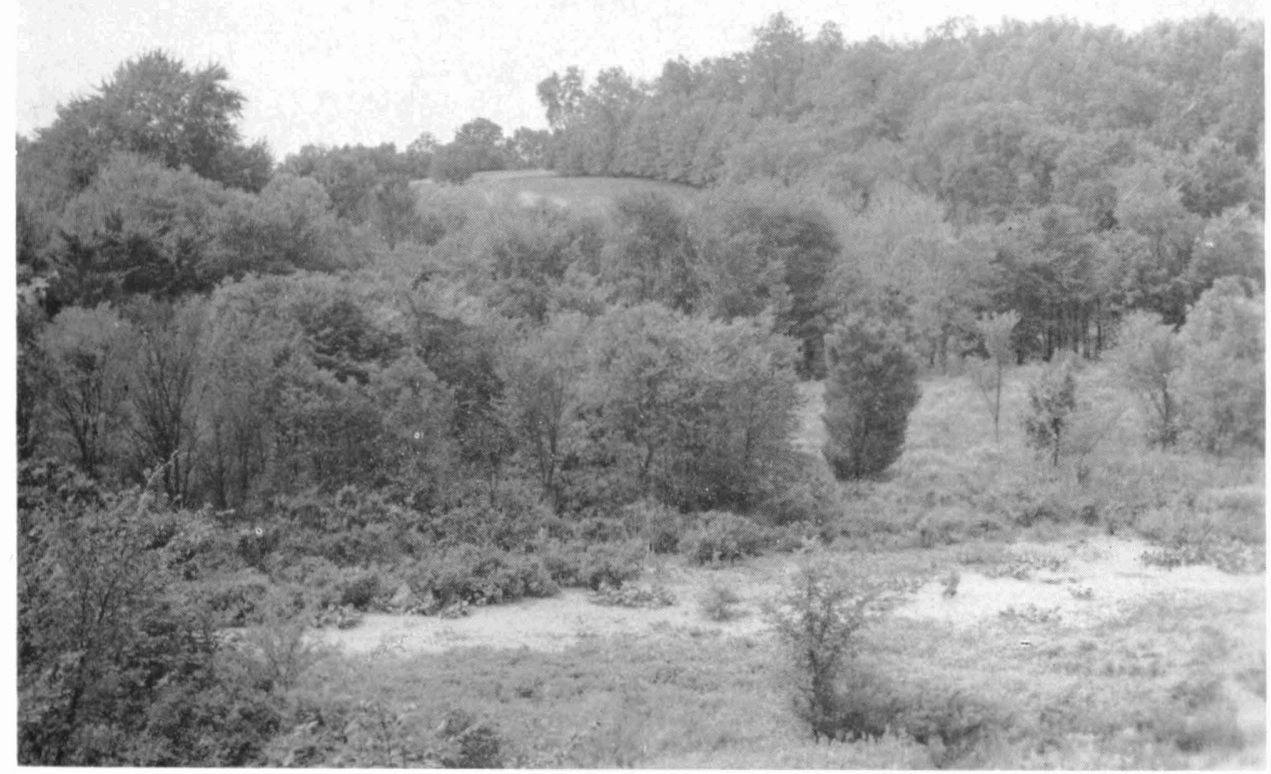

FIg. 1

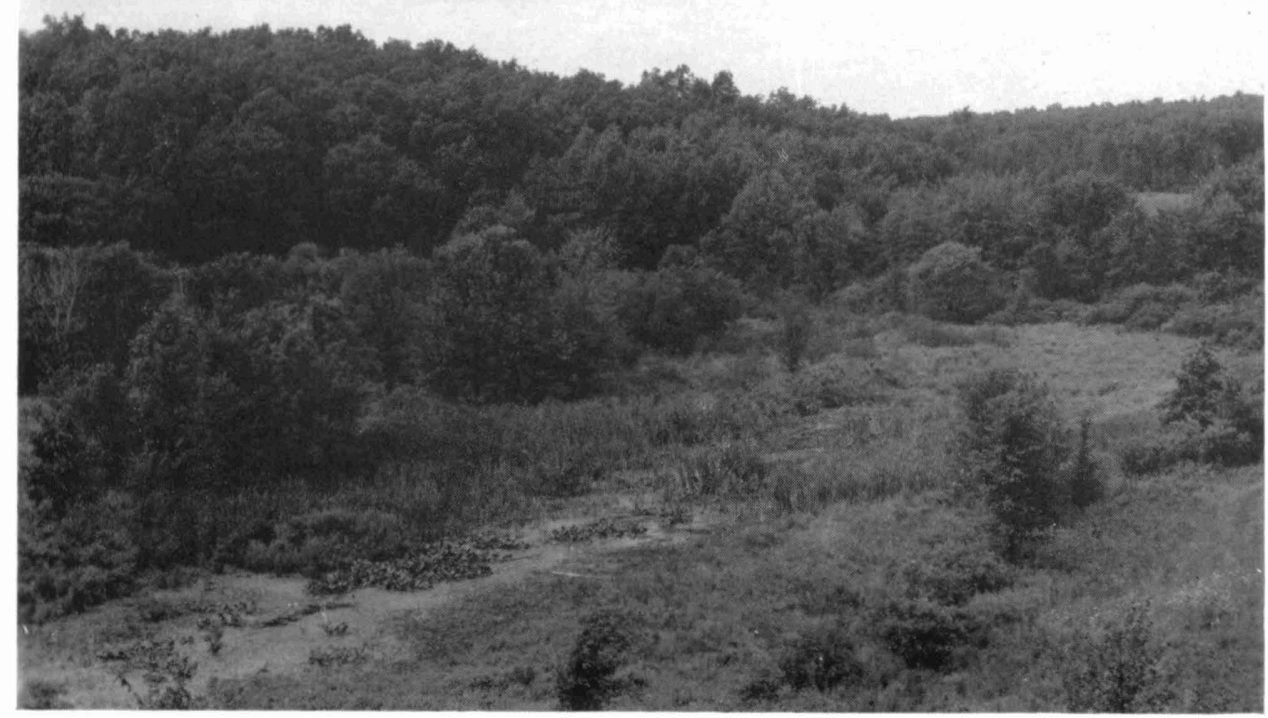

FIG. 2 


\section{PLATE VII}

Fig. 1. Station 6. An area of semipermanent marsh habitat. A narrow belt of marginal shrub-zone habitat in the upper right hand corner and a part of the tamarackpoison sumac labitat in the background.

Fig. 2. Burt Hollow. In the foreground may be seen an area of semipermanent marsh habitat over which an extensive growth of dogwood and spiraea has developed, thus forming patches of the wet shrub-zone habitat. Iack of ecotone between grassland and woodland is apparent in the background. 
PLATE VII

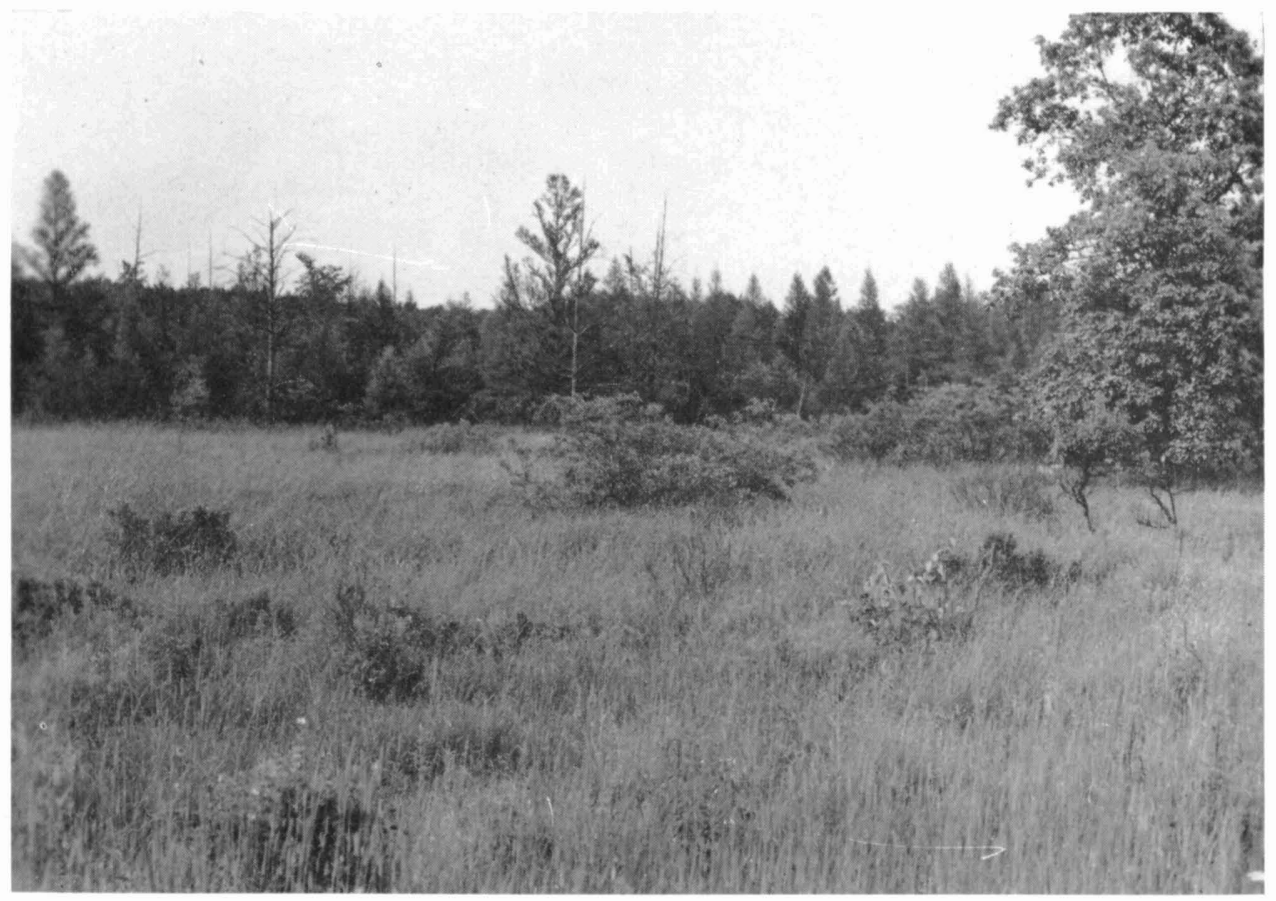

Fig. 1

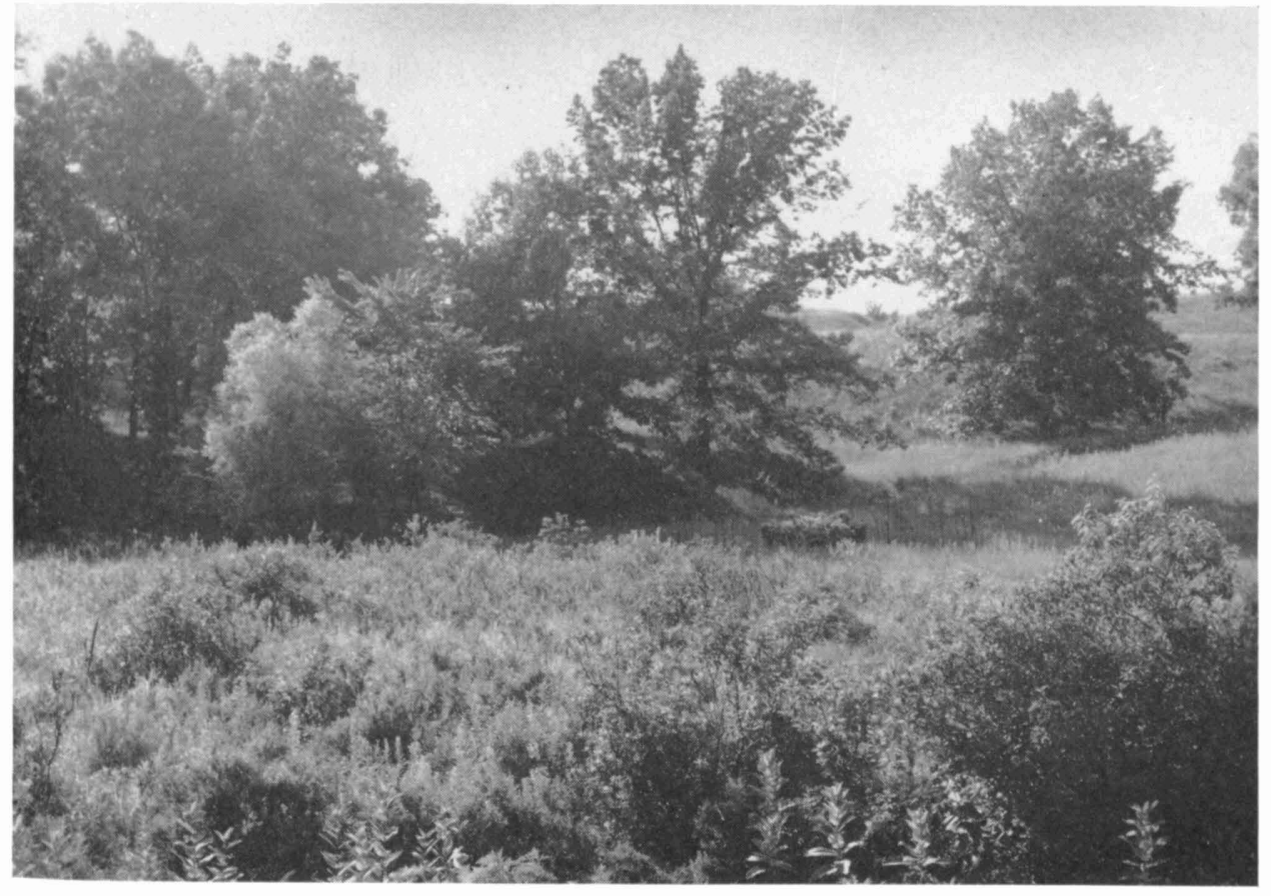

FIG. 2 


\section{PLATE VIII}

Fig. 1. Burt Hollow. Lack of ecotones between grassland and swamp and grassland and woodland is shown in the lower left hand corner and in the background.

Fig. 2. Station 1. Deer tracks in the foreground show the muddy character of the wetterrestrial stratum in late August. A belt of wet shrub-zone habitat lies just in front of the trees of the background. The deciduous-arboreal stratum, so characteristic of the upland forests, sometimes extends into the swamplands. 


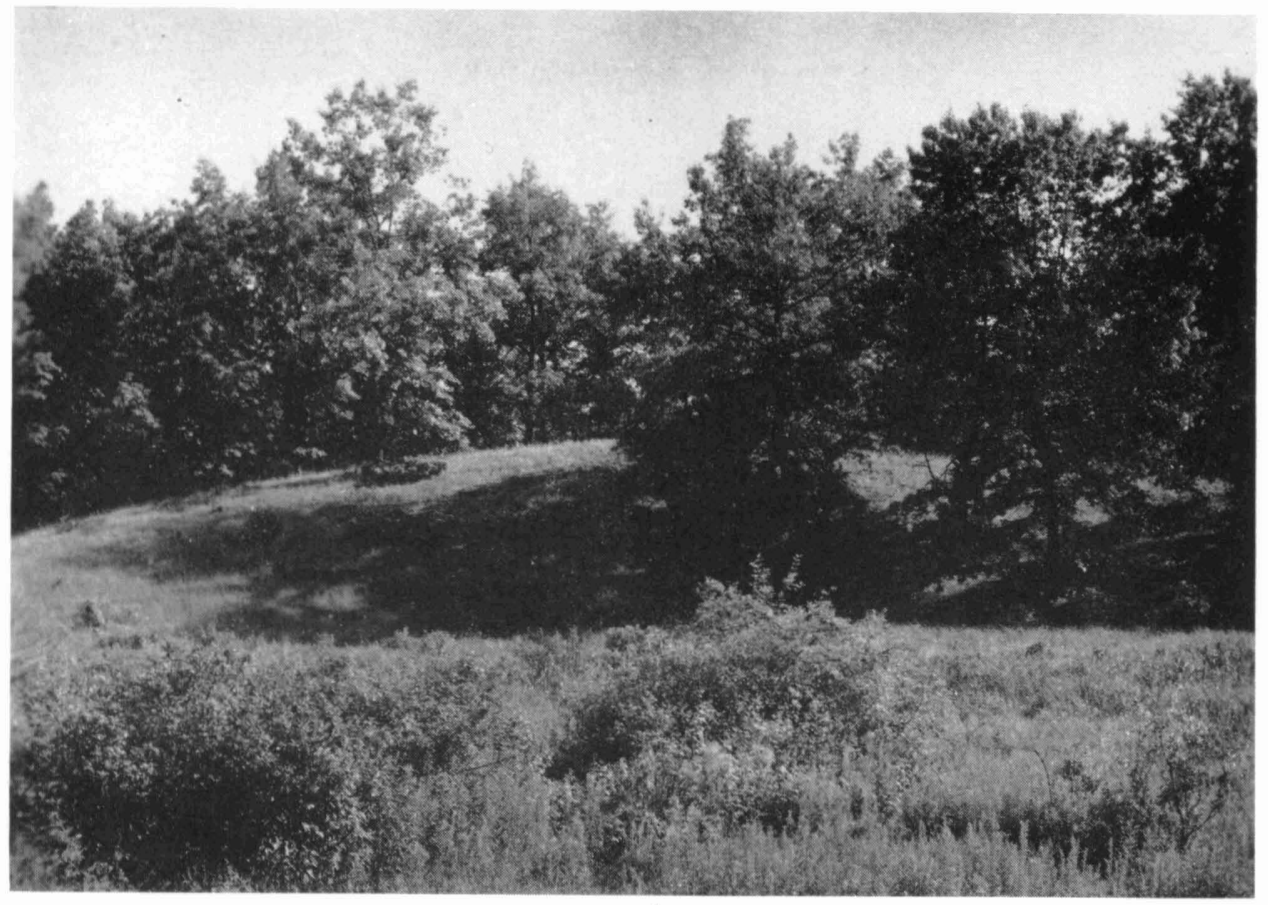

FIG. 1

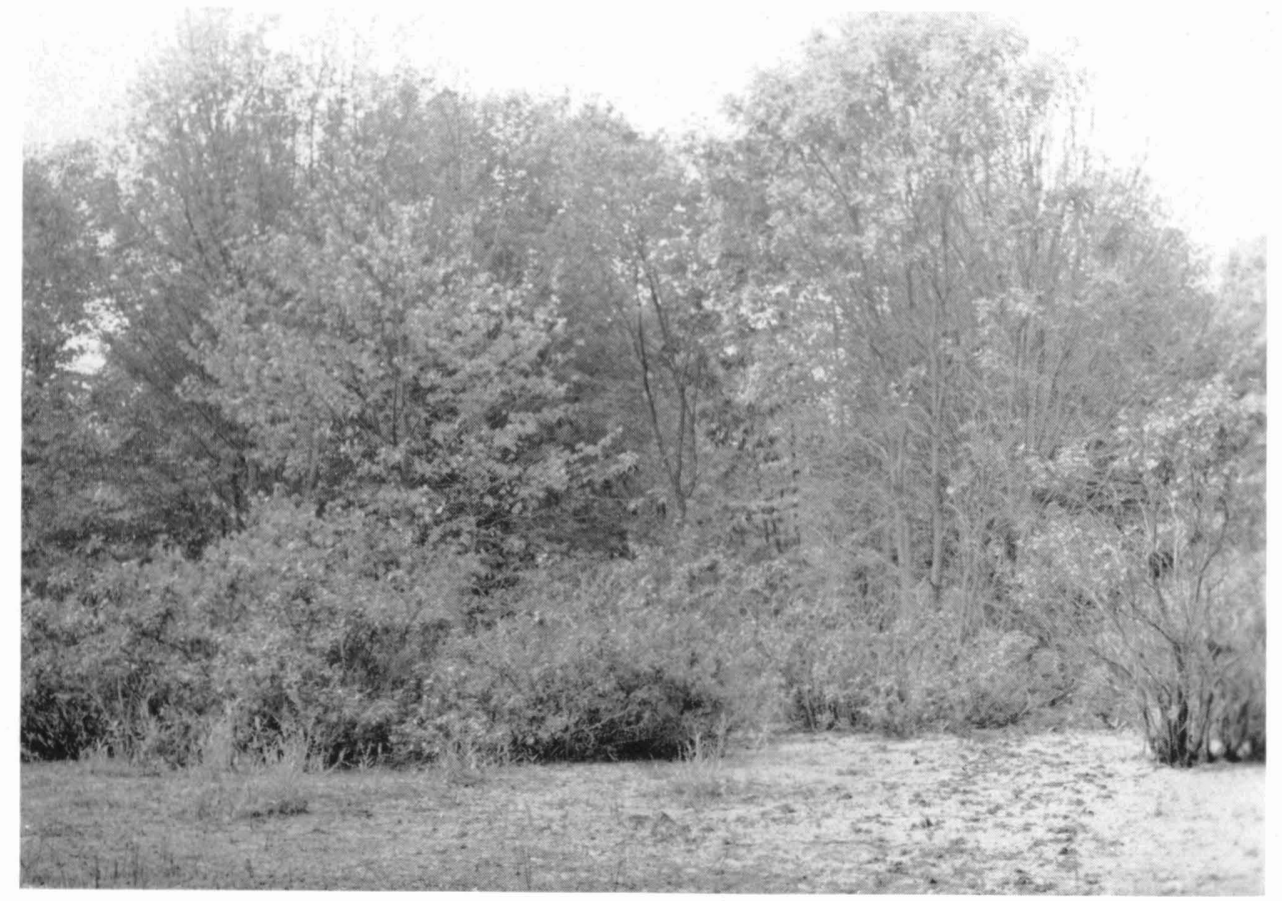

FIG. 2 


\section{PLATE IX}

FIG. 1. Station 1. This area is the same as that depicted by Fig. 1, Plate VIII. The photograph was taken from a west to east rather than from a south to north direction.

FIg. 2. Station 4. Tamarack islands oceur in the leatherleaf bogs. The heavily matted leatherleaf stratum of this bog habitat is underlain with a part of the sphagnum stratum. A narrow belt of sedge (extreme foreground) completely encircles the bog. 
PLATE IX

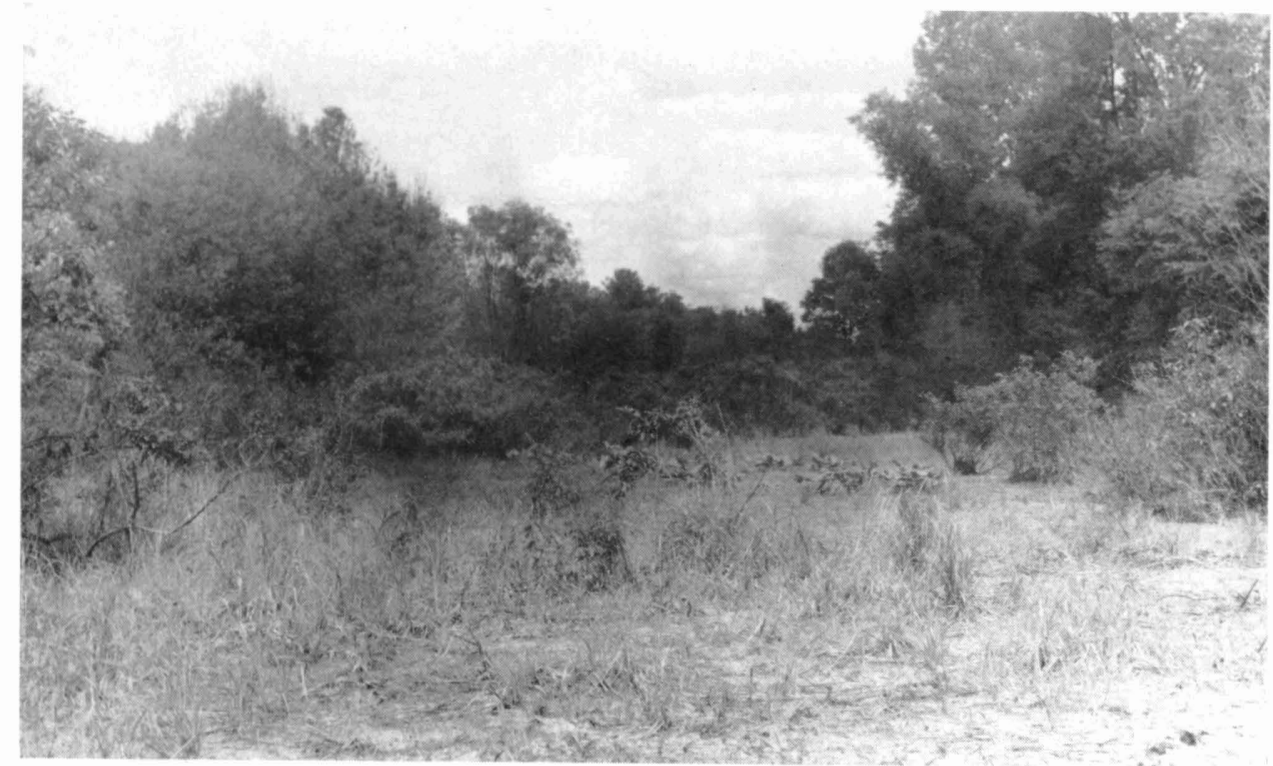

FIg. 1
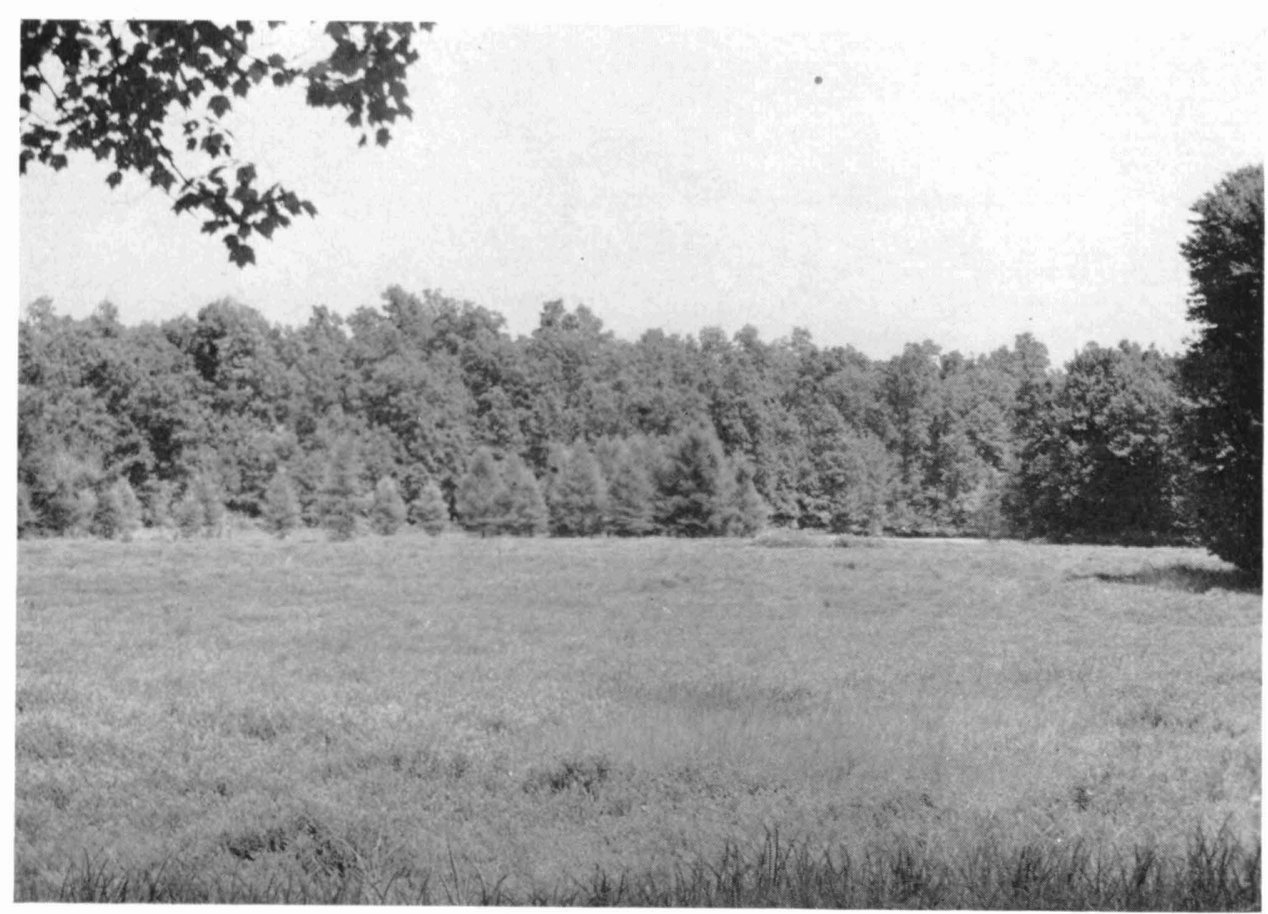

FIG. 2 
PLATE X

FIGS. 1 and 2. Station 8. The red maple-birch habitat is inundated for long periods each year. Few herbaceous plants grow on the ground, but fallen timber is covered with mats of mosses. Poison sumac grows luxuriantly around the periphery of the area. 
PLATE X

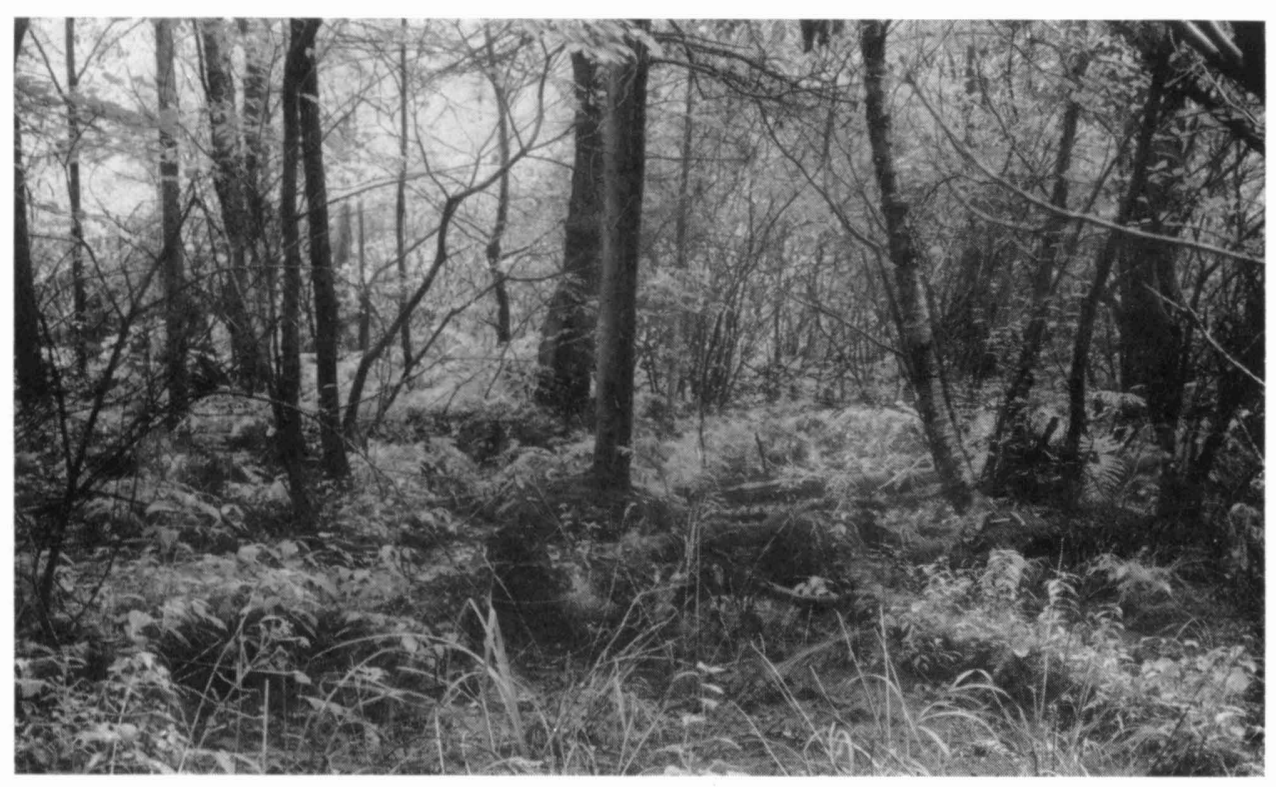

Fig. 1

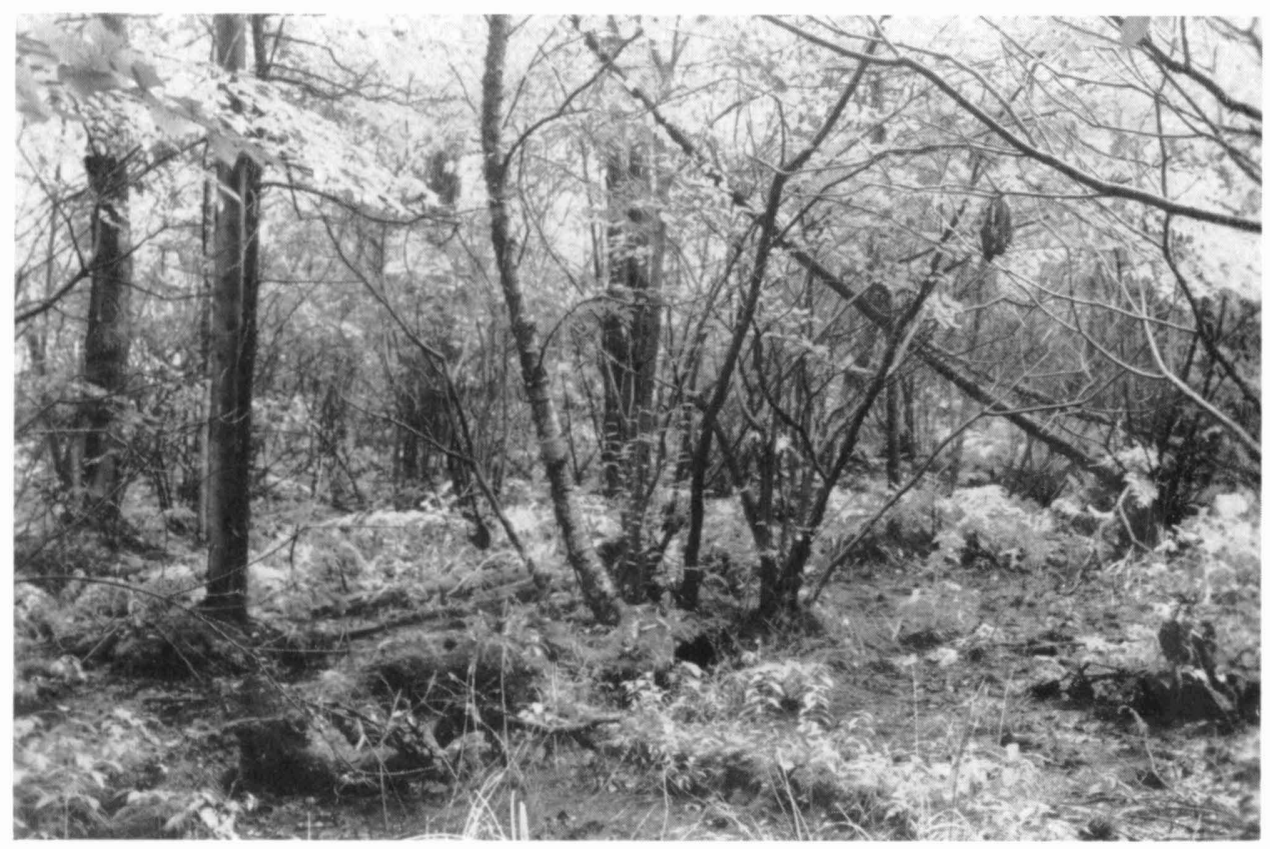

FIg. 2 

No. 24. A Comparative Life History Study of the Mice of the Genus Peromyscus. By ARTHUR SviHLA. (1932) Pp. 39 .......................................................... $\$ 0.50$

No. 25. The Moose of Isle Royale. By Adolph Murie. (1934) Pp. 44, 7 plates $\$ 0.70$

No. 26. Mammals from Guatemala and British Honduras. By ADOLPH MurIE. (1935) Pp. 30, 1 plate, 1 map insert

No. 27. The Birds of Northern Petén, Guatemala. By Josselyn Van Tyne. (1935) Pp. 46, 2 plates, 1 map

No. 28. Fresh-water Fishes Collected in British Honduras and Guatemala. By CARL L. HubBs. (1935) Pp. 22, 4 plates, 1 map

No. 29. A Contribution to a Knowledge of the Herpetology of a Portion of the Savanna Region of Central Petén, Guatemala. By L. C. STUART. (1935) Pp. 56, 4 plates, 1 figure, 1 map

No. 30. The Darters of the Genera Hololepis and Villora. By CARL L. HubBs and MotT Dwight Cannon. (1935) Pp. 93, 3 plates, 1 figure ...............

No. 31. Goniobasis of the Coosa River, Alabama. By Calvin Goodrich. (1936)

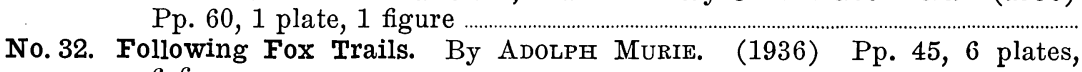
6 figures

No. 33. The Discovery of the Nest of the Colima Warbler (Vermivora crissalis).
By Jossely VAN TYNE. (1936) Pp. 11, colored frontis., 3 plates,

No. 33. The Discovery of the Nest of the Colima Warbler (Vermivora crissalis).
By JosselYN VAN TrNe. (1936) Pp. 11, colored frontis., 3 plates,

No. 33. The Discovery of the Nest of the Colima Warbler (Vermivora crissalis).
By JosseLYN VAN TYNE. (1936) Pp. 11, colored frontis., 3 plates,

No. 34. Mollusca of Petén and North Alta Vera Paz, Guatemala. By CALviN GOODRICH AND HENRY VAN DER Schalie. (1937) Pp. 50, 1 plate, 1 figure, 1 map

No. 35. A Revision of the Lamprey Genus Ichthyomyzon. By CARL L. HubBS AND Milton B. Trautman. (1937) Pp. 109, 2 plates, 5 figures, 1 map ......

No. 36. A Review of the Dragonflies of the Genera Neurocordulia and Platycordulia. By C. Francis Byers. (1937) Pp. 36, 8 plates, 4 maps .

No. 37. The Birds of Brewster County, Texas. By Josselyn VAN TyNe AND George Miksch SutTon. (1937) Pp. 115, colored frontis., 5 plates, 1 map

No. 38. Revision of Sciurus variegatoides, a Species of Central American Squirrel. By WilliaM P. HARris, JR. (1937) Pp. 42, 3 plates (2 colored), 3 figures, 1 map

No.39. Faunal Relationships and Geographic Distribution of Mammals in

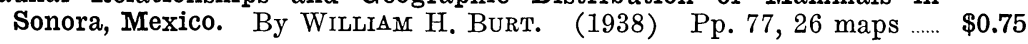

No.40. The Naiad Fauna of the Huron River, in Southeastern Michigan. By HENRY VAN DER SCHALIE. (1938) Pp. 83, 12 plates, 28 figures, 18 maps

\section{sis}

No. 41. The Life History of Henslow's Sparrow, Passerherbulus henslowi (Audu-
bon). By A. SIDNEY HYDE. (1939) Pp. 72,4 plates, 3 figures, 1 map
No. 42. Studies of the Fishes of the Order Cyprinodontes. XVI. A Revision

No. 41. The Life History of Henslow's Sparrow, Passerherbulus henslowi (Audu-
bon). By A. SIDNEY HYDE. (1939) Pp. 72, 4 plates, 3 figures, 1 map
No. 42. Studies of the Fishes of the Order Cyprinodontes. XVI. A Revision of the Goodeidae. By CarL L. Hubbs and C. L. Turner. (1939) Pp. 85, 5 plates

\section{....}

No.43. Aquatic Mollusks of the Upper Peninsula of Michigan. By CALvin
GoodRICH AND HENRY VAN DER SCHALIE. (1939) Pp. 45, 2 maps.........

No. 44. The Birds of Buckeye Lake, Ohio. By Milton B. Trautman. (1940) Pp. 466, 15 plates and a frontis., 2 maps

\section{$\$ 0.75$}

No.45. Territorial Behavior and Populations of Some Small Mammals in Southern Michigan. By William H. Burt. (1940) Pp. 58, 2 plates, 8

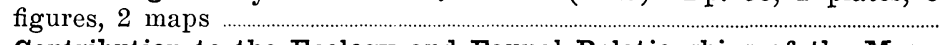

No.46. A Contribution to the Ecology and Faunal Relationships of the Mammals of the Davis Mountain Region, Southwestern Texas. By W. Frank Blair. (1940) Pp. 39, 3 plates, 1 map

No.47. A Contribution to the Herpetology of the Isthmus of Tehuantepec. IV. By Norman Har''weg and James A. Oliver. (1940) Pp. 31 ...................

No. 48. A Revision of the Black Basses (Micropterus and Huro) with Descriptions of Four New Forms. By Carl L. Hubbs and Reeve M. Bailey. (1940) Pp. 51, 6 plates, 1 figure, 2 maps 
No. 49. Studies on Neotropical Colubrinae. VIII. A Revision of the Genus Dryadophis Stuart. By L. C. Stuart. (1941) Pp. 106, 4 plates, 13 figures, 4 maps

No.50. A Contribution to the Knowledge of Variation in Opheodrys vernalis (Harlan), with the Description of a New Subspecies. By ARNoLd B. Grobman. (1941) Pp. 37, 2 figures, 1 map

No. 51. Mammals of the Lava Fields and Adjoining Areas in Valencia County, New Mexico. By EmmeT T. Hooper. (1941) Pp. 47, 3 plates, 1 map. $\$ 0.50$

No. 52. Type Localities of Pocket Gophers of the Genus Thomomys. By EmmeT

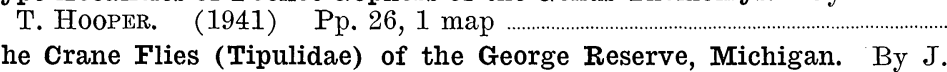
No. 53. The Crane Flies (Tipulidae) of the George Reserve, Michigan. By J.
SPEEd Rogers. (1942) Pp. 128, 8 plates, 1 map

No. 54. The Ecology of the Orthoptera and Dermaptera of the George Reserve, Michigan. By Irving J. Cantrall. (1942) Pp. 182, 10 plates, 2 maps $\$ 1.50$

No. 55. Birds from the Gulf Lowlands of Southern Mexico. By PIERCE BrodKORB. (1942) Pp. 88, 1 map

No. 56. Taxonomic and Geographic Comments on Guatemalan Salamanders of the Genus Oedipus. By L. C. Stuart. (1943) Pp. 33, 2 plates, 1 map $\$ 0.35$

Price lists are available for the Occasional Papers, Handbook Series, and Circulars of the Museum of Zoology. 



